\title{
Die Regulation der humanen H3-Histongene
}

\author{
Dissertation \\ zur Erlangung des Doktorgrades \\ der Mathematisch-Naturwissenschaftlichen Fakultäten \\ der Georg-August-Universität zu Göttingen
}

vorgelegt von

Heiner Kössler

aus Bonn

Göttingen 2003 
D 7

Referent: Prof. Dr. D. Doenecke

Korreferent: Prof. Dr. U. Grossbach

Tag der mündlichen Prüfung: 6.11.2003 


\section{Inhaltsverzeichnis}

Inhaltsverzeichnis

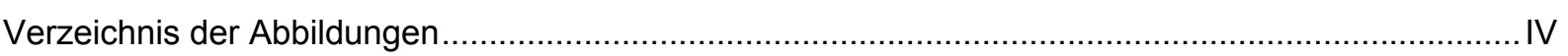

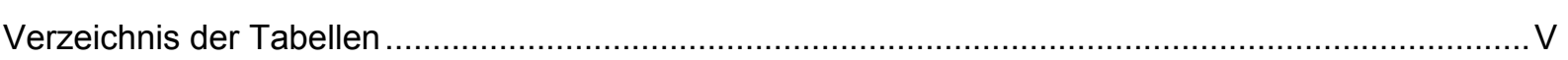

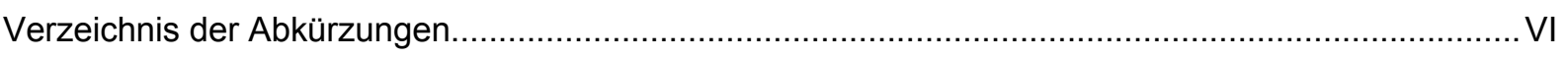

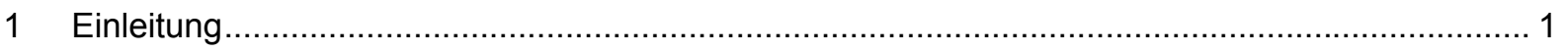

$1.1 \quad$ Histone und Histongene ........................................................................................ 1

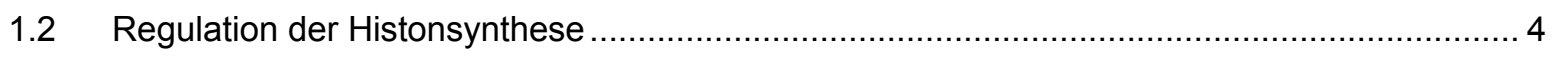

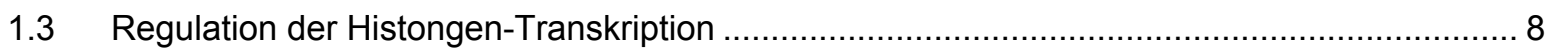

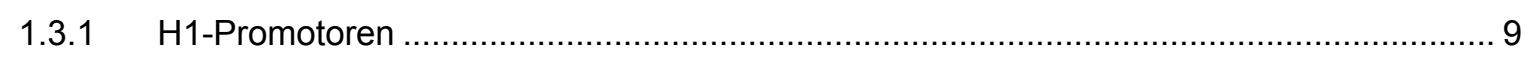

1.3.2 H2A/H2B-Promotoren ...................................................................................... 10

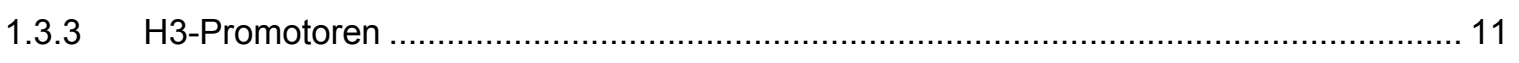

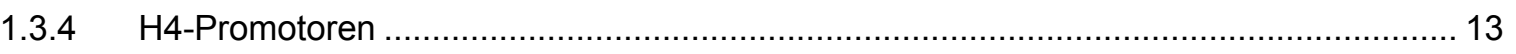

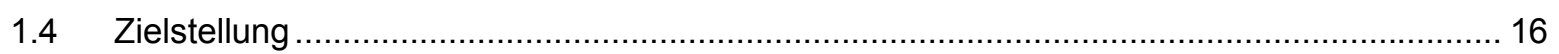

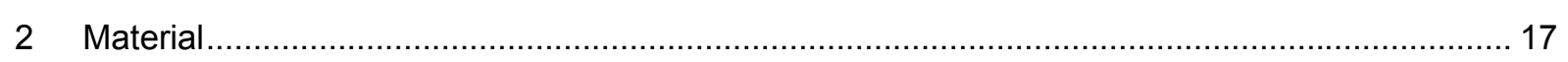

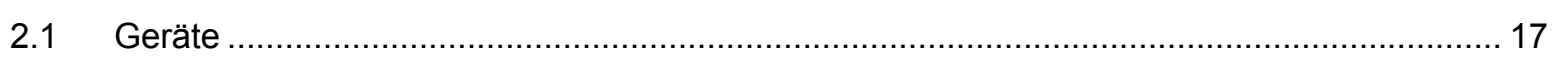

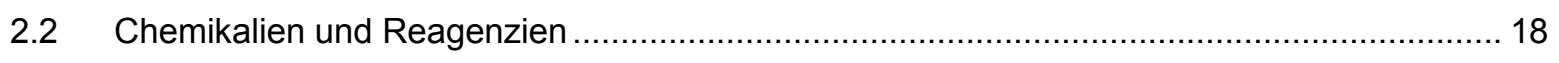

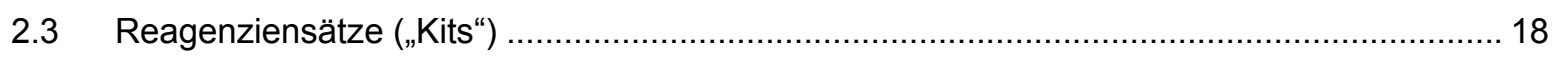

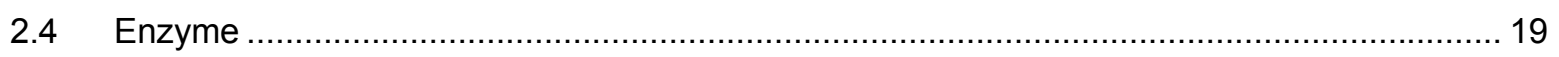

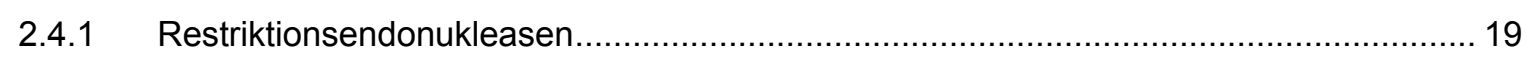

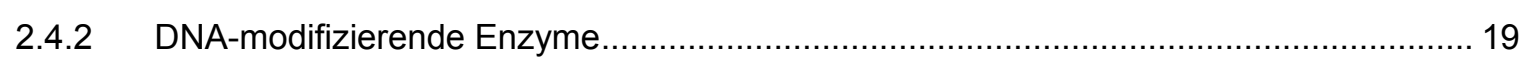

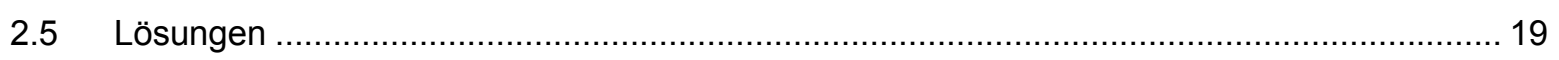

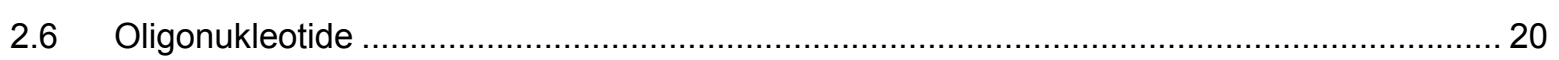

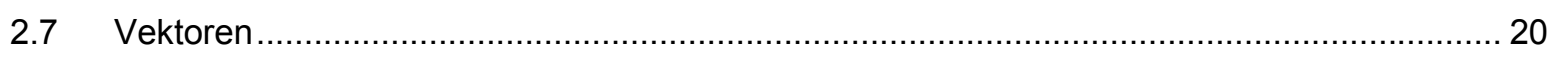

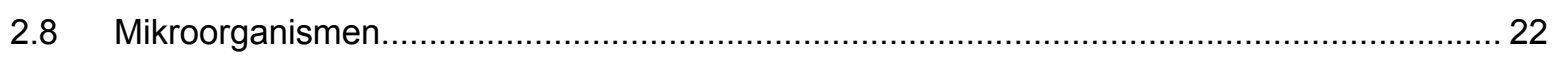

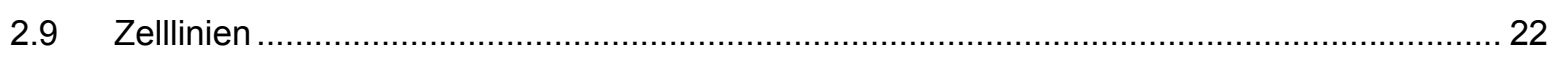

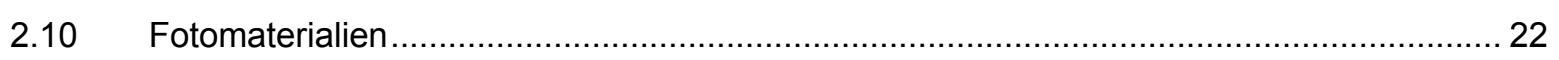

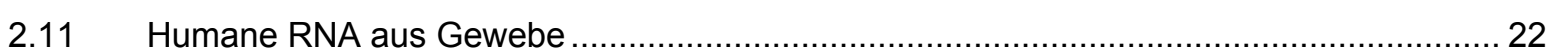

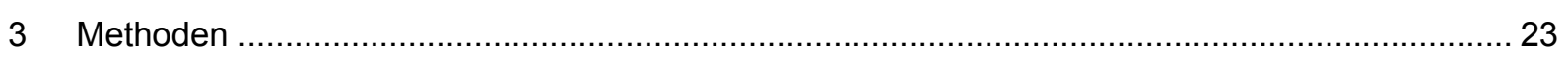

$3.1 \quad$ Allgemeine molekularbiologische Methoden ......................................................... 23

3.1.1 Konzentrationsbestimmung von DNA ......................................................... 23

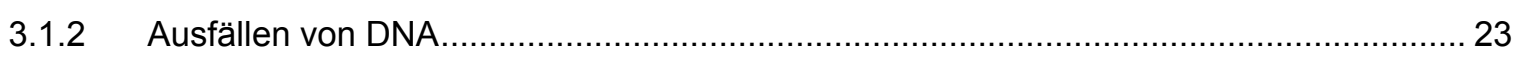

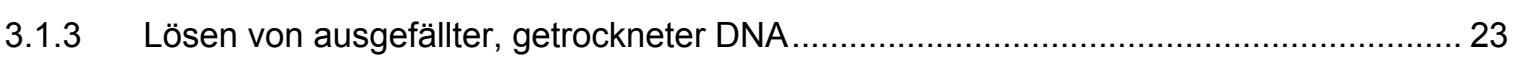

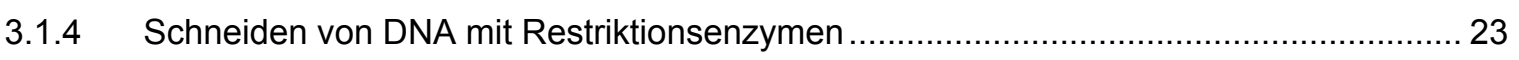

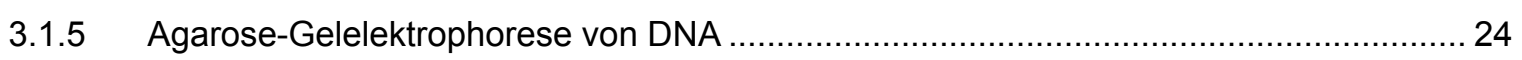

$3.1 .6 \quad$ Dephosphorylierung von DNA 5'-Enden.............................................................. 24

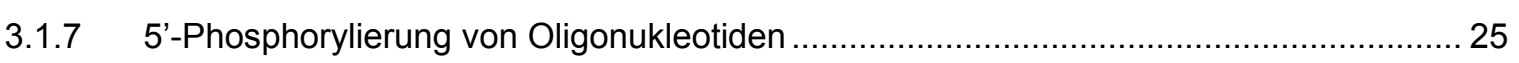

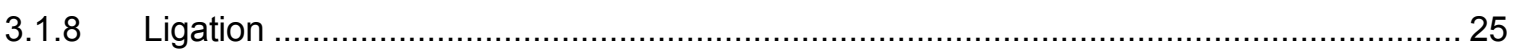

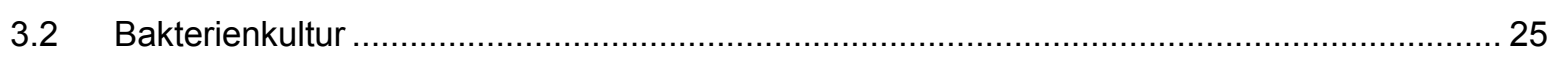

$3.2 .1 \quad$ Lagerung von Bakterienkulturen und Herstellung von „Stocks“ .................................... 25 
$3.2 .2 \quad$ Schnelle Präparation von Plasmiden aus Mini-Kulturen ....................................... 26

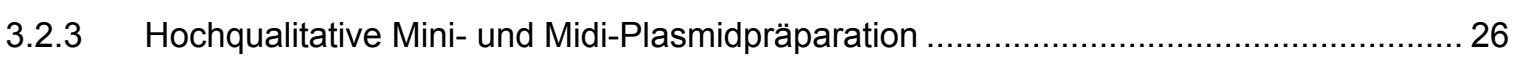

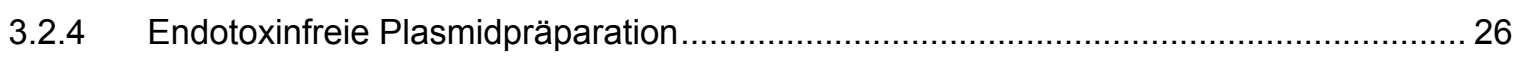

$3.2 .5 \quad$ Präparation von Transformations-kompetenten Bakterien ..................................... 27

3.2.6 Transformation von kompetenten Bakterien .......................................................... 27

$3.3 \quad$ Amplifikation von DNA mit der PCR-Reaktion .......................................................... 28

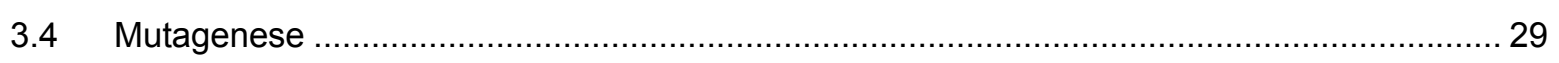

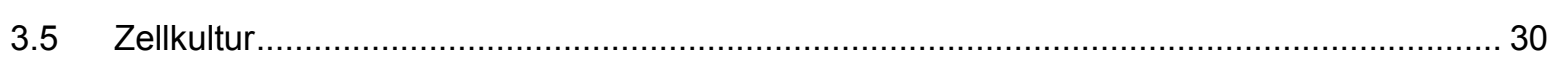

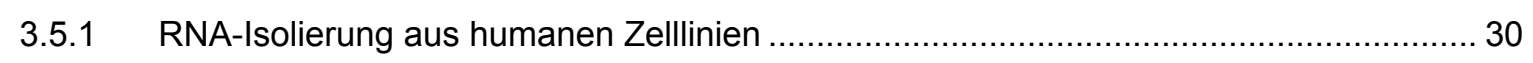

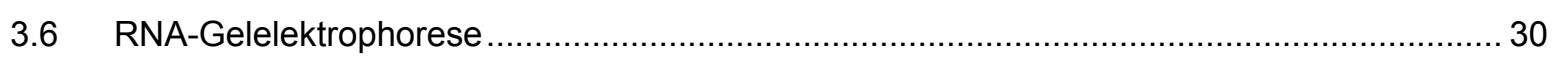

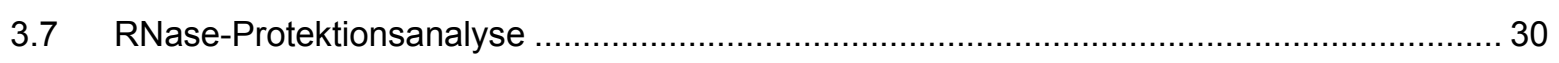

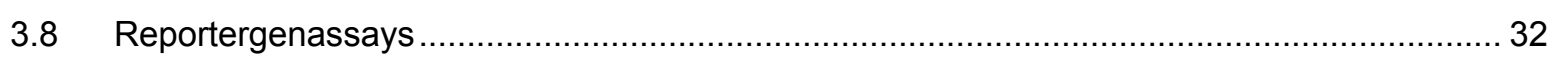

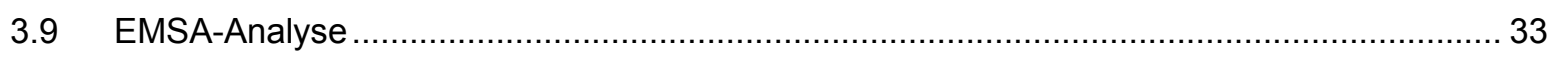

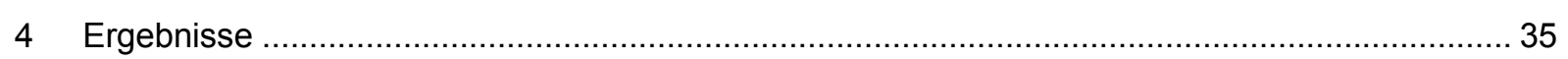

$4.1 \quad$ Sequenzanalyse der $11 \mathrm{H} 3-$ Promotoren ............................................................. 35

$4.2 \quad$ Expressionsanalyse der $11 \mathrm{H} 3-$ Histongene ..................................................................... 37

$4.2 .1 \quad$ Quantitative RNase-Protektionsanalyse ........................................................ 37

$4.2 .2 \quad$ Expressionsanalyse der $11 \mathrm{H} 3-$ Histongene in humanen Geweben ............................ 38

$4.2 .3 \quad$ Expressionsanalyse der $11 \mathrm{H} 3-$ Histongene in humanen Zelllinien ............................ 41

$4.3 \quad$ Reportergenanalyse von H3-Promotor-Deletionsreihen ................................................. 47

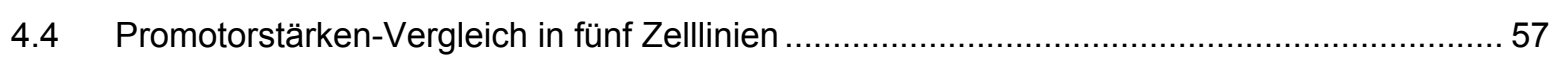

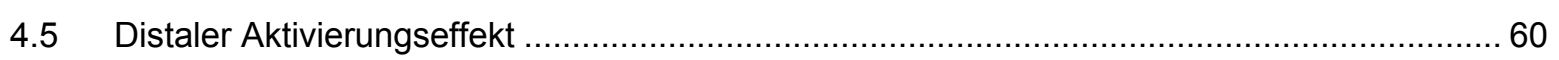

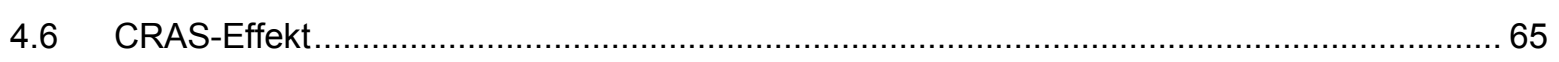

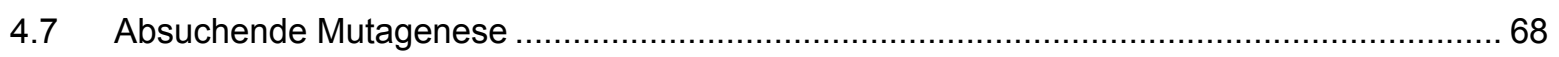

$4.8 \quad$ Mutagenese der CCAAT-Boxen des H3/k-Promotors ................................................ 71

$4.9 \quad$ Mutagenese der putativen HiNF-D-Bindungsstellen des $\mathrm{H} 3 / \mathrm{m}$-Promotors ........................ 74

$4.10 \quad$ Abstandsveränderungen im H3/k-Promotor ........................................................ 75

4.11 Bandshift-Analyse der CCAAT-Boxen des H3/k- und H3/m-Promotors .......................... 80

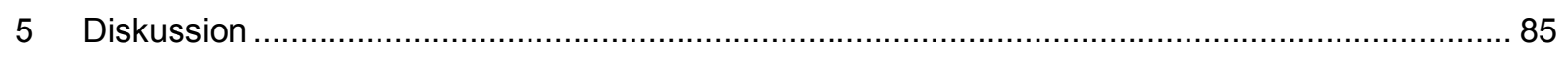

$5.1 \quad$ Histon-H3-Genexpression in humanem Gewebe und Tumorzelllinien ................................ 85

$5.1 .1 \quad$ Das aberrante Expressionsmuster von $\mathrm{H} 3$-Histongenen in Tumorzelllinien ................... 86

$5.1 .2 \quad$ Vergleich der Aktivität von Histon-H3-Promotoren in verschiedenen Zelllinien .............. 88

$5.1 .3 \quad$ Hypothesen zur Natur des aberranten H3-Expressionsmusters ................................. 89

5.2 Histon-H3-Promotoranalyse ............................................................................... 91

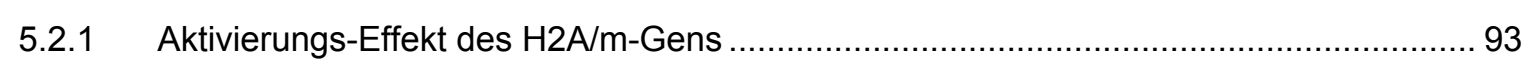

$5.3 \quad$ Mutagenese im H3/k- und H3/m-Promotor ............................................................... 95

$5.3 .1 \quad$ Mutagenese von putativen HiNF-D Bindungsstellen ............................................. 98

$5.3 .2 \quad$ Einfluss der Sequenz der CCAAT-Boxen im H3/k-Promotor ................................. 100

$5.3 .3 \quad$ Einfluss der Lage der CCAAT-Boxen im H3/k-Promotor .......................................... 102

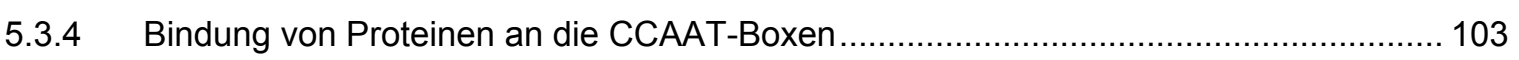

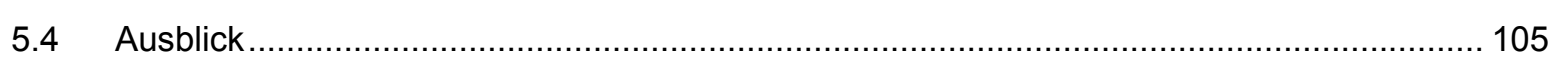




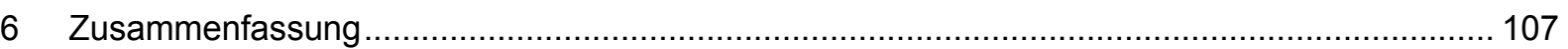

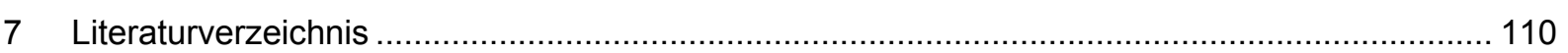

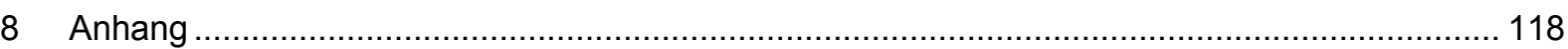

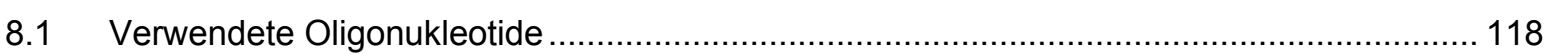

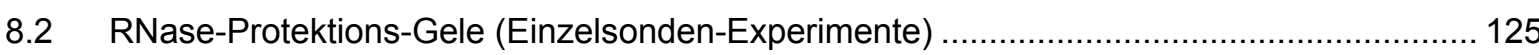




\section{Verzeichnis der Abbildungen}

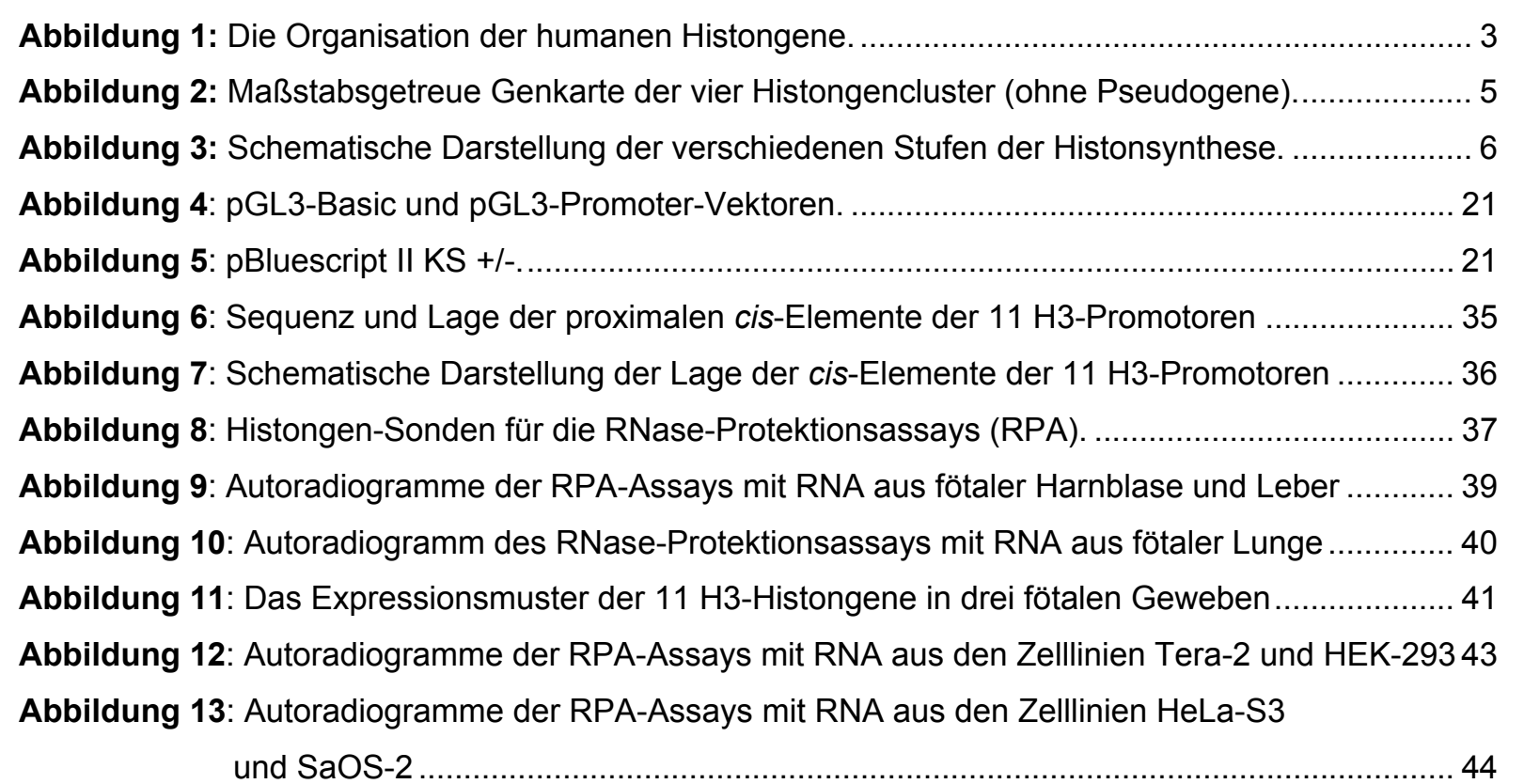

Abbildung 14: Das Expressionsmuster der $11 \mathrm{H}$-Histongene in acht humanen Zelllinien ...............45

Abbildung 15: PCR-Amplifikation von Histongenen aus chromosomaler DNA .......................... 47

Abbildung 16: Reportergenanalyse der H3/m-Promotor-Deletionsreihe in der Zelllinie HEK-293 ...... 50

Abbildung 17: Reportergenanalyse der H3/k-Promotor-Deletionsreihe in der Zelllinie HEK-293 ....... 51

Abbildung 18: Reportergenanalyse der H3/h-Promotor-Deletionsreihe in der Zelllinie HEK-293...... 52

Abbildung 19: Reportergenanalyse der H3/i-Promotor-Deletionsreihe in der Zelllinie HEK-293 ....... 53

Abbildung 20: Reportergenanalyse der H3/n-Promotor-Deletionsreihe in der Zelllinie HEK-293...... 54

Abbildung 21: Reportergenanalyse der H3/d-Promotor-Deletionsreihe in der Zelllinie HEK-293...... 55

Abbildung 22: Normierte Reportergenaktivitäten von Konstrukten in der Zelllinie HEK-293 ............ 57

Abbildung 23: Promotoraktivität von sechs H3-Promotoren in fünf Zelllinien ..............................59

Abbildung 24: Aktivitätsbestimmung von Reportergenkonstrukten zum distalen H2A/m-Effekt (I).... 62

Abbildung 25: Aktivitätsbestimmung von Reportergenkonstrukten zum distalen H2A/m-Effekt (II).... 63

Abbildung 26: Aktivitätsbestimmung von Reportergenkonstrukten zum distalen H2A/m-Effekt (III)... 64

Abbildung 27: Aktivitätsbestimmung von Reportergenkonstrukten zum distalen H2A/m-Effekt (IV) .. 66

Abbildung 28: Aktivitätsbestimmung von Reportergenkonstrukten zum CRAS-Effekt .....................67

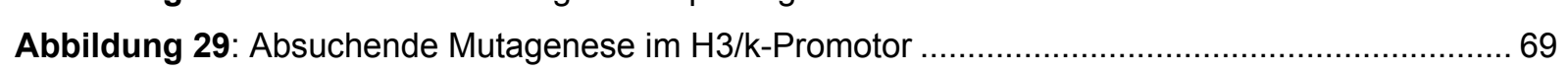

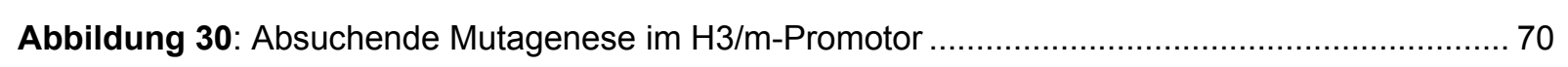

Abbildung 31: Spezifische Mutagenese der proximalen CCAAT-Box des H3/k-Promotors .............. 72

Abbildung 32: Spezifische Mutagenese der distalen CCAAT-Box des H3/k-Promotors................. 73

Abbildung 33: Spezifische Mutagenese der distalen CCAAT-Box des H3/m-Promotors ................. 76

Abbildung 34: Vergrößerung des Abstandes zwischen CCAAT- und TATA-Box .......................... 78

Abbildung 35: Veränderung des Abstands zwischen proximaler und distaler CCAAT-Box...............79

Abbildung 36: Autoradiogramme der EMSA-Assays der H3/k-CCAAT-Boxen ............................ 81

Abbildung 37: Autoradiogramme der EMSA-Assays der H3/m-CCAAT-Boxen ............................ 82 
Abbildung 38: Kompetition des NF-Y-Komplexes durch CCAAT-Oligonukleotide ..........................83

Abbildung 39: Sequenzvergleich der 3'-Prozessierungselemente der $11 \mathrm{H3}$-Histongene ............... 87

Abbildung 40: Vergleich der endogenen Expression und der Promotoraktivität von sechs

H3-Genen ........

Abbildung 41: Der funktionelle Grundaufbau der H3-Promotoren (schematische Darstellung)........ 108

\section{Verzeichnis der Tabellen}

Tabelle 1: Die elf humanen replikationsabhängigen H3-Histongene .................................. 12

Tabelle 2: Auswertung der Autoradiogramme der Einzelsonden-Experimente ............................... 125 


\section{Verzeichnis der Abkürzungen}

Zur Bezeichnung der physikalischen Größen wurden SI-Einheiten verwendet.

\begin{tabular}{|c|c|}
\hline A & Adenin \\
\hline ADP & Adenosindiphosphat \\
\hline $\mathrm{Amp}^{r}$ & Ampicillin-Resistenzgen \\
\hline APS & Ammoniumpersulfat \\
\hline ATP & Adenosintriphosphat \\
\hline bidest & bidestilliert \\
\hline $\mathrm{bp}$ & base pairs (Basenpaare) \\
\hline BSA & bovine serum albumine (Rinder-Serum-Albumin) \\
\hline C & Cytosin \\
\hline CB & Cajal body \\
\hline CBF & CCAAT-box binding factor \\
\hline CCE & cell cycle element (Zell-Zyklus-Element) \\
\hline CDK & cyclin dependent kinase (Cyclin abhängige Kinase) \\
\hline CDP & CCAAT displacement protein \\
\hline CDS & coding sequence (kodierende Sequenz) \\
\hline CH1UE & conserved $\mathrm{H} 1$ upstream element \\
\hline $\mathrm{Ci}$ & Curie \\
\hline CIP & calf intestinal phosphatase \\
\hline $\mathrm{cpm}$ & counts per minute (Impulse pro Minute) \\
\hline CRAS & coding region activating sequence \\
\hline CRE & cAMP response element \\
\hline CREB & cAMP response element binding protein \\
\hline CTP & Cytidintriphosphat \\
\hline dATP & 2'-desoxy-Adenosintriphosphat \\
\hline dCTP & 2'-desoxy-Cytidintriphosphat \\
\hline ddNTPs & 2', 3'-didesoxy-Nucleosidtriphosphate \\
\hline DEPC & Diethylpyrocarbonat \\
\hline dGTP & 2'-desoxy-Guanosintriphosphat \\
\hline DMEM & Dulbecco's MEM \\
\hline DNA & desoxyribonucleic acid (Desoxyribonucleinsäure) \\
\hline DNase & Desoxyribonuclease \\
\hline dNTP & 2'- desoxy-Nucleosidtriphosphat \\
\hline ds & double strand (Doppelstrang) \\
\hline DTT & Dithiothreitol \\
\hline dTTP & 2 - desoxy-Thymidintriphosphat \\
\hline
\end{tabular}




\begin{tabular}{|c|c|}
\hline E. coli & Escherichia coli \\
\hline EDTA & Ethylendiamintetraessigsäure \\
\hline EMSA & electrophoretic mobility shift assay \\
\hline FCS & fetal calf serum (fötales Kälber-Serum) \\
\hline G & Guanin \\
\hline $\mathrm{G}_{0}$-Phase & gap0 phase \\
\hline $\mathrm{G}_{1}$-Phase & gap1 phase \\
\hline $\mathrm{G}_{2}$-Phase & gap2 phase \\
\hline GTP & Guanosintriphosphat \\
\hline H1-SF & H1-motif specific factor \\
\hline HDE & Histone downstream element \\
\hline HFE & Haemochromatose-Gen \\
\hline HGC & Histongen-Cluster \\
\hline HiNF & histone nuclear factor \\
\hline HNE & HeLa nuclear extract \\
\hline IFN & Interferon \\
\hline IRF & interferon regulatory factor \\
\hline $\mathrm{kb}$ & Kilobasen \\
\hline $\mathrm{kDa}$ & kilo Dalton \\
\hline KDist & distale CCAAT-Box des H3/k-Promotors \\
\hline KProx & proximale CCAAT-Box des H3/k-Promotors \\
\hline LB-Medium & Luria Bertani-Medium \\
\hline $\operatorname{luc}^{+}$ & Luziferase kodierende Sequenz \\
\hline M-Phase & Mitose-Phase \\
\hline MEM & Minimum Essential Medium (Eagle) \\
\hline MCS & multiple cloning site \\
\hline MOPS & 3-N-Morpholinopropansulfonsäure \\
\hline MDist & distale CCAAT-Box des H3/m-Promotors \\
\hline MProx & proximale CCAAT-Box des H3/m-Promotors \\
\hline mRNA & messenger RNA \\
\hline mut & mutiert \\
\hline NF-Y & nuclear factor $Y$ \\
\hline NPAT & nuclear protein mapped to the AT-locus \\
\hline$O D_{600}$ & optische Dichte bei der Wellenlänge $600 \mathrm{~nm}$ \\
\hline PBS & phosphate buffered saline \\
\hline PCR & polymerase chain reaction (Polymerasekettenreaktion) \\
\hline pRB & Retinoblastom-Protein \\
\hline
\end{tabular}




\begin{tabular}{ll}
\hline RNA & ribonucleic acid (Ribonukleinsäure) \\
RNase & Ribonuclease \\
RPA & RNase Protection Assay \\
RPMI & Roswell Park Memorial Institute \\
RT & Raumtemperatur \\
S-Phase & Synthese-Phase \\
SDS & sodium dodecyl sulfate (Natriumdodecylsulfat) \\
SEM & Standardabweichung des Mittelwerts \\
SLBP & stem-loop binding protein \\
snRNA & short nuclear ribonucleic acid \\
snRNP & short nuclear ribonucleoprotein \\
SS & single strand (Einzelstrang) \\
SV40 & simian virus 40 \\
T & Thymin \\
TBE & Tris-Borsäure-EDTA \\
TBP & TATA-box binding protein \\
TE & Tris-EDTA \\
TEMED & N,N,N',N'-Tetramethylethylendiamin \\
TF & Transkriptions-Faktor \\
Tris & Tris-(Hydroxymethyl)-Aminomethan \\
TTP & Thymidintriphosphat \\
U & Uracil \\
U & unit \\
U/min & Umdrehungen pro Minute \\
üN & über Nacht \\
UMP & Uridinmonophosphat \\
UTP & Uridintriphosphat \\
UTR & Untranslatierte Region \\
UV & ultraviolett \\
Volume per volume (Volumen pro Volumen) \\
Thelume (Gewicht pro Volumen)
\end{tabular}




\section{Einleitung}

\subsection{Histone und Histongene}

Die DNA in eukaryonten Zellen ist mit zahlreichen Proteinen als Chromatin organisiert. Histone sind die Hauptbestandteile von Chromatin. Sie kompaktieren die DNA und verkürzen so ihre Konturlänge, die als nackte DNA pro diploidem Genom etwa $80 \mathrm{~cm}$ beträgt. Histone haben als basische Proteine eine hohe Affinität zur DNA. Es gibt fünf verschiedene Histon-Haupttypen: Das H2A-Histon, das H2B-Histon, das H3-Histon und das H4-Histon werden "Core-Histone" genannt, weil sie das zentrale Histon-Oktamer bilden, um welches sich die DNA wickelt. Das H1-Histon wird "Linker-Histon“ genannt. Es lagert sich von außen an die DNA an, die das Histon-Oktamer umspannt.

Die Histone bilden mit der DNA im Chromatin eine charakteristische Struktur (Kornberg 1974; Kornberg und Thomas 1974; Oudet et al. 1975): jeweils genau 146 Basenpaare der DNA wickeln sich in 1,75 linksdrehenden Windungen um ein HistonOktamer. Das Oktamer ist aus jeweils zwei Proteinen vom Histontyp H2A, H2B, H3 und $\mathrm{H} 4$ aufgebaut. Dabei bilden ein H3-Histon- und ein H4-Histon-Protein ein HeteroDimer. Die beiden Hetero-Dimere verbinden sich zu einem Tetramer. An das Tetramer (H3-Histon / H4-Histon) $)_{2}$ binden zwei (H2A-Histon / H2B-Histon) Dimere. Diese Struktur nennt man Core-Partikel, sie wurde von Luger et al. (1997) mit einer Auflösung von 2,8 $\AA$ bestimmt. Im Chromatin sind benachbarte Core-Partikel über die sogenannte "Linker-DNA“ miteinander verbunden, wobei die Länge der "LinkerDNA“ zwischen 50 und 100 Basenpaaren (bp) variiert (Kornberg 1977; Allan et al. 1980). An der Ein- und Austrittstelle der DNA-Doppelhelix am Core-Partikel ist ein Linker-H1-Histon assoziiert (Simpson 1978). Die Core-Partikel und die Linker-DNA mit dem H1-Histon bilden zusammen das Nukleosom, das man als den Grundbaustein des Chromatins betrachten kann. Eine lineare Kette von Nukleosomen wird als $10 \mathrm{~nm}$ DNA-Faser bezeichnet. Diese kann eine superhelikale Struktur bilden, die $30 \mathrm{~nm}$ DNA-Faser genannt wird (Thoma et al. 1979). Darüber hinaus wird die Existenz von weiteren, zum Teil übergeordneten ChromatinStrukturelementen vermutet. 
Die Histone sind entscheidende Strukturproteine im Chromatin. Darüber hinaus können sie - bevorzugt an ihren beweglichen Schwanzregionen - acetyliert, phosphoryliert, methyliert, ubiquitiniert und Poly-ADP-ribosyliert werden. Diese Modifikationen besitzen, soweit bekannt, regulatorische Funktionen: Zum Beispiel spielt die Acetylierung der Histone eine wichtige Rolle bei der Genregulation, während die Poly-ADP-Ribosylierung in Aspekte der DNA-Reperatur involviert ist.

Die Histon-Typen H2A, H2B, H3, und H1 bilden Protein- und Genfamilien mit mehreren Subtypen. Mit Ausnahme der H4-Histongenfamilie, die für ein identisches Protein kodiert, lassen sich alle Histongenfamilien in zwei Klassen untergliedern: Zum einen gibt es die replikationsabhängig-exprimierten Histongene („replikationsabhängige Histongene“), die in proliferierenden Zellen vor allem in der S-Phase exprimiert werden. Zum anderen gibt es die sogenannten „ReplacementHistongene“, die im Zellzyklus und auch in terminal differenzierten Zellen in geringer Menge konstitutiv exprimiert werden (Wu und Bonner 1981). Die ReplacementHistone ersetzen defekte oder abgebaute Histone in $\mathrm{G}_{0}-$ Zellen bzw. terminal differenzierten Zellen (Brown et al. 1985).

Die replikationsabhängig-expremierten Histongene (im Folgenden „replikationsabhängige Histongene“ genannt) weisen vier Besonderheiten auf, die sie von anderen Genen unterscheiden:

1. Die Histongene einer Histonfamilie liegen in mehrfacher Anzahl im Genom vor. Die individuellen Gene sind zwar auf DNA-Ebene nicht vollkommen identisch zueinander, kodieren aber für identische bzw. fast identische Proteine. Beispielsweise gibt es elf $\mathrm{H} 3$-Histongene, zehn davon kodieren für ein vollkommen identisches Protein, das H3.1-Histon, und eines, das H3/n-Gen, kodiert für das H3.2-Histon. Das H3.2-Histon unterscheidet sich vom H3.1-Histon lediglich in einer Aminosäure (Ser96 statt Cys96).

2. Sie enthalten - im Gegensatz zu üblichen eukaryontischen Genen - keine Introns.

3. Die Transkripte dieser Gene gehören zu den wenigen Ausnahmen bekannter Transkripte in menschlichen Zellen, die keinen Poly(A)-Schwanz tragen (Adesnik et al. 1972). Anstelle des Poly(A)-Schwanzes enthalten die Histon-mRNAs eine konservierte 3'-terminale 16 bp-Haarnadelstruktur („Stem-Loop“), die in der Histon-spezifischen prä-mRNA-3'-Prozessierung (Vasserot et al. 1989; 
Schümperli et al. 1990; Dominski und Marzluff 1999), dem Histon-mRNAKernexport (Williams et al. 1994) und der Histon-mRNA-Stabilität (Pandey und Marzluff 1987) involviert ist.

4. Sie befinden sich in vier Histongenclustern, in denen die Histongene in unmittelbarer Nachbarschaft auf unregelmäßige Weise angeordnet sind (siehe Abbildung $1_{\beta}$ und Abbildung 2\$) ${ }^{1}$. Es gibt drei Histongencluster unterschiedlicher Größe in enger Nachbarschaft auf Chromosom 6 und einen Histongencluster auf Chromosom 1 (Tripputi et al. 1986; Allen et al. 1991; Albig und Doenecke 1997; Albig et al. 1997a; Ahn und Gruen 1999) (siehe Abbildung 1, und Abbildung 2\$).

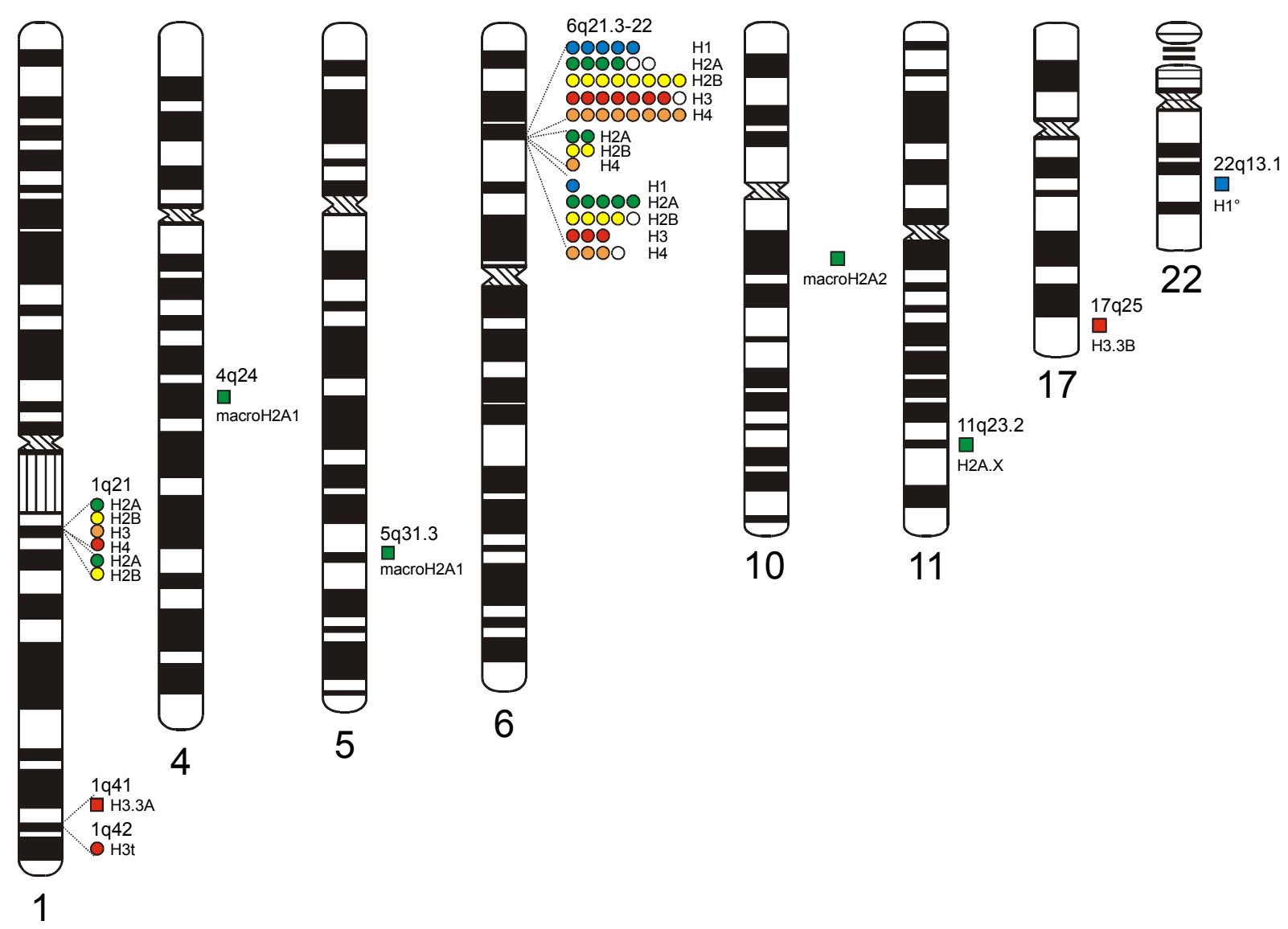

Abbildung 1: Die Organisation der humanen Histongene.

Eine chromosomale Kartierung der humanen Histongene. Dargestellt sind die Chromosomen mit Nummer und Bandenstruktur, die Histongene enthalten. Hellblau: H1-Histongene, grün: H2AHistongene; gelb: H2B-Histongene; rot: H3-Histongene; orange: H4-Histongene; weiß: HistonPseudogene. Kreise: Replikationsabhängige Histongene; Quadrate: Replacement-Histongene. Ergänzt nach: Albig und Doenecke (1997).

\footnotetext{
${ }^{1}$ Die Nummer im Index der Abbildungsnummer gibt die Seite an, auf der die Abbildung zu finden ist.
} 
Diese Besonderheiten ermöglichen eine hohe Histon-Syntheserate: Zum einen ist eine parallele Transkription auf mehreren Genen möglich, so dass schnell größere Mengen an Histon-prä-mRNA gebildet werden können. Zum anderen ist die Prozessierung der Histon-prä-mRNA zur mRNA im Vergleich zu anderen Genen beschleunigt, da keine Introns entfernt werden müssen. Die Synthese von großen Mengen der Histone ist in der S-Phase des Zellzyklus' nötig, um das Chromatin zu duplizieren. Die Histone stellen einen Großteil der Masse des Chromatins und werden in einem stöchiometrischen Verhältnis zur DNA-Menge benötigt (je ca. 200 bp DNA werden 9 Histonproteine benötigt).

Auch erlaubt z.B. die Histon-spezifische prä-mRNA-3'-Prozessierung Histonspezifische Regulationsmöglichkeiten der Histonsynthese (siehe 1.2 Regulation der Histonsynthese, $)$.

Die in der vorliegenden Arbeit untersuchten elf replikationsabhängigen $\mathrm{H} 3-$ Histongene befinden sich in drei der vier Histongencluster: sieben befinden sich im großen Histongencluster auf Chromosom 6, drei befinden sich im kleinen, centromerwärts gelegenen Histongencluster auf Chromosom 6 und ein Gen befindet sich im Histongencluster auf Chromosom 1 (siehe Abbildung 25 und Tabelle $11_{2}$ ).

Im Gegensatz zur den replikationsabhängigen Histongenen entsprechen die Replacement-Histongene den klassischen eukaryonten Genen: Sie besitzen in der Regel Introns (Brush et al. 1985), ihre Transkripte werden polyadenyliert und sie liegen im Genom einmalig und einzeln vor (siehe Abbildung 13). In der H3-HistongenFamilie gibt es zwei Replacement-Varianten: Das H3.3A-Gen liegt auf dem Chromosom 1 und das H3.3B-Gen liegt auf dem Chromosom 17 (Albig et al. 1995).

Darüber hinaus existieren Histongene, welche Testis-spezifisch exprimiert werden. Im Falle der H3-Histongen-Familie ist dies das H3/t-Gen (Albig et al. 1996; Witt et al. 1996), das sich auf Chromosom 1 in der Nähe des H3.3A-Gens befindet.

\subsection{Regulation der Histonsynthese}

Die Synthese der Histone in der S-Phase des Zellzyklus', ausgehend von den replikationsabhängigen Histongenen, ist ein stufenweiser Prozess (siehe Abbildung 35, übernächste Abbildung): Zunächst werden die Histongene transkribiert, anschließend erfolgt die Histon-spezifische 3'-Prozessierung der prä-mRNA zur 
Chr. 6 (6p22-6p21.3):
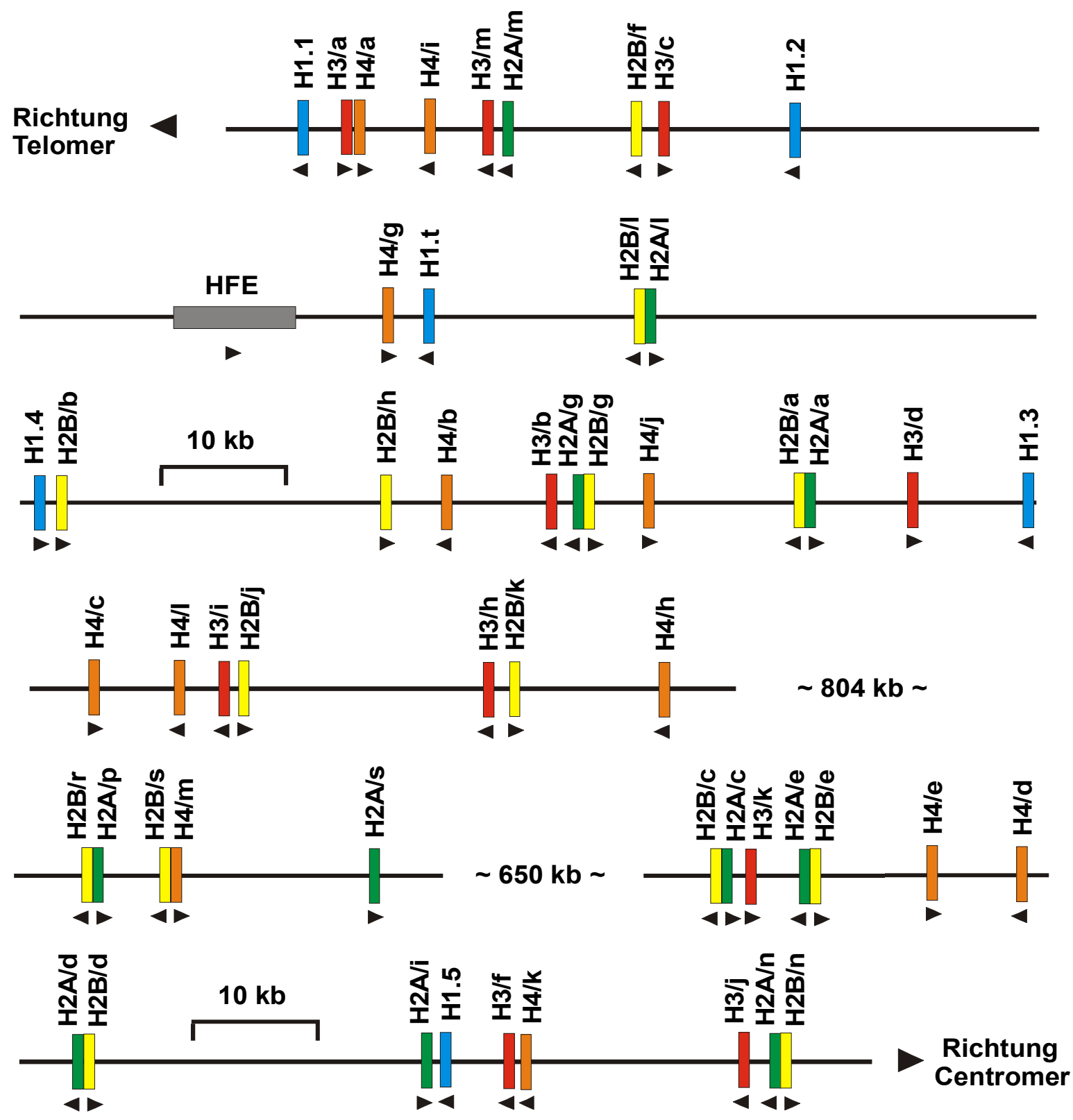

Chr. 1 (1q21-1q23):
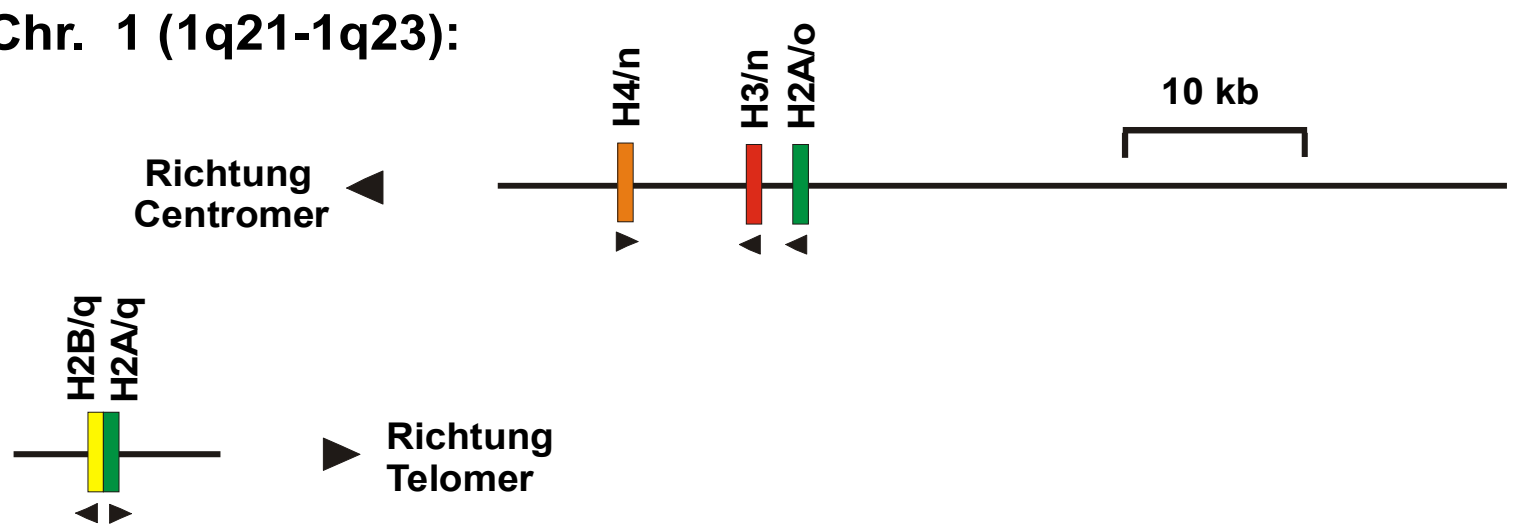

Abbildung 2: Maßstabsgetreue Genkarte der vier Histongencluster (ohne Pseudogene).

Hellblau: Histon H1, grün: Histon H2A; gelb: Histon H2B; rot: Histon H3; orange: Histon H4. Die Länge der Histongene wurde mit 846 bp dargestellt. HFE: Haemochromatose-Gen. 
mRNA und der Export der mRNA aus dem Zellkern ins Cytoplasma. Dort wird die mRNA translatiert. Die synthetisierten Histone werden anschließend in den Zellkern transportiert und dort ins Chromatin eingebaut.

In proliferierenden Zellen findet eine Histonsynthese fast ausschließlich in der S-Phase des Zellzyklus' statt. Die Regulation dieser zeitlich begrenzten Synthese erfolgt hauptsächlich, wenn nicht sogar vollständig, über variierende Histon-mRNAKonzentrationen. Die Histon-mRNA-Konzentrationen wiederum werden sowohl transkriptional als auch posttranskriptional reguliert (Schumperli 1986; Marzluff und Pandey 1988; Heintz 1991; Osley 1991; Stein et al. 1992; Marzluff und Duronio 2002).

Die Transkription der Histongene nimmt im Übergang von der $\mathrm{G}_{1}$ - zur S-Phase des Zellzyklus' stark zu und verdreifacht bis verfünffacht sich (DeLisle et al. 1983; Heintz et al. 1983). Sie bleibt während der S-Phase auf diesem hohen Niveau und fällt dann wieder auf das ursprüngliche Niveau ab.

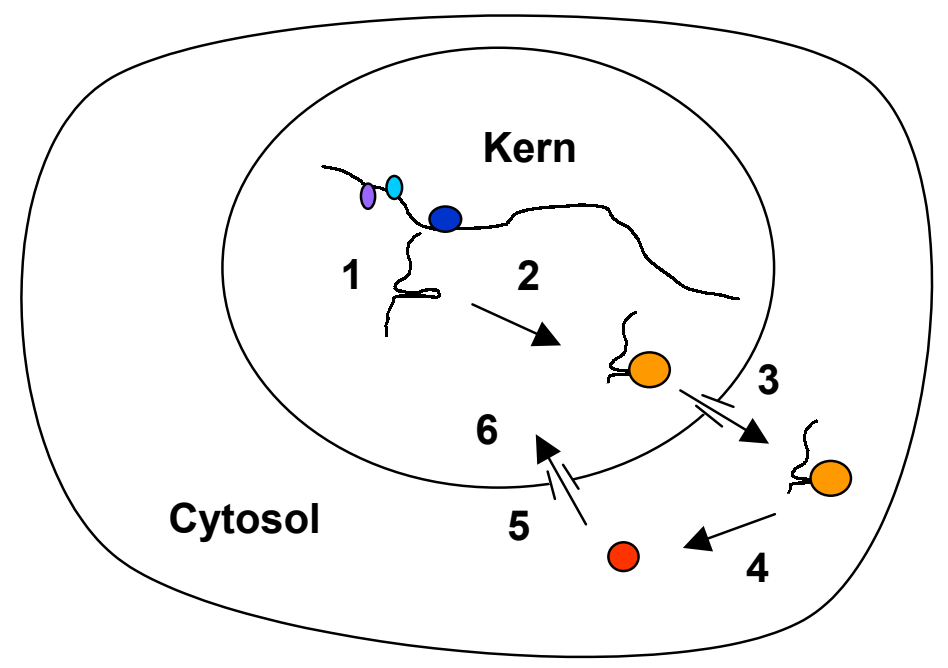

Abbildung 3: Schematische Darstellung der verschiedenen Stufen der Histonsynthese.

1. Transkription der Histongene durch die RNA-Polymerase II (in Dunkelblau, die beiden kleineren Ovale zeigen schematisch Transkriptionsfaktoren). 2. 3'-Prozessierung der Histon-prä-mRNA zur mRNA (gezeigt wird nur das SLBP-Protein in orange). 3. Kernexport der Histon-mRNA. 4. Translation der Histon-mRNA zu den Histon-Proteinen (hier beispielhaft ein H3-Histon-Protein als roter Kreis dargestellt). 5. Kernimport der Histone unter Beteiligung von Importfaktoren. 6. Verpackung der verschiedenen Histone mit DNA zu Nukleosomen.

Außerhalb der S-Phase ist die 3'-Prozessierung der Histon-prä-mRNA zur HistonmRNA ineffizient. Dies führt zum Abbau der Histon-prä-mRNA und damit zu einer äußerst niedrigen Syntheserate an Histon-mRNA (Stauber et al. 1986; Stauber und Schümperli 1988). Die Histon-prä-mRNA-3'-Prozessierung ist einschrittig und 
erfordert lediglich eine endonukleolytische Spaltung am 3'-Terminus (Dominski und Marzluff 1999): Dafür bindet das SLBP-Protein („Stem-Loop Binding Protein“) an den 3'-Stem-Loop der Histon-prä-mRNA. Anschließend bindet das U7-snRNP-Partikel an das „Histone Downstream Element“ (HDE), welches downstream des Stem-Loops gelegen ist. Das U7-snRNP-Partikel ist ein Komplex aus der U7-snRNA, welche einen 5'-Bereich enthält, der zum HDE komplementär ist, sieben Sm-Proteinen, darunter die neu identifizierten Proteine Lsm10 und Lsm11 (Pillai et al. 2001), und dem U7-snRNP-spezifischen Protein hZFP100. Das SLBP-Protein stabilisiert die Bindung des U7-snRNP-Partikels an die Histon-prä-mRNA über eine Interaktion mit dem hZFP100-Protein (Dominski et al. 2002). Zum Abschluss zerschneidet eine noch zu identifizierende Endonuklease die prä-mRNA am 3'-Terminus. Das SLBPProtein bleibt auch nach der Prozessierung an den Stem-Loop der Histon-mRNA gebunden (Marzluff und Duronio 2002).

Die ineffiziente 3'-Prozessierung der Histon-prä-mRNA außerhalb der S-Phase korreliert mit einer niedrigen Konzentration des SLBP-Proteins (Whitfield et al. 2000): Diese ist in der S-Phase zehnmal höher als in der $\mathrm{G}_{1}$-Phase. Das SLBP-Protein wird in stöchiometrischen Mengen für die 3'-Prozessierung, den Kernexport und die Stabilität der Histon-mRNA benötigt. Es wird am Ende der S-Phase phosphoryliert und degradiert (Whitfield et al. 2000). Da es außerhalb der S-Phase nur in geringen Konzentrationen vorkommt, ist in den übrigen Phasen des Zellzyklus' die Histon-prämRNA-3'-Prozessierung ineffizient.

Ein weiterer Faktor in der Zellzyklusregulation der Histon-mRNA-Konzentration ist die Stabilität der Histon-mRNA. Die Halbwertszeit der Histon-mRNA beträgt 45-60 Minuten in der S-Phase (und in der $\mathrm{G}_{1}$-Phase) und sinkt auf 10-15 Minuten am Ende der S-Phase (Heintz et al. 1983; Sittman et al. 1983). Der 3'-Stem-Loop der HistonmRNA ist wesentlich für die Regulation der Histon-mRNA-Stabilität (Pandey und Marzluff 1987). Vermutlich erfolgt aufgrund des Abbaus des SLBP-Proteins am Ende der S-Phase eine Destabilisierung der Histon-mRNA (Marzluff und Duronio 2002). Da der Abbau der Histon-mRNA an die Translation gekoppelt ist (Graves et al. 1987), könnte das SLBP-Protein die translatierte Histon-mRNA vor der Degradation schützen (Marzluff und Duronio 2002). Die Konzentration des SLBP-Proteins korreliert somit sowohl mit der Effektivität der Histon-prä-mRNA-Prozessierung, als auch mit der Stabilität der Histon-mRNA. 
Die fehlende Expression der replikationsabhängigen Histongene in terminal differenzierten Zellen ist sowohl transkriptional (Larson et al. 1989; Stein et al. 1989; van Wijnen et al. 1991a; Ramsey-Ewing et al. 1995) als auch posttranskriptional bedingt (Larson et al. 1992).

\subsection{Regulation der Histongen-Transkription}

Die Transkriptionsregulation der humanen replikationsabhängigen Histongene ist in jeder Histongen-Klasse unterschiedlich. Teilweise beobachtet man auch innerhalb einer Histongen-Klasse Unterschiede in der Transkriptionsregulation der individuellen Gene (van der Meijden et al. 1998; Trappe et al. 1999; Hampe 2000). Die Promotoren der einzelnen Histonklassen sind unterschiedlich aufgebaut und - soweit bekannt - klassenspezifisch reguliert (siehe unten). Wie die Transkription der verschiedenen Histonklassen angesichts der Stöchiometrie des Histon-Oktamers im Nukleosom quantitativ geregelt ist, und wie eine gemeinsame Zellzyklusregulation zustande kommt, ist noch weitestgehend unklar (siehe unten).

Trotz der Individualität der Promotoren der verschiedenen Histongen-Klassen gibt es einige Gemeinsamkeiten der replikationsabhängigen Histongenpromotoren: Alle besitzen eine TATA-Box, die als TBP-bindendes cis-Element für den Aufbau und die korrekte Positionierung des RNA-Polymerase II-Initialisierungskomplexes verantwortlich ist. Darüber hinaus besitzen die H1-, H2A-, H2B- und H3-Promotoren sogenannte „CCAAT“-Motive. In H4-Promotoren findet sich das „CCAAT“-Motiv nicht. Sowohl die TATA-Box als auch das CCAAT-Motiv sind Elemente, die in einer großen Anzahl von humanen Promotoren zu finden sind (Bucher und Trifonov 1988; Bucher 1990). TATA-Boxen sind Bindungsstellen für das TBP-Protein, welches Teil des generellen Transkriptionsfaktors TFIID ist. CCAAT-Boxen sind mögliche Bindungstellen für eine Vielzahl von Proteinen, die unterschiedliche Wirkung auf die Promotoraktivität haben. Zusätzlich existieren in den Promotoren der replikationsabhängigen Histongene cis-Elemente, die für die jeweilige Histongenklasse spezifisch sind. Im Folgenden soll eine Übersicht über die spezifischen Eigenheiten der Promotoren der verschiedenen Histongen-Klassen gegeben werden: Struktur, cis-Elemente und bisher identifizierte Transkriptionsfaktoren. Trotz der Vielzahl der bisher identifizierten cis-Elemente und Faktoren ist die genaue Identität der in vivo bindenden Faktoren, ihre genaue 
Funktion und ihr Zusammenspiel noch weitgehend unverstanden. Dies gilt für die Promotoren aller Histongen-Klassen. In der vorliegenden Arbeit wurde die Regulation der H3-Histongene erforscht.

\subsubsection{H1-Promotoren}

Die Promotoren der fünf replikationsabhängigen humanen $\mathrm{H} 1-G e n e \mathrm{H} 1.1$ bis $\mathrm{H} 1.5$ (Doenecke et al. 1994) weisen fünf putative cis-Elemente auf (Meergans et al. 1998):

1. Eine TATA-Box an der Position ca. -30 bis -24 bp vor dem Transkriptionsstart.

2. Im Abstand von 17 bp upstream der TATA-Box eine proximale CCAAT-Box. Hier wurde von Gallinari et al. (1989) die Bindung eines neuartigen, offenbar H1-spezifischen Faktors H1TF2 („H1 Transcription Factor 2“) beschrieben. Nach Martinelli und Heintz (1994) ist der Faktor ein Tetramer, das aus vier noch nicht bzw. noch nicht vollständig charakterisierten Polypeptidketten aufgebaut ist.

3. Ein G/C-reiches Motiv, das upstream in der Nähe der CCAAT-Box liegt und eine putative Sp1-Bindungsstelle ist.

4. Eine sogenannte H1-Box, bestehend aus dem Kern-Motiv AAACACA, die sich zirka an Position -115 befindet (Coles und Wells 1985). Das Histongen H1.1 enthält dieses Motiv als einziges replikationsabhängiges H1-Gen nicht. Allerdings beschrieben Dalton und Wells (1988) im Genom des Huhns in EMSAExperimenten die Bindung eines Faktors, den sie H1-SF nannten („H1-Motiv Specific Factor"). La Bella et al. (1989) fanden ebenfalls in EMSA-Experimenten eine Bindung an die H1-Box und nannten den Faktor H1TF1 („H1 Transkription Factor 1“). Die Identität dieses Faktors, der mit H1-SF identisch sein könnte, ist bisher unbekannt.

5. Ein CH1UE-Motiv (“Conserved H1 Upstream Element") TGTGTTA, welches sich ca. an Position -480 befindet (Duncliffe et al. 1995). Es handelt sich um ein Motiv, das zur H1-Box nahezu perfekt palindromisch ist.

Meergans et al. (1998) fanden in Reportergenassays des H1.3-Promotors in transienter Transfektion, dass alle fünf Elemente eine Rolle für die H1.3Promotoraktivität spielen. Das $\mathrm{CH} 1 \mathrm{UE}-M o t i v$ und die H1-Box schienen funktionell voneinander abhängig und in die Zellzyklusregulation des H1.3-Gens involviert zu sein. Von Ohshima et al. (2003) wurde für den H1.5-Promotor mit der Sequenz 
TGTCGCGATA ein weiteres, putatives cis-Element beschrieben. Es handelt sich um eine putative Bindungsstelle für ein humanes Homolog des Drosophila DREFProteins, hDREF/KIAA0785. Das Protein ist möglicherweise in die Regulation von Replikations- und Proliferations-spezifischen Genen involviert (Ohshima et al. 2003).

\subsubsection{H2A/H2B-Promotoren}

Es gibt 13 humane replikationsabhängige $\mathrm{H} 2 \mathrm{~A}-$ und 15 humane replikationsabhängige H2B-Gene (Albig et al. (1999), siehe auch Abbildung 25 ). Jeweils neun H2A- und neun H2B-Gene sind als divergente H2A/H2B-Genpaare organisiert. Sie besitzen ungefähr $320 \mathrm{bp}$ lange bipartite Promotoren (Albig et al. 1999). Die Promotoren der vier solitären H2A- und der sechs solitären H2B-Gene ähneln den bipartiten Promotoren der H2A/H2B-Genpaare, teilweise ist das jeweils andere Gen noch als Pseudogen erkennbar (Albig et al. 1999). Die Promotoren haben folgende Gemeinsamkeiten:

1. Alle H2A- und H2B-Gene besitzen eine TATA-Box.

2. In den Promotoren gibt es jeweils zwei Oct-1-Boxen mit der Konsensus-Sequenz ATGCAAAT (Sive und Roeder 1986). Eine davon befindet sich im Abstand von 8 bp upstream der TATA-Box des jeweiligen H2B-Gens. Eine weitere befindet sich mittig in den bipartiten Promotoren. Fletcher et al. (1987) zeigten, dass der Faktor OTF-1 an die Oct-1-Boxen bindet. Es konnte gezeigt werden, dass die Oct-1-Box für die Zellzyklusregulation der H2B-Expression notwendig ist (Sive und Roeder 1986; Fletcher et al. 1987; LaBella et al. 1988; Sturm et al. 1988).

3. Zwischen den beiden Oct-1-Boxen befindet sich eine CCAAT-Box.

4. Auf der H2A-Seite des bipartiten Promotors befinden sich neben der TATA-Box noch mindestens zwei CCAAT-Boxen.

Nach Albig et al. (1999) lassen sich die Promotoren der H2A/H2B-Gene in zwei Gruppen einteilen. Neun H2B- und fünf H2A-Gene besitzen einen bipartiten Promotor der Gruppe I. Sechs H2B- und sieben H2A-Gene besitzen einen bipartiten Promotor der Gruppe II. Bei den bipartiten H2A/H2B-Promotoren der Gruppe II wurden neben den gemeinsamen Elementen zusätzlich folgende putative Elemente identifiziert (Albig et al. 1999): 
1. Eine putative E2F-Bindungsstelle upstream der H2A-TATA-Box. Oswald et al. (1996) beschrieben die E2F-Bindungsstelle und zeigten, dass der Faktor E2F-1 daran bindet. Gemäß der Ergebnisse der Autoren war die Stelle für die Transkriptionsstärke und S-Phase-Abhängigkeit der untersuchten H2A-Gene erforderlich.

2. Nur 2 bp upstream der E2F-Bindungsstelle ein Oktanukleotid-Motiv (RT-1).

3. Auf der H2A-zugewandten Seite des bipartiten Promotors befinden sich drei CCAAT-Boxen im Vergleich zu zwei CCAAT-Boxen in den Gruppe I-Promotoren.

4. Neben dem zentralen Oct-1-Motiv befindet sich eine putative CRE/TRE-Box.

Trappe et al. (1999) untersuchten mit Reportergenassays den Effekt von Mutationen der oben genannten, zum Teil putativen cis-Elemente auf die Aktivität zweier bipartiter Promotoren (ein Gruppe I- und ein Gruppe II-Promotor) in transienter Transfektion. Die Aktivität der Promotoren wurde mit Hilfe von zwei verschiedenen Reportergenen in beiden Richtungen (Richtung H2A und Richtung H2B) ermittelt. Sie zeigten, dass alle oben genannten Elemente für die volle Aktivität der bipartiten Promotoren beider Gruppen in mindestens einer Richtung nötig waren. Die meisten Elemente aktivierten die Promotoren sogar in beiden Richtungen, so dass von einer partiell gemeinsamen Regulation der H2A- und H2B-Gene gesprochen werden kann.

\subsubsection{H3-Promotoren}

Im humanen Genom existieren $11 \mathrm{H} 3$-Histongene (siehe Abbildung 2 und Tabelle 1 12). Zu Beginn der Untersuchungen für die vorliegende Arbeit waren die Promotoren und die Expression der H3-Histongene wenig untersucht. Die Promotoren der humanen H3-Gene weisen kaum erkennbare Sequenzhomologien auf. Der H3/mPromotor ist der einzige detaillierter untersuchte humane H3-Promotor: Pauli et al. (1989) entdeckten im H3/m-Promotor mit Hilfe von DNase I-Sensitivitäts-Studien und DNase I-Footprinting zwei in vivo-Proteinbindungs-Stellen (-229 bis -184 und -148 bis -127 \{Bezug: ATG\}). Van Wijnen et al. (1991b) identifizierten mit EMSA-Analysen ein putatives ATF-bindendes Element im H3/m-Promotor an der Stelle -209 bis -185. Im EMSA-Gelshift wurden mehrere Banden erhalten, die mit der Bindung von verwandten Dimeren aus der ATF-Familie erklärt wurden. Im Bereich -148 bis -121, der eine CCAAT-Box enthält (die sogenannte distale CCAAT-Box), beobachteten die 
Autoren die Bindung eines Proteins, welches im EMSA-Experiment eine Bande der gleichen Laufhöhe wie der HiNF-B/NF-Y-Komplex des H1.5-Promotors (siehe H1Promotoren, aufwies. Zugleich konnte der genannte Bereich den HiNF-B-Komplex des H1.5-Promotors im EMSA-Experiment kompetieren. Schließlich wurde von van Wijnen et al. (1991b) gezeigt, dass der Promotor-Bereich von -148 bis -76 einen Komplex ausbildet, der mit dem HiNF-D-Komplex des H4/n-Gens (siehe 1.3.4 Promotoren in EMSA-Experimenten kreuzkompetiert.

Van den Ent et al. (1994) führten EMSA-Kompetitions-Experimente mit den Promotoren des H3/m-Gens, des H4/n-Gens und des H1.5-Gens durch. Promotorfragmente aller drei Promotoren lieferten HiNF-D-ähnliche Shift-Banden, die sich durch die H4-Site II des H4/n-Gens kompetieren ließen. In schwächerem Maße waren auch die $\mathrm{H} 3 / \mathrm{m}$ - und H1.5-Promotorfragmente in der Lage, die HiNF-Dähnlichen Shift-Banden zu kompetieren.

Tabelle 1: Die elf humanen replikationsabhängigen H3-Histongene

Die Bezeichnungen nach Albig und Doenecke (1997), die chromosomale Lage (HGC= HistongenCluster) und die EMBL Accession Number werden aufgeführt. Die Gene H3/a bis H3/m kodieren für den Subtyp H3.1, das Gen H3/n für den Subtyp H3.2 (siehe Histone und Histongene)

\begin{tabular}{|c|c|c|c|}
\hline Gen & Chromsomale Lage & $\begin{array}{l}\text { Accession } \\
\text { Number }\end{array}$ & Referenz \\
\hline $\mathrm{H} 3 / \mathrm{a}$ & 6p21.3-22 (großer HGC) & Z46261 & Albig et al. (1997a) \\
\hline $\mathrm{H} 3 / \mathrm{b}$ & 6p21.3-22 (großer HGC) & Z80784 & Albig et al. (1997a) \\
\hline $\mathrm{H} 3 / \mathrm{c}$ & 6p21.3-22 (großer HGC) & $X 57128$ & Kardalinou et al. (1993) \\
\hline $\mathrm{H} 3 / \mathrm{d}$ & 6p21.3-22 (großer HGC) & M60746 & Albig et al. (1991) \\
\hline$H 3 / f$ & 6p21.3-22 (kleiner HGC) & X83550 & Albig et al. (1997b) \\
\hline $\mathrm{H} 3 / \mathrm{h}$ & 6p21.3-22 (großer HGC) & Z80785 & Albig et al. (1997a) \\
\hline $\mathrm{H} 3 / \mathrm{i}$ & 6p21.3-22 (großer HGC) & Z80786 & Albig et al. (1997a) \\
\hline$H 3 / j$ & 6p21.3-22 (kleiner HGC) & Z83737 & Albig und Doenecke (1997) \\
\hline $\mathrm{H} 3 / \mathrm{k}$ & 6p21.3-22 (kleiner HGC) & Z83735 & Albig und Doenecke (1997) \\
\hline $\mathrm{H} 3 / \mathrm{m}$ & 6p21.3-22 (großer HGC) & $\begin{array}{l}\text { X00090 } \\
(\mathrm{M} 26150)\end{array}$ & $\begin{array}{l}\text { Zhong et al. (1983); } \\
\text { Marashi et al. (1986) }\end{array}$ \\
\hline$H 3 / n$ & 1q21 (HGC) & XM_059101 & $\begin{array}{l}\text { NCBI Annotation Project 2001; } \\
\text { Teilsequenz in Allen et al. (1991) }\end{array}$ \\
\hline
\end{tabular}


Eine Reihe von Publikationen zu Maus- oder Hamster-H3-Histongenen (Hurt et al. 1989; Hurt et al. 1991; Bowman und Hurt 1995; Bowman et al. 1996) beschreiben einen aktivierenden Effekt von cis-Elementen innerhalb der kodierenden Sequenz eines Maus-H3.2-Gens und eines Hamster-H3.2-Gens auf die Expression dieser Gene. Als putativer dort bindender Transkriptionsfaktor wurde das ubiquitär exprimierte Protein YY1 identifiziert (Eliassen et al. 1998). In einem Hamster-H3.2Promotor wurde eine AP-2 (Wu und Lee 1998) und eine YY1-Bindungsstelle (Wu und Lee 2001) identifiziert. Der H3.2-Promotor des Hamsters besitzt nur geringe Ähnlichkeit mit den humanen H3-Promotoren.

Zhao et al. (2000) und Ma et al. (2000) zeigten, dass ein sogenanntes humanes NPAT-Protein („Nuclear Protein mapped to the AT-Locus“) von Cyclin E/Cdk2 phosphoryliert wird. Das Protein lokalisiert in sogenannten Cajal-Bodies (CB), die subnukleare Körperchen sind und das Protein Coilin, das U7-snRNP und weitere Histon-mRNA-Prozessierungsfaktoren enthalten. Nicht alle Cajal-Bodies enthalten jedoch NPAT. Die NPAT-enthaltenden Cajal-Bodies assoziieren in der S-Phase mit den humanen Histongenclustern auf Chromosom 1 und 6 (und mit Chromosom 6 auch außerhalb der S-Phase)(Ma et al. 2000). In Reportergenassays wirkte eine Koexpression von NPAT stimulierend auf die Histonpromotoraktivität von $\mathrm{H} 4 / \mathrm{e}, \mathrm{H} 4 / \mathrm{n}$, $\mathrm{H} 2 \mathrm{~B} / \mathrm{r}$ und H3/a (Zhao et al. 2000). Daher vermuten die Autoren, dass NPAT die Zellzyklusregulation der Histongenexpression für sämtliche Histongenklassen vermitteln könnte. NPAT selbst bindet keine DNA und müsste daher über Interaktionspartner bei der Aktivierung der Histongenexpression wirken. Es sind bisher keine solchen Interaktionspartner identifiziert worden. Shopland et al. (2001) fanden allerdings, dass die Histongencluster nicht permanent mit Cajal-Bodies verbunden sind und die Histongenexpression nicht notwendigerweise die Anwesenheit von Cajal-Bodies benötigt.

\subsubsection{H4-Promotoren}

Im menschlichen Genom findet man 13 humane replikationsabhängige H4-Gene (siehe Abbildung 2\$). Von den H4-Promotoren wurde am ausführlichsten der Promotor des H4/n-Gens untersucht. Neben verschiedenen Bindungsstellen wurden unterschiedliche Faktoren gefunden, die auf die Aktivität des H4/n-Promotors 
Einfluss nehmen. Welche der im folgenden genannten Faktoren tatsächlich in vivo relevant sind und wie sie zusammenwirken, ist noch unklar.

Pauli et al. (1987) fanden im H4/n-Promotor zwei in vivo Protein/DNAInteraktionsregionen, die sie „Site I“ (-156 bis -113) und „Site II“ (-97 bis -47 \{Bez: ATG\}) nannten. Beide Regionen besitzen Sequenzhomologien in den anderen H4Promotoren, dabei ist die Site II innerhalb der replikationsabhängigen H4-Promotoren erheblich konservierter als Site I (Hampe 2000). Es wurde beschrieben, dass die volle Expression des H4/n-Gens zwei weitere Upstream-Bereiche benötigt (Helms et al. 1987; Kroeger et al. 1987; van der Houven van Oordt et al. 1992; Guo et al. 1997).

Birnbaum et al. (1995) konnten für die oben genannte Site I zwei bona fide cisElemente nachweisen: eine G-reiche Subregion, an die eine Bindung des Transkriptionsfaktors Sp1 vermutet wird, und upstream davon ein ATF-Element, welches Transkriptionsfaktoren aus der ATF-Familie binden soll. Die Site I-Region ist für maximale Promotoraktivität nötig, da Mutationen des Sp1-Elementes zu einer zirka sechsfachen Reduktion der Promotoraktivität führten.

Auch die proximalere Site II enthält mehrere cis-Elemente. Nach Ramsey-Ewing et al. (1994) ist sie für die Aktivität der H4-Promotoren entscheidend und zudem für die Zellzyklusregulation der H4-Promotoren verantwortlich. Für die Site-Il wurden drei bindende Faktoren bzw. Faktorfamilien beschrieben:

1. An die sogenannte M-Box (-88 bis -81, auch „CCE“ „Cell Cycle Element“ genannt) binden diverse Interferone bzw. Interferonpaare (vor allem IRF-1/IRF-3 bzW. IRF-1/IRF-7) binden (Xie et al. 2001). Die M-Box ist für die volle Aktivität des Promotors vonnöten und mit Sequenzvariationen auch in den Promotoren der anderen H4-Gene vorhanden. Die M-Box und die urprünglich HiNF-M genannten Interferone sollten als Transkriptionsfaktoren die Zellzyklusregulation des $\mathrm{H} 4 / \mathrm{n}$ Promotors vermitteln (Ramsey-Ewing et al. 1994; Vaughan et al. 1995; Aziz et al. 1998; Vaughan et al. 1998). Aziz et al. (1998) zeigten jedoch, dass H4/n-Promotoren, bei denen die M-Box mutiert war, nach wie vor korrekt Zellzyklus-reguliert waren, solange die unten beschriebene P-Box intakt war.

2. An die sogenannte P-Box $(-73$ bis -68$)$ bindet ein noch nicht näher charakterisiertes Protein, welches HiNF-P bzw. H4TF-2 genannt wird. In Reportergenanalysen führte eine Mutation der P-Box zu keinem Aktivitätsverlust des 
H4/n-Promotors in Tumorzellinien. Lediglich in einer IRF-1- und IRF-2-KnockoutDKO-Zelllinie beobachtete man Aktivitätsverluste.

3. An die sogenannte C-Box (-80 bis -74) und weitere, mit der M- und der P-Box überlappende Bereiche bindet der Proteinkomplex HiNF-D (van Wijnen et al. 1989; van Wijnen et al. 1991c; Aziz et al. 1998). Mit Hilfe von Supershift-Analysen wurde die Zusammensetzung des HiNF-D-Komplexes bestimmt. Er besteht aus den Zellzyklusregulatoren Cdc2 (Cdk1), Cyclin A und pRb (p105) (van Wijnen et al. 1994), sowie dem DNA-bindenden Homöodomänen-Protein CDP/Cut („CCAAT Displacement Protein") (van Wijnen et al. 1996). CDP/Cut ist ein Transkriptionsfaktor, der vermutlich nur in proliferierenden Zellen exprimiert wird und im Review von Nepveu (2001) als Repressor von differenzierungs- und entwicklungsspezifischen Genen beschrieben wurde. Aziz et al. (1998) beschrieben, dass HiNF-D für eine volle Aktivität des H4/n-Promotors in Tumorzellinien entbehrlich, aber in der IRF-1- und IRF-2-Knockout-DKO-Zelllinie nötig war. Der Faktor HiNF-D sorgte für einen korrekten zeitlichen Ablauf der Zellzyklusregulation der H4-Gene, die jedoch mit einer zeitlichen Verschiebung auch ohne seinen Einfluß stattfand (Aziz et al. 1998). Gupta et al. (2003) berichteten von einer reprimierenden Wirkung von CDP/Cut als Teil des HiNF-D-Komplexes auf die H4/n-Promotoraktivität.

Last et al. (1998) beschrieben, dass die ersten 210 bp der H4/n-kodierenden Sequenz reprimierende Wirkung auf den Thymidin-Kinase-Promotor hatten, wenn sie upstream desselben fusioniert wurden. Dies konnten sie mit Reportergenassays in transienter Transfektion in der HeLa-Zelllinie zeigen. Mit EMSA- und SupershiftExperimenten identifizierten sie den Faktor CDP/Cut (siehe oben), der mit drei putativen Repressorelementen in diesem Gen interagiert.

Last et al. (1999) fanden im H4/n-Promotor einige putative YY1-Bindungstellen. YY1 ist ein multifunktioneller Transkriptionsfaktor, der ubiquitär in Säuger-Zellen exprimiert wird und der die Transkription von Genen über verschiedene Mechanismen modulieren kann. In EMSA-Experimenten wurde eine Bindung von YY1 an die putativen YY1-Elemente beobachtet und in Reportergenassay eine stimulatorische Wirkung auf den Thymidin-Kinase-Promotor in transienter Transfektion festgestellt. 


\subsection{Zielstellung}

Eine der Besonderheiten der replikationsabhängigen Histongene besteht darin, dass sie in einer Vielzahl von Kopien vorliegen (siehe 1.1.). Im humanem Genom sind 11 replikationsabhängige $\mathrm{H} 3-G e n e$ vorhanden (ohne Pseudogene), die mit einer Ausnahme (in der eine Aminosäure anders ist) für ein identisches Protein kodieren. Diese Besonderheit wirft zahlreiche Fragen auf: Wie werden diese Gene in vivo exprimiert? Welchen Beitrag liefert jedes einzelne Gen zur H3-Gesamtexpression? Unterscheidet sich das H3-Expressionsmuster in verschiedenen normalen humanen Geweben und in verschiedenen humanen Zelllinien? Dient die Vielzahl der replikationsabhängigen Histongene auch dazu, Zelltyp-spezifische Unterschiede im Transkriptionsfaktor-Milieu auszugleichen, wie von Heintz (1991), Liu und Gorovsky (1996) und van der Meijden et al. (1998) vermutet? Wie ist die Expression der H3-Gene molekular reguliert, mit anderen Worten: wie funktionieren die H3-Promotoren? Korreliert das H3-Expressionsmuster in einem Zelltypus mit den dortigen H3-Promotoraktivitäten? Sind die H3-Promotoren in Struktur und Funktion ähnlich oder sogar identisch? Welches sind die entscheidenden cis-Elemente und welche Transkriptionsfaktoren binden daran? Gibt es Parallelen im H3-Promotoraufbau zu anderen Histongen-Klassen?

Um diese Fragen zu klären, sollte einerseits die Expression der H3-Gene in Gewebe und in verschiedenen Zellinien bestimmt werden. Anhand der H3-Expressionsdaten sollte zudem herausgefunden werden, welchen Einfluss die chromosomale Lage der H3-Gene auf ihre Expression ausübt.

Andererseits sollte angesichts der wenigen Arbeiten auf dem Gebiet der replikationsabhängigen $\mathrm{H} 3-$ Promotoren deren Struktur und Funktion aufgeklärt und die relevanten cis-Elemente identifiziert werden. Methodisch sollten sich die Untersuchungen auf Sequenzvergleiche, Reportergenassays und EMSA-Studien stützen. Es sollte mit Promotor-Deletionsreihen und Promotor-Mutationsreihen die funktionale Länge der H3-Promotoren bestimmt, relevante cis-Elemente gefunden und ihre Bedeutung für die H3-Promotoraktivität abgesichert werden. 


\section{Material}

\subsection{Geräte}

\section{L1-Labor:}

- Tischzentrifuge Sigma 1-15 (Sigma Laborzentrifugen, Osterode)

- Blockthermostat 5320 (Eppendorf, Hamburg)

- PCR-Gerät Gene Amp PCR System 2400 (Perkin Elmer /Applied Biosystems, Weiterstadt)

- Spectrophotometer Ultrospec 3000 (Amersham Pharmacia Biotech, Freiburg)

- Speed-Vac SC 100 (Savant, Holbrook, NY, USA) mit Kühlfalle

- Vakuumpumpe Typ RD 4 (Vacuubrand, Wertheim)

- Gefriertrockner Beta (Martin Christ GmbH, Osterode)

\section{L2-Labor:}

- Brutschrank Typ B5050 (Heraeus, Hanau)

- Kulturschüttler Incubator Shaker Model G 25 (New Brunswick Scientific Co. Inc., Edison, New Jersey, USA)

\section{Zellkultur:}

- Brutschrank Model CO24 (New Brunswick Scientific Co. Inc., Edison, New Jersey, USA)

- Brutschrank Cytoperm 2 (Heraeus, Hanau)

- Elektronisches Zellzählgerät CASY 1 TT (Schärfe Systems, Reutlingen)

- Sterilbank Herasafe Typ 18/2 (Heraeus, Hanau)

- Mikroskop Olympus CK40 - F200 (Olympus, Japan)

\section{Zentrifugen:}

- Varifuge 3.0R (Heraeus, Hanau)

- Sorvall RC 5B Plus (Kendro, Hanau)

\section{Isotopenlabor:}

- Geigerzähler LB122 (Berthold, Bad Wildbad)

- Szintillationszähler PW 4700 (Philips, Hamburg)

- Phosphorlmager (Molecular Dynamics, Krefeld)

- Phosphorlmager FLA-3000 (Fujifilm, Japan)

- BAS Cassette 2340 (Fujifilm, Japan)

- Geltrockner Drystar L-B (H. Hölzel GmbH, Wörth)

- Kühlfalle RVT 100 (Savant, Holbrook, NY, USA)

- Vakuumpumpe Typ RZ 5 (Vacuubrand, Wertheim) 
- Kühlzentrifuge EBA 12 R (Hettich, Tuttlingen)

- Tischzentrifuge Centrifuge 54145 (Eppendorf, Hamburg)

- Blockthermostat BT 100 (Kleinfeld Labortechnik)

- Blockthermostat 5320 (Eppendorf, Hamburg)

\section{UV-Labor:}

- UV-Schirm 366nm (Konrad Benda, Wiesloch)

- UV-Schirm Transilluminator Modell TM40 (UVP, San Gabriel, CA, USA)

- Gel-Dokumentationssystem E.A.S.Y (Herolab, Wiesloch) mit Video Copy Processor (Mitsubishi)

\section{Service-Labor:}

- Luminometer AutoLumat LB 953 (Berthold, Bad Wildbad)

- Sequenziergerät DNA-Sequencer Model 373 (Applied Biosystems, Weiterstadt)

- Sequenziergerät 3100 Genetic Analyser (Applied Biosystems (Weiterstadt) und Hitachi (Japan))

\subsection{Chemikalien und Reagenzien}

- Von Amersham Pharmacia Biotech (Buckinghamshire, GB): $5^{\prime}\left[\alpha^{32} P\right]-U T P$ (wässrige Lösung, spezifische Aktivität $3000 \mathrm{Ci} / \mathrm{mmol} ; 10 \mathrm{mCi} / \mathrm{ml}$ ), $5^{\prime}\left[\gamma^{32} \mathrm{P}\right]-A T P$ (wässrige Lösung, spezifische Aktivität $3000 \mathrm{Ci} / \mathrm{mmol} ; 10 \mathrm{mCi} / \mathrm{ml}$ )

- Von AppliChem (Darmstadt): Bacto-Agar, Hefeextrakt, Trypton

- Von Biochrom (Berlin): DMEM, FCS, HAM'S F12, MC COY'S 5A, MEM, RPMI 1640

- Von Merck (Darmstadt): Ammoniumacetat, Calciumchlorid, Ethanol, Formaldehyd, Isopropanol, $\mathrm{NaOH}$, Salzsäure, Triton X-100

- Von Peqlab Biotechnologie (Erlangen): peq Gold Agarose

- Von Ratiopharm (Ulm): Ampicillin (Binotal $\circledast$ )

- Von Roche Diagnostics (Mannheim): dATP, dCTP, dGTP, dTTP

- Von Roth (Karlsruhe): 30\% (w/v) Acrylamid - 0,8\% (w/v) Bisacrylamid- Lösung, Essigsäure, Natriumacetat, Natriumchlorid, Tris

- Von Serva (Heidelberg): Ammoniumpersulfat, $\beta$-Mercaptoethanol, EDTA, Glycerin, Maltose, TEMED

- Von Sigma (München): DEPC, Ethidiumbromid, Harnstoff, MOPS

\subsection{Reagenziensätze („Kits“)}

- Plasmidpräparation: Qiagen Plasmid Mini, Midi Kit (Qiagen, Hilden); E.Z.N.A.® Plasmid Miniprep Kit II (Peqlab Biotechnologie, Erlangen)

- Endotoxinfreie Plasmidpräparation: GenElute ${ }^{T M}$ Endotoxin-free Plasmid Midiprep Kit (Sigma, Saint Louis, USA); EndoFree Maxi-Plasmid-DNA-Isolierungs-Kit (Qiagen, Hilden)

- Aufreinigung von DNA aus Agarosegelen: QIAEX® II Agarose Gel Extraction Kit (Qiagen, Hilden); MinElute ${ }^{\mathrm{TM}}$ Gel Extraction Kit (Qiagen, Hilden) 
- $\quad$ Aufreinigung von PCR-Ansätzen: QIAquick PCR Purification Kit (Qiagen, Hilden); E.Z.N.A.® Cycle-Pure Kit (Peqlab Biotechnologie, Erlangen)

- DNA Sequenzierung: ABI PRISM ${ }^{\mathrm{TM}}$ Big Dye ${ }^{\mathrm{TM}}$ Terminator Cycle Sequencing Ready ReactionKit mit Ampli Taq ${ }^{\circledR}$ DNA-Polymerase FS (Applied Biosystems, Weiterstadt)

- Isolierung von Gesamt-RNA: RNeasy® Midi Kit (Qiagen, Hilden)

- Isolierung von chromosomaler DNA: Blood \& Cell Culture DNA Midi Kit (Qiagen, Hilden)

- $\quad$ In-vitro-Transkription: MAXIscript ${ }^{\mathrm{TM}}$ : In-vitro-Transkriptions-Kit (Ambion, Austin, USA)

- RNase-Protektion: RPA II ${ }^{\mathrm{TM}}$ : Ribonuclease-Protection-Assay-Kit (Ambion, Austin, USA)

- Mutagenese von Plasmiden: GeneEditor ${ }^{\mathrm{TM}}$ in vitro Site-Directed Mutagenesis System (Promega, Madison, USA)

- Transfektion von humanen Zellen: Effectene ${ }^{\mathrm{TM}}$ Transfection Kit (Qiagen, Hilden)

- Reportergen-Bestimmung: Dual-Luciferase ${ }^{\mathrm{TM}}$ Reporter Assay System (Promega, Madison, USA)

- $\quad$ Aufreinigung von Oligonukleotiden: Nucleotide Removal Kit (Qiagen, Hilden)

- Bandshift-Experimente: Gel Shift Assay Systems (Promega, Madison, USA)

\subsection{Enzyme}

\subsubsection{Restriktionsendonukleasen}

- Von Roche Diagnostics (Mannheim): $B c / \mathrm{I}$

- Von Gibco BRL (Eggenstein): Bgl I

- Von MBI Fermentas (Vilnius, Litauen): Eco RI, Hind III, Mlu I, Mun I, Sal I, Xho I

- Von New England Biolabs (Schwalbach): Afl III, Apo I, Ava I, Bam HI, Bst Ell, Dra I, Eco RV, Kpn I, Nco I, Not I, Sau3A I, Sma I, Spe I, Stu I

- Von Takara (Otsu, Shija, Japan): Bgl II, Eae I, Hinc II, Pst I, Sac I, Xho I

\subsubsection{DNA-modifizierende Enzyme}

- Alkalische Phosphatase aus Kälberdarm (CIP), EC 3.1.3.1 (Roche Diagnostics, Mannheim)

- Pwo DNA-Polymerase aus Pyrococcus woesei (für PCR), EC 2.7.7.7 (Roche Diagnostics, Mannheim)

- T4 DNA-Ligase, EC 6.5.1.1 (Roche Diagnostics, Mannheim bzw. MBI Fermentas, Vilnius, Litauen)

- $\quad$ T4 Polynukleotid-Kinase, EC 2.7.1.78 (New England Biolabs, Schwalbach)

\subsection{Lösungen}

- Ampicillin Stammlösung, steril: $100 \mathrm{mg} / \mathrm{ml}$ Ampicillin in bidest $\mathrm{H}_{2} \mathrm{O}$

- TBE-Puffer (10x): 0,9 M Tris-Base, pH 8,3; 0,9 M Borsäure; 0,025 M EDTA, autoklaviert

- TE-Puffer (10x): 100 mM Tris-HCl; 10 mM EDTA, pH 8,0, autoklaviert 
- 10\% APS-Lösung: $10 \%$ Ammoniumpersulfat in bidest $\mathrm{H}_{2} \mathrm{O}$, Aufbewahrung bei $-20^{\circ} \mathrm{C}$

- Calciumchlorid-Lösung: $50 \mathrm{mM} \mathrm{CaCl}_{2}$ in bidest $\mathrm{H}_{2} \mathrm{O}$, autoklaviert

- Ethidiumbromid-Stammlösung: $10 \mathrm{mg} / \mathrm{ml}$ Ethidiumbromid in bidest $\mathrm{H}_{2} \mathrm{O}$

- MOPS-Puffer (10x): 200 mM MOPS, pH 7,0; 30 mM Na-Acetat; 10 mM EDTA, autoklaviert

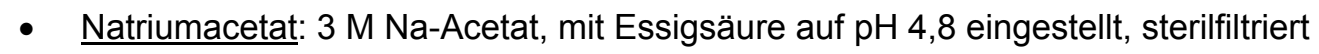

- Phosphate Buffered Saline (1x PBS): $137 \mathrm{mM} \mathrm{NaCl} ; 2,7 \mathrm{mM} \mathrm{KCl} ; 4,3 \mathrm{mM} \mathrm{Na}_{2} \mathrm{HPO}_{4} ; 1,47 \mathrm{mM}$ $\mathrm{KH}_{2} \mathrm{PO}_{4}, \mathrm{pH} 7,4$, autoklaviert

- 10x Reaktionspuffer für Alkalische Phosphatase (Roche Diagnostics): 0,5 M Tris-HCl, pH 8,5; 1 mM EDTA

- 10x Reaktionspuffer für T4 DNA Ligase (Roche Diagnostics): 50 mM Tris-HCl, pH 7,8; $10 \mathrm{mM}$ $\mathrm{MgCl}_{2} ; 20$ mM DTT; 1 mM ATP

- 1x Reaktionspuffer für T4 Polynukleotid Kinase (New England Biolabs, Schwalbach): 70 mM Tris- $\mathrm{HCl}, \mathrm{pH} \mathrm{7,6;10} \mathrm{mM} \mathrm{MgCl}_{2} ; 5 \mathrm{mM}$ Dithiothreitol

- 10x Reaktionspuffer mit $\mathrm{MgSO}_{4}$ für Pwo DNA-Polymerase (Roche Diagnostics): 100 mM Tris$\mathrm{HCl}, \mathrm{pH} 8,9 ; 250 \mathrm{mM} \mathrm{KCl} ; 50 \mathrm{mM}\left(\mathrm{NH}_{4}\right)_{2} \mathrm{SO}_{4} ; 20 \mathrm{mM} \mathrm{MgSO}_{4}$

- 10x Reaktionspuffer für Restriktionsendonucleasen

- Puffer L („Low Salt“): 100 mM Tris-HCl, pH 7,5; 100 mM MgCl$; 10$ mM DTT

- Puffer M (,Medium Salt“): $100 \mathrm{mM}$ Tris- $\mathrm{HCl}, \mathrm{pH} 7,5 ; 100 \mathrm{mM} \mathrm{MgCl}$; $10 \mathrm{mM}$ DTT; $500 \mathrm{mM} \mathrm{NaCl}$

- Puffer $\mathrm{H}$ (,High Salt"): $500 \mathrm{mM}$ Tris-HCl, pH 7,5; $100 \mathrm{mM} \mathrm{MgCl}_{2} ; 10 \mathrm{mM}$ DTT; $1000 \mathrm{mM} \mathrm{NaCl}$

- Puffer T (,Acetat"): $330 \mathrm{mM}$ Tris-Acetat, pH 7,9; $100 \mathrm{mM}$ Mg-Acetat; $5 \mathrm{mM}$ DTT; $660 \mathrm{mM} \mathrm{K-Acetat}$ (BSA-frei)

- $\operatorname{Trypsin-EDTA~(1x):~0,05\% ~(w/v)~Trypsin;~0,53~mM~EDTA~in~1x~PBS~}$

\subsection{Oligonukleotide}

- OHK1-21: von Interactiva (UIm).

- OHK22-68, OHK93 und OHK112-115: von MWG-Biotech (Ebersberg).

- OHK69-92, OHK94-111 und OHK116-118: von Metabion (Martinsried).

- OHK119-158: von Biospring (Frankfurt).

Sequenzen der Oligonukleotide und Beschreibung: siehe Anhang 8.1|Verwendete Oligonukleotide 18

\subsection{Vektoren}

- Von Promega (Madison, USA): pGL3-Basic, pGL3-promoter, pRL-CMV (siehe Abbildung 4 1 1)

- Von Stratagene (La Jolla, USA): pBluescript II KS (+) (siehe Abbildung 5 ${ }_{1}$ ) 


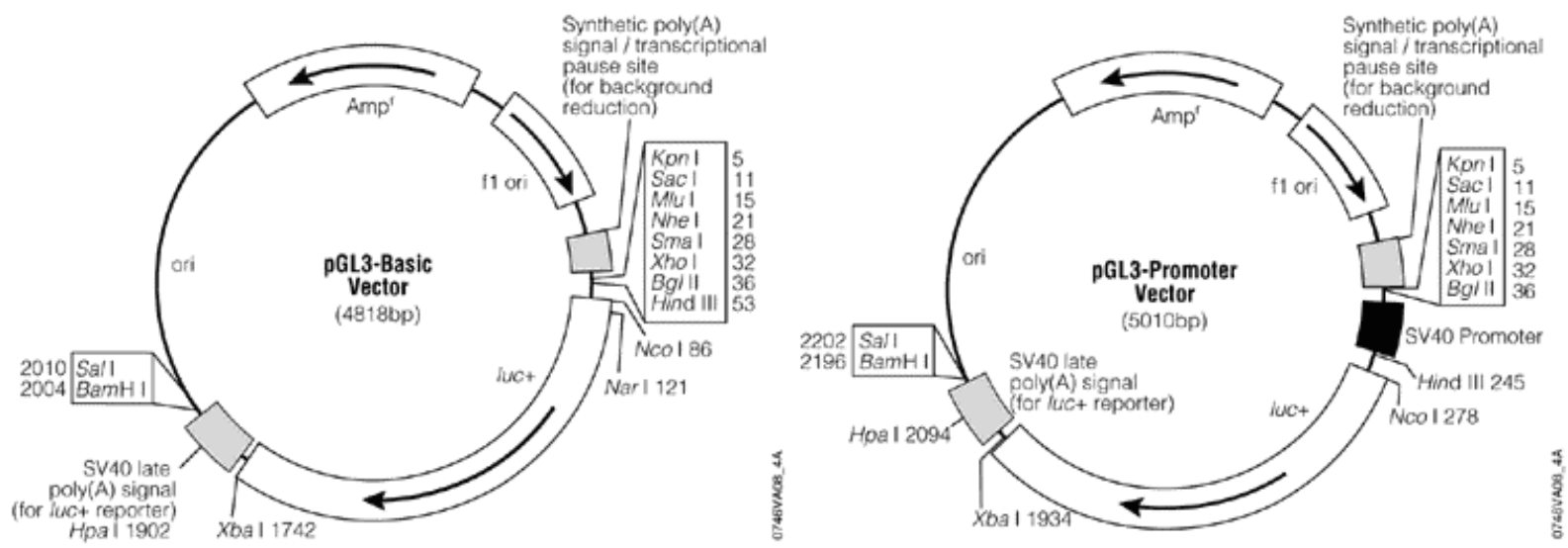

Abbildung 4: pGL3-Basic und pGL3-Promoter-Vektoren.

luc+: Firefly Luciferase kodierende Sequenz. Ampr: Ampicillin-Resistenz Gen. Die Lage der Multiple Cloning Sites (MCS), die zur Einklonierung von Promotoren bzw. Enhancern verwendet werden können, wird gezeigt. Des weiteren wird die Lage des synthetischen Poly(A)-Signals und des SV40Poly(A)-Signals angezeigt. Im Falle des pGL3-Promoter-Vektors wird zusätzlich die Lage des SV40Promotors angezeigt. Die Abbildungen stammen aus dem Katalog von Promega (Madison, USA).

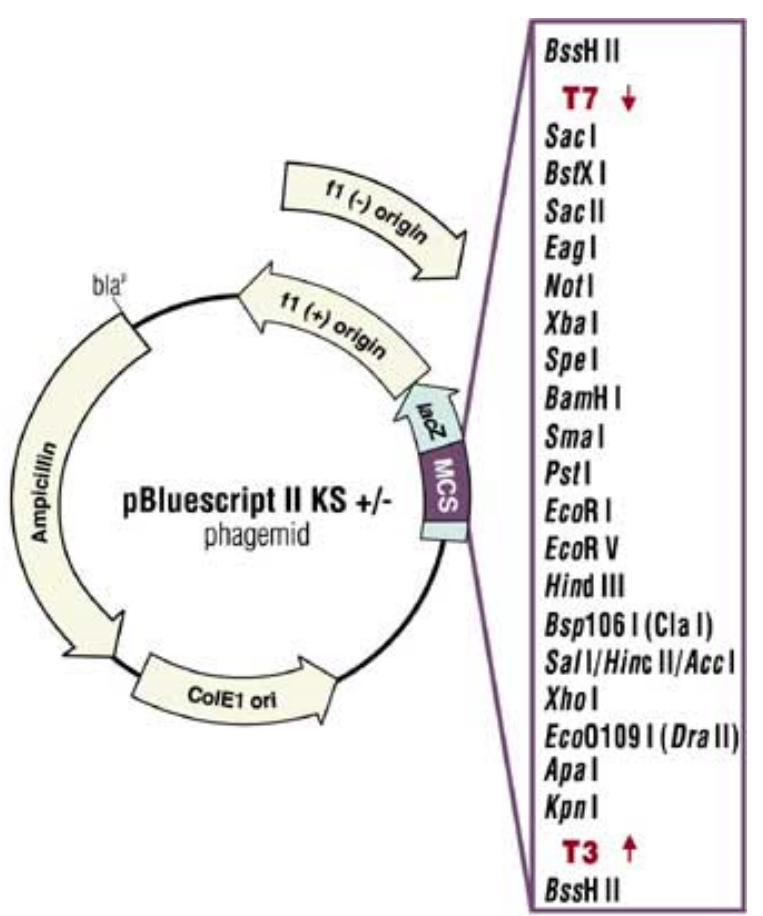

Abbildung 5: pBluescript II KS +/-.

MCS = Multiple Cloning Site. Die Restriktionsschnittstellen und die Lage der T7- und T3-Polymerase Startsequenzen sind rechts angegeben. Ampicillin = Ampicillin-Resistenz Gen. ColE1 ori = Origin für die Replikation in E. coli. Die Abbildung stammt aus dem Katalog von Stratagene (La Jolla, USA). 


\subsection{Mikroorganismen}

- Escherichia coli K12 Stamm DH5 $\left(\right.$ deoR, endA1, gyrA96, hsdR17( $\left.r_{k}{ }^{-} m_{k}{ }^{+}\right)$, recA1, relA1, supE44, thi-1, $\Delta$ (lacZYA-argFV169), $\phi 80 \delta l a c Z \Delta M 15, F^{-}, \lambda^{-}$) (Clontech, Palo Alto, USA)

- Escherichia coli JM109 (endA1, recA1, gyrA96, hsdR17 $\left(r_{k^{-}}, m_{k}+\right)$, relA1, supE44, $\lambda^{-}, \Delta$ (lacproAB), [F', traD36, proAB, lacl $\left.{ }^{\mathrm{a}} \mathrm{Z} \Delta \mathrm{M} 15\right]$ ) (Promega, Madison, USA)

- Escherichia coli BMH 71-18 mutS (thi, supE, $\Delta$ (lac-proAB), [mutS:Tn10] [F', proAB, lacl $\left.\left.{ }^{q} \mathrm{Z} \Delta \mathrm{M} 15\right]\right)$ (Promega, Madison, USA)

\subsection{Zelllinien}

- HL-60, SaOS-2 und Tera-2 (CLS, Heidelberg)

- Capan-1, HeLa, HeLa-S3, Hep-G2 und HEK-293 (DSMZ, Braunschweig)

- $\quad$ IMR-90 (ECACC, Salisbury, GB)

\subsection{Fotomaterialien}

- Cronex Röntgenfilm (Dupont, Bad Homburg)

- Entwicklerlösung (Kodak, Rochester, USA)

- Fixiererlösung (Kodak, Rochester, USA)

- Filterpapier Dick 2668 (Schleicher \& Schüll, Dassel)

- Filterpapier Dünn 2589 A (Schleicher \& Schüll, Dassel)

\subsection{Humane RNA aus Gewebe}

- Humane Gesamt-RNA aus fötaler Leber (Stratagene Europe, Amsterdam, Niederlande)

- Humane Gesamt-RNA aus fötaler Lunge (Stratagene Europe, Amsterdam, Niederlande)

- Humane Gesamt-RNA aus fötaler Blase (Stratagene Europe, Amsterdam, Niederlande)

- Humane Gesamt-RNA aus adulter Leber (Stratagene Europe, Amsterdam, Niederlande) 


\section{Methoden}

\subsection{Allgemeine molekularbiologische Methoden}

\subsubsection{Konzentrationsbestimmung von DNA}

Die Massen-Konzentration einer DNA-Lösung wurde durch die Bestimmung der Extinktion bei $260 \mathrm{~nm}$ ermittelt. Eine Extinktion von 1 entspricht dabei einer Massen-Konzentration von $50 \mathrm{ng} / \mathrm{\mu l}$. Das Verhältnis der Extinktion bei $260 \mathrm{~nm}$ und $280 \mathrm{~nm}$ ist dabei ein Maß für die Reinheit der DNA-Lösung. Für eine reine DNA-Lösung beträgt das Verhältnis 1,8 bis 2,0 .

\subsubsection{Ausfällen von DNA}

Das Ausfällen von DNA erfolgte nach Zugabe von 1/10 Volumen Natriumacetat-Puffer (siehe 2.5) und 2,5 Volumen absolutem Ethanol. Anschließend wurde $1 \mathrm{~h}$ bei $-80^{\circ} \mathrm{C}$ inkubiert und der Ansatz $30 \mathrm{~min}$ bei mindestens $15000 \mathrm{~g}$ zentrifugiert. Der Überstand wurde vorsichtig mit einer Pipette abgezogen, und das Pellet wurde mit $70 \%(\mathrm{v} / \mathrm{v})$ Ethanol gewaschen und erneut zentrifugiert. Nachdem der Überstand wieder vorsichtig abgezogen wurde, wurde das Pellet 3-5 min in der Speed-Vac getrocknet.

\subsubsection{Lösen von ausgefällter, getrockneter DNA}

Das Lösen von ausgefältter, getrockneter DNA in $1 \mathrm{x}$ TE-Puffer erfolgte bei $55^{\circ} \mathrm{C}$ im Wasserbad für $1 \mathrm{~h}$ unter gelegentlichem „Schnippen“.

\subsubsection{Schneiden von DNA mit Restriktionsenzymen}

Das Schneiden von DNA mit Restriktionsenzymen erfolgte mit folgendem $50 \mu$ l Reaktionsansatz:

- $\quad$ bis zu $5 \mu \mathrm{g}$ zu schneidende DNA

- $5 \mu \mathrm{l}$ 10x Puffer, passend zum Enzym

- ggf. $5 \mu \mathrm{l}$ 10x BSA-Lösung $(1 \mathrm{mg} / \mathrm{ml})$

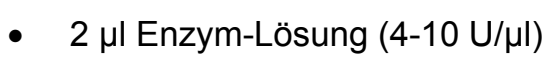

- mit sterilem bidest $\mathrm{H}_{2} \mathrm{O}$ auf $50 \mu$ auffüllen 
Die Inkubation erfolgte für 2-4 $\mathrm{h}$ bei der nach Herstellerangaben erforderlichen Temperatur, in der Regel bei $37^{\circ} \mathrm{C}$. Die Reaktionsansätze wurden anschließend mit der Agarose-Gelelektrophorese (siehe 3.1.5). oder mit einem der in 2.1.3 genannten PCR-Aufreinigungskits aufgereinigt.

Analytische Ansätze wurden mit folgendem $20 \mu$ Reaktionsansatz geschnitten:

- 2 2- 4 l Plasmid-Lösung (ca. $2 \mu g$ DNA)

- $2 \mu \mathrm{l} 10$ x Puffer

- ggf. $2 \mu \mathrm{l}$ 10x BSA-Lösung (1 mg/ml)

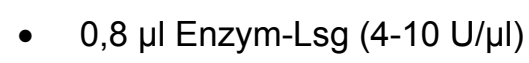

- mit sterilem bidest $\mathrm{H}_{2} \mathrm{O}$ auffüllen auf $20 \mu \mathrm{l}$

Die Inkubation des analytischen Reaktionsansatzes erfolgte für 1-2 $\mathrm{h}$ bei der nach Herstellerangaben erforderlichen Temperatur, in der Regel bei $37^{\circ} \mathrm{C}$.

\subsubsection{Agarose-Gelelektrophorese von DNA}

Die Agarose-Gelelektrophorese wurde mit 0,6 - 2,0 prozentigen Agarosegelen bei 3,5 $-4,5 \mathrm{~V} / \mathrm{cm}$ in 1x TBE Laufpuffer durchgeführt. Die Proben wurden in 1x DNA Probenpuffer aufgetragen. Die Anfärbung der Gele erfolgte 20 - 30 Minuten lang in einem Ethidiumbromid-Bad (Konzentration: $2,5 \mu \mathrm{g} / \mathrm{ml}$ Ethidiumbromid). Im Falle von präparativen DNA-Gelen wurden die gewünschten Banden, die auf einem UV-Schirm bei schwacher UV-Bestrahlung (366 nm) sichtbar wurden, aus dem Gel ausgeschnitten. Die ausgeschnittenen Banden wurden anschließend mit einem der in 2.1.3 genannten Aufreinigungs-Kits nach Herstellerangaben aufgearbeitet. Analytische Gele wurden unter kurzwelligerem UV-Licht fotografiert und dokumentiert (Gerät siehe 2.1.1).

Agarose-Gel: $0,6 \%-2,0 \%(w / v)$ Agarose in 1 x TBE

DNA Probenpuffer (6x): $15 \%$ (w/v) Ficoll 400; 0,25\% (w/v) Bromphenolblau oder Xylol-Cyanol

\subsubsection{Dephosphorylierung von DNA 5'-Enden}

Die Dephosphorylierung von DNA 5'-Enden erfolgte mit alkalischer Phosphatase aus Kälberdarm (alkaline Phosphatase from calf intestine (CIP), EC 3.1.3.1, Roche Diagnostics GmbH).

Folgender $140 \mu$ l Reaktionsansatz wurde gewählt:

- $5 \mu \mathrm{D}$ DNA

- 14 l 10x Dephosphorylierungspuffer (0,5 M Tris-HCl, pH 8,5; 1 mM EDTA)

- $\quad 5,6 \mu \mathrm{I} \mathrm{CIP}(1 \mathrm{U} / \mu \mathrm{l})(1 \mathrm{U}=$ Hydrolyse von $1 \mu \mathrm{mol}$ 4-Nitrophenyl-Phosphat/ min $)$

- mit bidest $\mathrm{H}_{2} \mathrm{O}$ auf $140 \mu$ lauffüllen

Die Reaktionsansätze wurden $4 \mathrm{~h}$ bei $37^{\circ} \mathrm{C}$ inkubiert und anschließend mit dem E.Z.N.A. ${ }^{\circledR}$ Cycle-Pure Kit (Peqlab) über DNA-bindende Säulen aufgereinigt. 


\subsubsection{5'-Phosphorylierung von Oligonukleotiden}

Die Oligonukleotide wurden mit T4-Polynukleotid-Kinase (NEB, $10 \mathrm{U} / \mu \mathrm{l}$ ) 5'-phosphoryliert. Folgender Reaktionsansatz wurde dabei gewählt:

- 100 pmol Oligonukleotid

- $2,5 \mu \mathrm{l}$ 10x Kinasepuffer (70 mM Tris-HCl, pH 7,6; $10 \mathrm{mM} \mathrm{MgCl}_{2} ; 5$ mM DTT)

- 5 U T4-Polynukleotid-Kinase

- $2,5 \mu \mathrm{l} 10 \mathrm{mM}$ ATP

- mit bidest $\mathrm{H}_{2} \mathrm{O}$ auf $25 \mu \mathrm{l}$ auffüllen

Der Reaktionsansatz wurde 30 min bei $37^{\circ} \mathrm{C}$ inkubiert und dann $10 \mathrm{~min}$ bei $70^{\circ} \mathrm{C}$ um die Kinase zu inaktivieren. Anschließend wurde der Reaktionsansatz bis zur Verwendung der phosphorylierten Oligonukleotide bei $-20{ }^{\circ} \mathrm{C}$ aufbewahrt. $\mathrm{Zu}$ beachten war, dass die Oligonukleotide nicht mit dem Gegenion Ammonium verbunden sein durften, da dieses die Kinasierung inhibiert.

\subsubsection{Ligation}

Die Ligation wurde über Nacht bei $16{ }^{\circ} \mathrm{C}$ im Wasserbad mit T4 DNA Ligase in 1x T4 DNA-Ligasepuffer durchgeführt. Bei Ligationen, die richtungsspezifisch durchgeführt wurden, wurden 50-150 fmol Vektoren und doppelt so viele Inserts eingesetzt. Bei Ligationen ohne Richtungsspezifikation wurden 50-150 fmol Vektoren und halb so viele Inserts eingesetzt, um multiple Insertionen in die Vektoren zu vermeiden.

10x T4 DNA-Ligasepuffer: 50 mM Tris- $\mathrm{HCl}, \mathrm{pH}$ 7,8; 10 mM MgCl$; 20$ mM DTT; 1 mM ATP

\subsection{Bakterienkultur}

Die in 2.9 genannten Bakterienstämme wurden entweder als Flüssigkulturen oder als Kolonien auf Agarplatten angezogen. Flüssigkulturen wurden in LB-Medium, ggf. mit Antibiotika-Zusatz, über Nacht bei $37^{\circ} \mathrm{C}$ und $250-280 \mathrm{U} / \mathrm{min}$ angezogen. Kolonien auf Agarplatten wurden auf LB-Agar (ggf. mit Antibiotika-Zusatz) über Nacht bei $37^{\circ} \mathrm{C}$ im Brutschrank inkubiert.

LB-Medium: $10 \mathrm{~g} / \mathrm{l}$ Typton; $5 \mathrm{~g} / \mathrm{l} \mathrm{Hefeextrakt;} 10 \mathrm{~g} / \mathrm{l} \mathrm{NaCl} ; 2 \mathrm{~g} / \mathrm{l}$ Maltose

LB-Agar: LB-Medium mit $15 \mathrm{~g} / \mathrm{l} \mathrm{Bacto-Agar}$

\subsubsection{Lagerung von Bakterienkulturen und Herstellung von „Stocks“}

Bakterienkulturen wurden ca. 2 Wochen bei $4{ }^{\circ} \mathrm{C}$ auf LB-Agarplatten gelagert oder als "Stock“ unbegrenzt in LB-Medium mit $20 \%(\mathrm{v} / \mathrm{v})$ Glycerin bei $-80{ }^{\circ} \mathrm{C}$ tiefgefroren. Dazu wurden $500 \mu \mathrm{l}$ einer Übernachtkultur mit $1 \mathrm{ml}$ sterilem 60\% (v/v) Glycerin versetzt und tiefgefroren. 


\subsubsection{Schnelle Präparation von Plasmiden aus Mini-Kulturen}

3,5 ml LB-Medium wurden mit einer Bakterienkolonie angeimpft. Dies erfolgte entweder mit einer Kolonie von einer Agarplatte oder mit 5-10 $\mu$ einer Stock-Lösung. Die Kultur wurde über Nacht bei $37{ }^{\circ} \mathrm{C}$ und 280-300 U/ min im Schüttelinkubator inkubiert. $2 \mathrm{ml}$ der üN-Kultur wurden in einem $2 \mathrm{ml}$ Reagiergefäß bei $1000 \mathrm{~g} 3 \mathrm{~min}$ lang zentrifugiert und der Überstand dekantiert. Das Bakterienpellet wurde in $300 \mu \mathrm{l}$ P1-Puffer resuspendiert. Dann wurde $300 \mu \mathrm{l}$ P2-Puffer zugegeben, das Cup dreimal invertiert und 5 min bei RT inkubiert. Anschließend wurde $300 \mu$ leiskalter P3-Puffer zugegeben, das Cup zweimal invertiert und 10 min auf Eis inkubiert.

Das nach Zugabe von P3-Puffer enstandene weiß-flockige Präzipitat wurde 15 min bei mindestens $15000 \mathrm{~g}$ in einer Tischzentrifuge zentrifugiert. Der klare Überstand (ca. 800 $\mu \mathrm{l}$ ), der durch Unterstechen einer sich oben befindenden Haut mit einer Pipette gewonnen werden konnte, wurde mit 0,7 Volumen Isopropanol versetzt und mindestens $30 \mathrm{~min}$ bei $15000 \mathrm{~g}$ bei RT zentrifugiert. Der Überstand wurde verworfen, das DNA-Pellet mit $70 \%$ eiskaltem Ethanol gewaschen und erneut 10 min zentrifugiert. Der Überstand wurde verworfen und das Pellet $5 \mathrm{~min}$ in der Speed-Vac getrocknet. Anschließend wurde das Pellet mit $70 \mu \mathrm{l}$ TE-Puffer versetzt und $1 \mathrm{~h}$ bei $55^{\circ} \mathrm{C}$ unter gelegentlichem „Schnippen“ gelöst.

Pufferzusammensetzung nach Qiagen Plasmid Purification Handbook 11/ 98 :

P1-Puffer: (Aufbewahrung bei $4{ }^{\circ} \mathrm{C}$ nach RNase A Zugabe): $50 \mathrm{mM}$ Tris $\mathrm{Cl}, \mathrm{pH}$ 8,0; $10 \mathrm{mM}$ EDTA; $100 \mu \mathrm{g} / \mathrm{ml}$ RNase A

P2-Puffer: $200 \mathrm{mM} \mathrm{NaOH} ; 1 \%$ (w/v) SDS

P3-Puffer: 3,0 M Kalium-Acetat pH 5,5

\subsubsection{Hochqualitative Mini- und Midi-Plasmidpräparation}

Für eine Mini-Plasmidpräparation wurden $3,5 \mathrm{ml}$ und für eine Midi-Präparation $50 \mathrm{ml}$ LB-Medium mit Bakterien angeimpft und über Nacht im Schüttelinkubator bei $37{ }^{\circ} \mathrm{C}$ und $280 \mathrm{U} / \mathrm{min}$ inkubiert. Anschließend wurden die Bakterien bei $1000 \mathrm{~g}$ für 3 min pelletiert und der Kulturüberstand dekantiert.

Die Aufarbeitung der Bakterien und die Isolierung der Plamid-DNA erfolgte mit einem der beiden in 2.3 genannten Kits für Plasmidpräparationen (Qiagen Plasmid Mini, Midi Kit bzw. E.Z.N.A.® Plasmid Miniprep Kit II) nach Herstellerangaben. Üblicherweise wurden in einer Mini-Plasmidpräparation 10-25 $\mu$ g Plasmid-DNA und in einer Midi-Plasmidpräparation $40 \mu \mathrm{g}$ gereinigte Plasmid-DNA erhalten.

\subsubsection{Endotoxinfreie Plasmidpräparation}

Die endotoxinfreie Plasmidpräparation wurde jeweils mit einem der beiden in 2.3 genannten Kits durchgeführt (GenEluteTM Endotoxin-free Plasmid Midiprep Kit bzw. EndoFree Maxi-Plasmid-DNAIsolierungs-Kit). Zunächst wurden 2-3 ml einer Bakterienvorkultur angeimpft und ca. $8 \mathrm{~h}$ bei $37^{\circ} \mathrm{C}$ und 
$280 \mathrm{U} / \mathrm{min}$ im Schüttelinkubator bis zur sichtbaren Trübung angezogen. Anschließend wurden $25 \mathrm{ml}$ LB-Medium mit $100 \mu \mathrm{g} / \mathrm{ml}$ Ampicillin in Erlenmeyerkolben mit Schikanen mit $125 \mu \mathrm{l}$ der Vorkultur (1:200) angeimpft und $17 \mathrm{~h}$ im Schüttelinkubator bei $37^{\circ} \mathrm{C}$ und $230 \mathrm{U} / \mathrm{min}$ inkubiert. Die Kultur wurde dann auf Eis abgekühlt und in einem $50 \mathrm{ml}$ Falcon-Röhrchen bei $4{ }^{\circ} \mathrm{C}$ und $4000 \mathrm{U} / \mathrm{min}$ in der Varifuge 3.0R zentrifugiert. Der Überstand wurde abdekantiert und das Bakterienpellet nach Herstellerangaben weiterverarbeitet. Für das GenEluteTM Endotoxin-free Plasmid Midiprep Kit wurde die Bakterienkultur in einem $15 \mathrm{ml}$ Falcon-Röhrchen zentrifugiert und nach dem ersten Abdekantieren des Überstandes erneut befüllt und zentrifugiert. Es wurden üblicherweise $200-400 \mu \mathrm{g}$ endotoxinfreie Plasmid-DNA erhalten, aliquotiert und bis zur Verwendung bei $-20^{\circ} \mathrm{C}$ gelagert.

\subsubsection{Präparation von Transformations-kompetenten Bakterien}

100 ml LB-Medium wurden mit 2 ml einer LB-Übernachtkultur von E. coli DH5a angeimpft (Verhältnis 1:50). Diese Kultur wurde dann ca. $2-2,5 \mathrm{~h}$ bei $37^{\circ} \mathrm{C}$ im Schüttelinkubator wachsen gelassen bis ihre $\mathrm{OD}_{600}$ einen Wert von 0,6 bis 0,9 erreichte. Dann wurde die Kultur 30 Minuten auf Eis inkubiert. Anschließend wurde die Lösung in zwei $50 \mathrm{ml}$ Falconröhrchen überführt und bei $4{ }^{\circ} \mathrm{C}$ mit $4000 \mathrm{U} / \mathrm{min}$ 10 min lang in einer Heraeus Varifuge 3.0R zentrifugiert. Jedes Pellet wurde in $25 \mathrm{ml}$ eiskaltem $50 \mathrm{mM}$ $\mathrm{CaCl}_{2}$ resuspendiert. Die Suspension wurde 30 Minuten auf Eis inkubiert und erneut bei $4{ }^{\circ} \mathrm{C}$, $4000 \mathrm{U} / \mathrm{min} 10$ Minuten zentrifugiert. Beide Pellets wurden gut vom Überstand befreit und zusammen in insgesamt $5 \mathrm{ml} 50 \mathrm{mM} \mathrm{CaCl}_{2}$ resuspendiert. Die Suspension wurde anschließend mindestens 2-3 h auf Eis inkubiert. Dann wurde $1 \mathrm{ml}$ reines Glycerin zugegeben, gemischt und die Suspension in $100 \mu \mathrm{l}$ Aliquots in flüssigem Stickstoff eingefroren. Die Aliquots wurden anschließend bis zur Verwendung bei $-80^{\circ} \mathrm{C}$ gelagert.

\subsubsection{Transformation von kompetenten Bakterien}

70-100 $\mu \mathrm{l}$ Transformations-kompetenter Bakterien wurden zu den Ligationsansätzen (20 $\mu \mathrm{l})$ in einem 1,5 ml Eppendorf-Gefäß gegeben. Im Falle einer Retransformation wurden 50 ng Plasmid in Lösung zu den 70-100 $\mu$ l Transformations-kompetenten Bakterien gegeben. Der Transformationsansatz wurde anschließend vorsichtig gemischt und 30 Minuten auf Eis inkubiert. Danach wurde die Lösung in einem Wasserbad exakt zwei Minuten inkubiert und anschließend sofort für fünf Minuten auf Eis inkubiert. Dann wurden $1 \mathrm{ml}$ LB-Medium zugegeben und die Eppendorf-Gefäße 75-90 Minuten bei $37^{\circ} \mathrm{C}$ und $260 \mathrm{U} / \mathrm{min}$ geschüttelt. Anschließend wurden die Eppendorf-Gefäße 3 Minuten bei $1000 \mathrm{~g}$ in einer Tischzentrifuge (Sigma 1-15) zentrifugiert und der Überstand wurde bis auf $150 \mu \mathrm{l}$ abgenommen. Das Pellet wurde wieder resupendiert und die komplette Suspension wurde auf LBPlatten (mit 50-100 $\mu \mathrm{g} / \mathrm{ml}$ Ampecillin) ausplattiert. Die Inkubation erfolgte über Nacht in einem $37^{\circ} \mathrm{C}$ Brutschrank. 


\subsection{Amplifikation von DNA mit der PCR-Reaktion}

Die Polymerase Kettenreaktion (PCR) zur Amplifizierung von DNA wurde mit Pwo DNA-Polymerase (EC 2.7.7.7) (Roche Diagnostics $\mathrm{GmbH}$ ) aus Pyrococcus woesei durchgeführt. Folgende Reaktionsbedingungen wurden gewählt:

- $10 \mathrm{mM}$ Tris- $\mathrm{HCl} \mathrm{pH} 8,85\left(20^{\circ} \mathrm{C}\right)$

- $25 \mathrm{mM} \mathrm{KCl}$

- $5 \mathrm{mM}\left(\mathrm{NH}_{4}\right)_{2} \mathrm{SO}_{4}$

- $2 \mathrm{mM} \mathrm{Mg}_{2} \mathrm{SO}_{4}$

- $200 \mu \mathrm{M}$ dNTPs (dATP, dCTP, dGTP, dTTP)

- 350 nM Upstream und Downstream-Primer (26 pmol bei einem $75 \mu$ l Ansatz)

- $40 \mathrm{ng} / 50 \mu \mathrm{l}$ Cosmid-DNA oder $7 \mathrm{ng} / 50 \mu \mathrm{l}$ Plasmid-DNA oder 40-400 ng/ $50 \mu \mathrm{l}$ humane chromosomale DNA

Die PCR-Reaktion wurde mit einem GeneAmp PCR System 2400 (Perkin Elmer) Gerät durchgeführt. Wurden bei der PCR Primer verwendet, die an ihrem 5'-Ende zu dem Templat nicht komplementäre Basen enthielten (zum Zwecke der Einführung einer Schnittstelle), so wurde folgendes Programm verwendet (die Hybridisierungstemperaturen II.2, III.2 und IV.2 und die Elongationszeiten II.3, III.3 und IV.3 wurden je nach Experiment variiert):

I)

$1.94^{\circ} \mathrm{C} 2 \min$

II) 5 Zyklen:

1. $94^{\circ} \mathrm{C} 15 \mathrm{~s}$

2. $52{ }^{\circ} \mathrm{C} 30 \mathrm{~s}$

3. $72{ }^{\circ} \mathrm{C} 1 \min 30 \mathrm{~s}$

III) 10 Zyklen:

1. $94^{\circ} \mathrm{C} 15 \mathrm{~s}$

2. $61{ }^{\circ} \mathrm{C} 30 \mathrm{~s}$ (sinkt um $0,4{ }^{\circ} \mathrm{C}$ pro Zyklus)

3. $72{ }^{\circ} \mathrm{C} 1 \min 30 \mathrm{~s}$

IV) 17 Zyklen:

1. $94^{\circ} \mathrm{C} \mathrm{C} 15 \mathrm{~s}$

2. $57,4{ }^{\circ} \mathrm{C} 30 \mathrm{~s}$ (sinkt um $0,4{ }^{\circ} \mathrm{C}$ pro Zyklus)

$3.72{ }^{\circ} \mathrm{C} 1 \mathrm{~min} 30 \mathrm{~s}$ (steigt um $10 \mathrm{~s}$ pro Zyklus)

V)

1. $72{ }^{\circ} \mathrm{C} 5 \mathrm{~min}$

2. $4{ }^{\circ} \mathrm{C}$ bis zur Entnahme

Erfolgte eine Amplifikation von DNA aus einer Plasmid-Quelle oder aus humaner chromosomaler DNA mit vollständig komplementären Primern, so wurde folgendes Rahmen-Programm verwendet (die Hybridisierungs-Temperaturen II.2 und III.2 und die Elongationszeiten II.3 und III.3 wurden je nach Experiment variiert): 
I)

II) 12 Zyklen:
1. $94{ }^{\circ} \mathrm{C} 4 \mathrm{~min}$

1. $94{ }^{\circ} \mathrm{C} 15 \mathrm{~s}$

2. $58^{\circ} \mathrm{C} 30 \mathrm{~s}$ (sinkt um $0,4^{\circ} \mathrm{C}$ pro Zyklus)

3. $72{ }^{\circ} \mathrm{C} 45 \mathrm{~s}$

III) 24 Zyklen:

1. $94{ }^{\circ} \mathrm{C} \mathrm{C} 15 \mathrm{~s}$

2. $53,2{ }^{\circ} \mathrm{C} 30 \mathrm{~s}$ (sinkt um $0,2{ }^{\circ} \mathrm{C}$ pro Zyklus)

3. $72{ }^{\circ} \mathrm{C} 45 \mathrm{~s}$ (steigt um $5 \mathrm{~s}$ pro Zyklus)

IV)

1. $72{ }^{\circ} \mathrm{C} 7 \mathrm{~min}$

2. $4{ }^{\circ} \mathrm{C}$ bis zur Entnahme

Wurde als Quelle humane chromosomale DNA verwendet, wurden - um unspezifische Effekte zu minimieren - die Primer erst zugegeben, nachdem der Ansatz bereits 2 min bei $94{ }^{\circ} \mathrm{C}$ denaturiert worden war. Die Aufarbeitung der PCR-Reaktionen erfolgte mit einem der in 2.3 genannten Kits nach Herstellerangaben über DNA-bindende Mini-Säulen.

\subsection{Mutagenese}

Die Mutagenese von Plasmiden wurde mit dem GeneEditor ${ }^{\mathrm{TM}}$ in vitro Site-Directed Mutagenesis System von Promega (Madison, USA) nach Herstellerangaben durchgeführt. Hierbei wurde zunächst die Template-Plasmid-DNA alkalisch denaturiert und anschließend mit zwei phosphorylierten mutagenisierenden Primern hybridisiert: Der eine Primer war Teil des Kits und modifizierte das Ampicillin-Resistenzgen $\mathrm{Amp}^{\mathrm{r}}$, so dass eine verbesserte Resistenz gegen einen nicht näher spezifizierten Antibiotika-Mix des Kits eingeführt wurde. Der andere, selbstentworfene Primer mutagenisierte dann die jeweils zu mutierende Stelle im Plasmid, indem er nicht-komplementäre, fehlende oder zusätzliche Basen enthielt. Die Phosphorylierung des selbstentworfenen Primers erfolgte mit T4 Polynukleotid-Kinase und ATP wie unter $3.1 .7_{25}$ beschrieben. Die Hybridisierung der beiden phosphorylierten Primer mit der denaturierten Template-DNA erfolgte im PCR-Gerät nach folgendem Programm: I) $75^{\circ} \mathrm{C} 3,5 \mathrm{~min}$ II) 25 Zyklen $75^{\circ} \mathrm{C} 1,5 \mathrm{~min}\left(-1,5^{\circ} \mathrm{C}\right.$ pro Zyklus) III) $37^{\circ} \mathrm{C}$ bis zur Entnahme. Dann erfolgte eine Komplettsynthese des Gegenstranges ausgehend von den beiden mutagenen Primern und die Ligation der resultierenden DNA-Stränge unter Verwendung des Kits nach Herstellerangaben. Anschließend wurden die Hybrid-Plasmide in kompetente E. coli BMH 71-18 mutS transformiert und über Nacht in einer LB-Flüssigkultur mit dem speziellen Antibiotika-Mix des Kits angezogen. Danach wurde eine hochqualitative Mini-Plasmidpräparation und eine erneute Transformation der resultierenden Plasmid-DNA in hochkompetente $E$. coli JM109 Zellen durchgeführt. Diese wurden auf einer LB-Agarplatte mit $100 \mu \mathrm{g} / \mathrm{ml}$ Ampicillin und dem Antibiotika-Mix ausplattiert und über Nacht bei $37^{\circ} \mathrm{C}$ inkubiert. Die Plamide der resultierenden Klone wurden in schnellen oder qualtitativen Mini-Plasmidpräparationen isoliert und mit Hilfe von Restriktionsverdau und DNA-Sequenzierung überprüft. 


\subsection{Zellkultur}

HL-60, Hep-G2, Capan-1 und SaOS-2 Zellen wurden in RPMI Medium, HeLa-S3 Zellen in Ham's F12 Medium, HEK-293 Zellen in Dulbecco's MEM-Medium, Tera-2 Zellen in McCoy's 5a-Medium und IMR-90 Zellen in MEM-Medium jeweils mit $10 \% \mathrm{FCS}$ bei $37^{\circ} \mathrm{C}$ und $5 \% \mathrm{CO}_{2}$ kultiviert.

\subsubsection{RNA-Isolierung aus humanen Zelllinien}

Ungefähr 50 Millionen Zellen wurden von jeder Zelllinie geerntet. Die RNA-Präparation wurde mit dem RNeasy Midi Kit von Qiagen nach Herstellerangaben durchgeführt. Die Ausbeute betrug je nach Zelllinie zwischen $170 \mu \mathrm{g}$ und $450 \mu \mathrm{g}$ RNA.

\subsection{RNA-Gelelektrophorese}

Um die Qualität von RNA zu überprüfen, wurde ein denaturierendes Formaldydgel durchgeführt. Zur Herstellung des hierzu verwendeten MOPS-Gels wurden zunächst $200 \mathrm{mg}$ Agarose in $16 \mathrm{ml}$ bidest $\mathrm{H}_{2} \mathrm{O}$ aufgekocht und auf $55^{\circ} \mathrm{C}$ temperiert. Anschließend wurden $2 \mathrm{ml}$ 10x MOPS-Puffer und $2 \mathrm{ml} 37 \%$ (v/v) Formaldehyd zugegeben und das Gel gegossen. Als Laufpuffer wurde MOPS-Puffer verwendet. $3 \mu \mathrm{g}$ RNA wurden mit $1 \mu \mathrm{l}$ 10x MOPS-Puffer und $2 \mu \mathrm{l} 37 \%$ (v/v) Formaldehyd versetzt. Anschließend wurden die Proben 15 min bei $65^{\circ} \mathrm{C}$ denaturiert. Dann wurden die Proben mit $3 \mu$ RNA-Auftragspuffer und $2 \mu \mathrm{l} 1 \mathrm{mg} / \mathrm{ml}$ Ethidiumbromid-Lösung versetzt, gemischt und in die Geltaschen pipettiert. Die Gelelektrophorese wurde bei 20 mA durchgeführt und die RNA auf dem UV-Schirm sichtbar gemacht, und mit dem in 2.1 genannten Geldokumentationssystem dokumentiert.

MOPS-Gel (RNA): 1,0 \% (w/v) Agarose; 1x MOPS-Puffer; 3,7 \% (v/v) Formaldehyd

RNA-Auftragspuffer: 1 mM EDTA; 0,1 \% (w/v) Bromphenolblau; $50 \%(v / v)$ Glycerin

\subsection{RNase-Protektionsanalyse}

Die Bestimmung der RNA-Konzentrationen der 11 replikationsabhängigen H3 Histongene erfolgte mit RNase-Protektions-Experimenten. Zunächst wurden mit Hilfe der In-vitro-Transkription zur endogenen mRNA komplementäre und radioaktiv markierte Antisense-RNA-Sonden hergestellt. Anschließend erfolgte eine Hybridisierung der Antisense-RNA mit der zu untersuchenden RNA und eine RNaseVerdauung, bei der die nicht hybridisierte Einzelstrang RNA abgebaut wurde. Die RNA konnte gelelektrophoretisch aufgetrennt und mit Hilfe eines Phosphorlmager-Systems sichtbar gemacht und quantifiziert werden.

Für die In-vitro-Transkription wurden linearisierte DNA-Stränge benötigt, die die entsprechenden DNAAbschnitte downstream von T3- oder T7-Polymerase Startsequenzen enthielten. Es wurden also zunächst die benötigten DNA-Fragmente in die MCS des pBluescript II KS (+) einkloniert, welche zu 
beiden Seiten von einer T3- bzw. T7-Polymerase-Startsequenz flankiert ist. Anschließend wurden die Plasmide durch geeignete Restriktionsverdauung linearisiert und mit dem QIAquick-PCR-PurificationKit (Qiagen, Hilden) aufgereinigt. Die Qualität und Quantität der linearisierten DNA wurde auf einem analytischen Gel überprüft. Die In-vitro-Transkription wurde mit dem MAXIscript ${ }^{\mathrm{TM}}$ : In-vitroTranskriptions-Kit (Ambion, Austin, USA) nach Herstellerangaben durchgeführt. Zunächst wurde für alle im Experiment zu präparierenden Antisense-RNA-Sonden ein Mastermix aus Puffer und Nukleotiden hergestellt (siehe unten) und aliquotiert. Anschließend wurden $2 \mu$ Plasmid-Lösung (ca. $800 \mathrm{ng}$ DNA), $5 \mu \mathrm{l}\left[\alpha^{-32} \mathrm{P}\right]$-UTP (wässrige Lösung, spezifische Aktivität $3000 \mathrm{Ci} / \mathrm{mmol} ; 10 \mathrm{mCi} / \mathrm{ml}$ ) und $2 \mu$ Polymerase (10U/ $\mu$ l) (T3 oder T7) zugesetzt, gemischt und $1 \mathrm{~h}$ bei $37^{\circ} \mathrm{C}$ inkubiert. Parallel zu den Histon-H3-Sonden wurde immer eine $\beta$-Actin-Sonde präpariert, die als interner Standard eingesetzt wurde. Die Präparation der $\beta$-Actin-Sonde erfolgte analog zur Herstellung der HistonH3-Sonden, allerdings wurde die Sonde schwächer markiert, um die Gele besser auswertbar zu

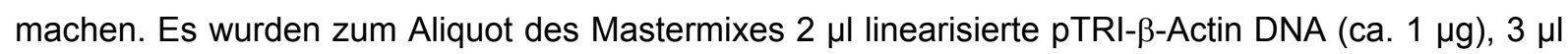
$50 \mu \mathrm{M}$ UTP (nicht markiert), $1 \mu \mathrm{l}\left[\alpha^{32} \mathrm{P}\right.$ ]-UTP (wässrige Lösung, spezifische Aktivität $3000 \mathrm{Ci} / \mathrm{mmol}$; $10 \mathrm{mCi} / \mathrm{ml}$ ), $1 \mu \mathrm{l}$ bidest $\mathrm{H}_{2} \mathrm{O}$ und $2 \mu \mathrm{l}$ T3-Polymerase zugesetzt und ebenfalls $1 \mathrm{~h}$ bei $37^{\circ} \mathrm{C}$ inkubiert. Die weitere Behandlung verlief analog zu den Histon-H3-Sonden.

\section{Mastermix:}

- $2 \mu \mathrm{l} 10 x$ Transkriptionspuffer

- $1 \mu \mathrm{l} 10 \mathrm{mM}$ ATP

- $1 \mu \mathrm{l} 10 \mathrm{mM}$ CTP

- $1 \mu \mathrm{l} 10 \mathrm{mM}$ GTP

- $\quad 1 \mu \mathrm{l} 50 \mu \mathrm{M}$ UTP (nicht markiert)

- $5 \mu$ l bidest $\mathrm{H}_{2} \mathrm{O}$

Um die Template-DNA zu degradieren, wurde $1 \mu \mathrm{l}$ DNase I zugesetzt und 15 min bei $37^{\circ} \mathrm{C}$ inkubiert. Anschließend wurden die Antisense-RNA-Sonden über ein denaturierendes Harnstoff-PolyacrylamidGel aufgereinigt. Hierzu wurden die Proben mit $21 \mu \mathrm{l}$ Auftragspuffer versetzt (Teil des RPA II Ribonuclease-Protection-Assay-Kits (Ambion, Austin, USA)) und 4 min bei $95{ }^{\circ} \mathrm{C}$ gekocht. Davon wurden dann $21 \mu \mathrm{l}$ auf das Harnstoff-Gel aufgetragen.

Harnstoff-Polyacrylamid-Gel:

- $36 \mathrm{~g}$ Harnstoff

- $7,5 \mathrm{ml} 10 x \mathrm{TBE}$

- $12,5 \mathrm{ml} 30 \%$ Acrylamid

- $25 \mu \mathrm{T}$ TEMED

- mit bidest $\mathrm{H}_{2} \mathrm{O}$ auf $74 \mathrm{ml}$ Volumen auffüllen

- $1 \mathrm{ml} 10 \%$ APS zur Polymerisation

Das Harnstoff-Polyacrylamid-Gel war $25 \mathrm{~cm}$ lang und $1 \mathrm{~mm}$ dick. Als Laufpuffer wurde 1x TBE verwendet. Nach einem Vorlauf bei $380 \mathrm{~V}$ für $1 \mathrm{~h}$ für ca. $2,5 \mathrm{~h}$ wurden die Proben aufgetragen und bei 
$480 \mathrm{~V}$ laufen gelassen, bis der Bromphenolblau-Farbstoff im Auftragspuffer ca. 3/4 der Gellänge durchlaufen hatte. Das Gel wurde auf Filterpapier aufgezogen, mit Klarsichtfolie abgedeckt und zur Orientierung markiert. Anschließend wurde für 5 min eine Autoradiographie durchgeführt und der entwickelte und fixierte Film wurde passgenau auf dem Gel befestigt. Nun konnten die Gelstücke identifiziert und mit dem Skalpell ausgeschnitten werden, die die markierte Sonde in voller Länge enthielten. Die Gelfragmente wurden in $300 \mu$ l Probenelutionspuffer (Teil des RPA II ${ }^{\mathrm{TM}}$ : RibonucleaseProtection-Assay-Kits (Ambion, Austin, USA)) aufgenommen und über Nacht bei $4{ }^{\circ} \mathrm{C}$ inkubiert. Die Aktivität des Überstandes wurde im Scintillationszähler bestimmt.

Nachdem die Sonden präpariert waren, erfolgte das eigentliche RNase-Protektions-Experiment mit dem RPA II ${ }^{\mathrm{TM}}$ : Ribonuclease-Protection-Assay-Kit (Ambion, Austin, USA) nach Herstellerangaben. Es wurden $10 \mu \mathrm{g}$ Gesamt-RNA mit $20000 \mathrm{cpm}$ Antisense-Sonde (mit Korrekturfaktor $\mathrm{f}=$ Länge der Antisense-Sonde in bp / 300 bp), $800 \mathrm{cpm} \quad \beta$-Actin-Sonde und $2 \mu \mathrm{l}$ Ammoniumacetat zusammengegeben und mit bidest $\mathrm{H}_{2} \mathrm{O}$ auf $20 \mu \mathrm{l}$ aufgefüllt. Dann wurden $50 \mu \mathrm{l}$ absolutes EtOH zugegeben, gemischt und $1 \mathrm{~h}$ bei $-20{ }^{\circ} \mathrm{C}$ inkubiert. Anschließend wurden die Ansätze bei $4{ }^{\circ} \mathrm{C}$ für $30 \mathrm{~min}$ bei $13000 \mathrm{U} / \mathrm{min}$ in der Kühlzentrifuge EBA $12 \mathrm{R}$ (Hettich, Tuttlingen) zentrifugiert. Die Überstände wurden vorsichtig mit einer Pipette abgezogen und die Pellets $10 \mathrm{~min}$ an der Luft getrocknet. Anschließend wurden den Ansätzen $20 \mu \mathrm{l}$ Hybridisierungslösung (im Kit enthalten) zugegeben und über Nacht bei $50{ }^{\circ} \mathrm{C}$ im Wasserbad inkubiert. Dann erfolgte die Verdauung mit RNaseA/ RNase T1 und die Aufarbeitung des Ansatzes nach Herstellerangaben. Anschließend wurden die Ansätze auf ein Harnstoff-Polyacrylamid-Gel aufgetragen und unter gleichen Bedingungen wie bei der Präparation der Antisense-RNA-Sonden einer Elektrophorese unterzogen. Als Größenmarker dienten [ $\left.{ }^{32} \mathrm{P}\right]-$ markierte Sau 3AI-Fragmente von pUC19 DNA. Die Gele wurden auf Filterpapier aufgezogen, mit Klarsichtfolie überdeckt und im Geltrockner Drystar L-B (H. Hölzel GmbH, Wörth) für $4 \mathrm{~h}$ bei $50{ }^{\circ} \mathrm{C}$ im Ölpumpenvakuum getrocknet. Anschließend wurden die getrockneten Gele auf eine mit Europium beschichtete Platte "Storage Phosphor Screen" 35 x 43 cm (Molecular Dynamics, Krefeld) gelegt. Durch die radioaktive Strahlung wurden die Europium-Atome angeregt und diese phosphoreszierten. Diese Strahlung wurde dann von dem Phosphorlmager (Molecular Dynamics, Krefeld) ortsgenau eingescannt. Die quantitative Auswertung der Phosphorlmager-Bilder erfolgte mit der Software ImageQuant ${ }^{\mathrm{TM}}$.

\subsection{Reportergenassays}

Reportergenassays wurden mit dem Dual-Luciferase ${ }^{\mathrm{TM}}$ Reporter Assay System (Promega, Madison, USA) durchgeführt. Es wurden Reportergenkonstrukte hergestellt, die auf den Vektoren pGL3-basic bzw. pGL3-promoter basierten (siehe 2.8 Vektoren). Der pGL3-basic Vektor enthält das luc ${ }^{+}-G e n$, welches die Firefly-Luziferase kodiert. In diesen Vektor wurden potentielle Promotoren einkloniert. Fusionsstelle war immer das Startcodon (ATG) des luc ${ }^{+}$-Gens. Der pGL3-promoter Vektor enthält das luc ${ }^{+}-$Gen mit dem SV40-Promotor. In dieses Konstrukt wurden potentielle Enhancer einkloniert. Das Konstrukt pRL-CMV enthält das Gen für die Renilla-Luziferase unter Kontrolle des CMV-Promotors und wurde stets als interner Standard kotransfiziert. 
Die Reportergenkonstrukte wurden in endotoxinfreier Plasmid-DNA-Qualität präpariert und ihre Konzentration wurde spektroskopisch bestimmt. Humane Zellen einer Zelllinie wurden in 6-WellPlatten ausgesät und bis zu einer Konfluenz von $40-80 \%$ angezogen. Anschließend erfolgte die Transfektion von, je nach Plasmidgröße, 400 - 600 ng eines Reportergenkonstrukts zusammen mit $10 \mathrm{ng}$ des pRL-CMV Vektors. Die Transfektion wurde mit dem Effectene ${ }^{\mathrm{TM}}$ Transfection Kit (Qiagen, Hilden) nach Herstellerangaben durchgeführt. Die Zellen wurden, je nach Zelllinie 18 - $48 \mathrm{~h}$ inkubiert und anschließend nach Vorschrift des Dual-Luciferase ${ }^{\mathrm{TM}}$ Reporter Assay Systems (Promega, Madison, USA) gewaschen und lysiert. Das Lysat wurde zentrifugiert und bis zur Doppelbestimmung der Firefly- und Renilla-Luziferase-Aktivitäten auf Eis gekühlt. Diese erfolgte nach Herstellerangaben in dem Luminometer AutoLumat LB 953 (Berthold, Bad Wildbad). Dabei wurde zunächst mit Beetle Luciferin die Firefly-Luziferase-Aktivität bestimmt und anschließend - nach Löschung der FireflyLuziferase-Aktivität - mit Coelenterazine die Renilla-Luziferase-Aktivität. Das Verhältnis FireflyLuziferase-Aktivität zu Renilla-Luziferase-Aktivität war dann das dimensionslose Maß für die Aktivität eines Reportergenkonstrukts. Jede Bestimmung der Aktivität eines Reportergenkonstrukts war eine Statistik aus mindestens vier voneinander unabhängigen Transfektionen und nachfolgenden Luziferase-Aktivitätsbestimmungen (in einigen Versuchreihen wurden fünf und mehr Experimente durchgeführt).

\subsection{EMSA-Analyse}

Die EMSA-Experimente wurden mit doppelsträngigen Oligonukleotiden durchgeführt. Hierfür wurden jeweils 500 pmol der beiden komplementären Oligonukleotide mit $2 \mu \mathrm{l} 1 \mathrm{M} \mathrm{NaCl}$ versetzt und mit bidest $\mathrm{H}_{2} \mathrm{O}$ auf $20 \mu \mathrm{l}$ Endvolumen verdünnt. Der Ansatz wurde nun im PCR-Gerät Gene Amp PCR System 2400 (Perkin Elmer /Applied Biosystems, Weiterstadt) auf $75^{\circ} \mathrm{C}$ erhitzt und innerhalb von $2 \mathrm{~h}$ kontinuierlich auf $40{ }^{\circ} \mathrm{C}$ abgekühlt. Anschließend wurden die Ansätze bei $-20^{\circ} \mathrm{C}$ bis zur Verwendung gelagert. Die doppelsträngigen Oligonukleotide wurden dann mit $\left[{ }^{32} \mathrm{P}\right]$ radioaktiv markiert. Hierfür wurde folgender Ansatz gewählt:

- $\quad 2 \mu \mathrm{l} 1,75 \mathrm{pmol} / \mu \mathrm{l}$ doppelsträngiges Oligonukleotid

- 1 ul 10x T4-Kinase-Puffer

- $5 \mu$ l bidest $\mathrm{H}_{2} \mathrm{O}$

- $1 \mu \mathrm{l} \mathrm{T4-Polynukleotid-Kinase}$

- $1 \mu \mathrm{l} 5^{\prime}\left[\gamma^{32} \mathrm{P}\right]-A T P$ (wässrige Lösung, spezifische Aktivität $3000 \mathrm{Ci} / \mathrm{mmol} ; 10 \mathrm{mCi} / \mathrm{ml}$ )

Der Ansatz wurde 30 min bei $37^{\circ} \mathrm{C}$ inkubiert und anschließend mit Hilfe des Nucleotide Removal Kits (Qiagen, Hilden) aufgereinigt. Dabei wurde das gereinigte und markierte doppelsträngige Oligonukleotid mit $100 \mu$ EB-Puffer von der Säule eluiert und die Aktivität wurde im Scintillationszähler bestimmt. Üblicherweise wurden Volumenaktivitäten von 75000 - $150000 \mathrm{cpm} / \mu \mathrm{l}$ erhalten.

Die Bandshift-Experimente wurden mit dem Gel Shift Assay Systems Kit (Promega, Madison, USA) nach Herstellerangaben durchgeführt. Die Bindungsreaktionen wurden nach folgendem Ansatz durchgeführt: 
- $2 \mu \mathrm{l} 5 \mathrm{x}$ Bindungspuffer (Kitkomponente)

- ggf. $2 \mu \mathrm{l} \mathrm{HeLa} \mathrm{Kernextrakt} \mathrm{(Kitkomponente)}$

- ggf. Zusatz von unmarkiertem, doppelsträngigem Kompetitor-Oligonukleotid

- mit bidest $\mathrm{H}_{2} \mathrm{O}$ auf $9 \mu \mathrm{l}$ Endvolumen auffüllen

Dieser Ansatz wurde nun 10 min bei Raumtemperatur präinkubiert, dann wurde $1 \mu$ ler markierten Oligonukleotid-Lösung zugegeben, kurz gemischt und durch leichte Zentrifugation am Boden des Reaktionsgefäßes gesammelt. Anschließend wurde der Ansatz 20 min bei Raumtemperatur inkubiert und dann auf ein EMSA-Gel aufgetragen. Das EMSA-Gel war $19 \mathrm{~cm}$ breit, $26 \mathrm{~cm}$ lang und $1 \mathrm{~mm}$ dick.

Das EMSA-Gel wurde $2 \mathrm{~h}$ bei $400 \mathrm{~V}$ laufen gelassen, anschließend wurde das Gel auf Filterpapier aufgezogen, mit Klarsichtfolie bedeckt und im Geltrockner Drystar L-B (H. Hölzel GmbH, Wörth) für $4 \mathrm{~h}$ bei $50^{\circ} \mathrm{C}$ im Ölpumpenvakuum getrocknet. Anschließend wurden die getrockneten Gele in eine BAS Cassette 2340 (Fujifilm, Japan) gelegt, welche einen Phosphorlmager-Screen enthielt. Dieser wurde nach $4 \mathrm{~h}$ Auflagezeit im Phosphorlmager FLA-3000 (Fujifilm, Japan) eingescannt und mit der Software „Aida 2.2 (Advanced Image Data Analyzer)“ quantitativ ausgewertet.

EMSA-Gel: (75 ml Endvolumen): 3,75 ml $10 \times$ TBE; $10 \mathrm{ml}$ Acrylamidlösung (30\% w/v, 0,8 \% (w/v) Bisacrylamid); $3,13 \mathrm{ml} 60 \%$ v/v Glycerin; $57,5 \mathrm{ml}$ bidest $\mathrm{H}_{2} \mathrm{O}$; Polymerisationsstart durch Zugabe von: $38 \mu \mathrm{l}$ TEMED; $563 \mu \mathrm{l}$ 10\% APS 


\section{Ergebnisse}

\subsection{Sequenzanalyse der 11 H3-Promotoren}

Die Sequenzen der 11 Histon-H3-Promotoren (je 500 bp upstream des Startcodons) wurden mit den Programmen „Pileup“ des GCG-Programmpaketes, "MACAW“ (Schuler et al. 1991) und mit selbst geschriebenen Suchalgorithmen analysiert. Dabei wurden folgende drei Abschnitte mit Sequenz-Ähnlichkeiten gefunden:

1. In allen $11 \mathrm{H} 3$-Promotoren findet sich upstream des Transkriptionsstarts eine TATA-Box (siehe Abbildung 6,85 und Abbildung $7_{36}$ ) und dann eine (proximale) CCAAT-Box. Der Abstand zwischen den beiden Boxen (Start CCAAT-Box bis Start TATA-Box) beträgt beim $\mathrm{H} 3 / \mathrm{c}-$ und $\mathrm{H} 3 / \mathrm{h}-\mathrm{Gen} 20$ bp und in den restlichen neun Promotoren 22 bp.

\begin{tabular}{|c|c|}
\hline Elemente: & CCAAT-BOX \\
\hline $\mathrm{H} 3 / \mathrm{a}:$ & CTTAAAGATAGACCAATCAGAGTGTGTAACGTCATATTTAGCGT \\
\hline H3/b: & TGGGCGTCTCCACCAATCGAGCTGCAGGGGAA----------AG \\
\hline н3/c: & GTCACTCTTCAGCCAATGATTTTATCGCGCGGGACTTTTGAAA- \\
\hline H3/d: & CTACGGCCACTTCCGGAATTTAGCAACCGATCACTAACAGGGAT \\
\hline H3/f : & TTAAACTGGGAGCCAATTCCGTGTGTGAGACGTGGCATGGCAC- \\
\hline $\mathrm{H} 3 / \mathrm{h}:$ & TGGACTCTTCAGCCAATGGTTTTGTTGCGCGGGTCTTTTGAAA- \\
\hline H3/i : & ATCACAAGTCCTATCACACTACATAATTCAGGGCGCGAAACTGG \\
\hline н3/j: & ACCAAATGAAGATAGTATTAACAACCAACCAGGTTTTTCCTACA \\
\hline H3/k: & TTGAGTCCTTCGCCAATCCGGTTACTGTTGGGTAGGCCTTCAGC \\
\hline $\mathrm{H} 3 / \mathrm{m}:$ & CACAGAGATGGACCAATCCAAGAAGGGCGCGGGGATTTTTGAAT \\
\hline $\mathrm{H} 3 / \mathrm{n}:$ & GTGACGTCACAGCCAATGGACAGCCAGCGCGGGATTTTCAATT- \\
\hline Konsensus: & RRCCAAT \\
\hline Elemente: & CСАAT-BOX $\quad$ TATA-BOX \\
\hline н3/a : & СТTСТАТСАТСCAATCACTGCACTTTACAСАСTATAAATAGAGC \\
\hline H3/b: & GCTGCCTTGTCCAATCAGAACAGGGGTGTCTTTATATATACGGG \\
\hline н3/ C: & TATTACAGGACCAATCAGAAT--GTTTCTCACTATATTTAAAGG \\
\hline H3/d: & СGTCCACAАTCCAATCAGAGTGATTCTGTTCCTATATAGAGGGG \\
\hline H3/f : & АGTCTACTGTCCAATCAGAACGCGAGGGCAGCTATAAATACCGG \\
\hline H3/h: & ATCAACAAGGCCAATTAGAAT--GTTTCTGAGTATATATAAGGG \\
\hline H3/i: & AAGATTCGGACCAATCAGAAGGACTTTGCCTTTATAAATAGGAG \\
\hline H3/j: & ACAGTTCTGACCAATCAGGATCAGATCATCGTTATAAATTCTGG \\
\hline H3/k: & ATACTTTTGTCCAATCAGCTTCAGACTCTCACTATAAATAAGCG \\
\hline H3 $/ \mathrm{m}:$ & TTTCTTGGGTCCAATAGTTGGTGGTCTGACTCTATAAAAGAAGA \\
\hline H3/n : & ATTGTTCCGCCCAATCGGGAAAAGACTGTGCTTATAAAGACGGC \\
\hline Konsensus: & $\begin{array}{ll}\text { R CCAATCA } & \text { YTATAWATAVRGG }\end{array}$ \\
\hline
\end{tabular}

Abbildung 6: Sequenz und Lage der proximalen cis-Elemente der 11 H3-Promotoren

Die Sequenz und Lage der TATA-Boxen und der proximalen und distalen CCAAT-Boxen mit Konsensussequenzen sind dargestellt. Die unten gezeigten Sequenzen schließen sich nahtlos an die oben gezeigten Sequenzen an. R: (A/G); Y: (C/T); W: (A/T); V: (A/C/G). 
2. Neun der 11 H3-Promotoren enthalten zusätzlich eine zweite, distale CCAATBox upstream der proximalen CCAAT-Box. Einige der H3-Gene besitzten darüber hinaus in verschiedenen Abständen bis zu zwei weitere CCAAT-Boxen (Abbildung $7{ }_{6} 6$ ).

3. Der $\mathrm{H} 3 / \mathrm{m}$ - und der $\mathrm{H} 3 / \mathrm{n}$-Promotor enthalten jeweils eine ATF-Box (das $8 \mathrm{bp}$ palindromische TGACGTCA-Motiv, an das Transkriptionsfaktoren der ATFFamilie binden), die im H3/m-Promotor von van Wijnen et al. (1991b) identifiziert wurde. Sie findet sich in den anderen H3-Promotoren nicht.

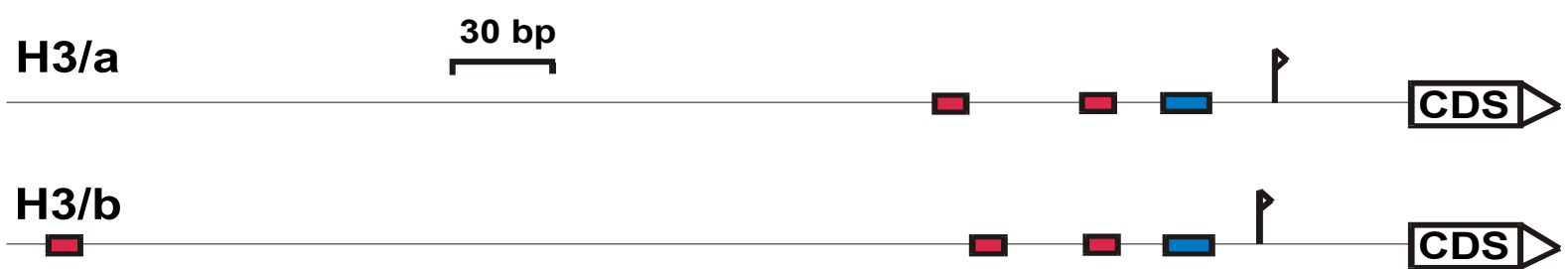

$\mathrm{H} 3 / \mathrm{c}$

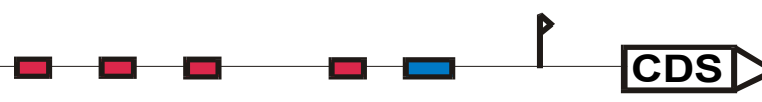

H3/d

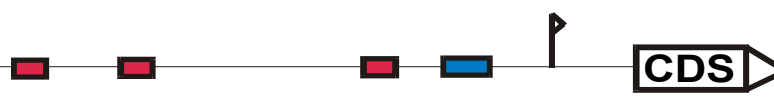

H3/f

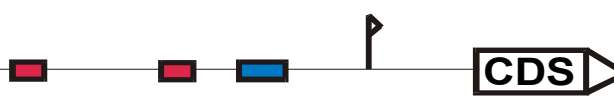

$H 3 / h$
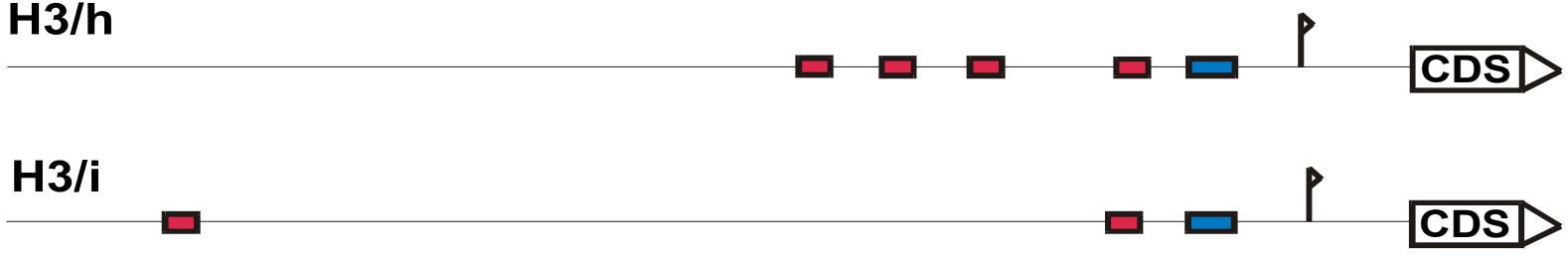

H3/j

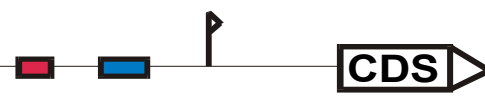

H3/k
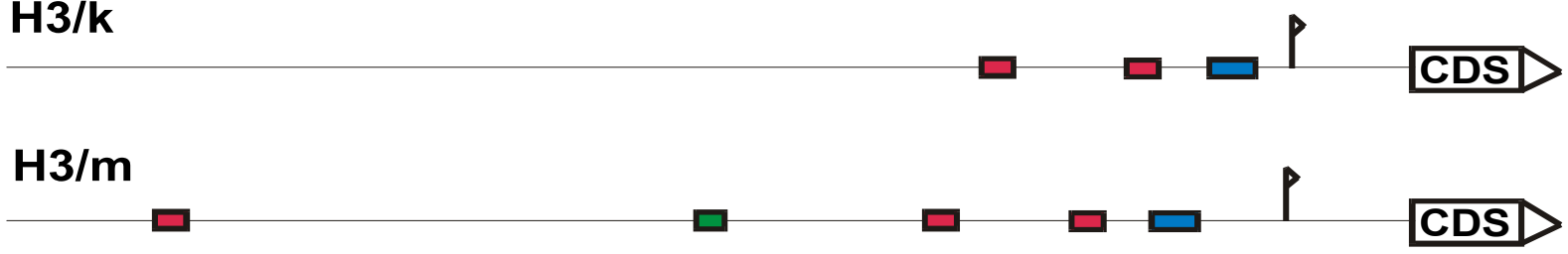

$H 3 / n$

Abbildung 7: Schematische Darstellung der Lage der cis-Elemente der $11 \mathrm{H} 3-$ Promotoren

400 Basenpaare upstream der Startcodons sind dargestellt. CDS: kodierende Sequenz; Fahnen: Transkriptionsstartstellen; blaue Boxen: TATA-Boxen; rote Boxen: CCAAT-Boxen; grüne Boxen: ATFBoxen. 


\subsection{Expressionsanalyse der $11 \mathrm{H} 3-$ Histongene}

\subsubsection{Quantitative RNase-Protektionsanalyse}

Das Expressionsmuster der elf replikationsabhängig-expremierten $\mathrm{H} 3-$ Histongene (im Folgenden „replikationsabhängige Histongene“ genannt) sollte in drei fötalen humanen Geweben und in humanen Zellinien bestimmt werden (siehe 1.4 Zielstellung $_{6}$ ). Aufgrund der hohen Ähnlichkeit der kodierenden Sequenzen der $11 \mathrm{H} 3-$-Gene wurden für die Bestimmung der H3-Expressionsmuster quantitative RNase Protektionsassays verwendet. Für die Präparation der RNA-AntisenseSonden wurden zunächst Fragmente der elf H3-Histongene in die Multiple Cloning Site (MCS) des pBluescript KS+-Vektors subkloniert (siehe Abbildung 8, 37 ).

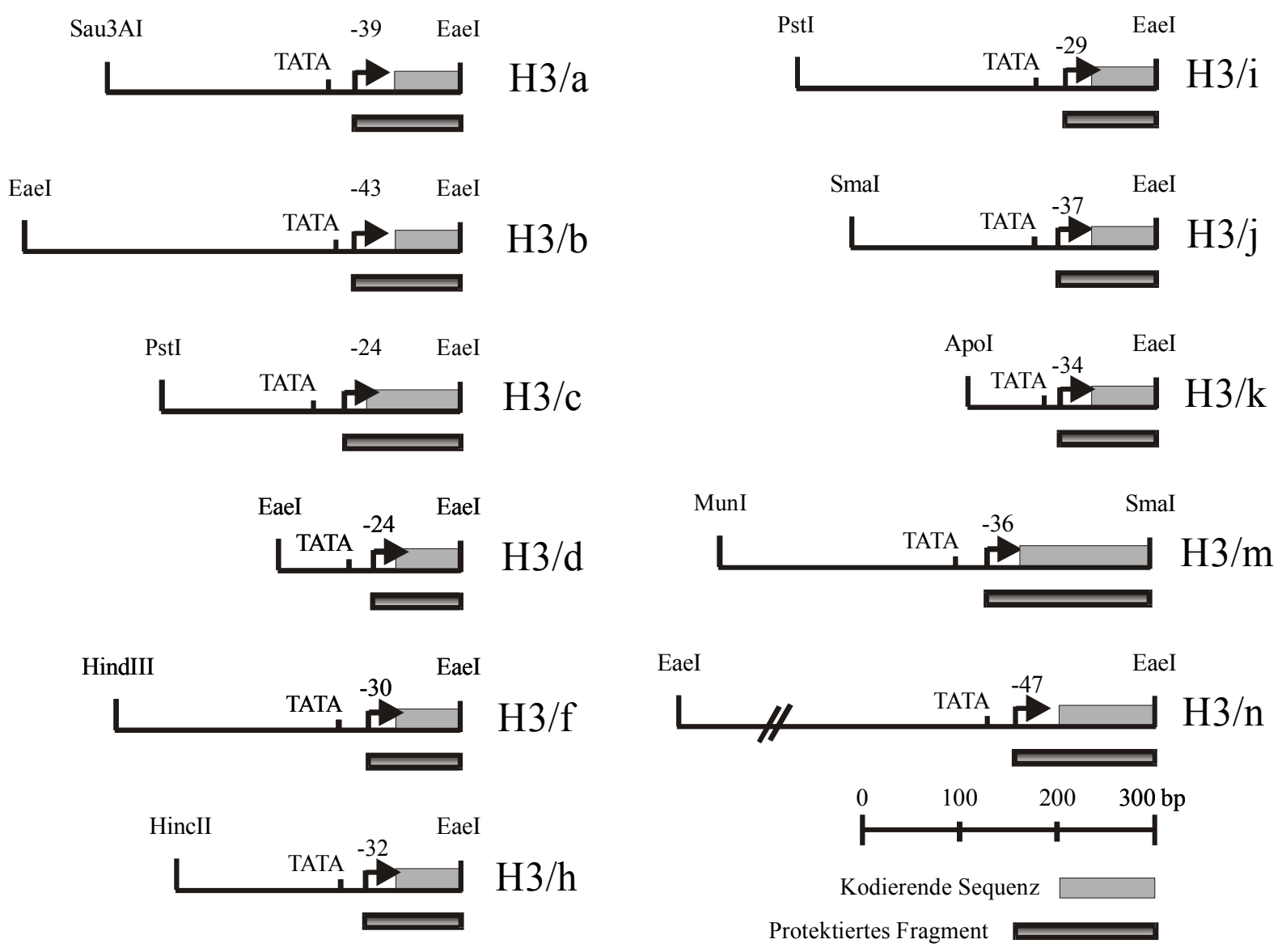

Abbildung 8: Histongen-Sonden für die RNase-Protektionsassays (RPA).

Klonierte Fragmente der 11 humanen replikationsabhängigen Histon-H3-Gene wurden für die Herstellung von $\left[{ }^{32} \mathrm{P}\right]-$ markierter Antisense-RNA verwendet. Gezeigt werden die zur Klonierung verwendeten Restriktionsschnittstellen, die Lage der kodierenden Sequenz, die Transkriptionsstartstelle mit Nummer der ersten Base bezogen auf das Startcodon (Genauigkeit \pm 3 bp), die Position der TATA-Box und die Länge der zu erwartenden protektierten Fragmente in den RNase-Protektionsassays. 
Die elf subklonierten H3-Histongenfragmente enthielten 95-175 Basenpaare downstream und 130-650 Basenpaare upstream der Transkriptionsstartstelle (Abbildung $8 \beta_{7}$ ). Die Herstellung der elf $\mathrm{H} 3-S o n d e n$ in der In-vitro-Transkription, die gemäß 3.7 RNase-Protektionsanalyse $\beta_{0}$ durchgeführt wurde, erfolgte simultan und stellte so eine einheitliche Markierung sicher. Um die Vergleichbarkeit der Messreihen sicherzustellen, wurde ein Mastermix mit den benötigten Reagenzien und die gleiche [ $\alpha^{32}$ P]-UTP-Stammlösung verwendet. Bei jeder Hybridisierungsreaktion diente $\left[\alpha^{32} \mathrm{P}\right]$-UTP-markierte $\beta$-Actin-Antisense-RNA als interner Standard. Dadurch konnten Schwankungen herausgerechnet werden, die sich aus Pipettierungenauigkeiten bei der Zugabe der Gesamt-RNA oder aus der Aufarbeitung der Hybridisierungsreaktionen ergaben.

Die Hybridisierungsreaktionen (siehe 3.7 RNase-Protektionsanalyse $\beta_{0}$ ) wurden unter identischen Bedingungen parallel durchgeführt und auf demselben Gel analysiert.

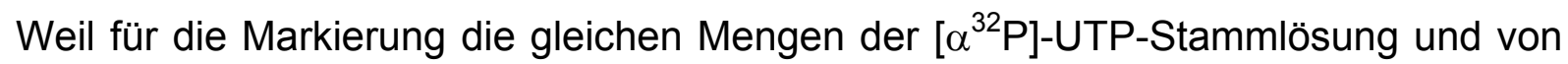
unmarkiertem UTP verwendet wurden, war die spezifische Aktivität der Sonden jeweils eine Funktion der Anzahl an eingebautem UMP. Die relative Expression der einzelnen H3-Gene berechnet sich deshalb als Signalintensität des protektierten Fragments (standardisiert durch die $\beta$-Actin-Intensität) dividiert durch die Anzahl von UMP, die das protektierte Fragment enthielt.

Die Ergebnisse der quantitativen RNase-Protektionsanalyse sind in den Kapiteln 4.2.2 (Gewebe) und 4.2.3 (Zellinien) beschrieben.

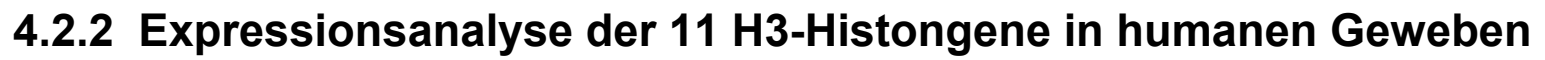

Das Expressionsmuster der elf replikationsabhängigen $\mathrm{H} 3-$ Histongene wurde in drei fötalen humanen Geweben (Blase, Leber, Lunge) mit der oben beschriebenen (4.2.1 37 ) quantitativen RNase Protektionsanalyse (RPA) bestimmt (siehe 1.4 Zielstellung $_{6}$ ). Eine Expression aller elf $\mathrm{H} 3-\mathrm{Gene}$ wurde in fötaler Leber, Lunge und Blase nachgewiesen (Abbildung 9 939 , Abbildung 10, und Abbildung 114 1 ). Die Gesamtmenge an H3-mRNA wurde durch Addition der mRNA-Einzelmengen der 11 H3-Gene berechnet. Der relative Beitrag der einzelnen Gene zur Gesamtmenge an H3-mRNA variierte zwischen $0,7 \%$ und $27 \%$. Die beiden Gene $H 3 / m$ und $H 3 / n$ wurden stark exprimiert und stellten zusammen je nach Gewebetyp zwischen $37 \%$ und $43 \%$ der Gesamtmenge an H3-mRNA. 


\section{Fötale Blase}

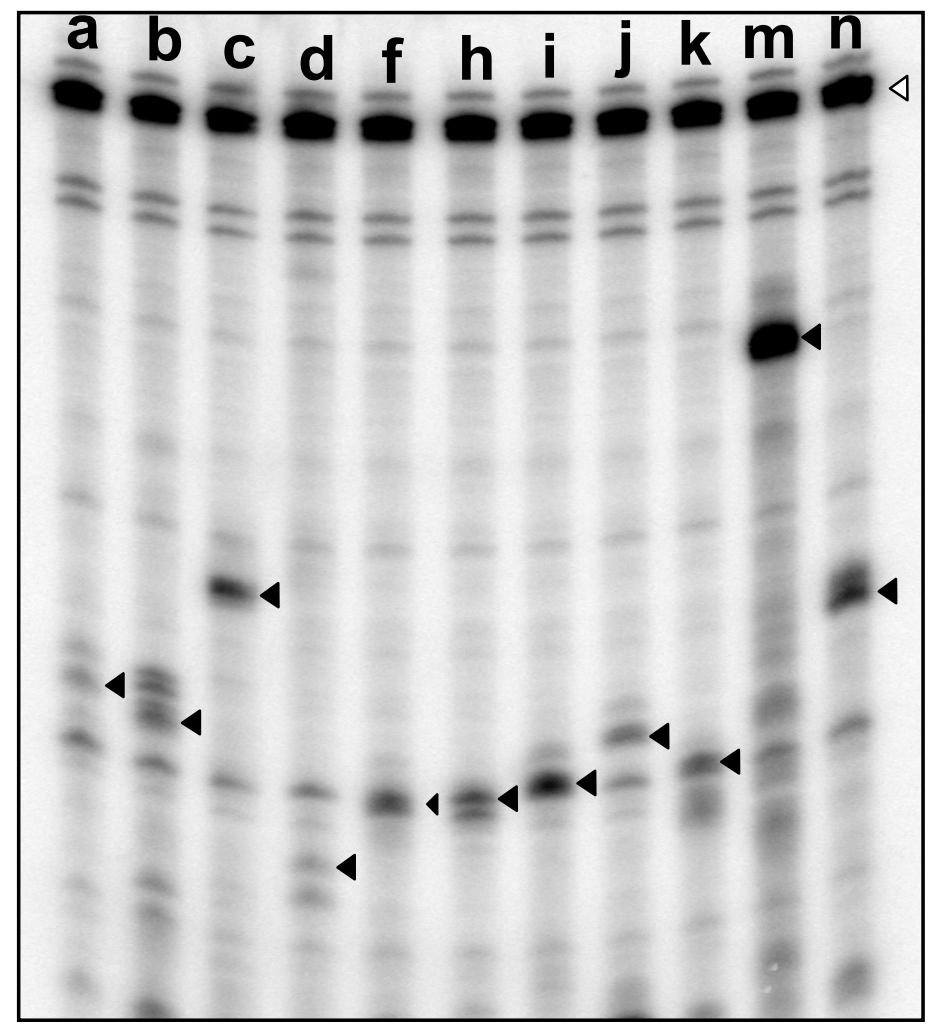

\section{Fötale Leber}

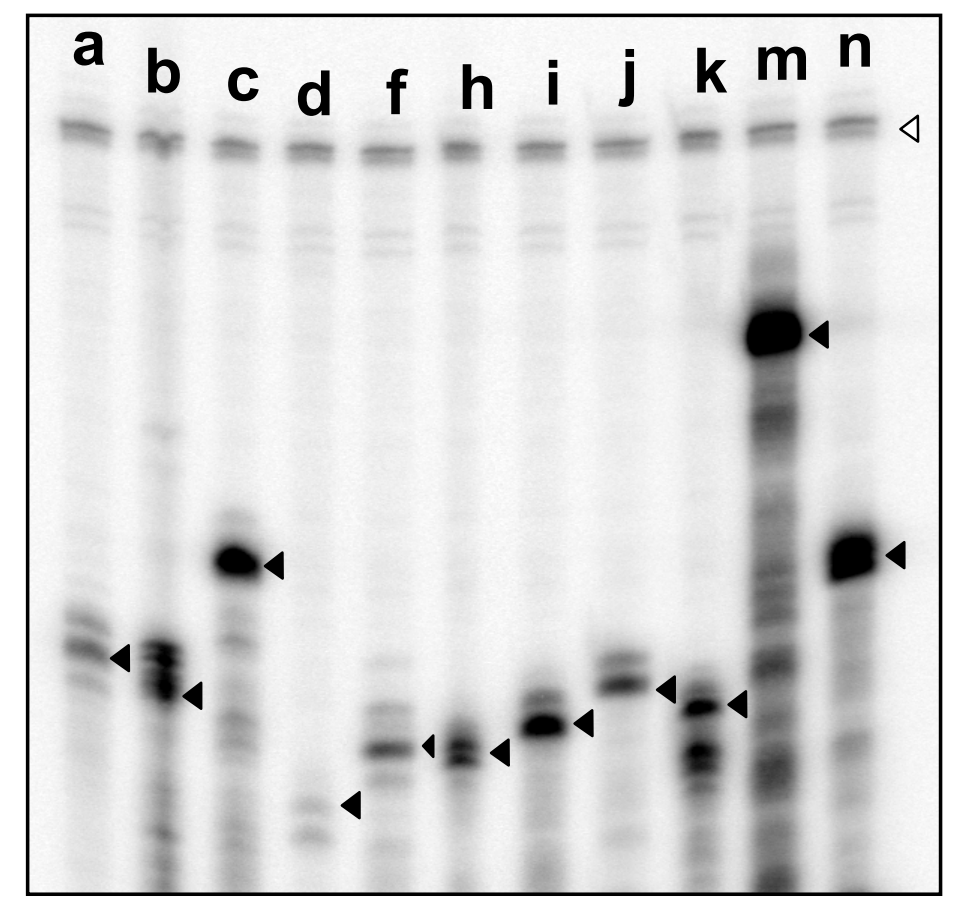

Abbildung 9: Autoradiogramme der RPA-Assays mit RNA aus fötaler Harnblase und Leber

Die protektierten H3-mRNA-Banden sind mit gefüllten Dreiecken markiert. Die protektierten $\beta$-ActinBanden sind mit einem offenen Dreieck gekennzeichnet. Doppelbanden werden als Resultat von alternativen Transkriptions-Startstellen gedeutet. 


\section{Fötale Lunge}

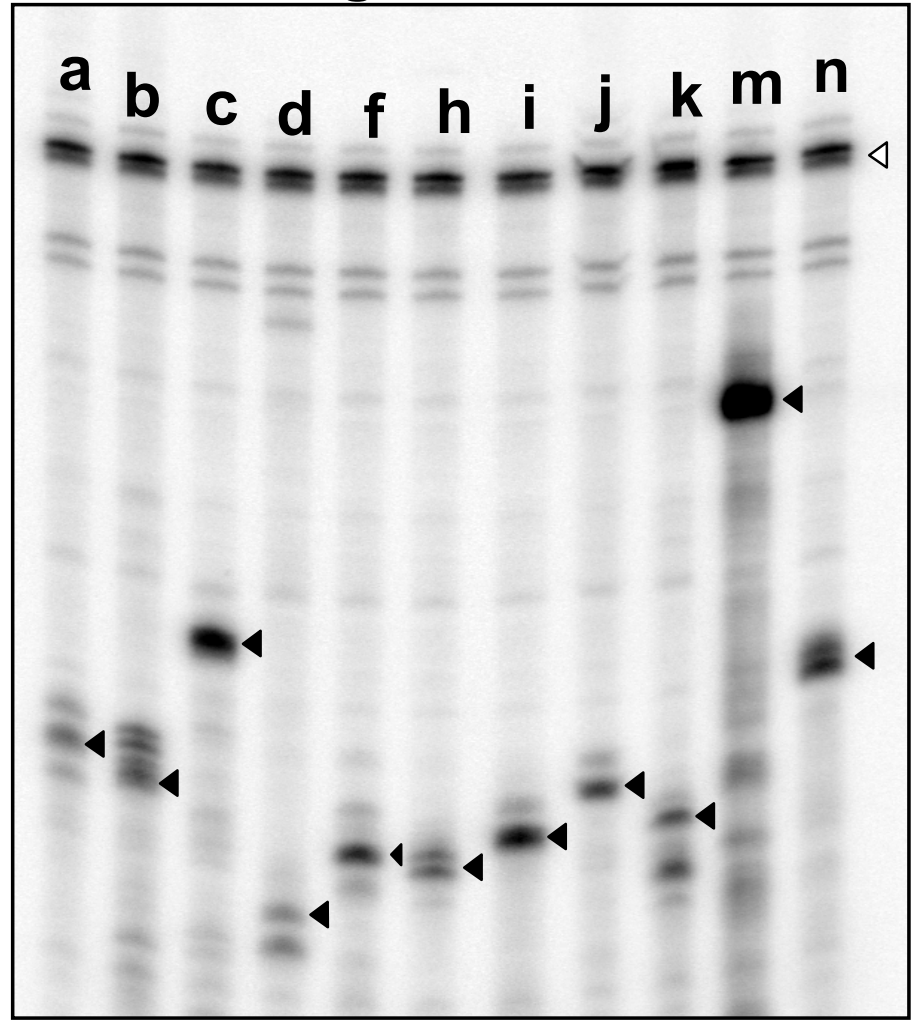

Abbildung 10: Autoradiogramm des RNase-Protektionsassays mit RNA aus fötaler Lunge

Die protektierten H3-mRNA-Banden sind mit gefüllten Dreiecken markiert. Die protektierten $\beta$-ActinBanden sind mit einem offenen Dreieck gekennzeichnet. Doppelbanden werden als Resultat von alternativen Transkriptions-Startstellen gedeutet.

Weitere vier Gene, $\mathrm{H} 3 / \mathrm{b}, \mathrm{H} 3 / \mathrm{c}, \mathrm{H} 3 / \mathrm{i}$ und $\mathrm{H} 3 / \mathrm{k}$, wurden mittelstark exprimiert und stellten zusammen zwischen $36 \%$ und $39 \%$ der Gesamt-H3-mRNA. Die übrigen fünf Gene $\mathrm{H} 3 / \mathrm{a}, \mathrm{H} 3 / \mathrm{d}, \mathrm{H} 3 / \mathrm{f}, \mathrm{H} 3 / \mathrm{h}$ und $\mathrm{H} 3 / \mathrm{j}$ wurden schwächer exprimiert und stellten zusammen zwischen $18 \%$ und $27 \%$ der Gesamt-H3-mRNA. In adultem Lebergewebe lag die Menge der replikationsabhängigen H3-mRNAs unterhalb der Nachweisgrenzen (Daten werden nicht gezeigt). Da die Zellteilungsrate bei diesem Gewebe sehr klein ist, bestätigt dieser Befund, dass die untersuchten elf H3Histongene tatsächlich nur im wachsendem Fötalgewebe, also replikationsabhängig exprimiert werden.

Zusammenfassend zeigen diese Daten, dass alle elf replikationsabhängigen $\mathrm{H} 3-$ Histongene mit unterschiedlicher individueller Stärke in den drei fötalen humanen Geweben aus Blase, Leber und Lunge exprimiert wurden (siehe Abbildung 11 $11_{1}$ ). Das H3-Expressionsmuster war in allen drei Gewebtypen ähnlich. 
Fötale Blase

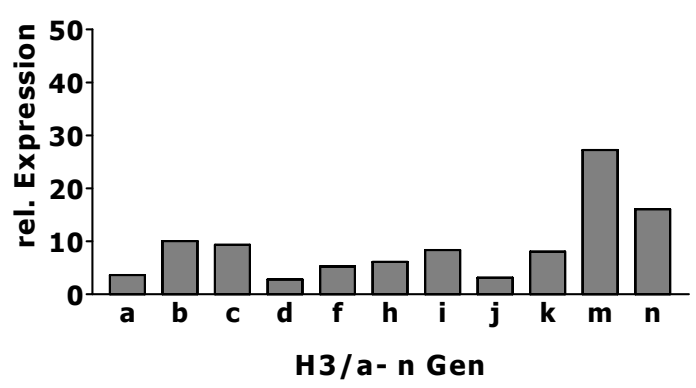

Fötale Lunge

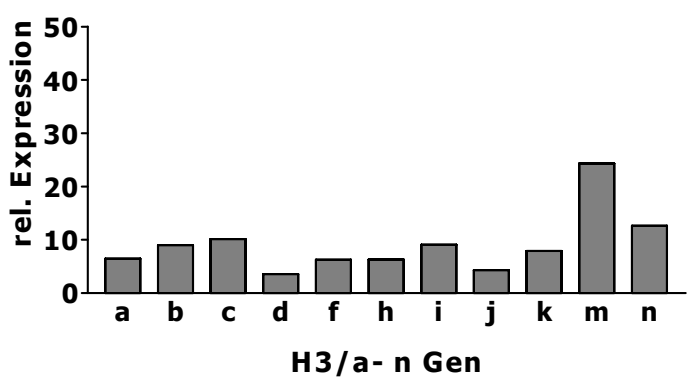

Fötale Leber

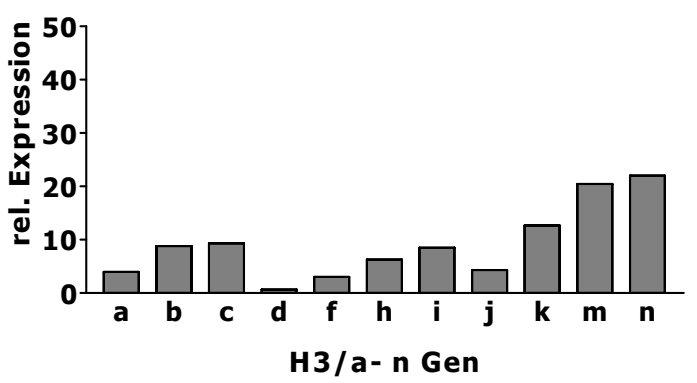

Abbildung 11: Das Expressionsmuster der $11 \mathrm{H} 3$-Histongene in drei fötalen Geweben

Die quantitativen Ergebnisse der RNase-Protektionsassays mit RNA aus den humanen fötalen Geweben Blase, Leber und Lunge sind dargestellt, die über Phosphorlmager-Analyse bestimmt wurden. Die relative Expressionsrate wird als Prozentsatz der Gesamt-H3-mRNA der replikationsabhängigen $\mathrm{H} 3-$ Gene dargestellt. Die Expression wurde mit einem quantitativen RNaseProtektionsassay bestimmt (siehe 4.2.1 ${ }_{7}$ ).

\subsubsection{Expressionsanalyse der $11 \mathrm{H} 3$-Histongene in humanen Zelllinien}

Nachdem in verschiedenen fötalen Geweben eine Expression der elf replikationsabhängigen $\mathrm{H} 3$-Histongene nachgewiesen worden war, ergab sich die Frage, ob auch in humanen Tumorzellinien eine generelle Expression aller H3-Gene $\mathrm{zu}$ beobachten ist (siehe auch 1.4 Zielstellung $_{6}$ ). Daher wurde das H3Expressionsmuster in acht humanen Zelllinien (HeLa-S3, HEK-293, SaOS-2, Tera-2, HL-60, Hep-G2, IMR-90 und Capan-1) bestimmt.

In den Zelllinien HeLa-S3, HEK-293, Tera-2 und SaOS-2 wurde das H3-Expressionsmuster mit der oben beschriebenen $\left(4.2 .1_{37}\right)$ quantitativen RNase Protektionsanalyse (RPA) bestimmt; allerdings wurde die H3/d-Expression nicht analysiert. In einer weiteren Untersuchungsreihe wurde für jede der acht untersuchten humanen Zellinien die Gesamt-RNA mit jeweils einer einzigen H3-Sonde hybridisiert (siehe Anhang 8.2. 25 ). Daraus konnten die H3-Expressionsmuster in den Zelllinien Hep-G2, Capan-1, IMR-90 und HL-60 berechnet werden (siehe $8.2{ }_{25}$ und Tabelle 2. 25 ). 
Die Ergebnisse sind in Abbildung 12, Abbildung 13,4 und Abbildung 14, dargestellt. Das Expressionsmuster in der diploiden Zelllinie IMR-90 ähnelte dem Muster in den fötalen Geweben (vergleiche Abbildung 11 1 1 ). Im Gegensatz dazu zeigten die Zellinien HEK-293, HeLa-S3, SaOS-2, HL-60, Hep-G2 und Capan-1 davon vollkommen verschiedene, abweichende Expressionsmuster. Diese Zelllinien exprimierten im wesentlichen die Histongene $H 3 / m$, $H 3 / n$ und $H 3 / k$, während die anderen $\mathrm{H} 3-\mathrm{Gene}$ nur in geringen Mengen oder gar nicht exprimiert wurden. Die Autoradiogramme wurden quantitativ ausgewertet. Die Ergebnisse sind in Abbildung $14_{45}$ zusammengefasst.

Im Detail fand man folgende, von humaner Gewebe-RNA abweichende Expressionsmuster: In der Zelllinie SaOS-2 betrug der Anteil der $\mathrm{H} 3 / \mathrm{m}$ - und $\mathrm{H} 3 / \mathrm{n}$ mRNA an der Gesamt-H3-mRNA 73\%, während die H3/c-, H3/d- und H3/j-Gene gar nicht exprimiert wurden. In der HeLa-S3 Zelllinie betrug der Anteil der mRNA der vier Gene $\mathrm{H} 3 / \mathrm{h}, \mathrm{H} 3 / \mathrm{k}, \mathrm{H} 3 / \mathrm{m}$ und $\mathrm{H} 3 / \mathrm{n}$ an der Gesamt H3-mRNA 86\%, während - ähnlich wie in der SaOS-2-Zelllinie - die Gene H3/c, H3/d, H3/f und H3/j nicht exprimiert wurden. In der schnell wachsenden HEK-293-Zelllinie wich das H3-Expressionsmuster noch deutlicher von der natürlichen Gewebe-Expression ab als in den SaOS-2- und HeLa-S3-Zelllinien: Hier waren die drei Histongene $\mathrm{H} 3 / \mathrm{k}, \mathrm{H} 3 / \mathrm{m}$ und $\mathrm{H} 3 / \mathrm{n}$ an $89 \%$ der $\mathrm{H} 3-$ Expression beteiligt, während die fünf Histongene $\mathrm{H} 3 / \mathrm{c}, \mathrm{H} 3 / \mathrm{d}$, $H 3 / f, H 3 / h$ und $H 3 / j$ nicht exprimiert wurden. In der Hep-G2 Zelllinie stellen die fünf Gene $H 3 / b, H 3 / c, H 3 / k, H 3 / m$ und $H 3 / n$ 99\% der Gesamt-H3-mRNA, während H3/i kaum und die restlichen H3-Gene gar nicht exprimiert wurden. Die HL-60-Zelllinie zeigte weniger starke Unterschiede zum Gewebe-Expressionsmuster. Aber auch hier zeigte sich eine Anormalität: die drei Gene $\mathrm{H} 3 / \mathrm{d}, \mathrm{H} 3 / \mathrm{h}$ und $\mathrm{H} 3 / \mathrm{i}$ wurden nicht exprimiert. In der Tera-2-Zelllinie wurden im Gegensatz zu den anderen Tumorzelllinien alle elf $\mathrm{H} 3-\mathrm{Gene}$ exprimiert. Dieser Unterschied könnte in der pluripotenten Natur dieser Zelllinie begründet sein (Andrews 1988). Es ist bemerkenswert, dass in der Tera-2-Zellinie mit Ausnahme von $\mathrm{H} 3 / \mathrm{m}$ und $\mathrm{H} 3 / \mathrm{n}$ alle übrigen Gene in etwa gleich stark exprimiert wurden. Das Expressionsmuster in der Pankreas-Zelllinie Capan-1 war wie ein Intermediat zwischen dem Muster in der Tera-2-Zelllinie und dem Muster der anderen Tumor-Zelllinien. Das $\mathrm{H} 3 / \mathrm{n}-$ Gen wurde wie in der Zelllinie Tera-2 stark exprimiert und zwei Gene (H3/d und H3/h) wurden nicht exprimiert. 

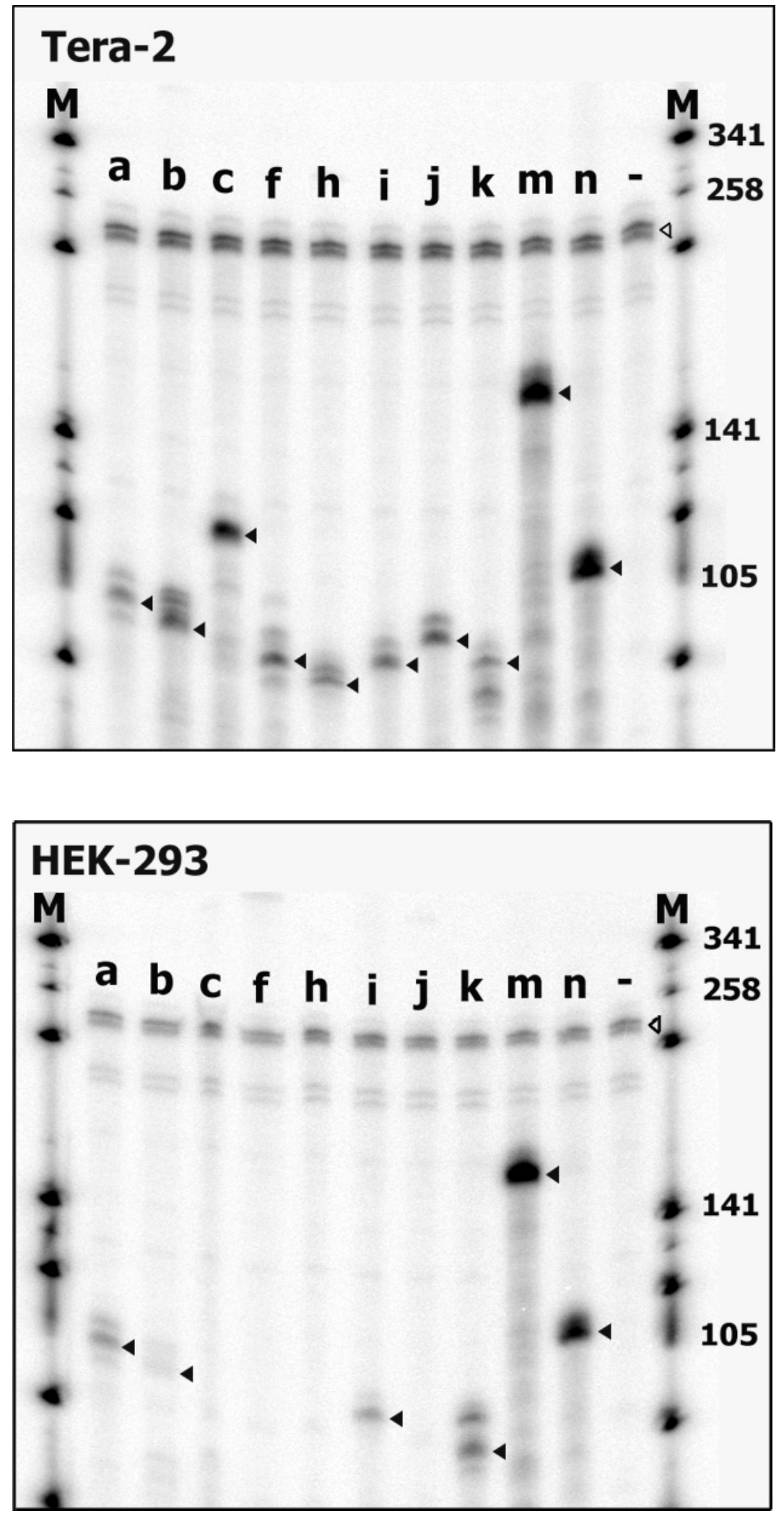

Abbildung 12: Autoradiogramme der RPA-Assays mit RNA aus den Zelllinien Tera-2 und HEK-293

Die protektierten H3-mRNA-Banden sind mit gefüllten Dreiecken markiert. Die protektierten $\beta$-ActinBanden sind mit einem offenen Dreieck gekennzeichnet. Doppelbanden werden als Resultat von alternierenden Transkriptions-Startstellen gedeutet. Die Nummern auf der rechten Seite geben die Größe von pUC19/ Sau 3AI-Fragmenten in den Markerspuren (M) in Basenpaaren an. 


\section{HeLa-S3}

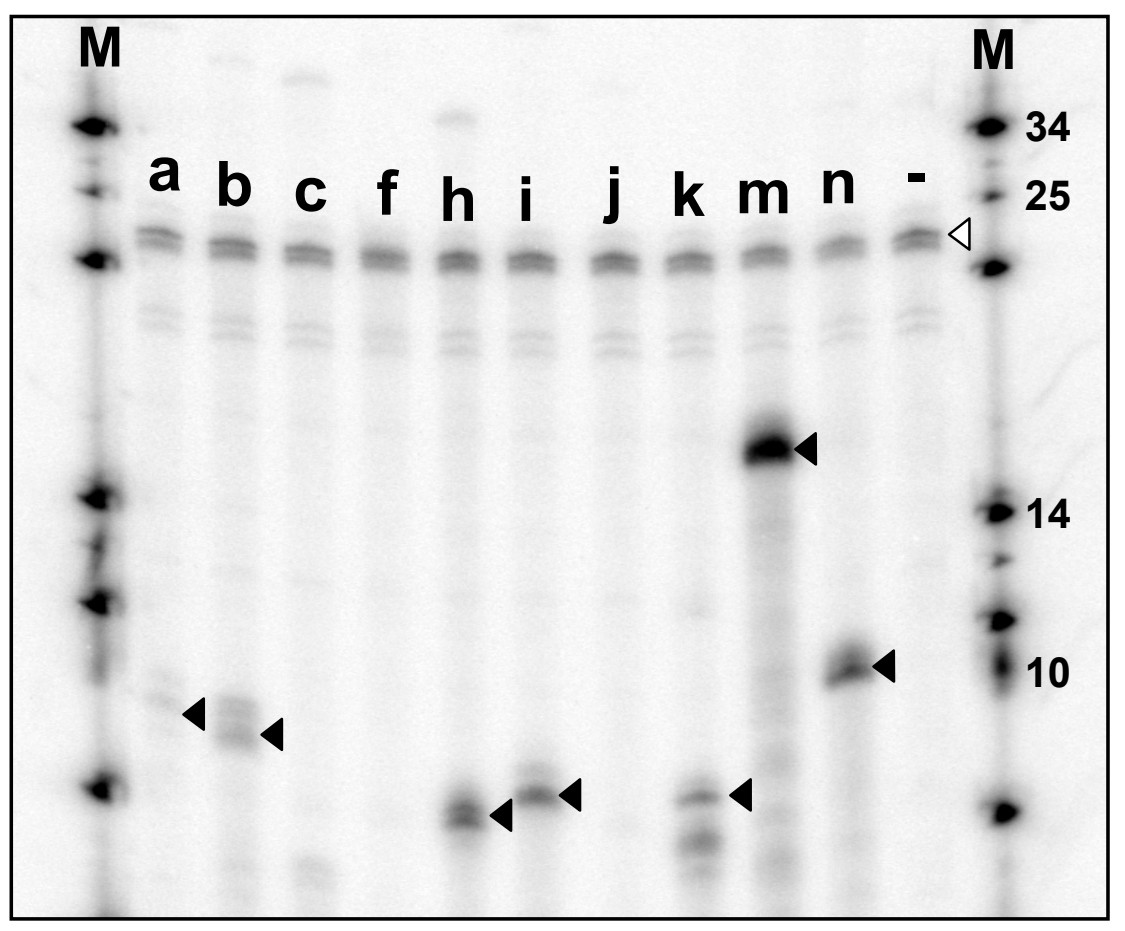

\section{SaOS-2}

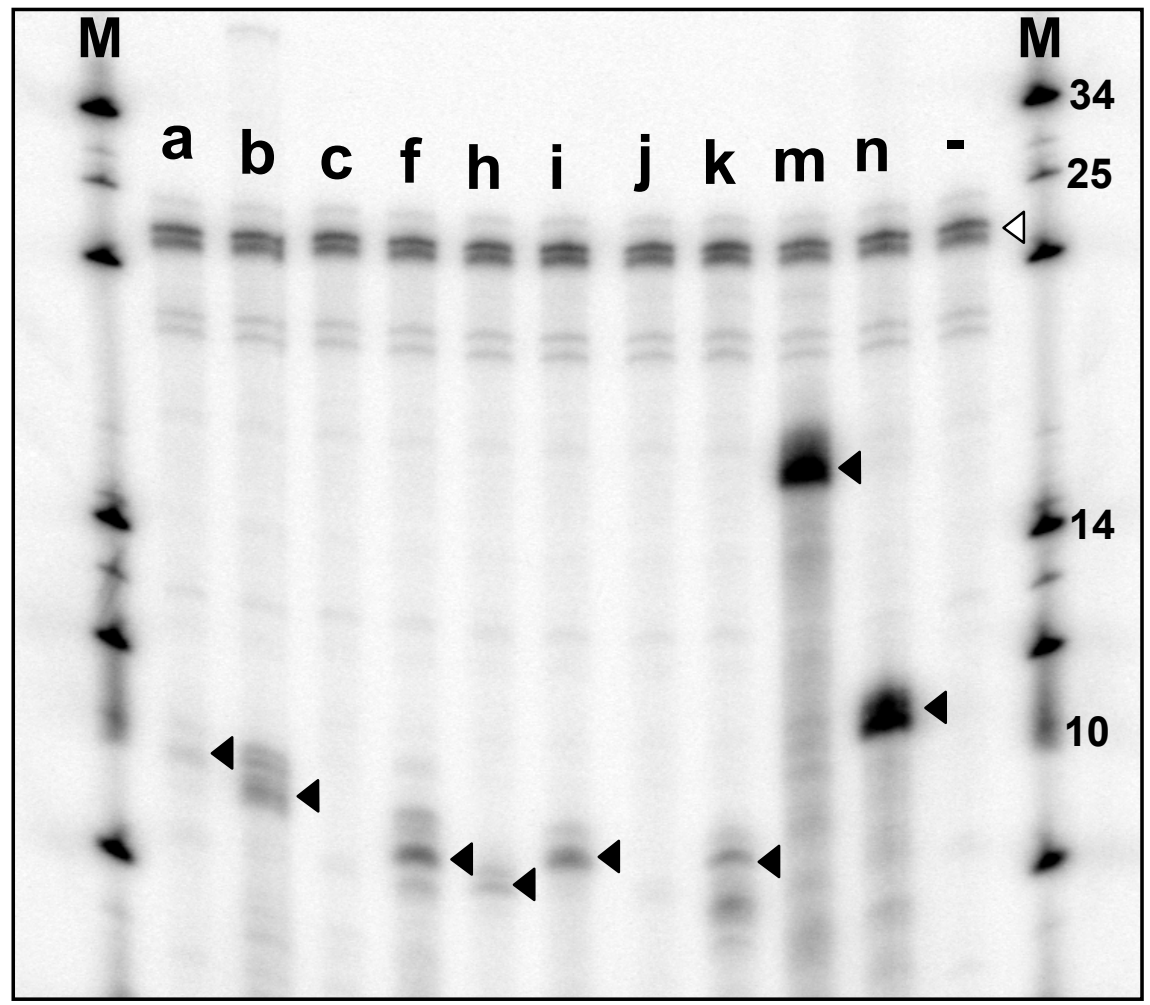

Abbildung 13: Autoradiogramme der RPA-Assays mit RNA aus den Zellinien HeLa-S3 und SaOS-2

Die protektierten H3-mRNA-Banden sind mit gefüllten Dreiecken markiert. Die protektierten $\beta$-ActinBanden sind mit einem offenen Dreieck gekennzeichnet. Doppelbanden werden als Resultat von alternierenden Transkriptions-Startstellen gedeutet. Die Nummern auf der rechten Seite geben die Größe von pUC19/ Sau 3AI-Fragmenten in den Markerspuren (M) in Basenpaaren an. 
HeLa-S3

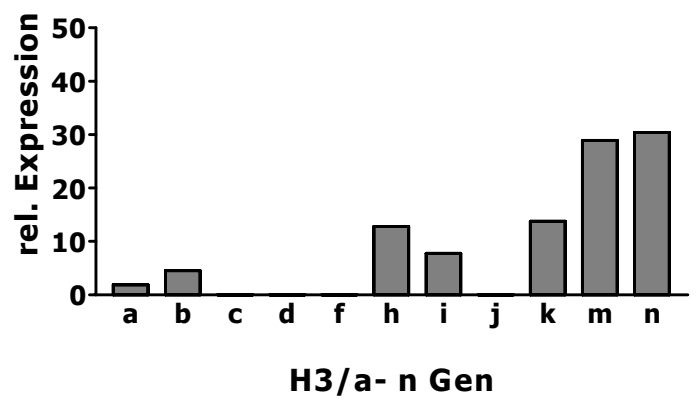

SaOS-2

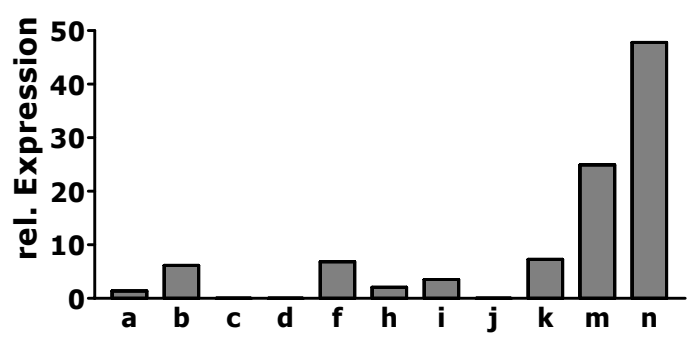

H3/a- n Gen

HL-60

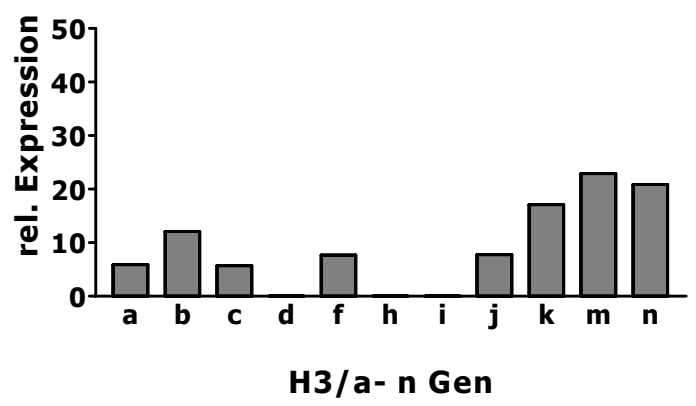

IMR-90

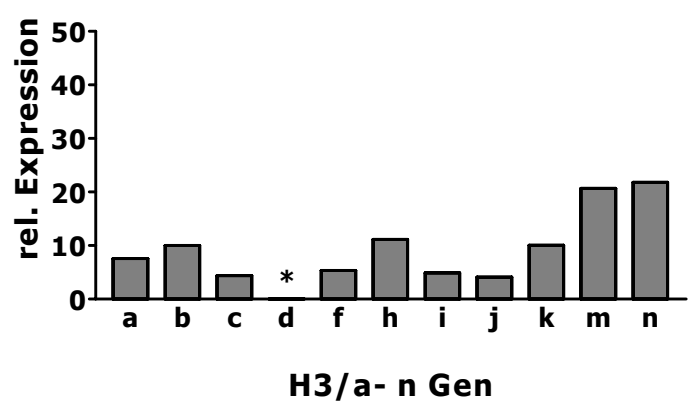

HEK-293

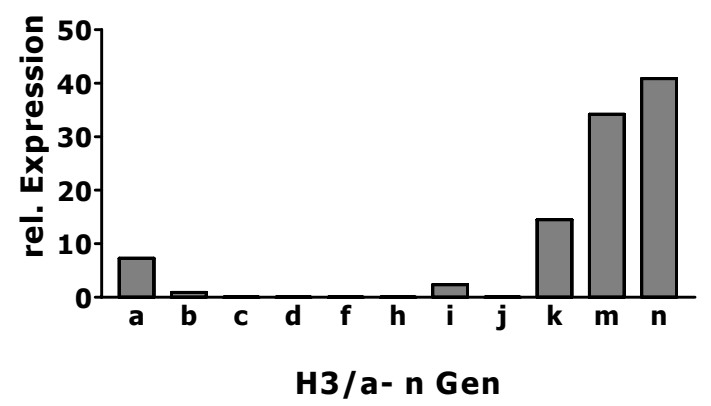

Tera-2

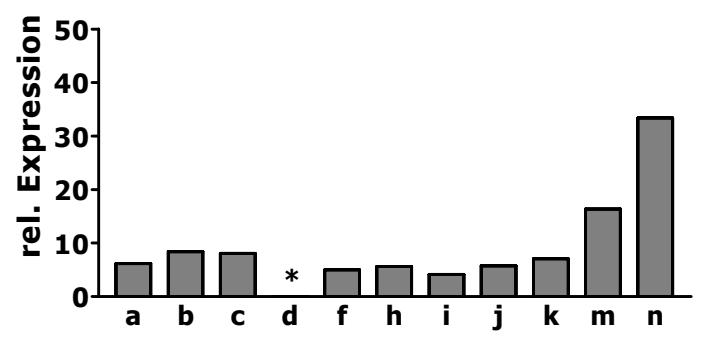

H3/a- n Gen

Hep-G 2

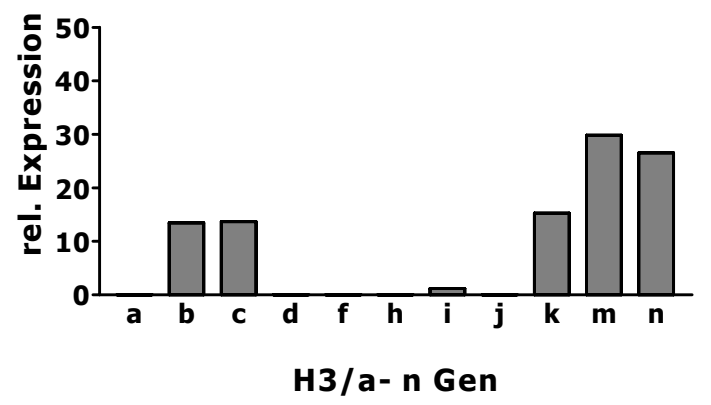

Capan-1

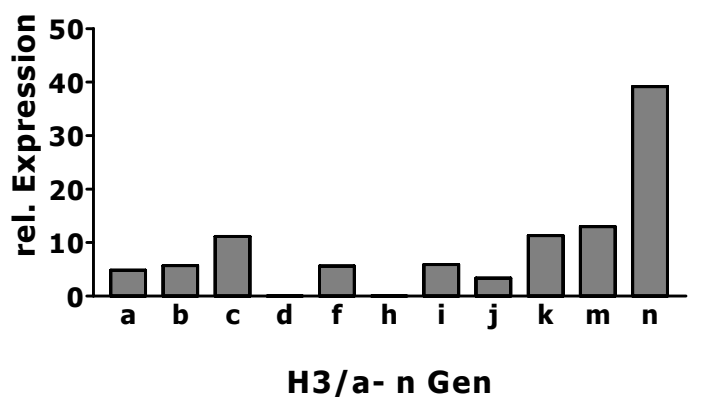

Abbildung 14: Das Expressionsmuster der $11 \mathrm{H} 3$-Histongene in acht humanen Zelllinien

Die quantitativen Ergebnisse der RNase-Protektionsassays (siehe 4.2 .1 ;7) mit RNA aus acht humanen Zelllinien sind dargestellt, die über Phosphorlmager-Analyse bestimmt wurden. Die relative Expressionsrate wird als Prozentsatz der Gesamt-H3-mRNA der replikationsabhängigen H3-Gene dargestellt. In einer anderen Experimentreihe wurde eine schwache Expression des H3/d-Gens in den Zelllinien IMR-90 und Tera-2, nicht jedoch in den anderen Zelllinien beobachtet. Die H3-Expressionsmuster in den Zellinien Hep-G2, Capan-1, IMR-90 und HL-60 wurden wie in Tabelle 2125 beschrieben mit Hilfe von Einzelsonden-Experimenten 8.2 25) bestimmt. 
Eine Möglichkeit, diese unterschiedlichen Expressionsstärken zu erklären, könnte in der gegenseitigen Beeinflussung zwischen benachbarten Histongenen bzw. in übergeordneten Regulationsmechanismen liegen. Es ist also denkbar, dass bei der Expressionsregulation die Position der H3-Gene in den Histongenclustern wichtig ist. Zur Prüfung dieser Möglichkeit wurden deshalb die Expressionsstärken in verschiedenen Zelllinien mit den gegenseitigen Entfernungen der H3-Histongene auf der DNA in Beziehung gesetzt. Wenn die Gene in bestimmten Teilen eines Clusters zusammen aktiviert bzw. deaktiviert würden, könnte man vermuten, dass benachbarte Gene - zumindest bis zu einem gewissen Grad - gemeinsam reguliert werden. In sechs Fällen sind sich H3-Gene näher als $20 \mathrm{~kb}$ : H3/h und H3/i (20,4 kb), $H 3 / c$ und $H 3 / m$ (13,4 kb), $H 3 / m$ und $H 3 / a(10,8 \mathrm{~kb}), H 3 / j$ und $H 3 / f(18,1 \mathrm{~kb})$. Ein Vergleich der Expressionsstärken der benachbarten Gene in allen verwendeten Zelllinien zeigt, dass die Paare $\mathrm{H} 3 / \mathrm{i}-\mathrm{H} 3 / \mathrm{h}$ und $\mathrm{H} 3 / \mathrm{j}-\mathrm{H} 3 / \mathrm{f}$ Anzeichen einer gemeinsamen, Zelllinien-spezifischen Aktivierung bzw. Inaktivierung zeigen, während dies bei den Paaren $\mathrm{H} 3 / \mathrm{c}-\mathrm{H} 3 / \mathrm{m}$ und $\mathrm{H} 3 / \mathrm{m}-\mathrm{H} 3 / \mathrm{a}$ nicht der Fall ist (siehe Abbildung $14_{45}$ ). Das H3/d-Gen befindet sich zwar in der Nähe von zwei weiteren H3-Genen, bliebt aber wegen mangelhafter Datenlage unberücksichtigt, da es nur in einer der transformierten Zelllinien exprimiert wurde.

Ein denkbare Ursache für die fehlende Expressionsaktivität mancher Gene in bestimmten Zelllinien könnte in chromosomalen Mutationen oder Deletionen begründet sein: Beispielsweise könnte die fehlende Expression des $\mathrm{H} 3 / \mathrm{h}-\mathrm{Histongens}$ in der HL-60-Zelllinie darauf zurückzuführen sein, dass das Gen mutiert ist oder gar nicht existiert. Die PCR an chromosomaler DNA (Abbildung 15,7) und die anschließende Sequenzierung der PCR-Produkte ergab, dass in der HL-60-Zelllinie die Gene H3/h und H3/i ohne Mutationen im Genom vorhanden sind. Gleiches gilt auch für die Histongene $\mathrm{H} 3 / \mathrm{c}$ und $\mathrm{H} 3 / \mathrm{h}$, die in der HEK-293-Zelllinie nicht exprimiert werden. (Es wurde lediglich eine unbedeutende Basenvariation im Promotor beobachtet). Diese Gene sind also vorhanden, wurden aber nicht exprimiert. Diese Ergebnisse an ausgewählten Genen lassen die Annahme plausibel erscheinen, dass auch in den übrigen Zelllinien die Histongene in unmutierter Form vorkommen und dass die Ursache für die fehlende Expression einiger H3-Histongene in einigen Tumorzellinien an anderer Stelle zu suchen ist. 


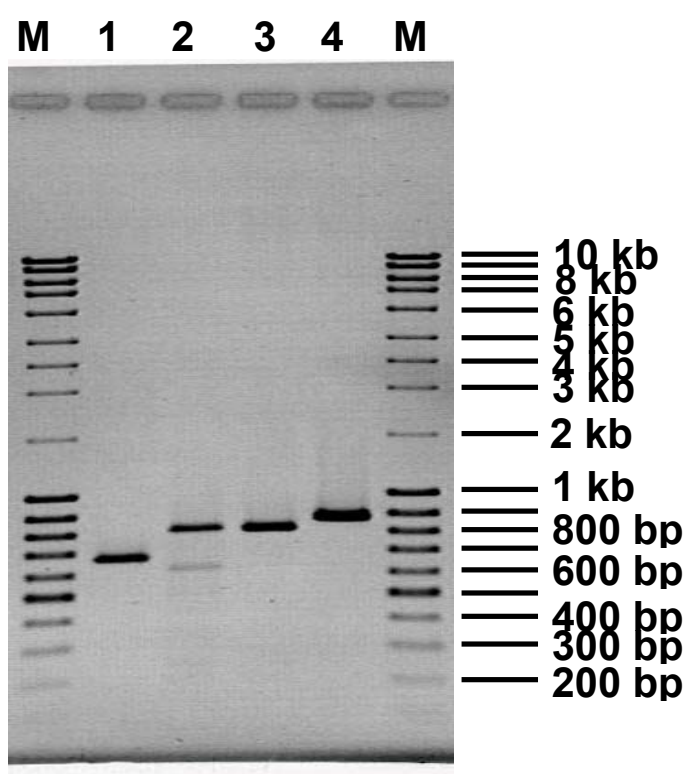

Abbildung 15: PCR-Amplifikation von Histongenen aus chromosomaler DNA

M: MassRuler'm-Mix-DNA-Leiter (MBI) 1: H3/i aus HL-60 chr. DNA (676 bp erwartet) 2: H3/h aus HL-60 chr. DNA (821 bp erwartet) 3: H3/h aus HEK-293 chr. DNA (821 bp erwartet) 4: H3/c aus HEK-293 chr. DNA (877 bp erwartet).

Das Expressionsmuster der elf replikationsabhängigen $\mathrm{H} 3-$ Histongene wurde in den acht humanen Zelllinien (HeLa-S3, HEK-293, SaOS-2, Tera-2, HL-60, Hep-G2, IMR-90 und Capan-1) mit quantitativer RNase Protektionsanalyse (RPA) bestimmt (Abbildung 1445). Das H3-Expressionsmuster in der diploiden Zelllinie IMR-90 ähnelt dem der drei fötalen Gewebearten (vergleiche Abbildung 114 1 ), während die übrigen untersuchten Zelllinien, die Tumorzelllinien sind, davon stark abweichende, anormale d.h. aberrante Expressionsmuster zeigten: Die Gesamt-H3-mRNA bestand in diesen Zelllinien im wesentlichen aus nur zwei bis fünf verschiedenen individuellen H3mRNAs, und einige Gene wurden gar nicht oder nur sehr schwach exprimiert. Die fehlende Expression einiger H3-Gene in einigen Tumorzellinien wurde nicht durch chromosomale Mutationen oder Deletionen verursacht.

\subsection{Reportergenanalyse von H3-Promotor-Deletionsreihen}

Entscheidende Grundlage einer unterschiedlichen Expression verschiedener Gene kann in der jeweiligen Promotorstärke liegen. Daher wurden Reportergenanalysen ausgewählter H3-Gene durchgeführt. Die funktionale Länge der H3-Promotoren sollte bestimmt, die Lage von cis-regulatorischen Elementen in den Promotoren aufgeklärt und die möglichen Einflüsse von Upstream-Sequenzen untersucht werden. Dafür wurden Reportergenassays mit Deletionsreihen von 6 H3-Genen 
durchgeführt: $\mathrm{H} 3 / \mathrm{d}, \mathrm{H} 3 / \mathrm{h}, \mathrm{H} 3 / \mathrm{i}, \mathrm{H} 3 / \mathrm{k}, \mathrm{H} 3 / \mathrm{m}$ und $\mathrm{H} 3 / \mathrm{n}$ (Begründung der Auswahl in Kapitel 5.29 ). Die Promotorfragmente mit einer Länge von 60 bis 1970 bp (bezogen auf Startcodon) wurden mit der PCR-Technik aus vorhandenen Plasmiden und Cosmiden amplifiziert und in den pGL3-basic Vektor kloniert. Als Fusionstelle wurde jeweils das Startcodon der H3-Gene und der kodierenden Sequenz der Luziferase gewählt. Die Reportergen-Konstrukte wurden durch Sequenzierung auf korrekten Einbau des Promotorfragments überprüft und in Endotoxin-freier Qualität präpariert. Anschließend wurde die Zelllinie HEK-293 mit diesen Plasmiden transfiziert, wie unter Material und Methoden beschrieben. Zusätzlich zu jedem Reportergenkonstrukt wurde das Renilla-Luziferase-Standard-Plasmid pRL-CMV transient transfiziert. Nach $18 \mathrm{~h}$ wurden die Luziferase-Aktivitäten bestimmt. Jedes Konstrukt wurde in den Promotor-Deletionsreihen mindestens fünfmal transfiziert und die jeweilige Luziferase-Aktivität mit der Renilla-Aktivität standardisiert.

Die gewählten Konstrukte und die Resultate sind in Abbildung 16, bis Abbildung $21_{55}$ mitsamt der SEM-Standardabweichung dargestellt. Die Standardabweichungen geben den Fehlerbereich der Aktivitätsbestimmung in der transienten Transfektion wieder. Die Messungen wurden jeweils mit Plasmiden einer Endotoxin-freien MaxiPräparation durchgeführt. Kontrollversuche ergaben jedoch, dass bei verschiedenen Plasmidpräparationen die Aktivitäten der Konstrukte bis zu etwa $25 \%$ voneinander abweichen konnten.

Die gemessenen Aktivitäten wurden relativ zum jeweils stärksten Konstrukt in Beziehung gesetzt, das auf den Indexwert von 100\% gesetzt wurde. Die Konstrukte, die nur die TATA-Box enthielten, besaßen nahezu keine Aktivität $(<1 \%)$. Eine Ausnahme stellte nur das kurze Konstrukt von $\mathrm{H} 3 / \mathrm{d}$ dar (2,6\%). Verlängerte man die Promotoren, so dass sie neben der TATA-Box auch die jeweilige proximale CCAATBox enthielten, so variierte die Aktivität bei den verschiedenen Genen: Bei dem H3/hund $\mathrm{H} 3 / \mathrm{m}-\mathrm{Gen}$ beobachtete man keine nennenswerte Steigerung der Aktivität, während beim $\mathrm{H} 3 / \mathrm{k}-\mathrm{Gen}$ der Minimalpromotor aus proximaler CCAAT-Box und TATA-Box immerhin eine relative Aktivität von $14 \%$ entfaltete. Eine ähnliche relative Höhe erreichte das entsprechende Konstrukt beim H3/i-Gen. Auch bei dem H3/nund dem $\mathrm{H} 3 / \mathrm{d}-\mathrm{Gen}$ beobachtete man durch die Einbeziehung der proximalen CCAAT-Box eine kleine Basal-Aktivität von 1,7\% bzw. 5,5\% 
Die Konstrukte, die zusätzlich zur proximalen CCAAT-Box die zweite, distale CCAAT-Box enthielten, erreichten 35\%- $75 \%$ der maximal möglichen Promotorstärke. Eine Ausnahme war hier der H3/i-Promotor, der allerdings im Bereich bis zu 350 bp vor der TATA-Box keine zweite CCAAT-Box besaß. Längere Konstrukte, die zusätzlich zu den zwei CCAAT-Boxen weitere Upstream-Bereiche enthielten, zeigten bei den verschiedenen Genen unterschiedliche Aktivitäten: Beim H3/d-Gen bewirkte der 452 bp-Promotor keine höhere Aktivität als der 198 bpPromotor. Erst ein Promotor der Länge 1369 bp bewirkte die volle (um den Faktor 2 höhere) Aktivität, die auch beim 1827 bp-Promotor nicht wesentlich höher war. Beim H3/h-Gen war der 147 bp-Promotor, der im Vergleich zum 97 bp-Promotor zwei weiteren CCAAT-Boxen besaß, doppelt so aktiv wie der 97 bp-Promotor $(80 \%$ der Maximalaktivität). Sämtliche längeren H3/h-Promotorkonstrukte besaßen keine bedeutend höheren Promotoraktivitäten. Bei der H3/k-Reihe erreichte man die maximale Aktivität schon mit den ersten 133 Basenpaaren, die die beiden CCAATBoxen und die TATA-Box enthielten. Die H3/k-Reihe verhielt sich somit ähnlich wie die H3/h-Reihe. Beim H3/m-Gen war der 227 bp-Promotor, der zusäztlich eine ATFBox enthielt, im Vergleich zum 129 bp-Rumpfpromotor mit den beiden CCAAT-Boxen um den Faktor 3 aktiver (25\% der Maximalaktivität). Wenn man das längste Konstrukt, das das $\mathrm{H} 2 \mathrm{~A} / \mathrm{m}-\mathrm{Gen}$ enthielt, beim Aktivitätsvergleich nicht berücksichtigen will, so erreichten diese 227 bp des Promotors sogar nahezu 100\% Aktivität, da der 983 bp-Promotor keine nennenswert höhere Aktivität besaß. Das mit 1933 bp längste Konstrukt, welches zusätzlich zum H3/m-Gen auch das komplette H2A/m-Gen mitsamt 404 bp-Promotor enthält, erreichte eine Aktivitätssteigerung um den Faktor 3 auf 100\% Maximalaktivität (siehe Abbildung 16;0).

Beim H3/n-Gen war die Aktivität des 233 bp-Promotors im Vergleich zum 140 bpRumpfpromotor mit den zwei CCAAT-Boxen, der TATA-Box und der ATF-Box leicht gesteigert. Bemerkenswert war die schwächere Aktivität des 360 bp-Promotors. Unter Einbeziehung von 658 bp bzw. 1027 bp des Promotors wurde die volle Aktivität erreicht.

Längere H3/i-Promotor-Konstrukte, die zusätzlich zum H3/i-Minimalpromotor, der nur die proximale CCAAT-Box und die TATA-Box enthielt, weitere Upstream-Bereiche enthielten, waren um so aktiver, je länger sie waren. Dies war jedoch ein moderater Effekt. Ein kleiner Aktivitätssprung ergab sich nach Einbeziehung einer zweiten CCAAT-Box, die allerdings 350 bp von der proximalen CCAAT-Box entfernt ist. 

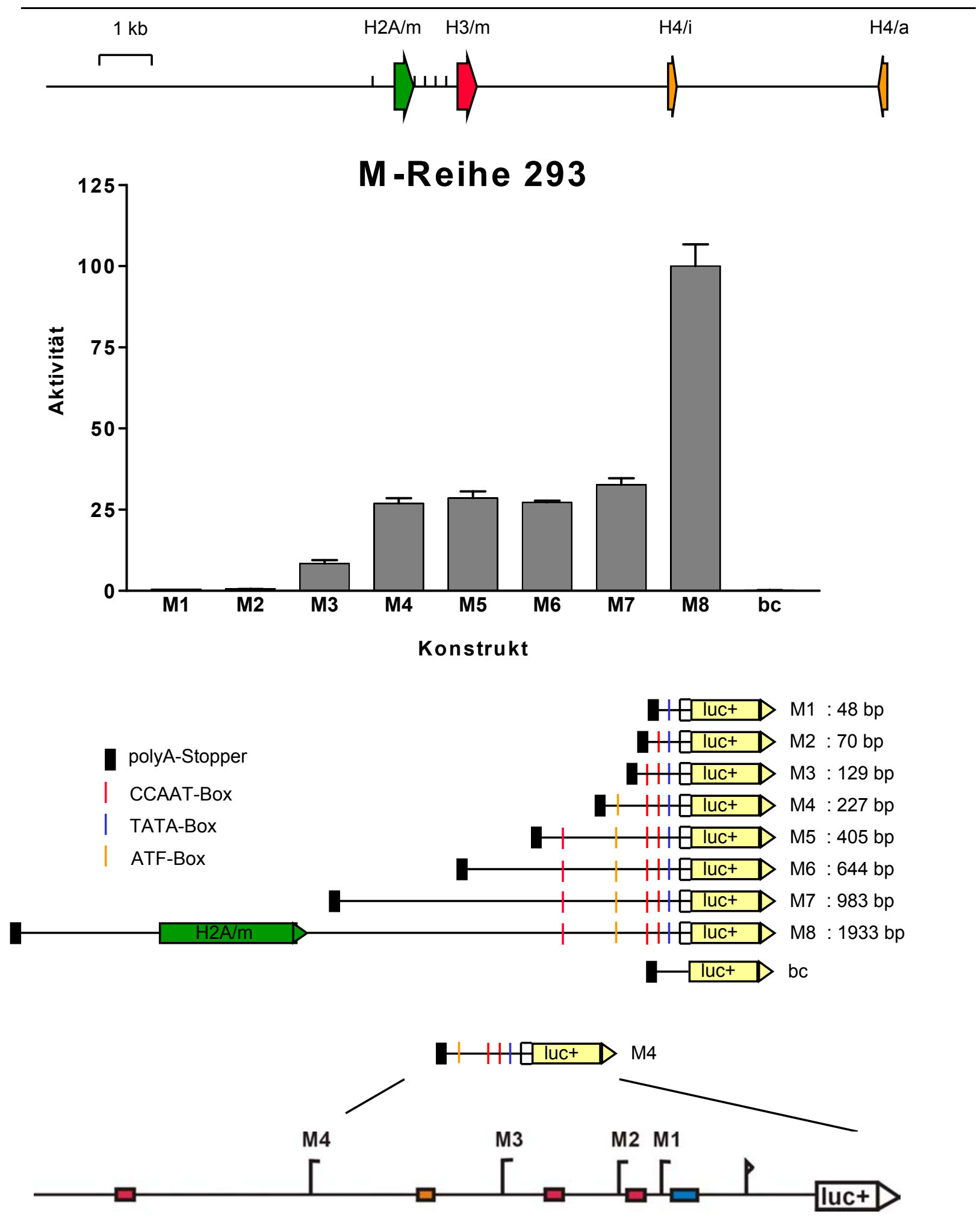

Abbildung 16: Reportergenanalyse der H3/m-Promotor-Deletionsreihe in der Zelllinie HEK-293

Oben: chromosomale Umgebung des $\mathrm{H} 3 / \mathrm{m}$-Gens (insgesamt $16 \mathrm{~kb}$ ). Mitte: Reportergenaktivität der Deletionskonstrukte M1-M8 (bc: pGL3-basic-Vektor als Negativkontrolle); Statistik aus fünf Messreihen mit SEM (M8-Aktivität = Indexwert 100\%). Unten: Schematische Darstellung der Deletionskonstrukte (luc+: Firefly-Luziferase-kodierende Sequenz) mit Angabe der Längen (Bezug: Transkriptionsstart) der Promotoren (Fusionsstelle: ATG). Ganz unten: Detailliertere Darstellung der kurzen Deletionskonstrukte M1-M4; rote Boxen: CCAAT-Boxen; blaue Box: TATA-Box; orange Box: ATF-Box. 

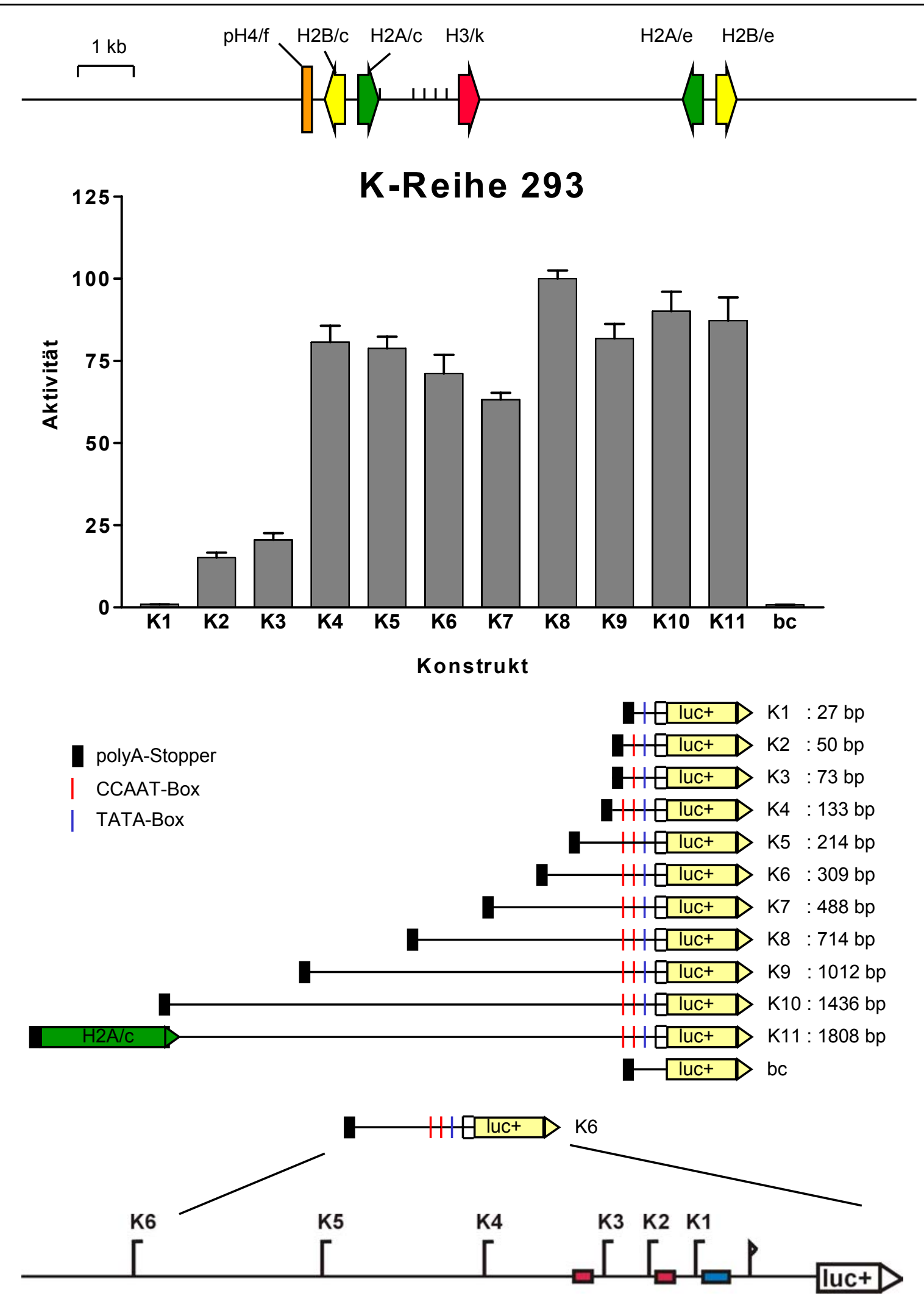

Abbildung 17: Reportergenanalyse der H3/k-Promotor-Deletionsreihe in der Zelllinie HEK-293

Oben: chromosomale Umgebung des H3/k-Gens (insgesamt $16 \mathrm{~kb}$ ). Mitte: Reportergenaktivität der Deletionskonstrukte K1-K11 (bc: pGL3-basic-Vektor als Negativkontrolle); Statistik aus fünf Messreihen mit SEM (K8-Aktivität = Indexwert 100\%). Unten: Schematische Darstellung der Deletionskonstrukte (luc+: Firefly-Luziferase-kodierende Sequenz) mit Angabe der Längen (Bezug: Transkriptionsstart) der Promotoren (Fusionsstelle: ATG). Ganz unten: Detailliertere Darstellung der kurzen Deletionskonstrukte K1-K6; rote Boxen: CCAAT-Boxen; blaue Box: TATA-Box. 

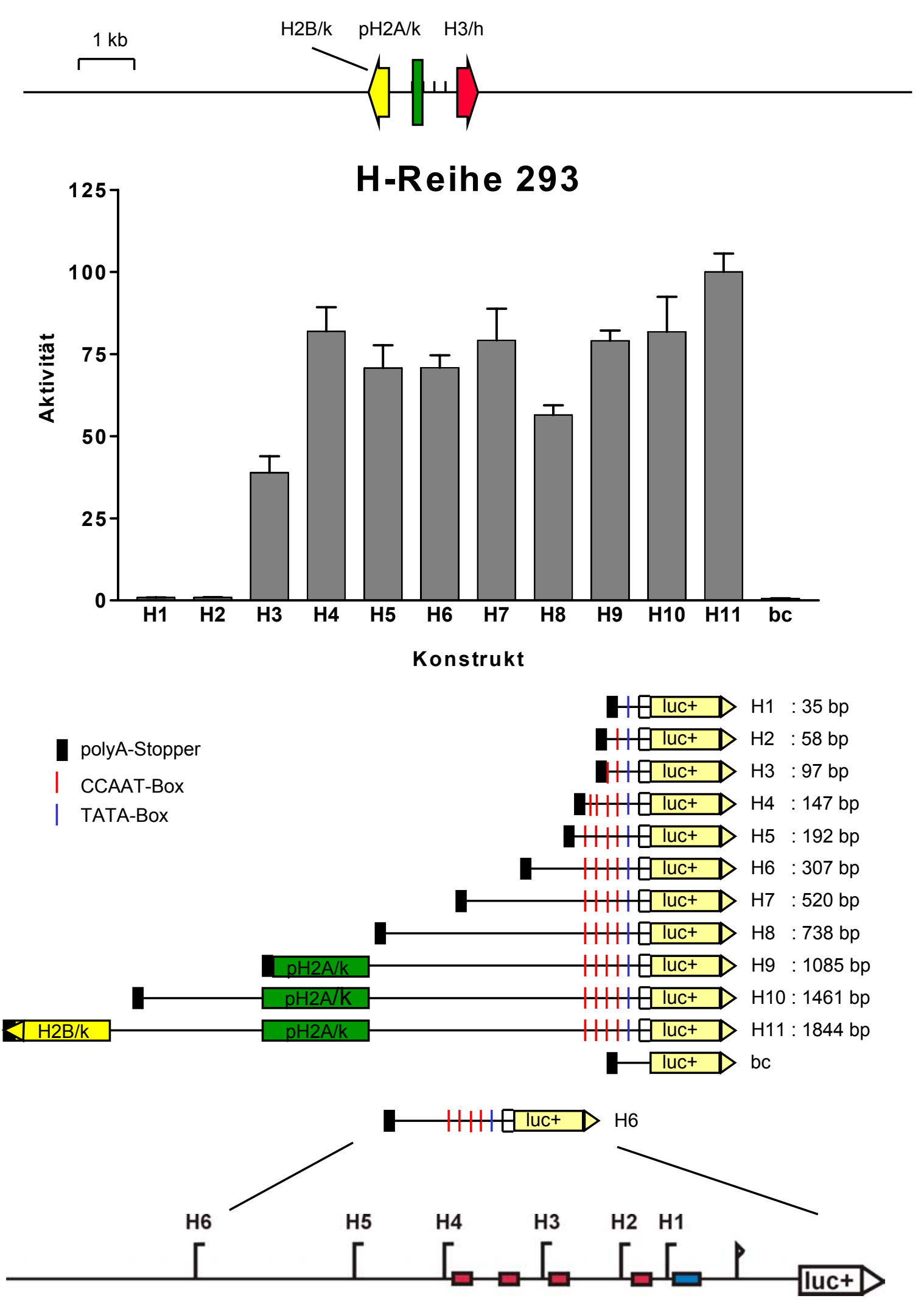

Abbildung 18: Reportergenanalyse der H3/h-Promotor-Deletionsreihe in der Zelllinie HEK-293

Oben: chromosomale Umgebung des H3/h-Gens (insgesamt $16 \mathrm{~kb}$ ). Mitte: Reportergenaktivität der Deletionskonstrukte H1-H11 (bc: pGL3-basic-Vektor als Negativkontrolle); Statistik aus fünf Messreihen mit SEM (H11-Aktivität $=$ Indexwert 100\%). Unten: Schematische Darstellung der Deletionskonstrukte (luc+: Firefly-Luziferase-kodierende Sequenz) mit Angabe der Längen (Bezug: Transkriptionsstart) der Promotoren (Fusionsstelle: ATG). Ganz unten: Detailliertere Darstellung der kurzen Deletionskonstrukte H1-H6; rote Boxen: CCAAT-Boxen; blaue Box: TATA-Box. 

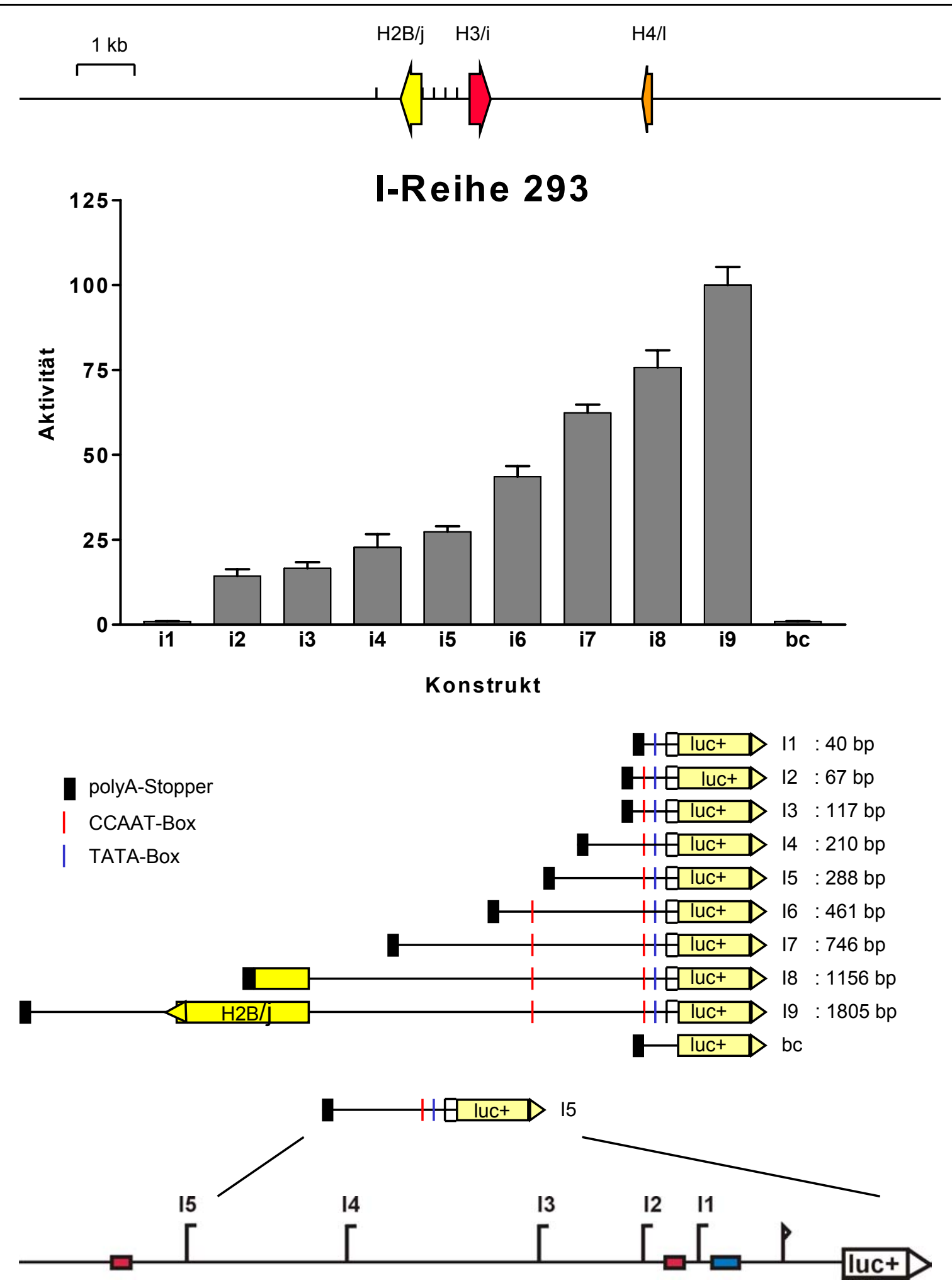

Abbildung 19: Reportergenanalyse der H3/i-Promotor-Deletionsreihe in der Zelllinie HEK-293

Oben: chromosomale Umgebung des H3/i-Gens (insgesamt $16 \mathrm{~kb}$ ). Mitte: Reportergenaktivität der Deletionskonstrukte 11-19 (bc: pGL3-basic-Vektor als Negativkontrolle); Statistik aus fünf Messreihen mit SEM (I9-Aktivität $=$ Indexwert 100\%). Unten: Schematische Darstellung der Deletionskonstrukte (luc+: Firefly-Luziferase-kodierende Sequenz) mit Angabe der Längen (Bezug: Transkriptionsstart) der Promotoren (Fusionsstelle: ATG). Ganz unten: Detailliertere Darstellung der kurzen Deletionskonstrukte I1-I5; rote Boxen: CCAAT-Boxen; blaue Box: TATA-Box. 

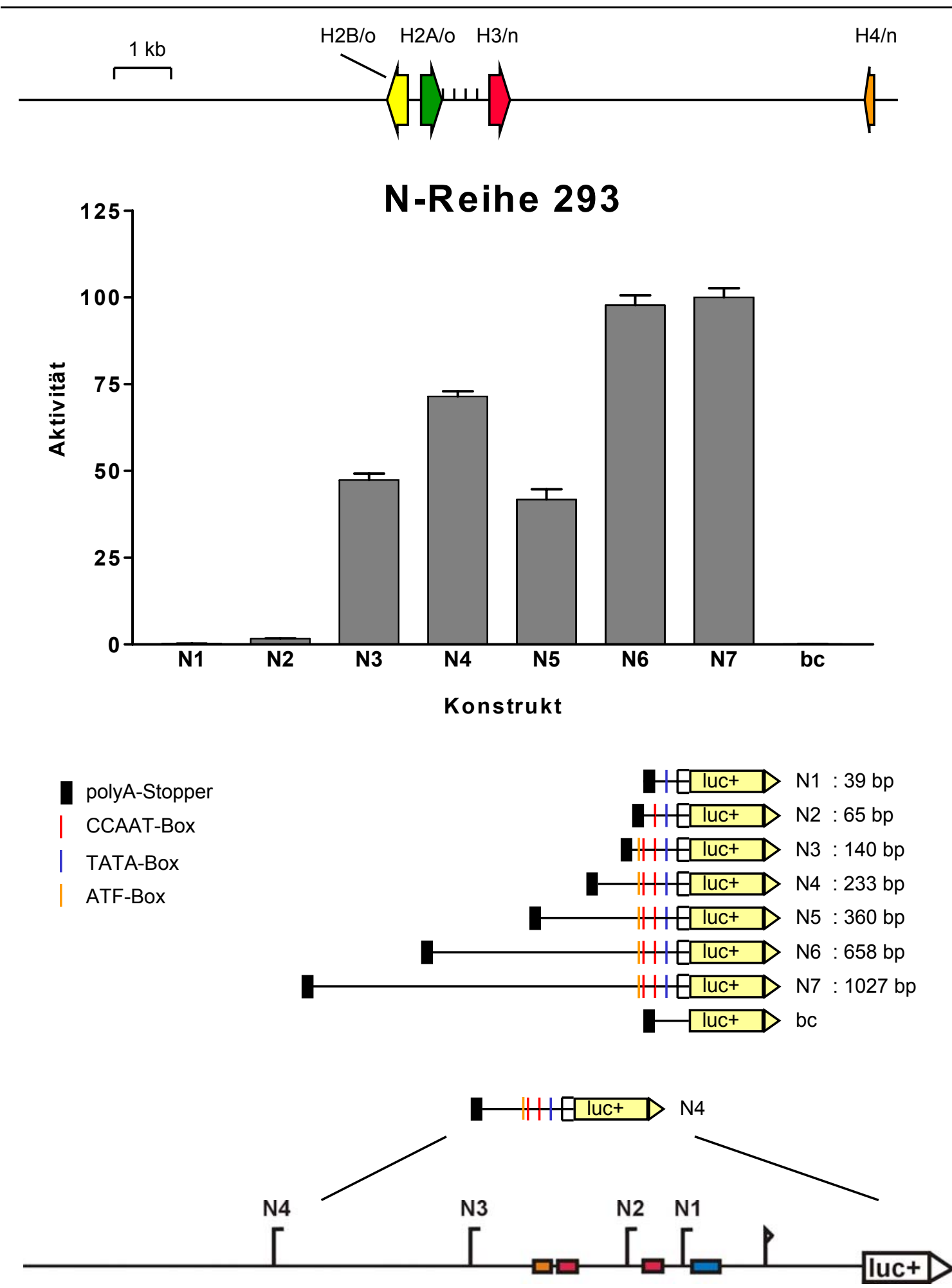

Abbildung 20: Reportergenanalyse der H3/n-Promotor-Deletionsreihe in der Zelllinie HEK-293

Oben: chromosomale Umgebung des H3/n-Gens (insgesamt $16 \mathrm{~kb}$ ). Mitte: Reportergenaktivität der Deletionskonstrukte N1-N7 (bc: pGL3-basic-Vektor als Negativkontrolle); Statistik aus fünf Messreihen mit SEM (N7-Aktivität = Indexwert 100\%). Unten: Schematische Darstellung der Deletionskonstrukte (luc+: Firefly-Luziferase-kodierende Sequenz) mit Angabe der Längen (Bezug: Transkriptionsstart) der Promotoren (Fusionsstelle: ATG). Ganz unten: Detailliertere Darstellung der kurzen Deletionskonstrukte N1-N4; rote Boxen: CCAAT-Boxen; blaue Box: TATA-Box; orange Box: ATF-Box. 

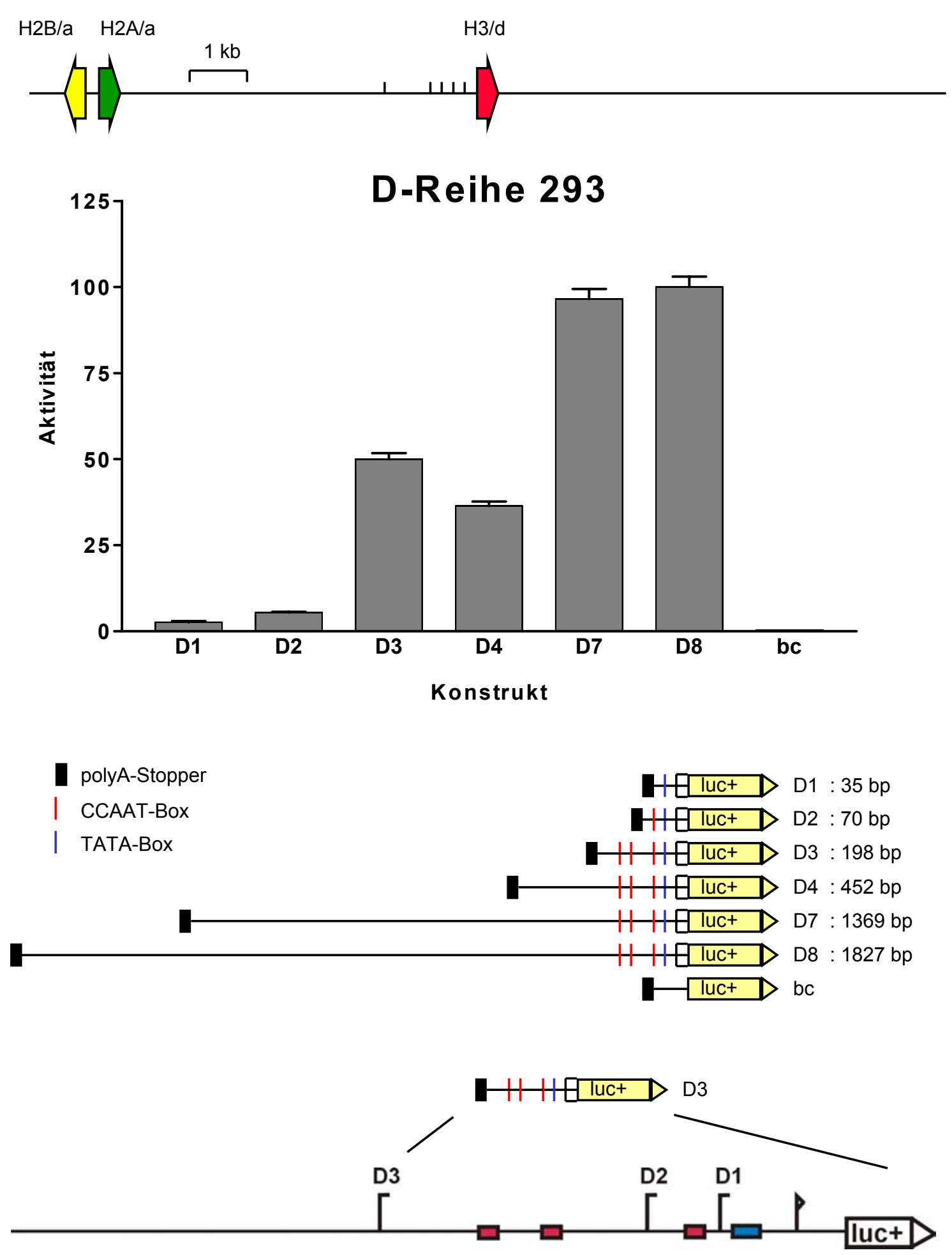

Abbildung 21: Reportergenanalyse der H3/d-Promotor-Deletionsreihe in der Zelllinie HEK-293

Oben: chromosomale Umgebung des H3/d-Gens (insgesamt $16 \mathrm{~kb}$ ). Mitte: Reportergenaktivität der Deletionskonstrukte D1-D8 (bc: pGL3-basic-Vektor als Negativkontrolle); Statistik aus fünf Messreihen mit SEM (D8-Aktivität = Indexwert 100\%). Unten: Schematische Darstellung der Deletionskonstrukte (luc+: Firefly-Luziferase-kodierende Sequenz) mit Angabe der Längen (Bezug: Transkriptionsstart) der Promotoren (Fusionsstelle: ATG). Ganz unten: Detailliertere Darstellung der kurzen Deletionskonstrukte D1-D3; rote Boxen: CCAAT-Boxen; blaue Box: TATA-Box. 
Wenn man einen proximalen Promotor so definiert, dass er einen voll funktionsfähigen Bereich innerhalb von 500 Basenpaaren upstream des Transskriptionsstarts umfaßt, dann haben die proximalen Promotoren der H3-Gene höchstens folgende Längen (bezogen auf den Transkriptionsstart): $\mathrm{H} 3 / \mathrm{m} 228 \mathrm{bp}$, H3/k 99 bp, H3/h 115 bp, H3/n 186 bp und H3/d 176 bp. Beim H3/i ist kein solcher proximaler Promotor definierbar, da die Aktivität der Konstrukte mit steigender Länge kontinuierlich stieg.

Durch Transfektion in parallelen Experimenten von funktionalen Promotoren der sechs Gene H3/d (Konstrukt D7), H3/h (Konstrukt H10), H3/i (Konstrukt 18), H3/k (Konstrukt K10), H3/m (Konstrukt M7) und H3/n (Konstrukt N6) unter identischen Bedingungen in der HEK-293-Zelllinie konnten die Promotoraktivitäten der Gene untereinander verglichen werden (siehe 4.4 Promotorstärken-Vergleich in fünf

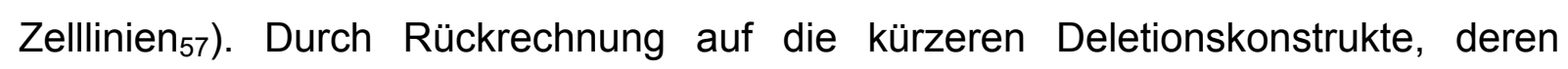
Aktivität relativ zu den oben genannten Konstrukten in den Promotor-Deletionsreihen bestimmt wurde (Abbildung 16, 50 -Abbildung 21,55), wurden deren Aktivitäten auch zwischen verschiedenen Genen vergleichbar (Abildung 22, 37 ). Die Konstrukte, die nur die TATA-Boxen enthielten, hatten eine Aktivität von $0,26 \%$ bis 2,3\% bezogen auf das Konstrukt N3 (H3/n Deletionskonstrukt 3). Die Konstrukte, die nur die TATABox und die proximale CCAAT-Box enthielten, hatten eine Aktivität von $0,88 \%$ bis $4,8 \%$ bezogen auf N3. Die Konstrukte, die eine TATA-Box und genau zwei CCAATBoxen ohne weitere Elemente enthielten, hatten eine Aktivität von $24 \%$ bis $42 \%$ bezogen auf N3. Die Konstrukte D3, H4, M4 und N3 enthielten zusätzlich weitere Elemente (D3: eine weitere CCAAT-Box, H4: zwei weitere CCAAT-Boxen, M4: eine ATF-Box und N3: eine putative ATF-Box) und zeigten Aktivitäten von $44 \%$ bis $100 \%$ bezogen auf $\mathrm{N} 3$.

Die funktionelle Struktur der H3-Promotoren wurde in Reportergenassays mit Deletionsreihen der folgenden sechs H3-Gene aufgeklärt: H3/d, H3/h, H3/i, H3/k, $\mathrm{H} 3 / \mathrm{m}$ und $\mathrm{H} 3 / \mathrm{n}$. Die funktionale Länge der Promotoren betrug 99 - 228 Basenpaare (H3/m 228 bp, H3/k 99 bp, H3/h 115 bp, H3/n 186 bp und H3/d 176 bp). Diese funktionalen Promotoren enthalten die folgenden im Sequenzvergleich (siehe 4.1,5) identifizierten cis-Elemente: eine TATA-Box, eine proximale CCAAT-Box, eine distale CCAAT-Box, und gegebenenfalls eine ATF-Box bzw. weitere CCAAT-Boxen. Der Einfluß von Upstream-Sequenzen war bei den sechs untersuchten Promotoren 
unterschiedlich: Beim $\mathrm{H} 3 / \mathrm{m}$-Promotor wurde eine aktivierende Wirkung des $\mathrm{H} 2 \mathrm{~A} / \mathrm{m}$ Gens auf die $\mathrm{H} 3 / \mathrm{m}$-Promotoraktivität festgestellt. Auch beim H3/i-Promotor zeigte sich eine aktivierende Wirkung des upstream gelegenen H2B/j-Gens. Beim H3/dund $\mathrm{H} 3 / \mathrm{n}$-Promotor ergaben sich leichte Aktivitätssteigerungen durch UpstreamBereiche, deren Ursache unbekannt ist. Beim H3/k- und H3/h-Promotor bewirkten die Upstream-Bereiche keine Aktivitätssteigerung. Mit Hilfe der in 4.457 beschriebenen Experimente konnten die Promotoraktivitäten der sechs untersuchten H3-Promotoren untereinander verglichen werden (Abbildung 22 37 ).

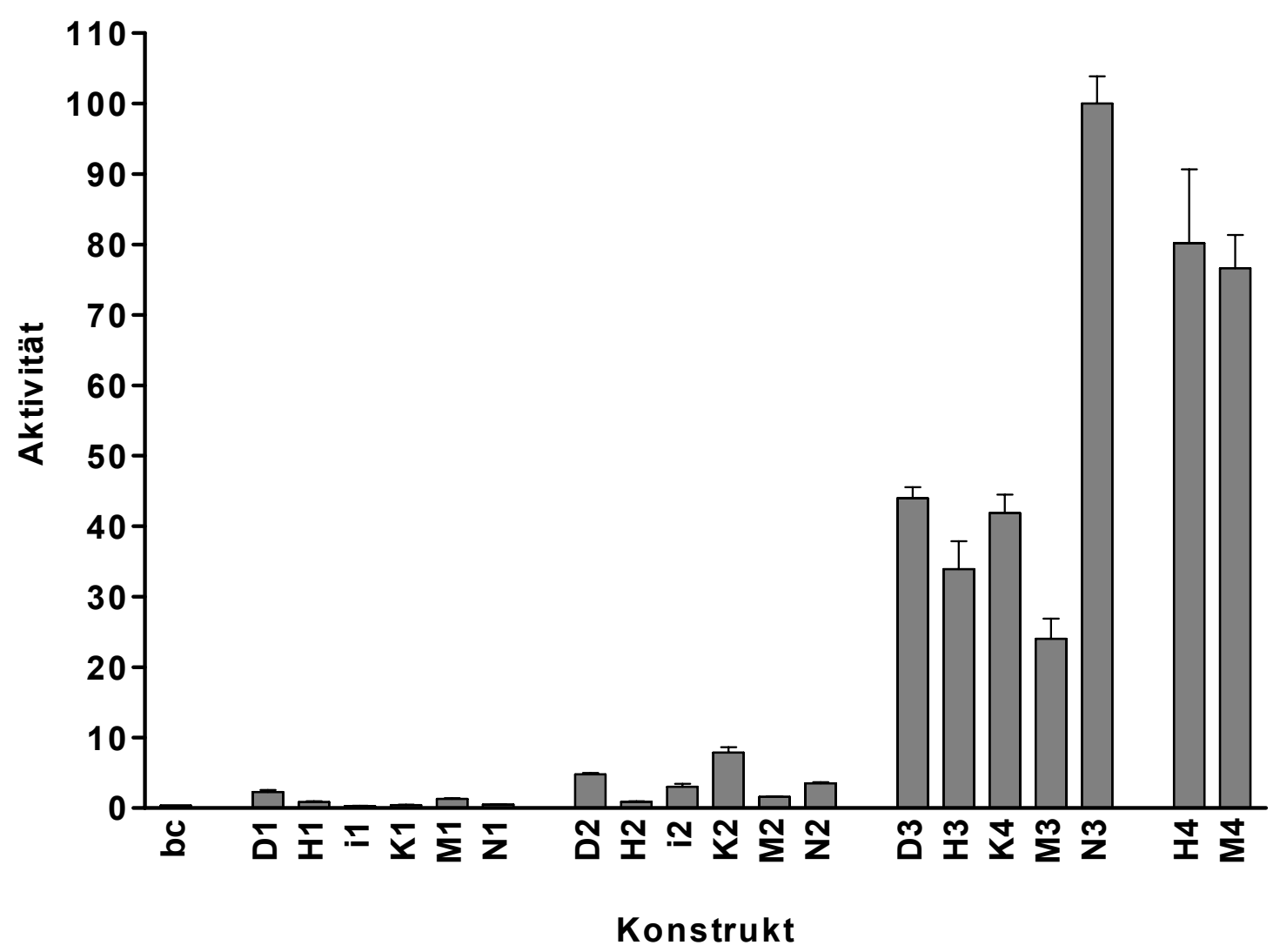

Abbildung 22: Normierte Reportergenaktivitäten von Konstrukten in der Zelllinie HEK-293

Durch Vergleich der Reportergenaktivitäten der verschiedenen H3-Promotoren in der Zelllinie HEK-293 (siehe 4.4,7) konnten die in Abbildung 16, bis Abbildung 21,5 dargestellten Reportergenassays der Promotor-Deletionsreihen der sechs H3-Gene H3/d, H3/h, H3/i, H3/k, H3/m und $\mathrm{H} 3 / \mathrm{n}$ in der Zelllinie HEK-293 normiert werden. Die Aktivität des Konstruktes N3 wurde auf den Indexwert 100\% gesetzt. Die Konstrukte D1-M4 sind in Abbildung 16, 0 bis Abbildung 21, 5 dargestellt. bc: pGL3-basic-Vektor als Negativkontrolle.

\subsection{Promotorstärken-Vergleich in fünf Zelllinien}

Nachdem die Promotoren der Gene H3/d, H3/h, H3/i, H3/k, H3/m und H3/n in Reportergenassay-Deletionsreihen in der Zelllinie HEK-293 näher charakterisiert 
worden waren, stellte sich die Frage, inwieweit die H3-Expressionsmuster und die Promotoraktivitäten in Zelllinien untereinander korrelierbar wären. Daher wurden die Promotoraktivitäten der Gene in fünf Zellinien miteinander verglichen. Die fünf gewählten Zelllinien waren die Teratocarinom-Zelllinie Tera-2, die transformierte Zelllinie HEK-293, die Tumorzelllinien HeLa-S3 und Hep-G2 und die diploide Fibroblasten-Zelllinie IMR-90. Hierzu wurden jeweils Konstrukte der Länge zwischen 704 Basen $(\mathrm{H} 3 / \mathrm{n})$ und 1492 Basen $(\mathrm{H} 3 / \mathrm{h})$ gewählt, die - ohne den distalen Aktivierungseffekt beim $\mathrm{H} 3 / \mathrm{m}-\mathrm{Gen}$ zu berücksichtigen - die voll funktionsfähigen Promotoren enthielten (siehe 4.3.7). Die Reportergenkonstrukte wurde in parallelen Experimenten transfiziert, die transfizierten Zellen wurden unter identischen Bedingungen kultiviert und aufgearbeitet, und die Bestimmung der LuziferaseAktivitäten erfolgte parallel unter identischen Bedingungen. Die Promotoraktivitäten wurden in transienten Reportergenassays in den fünf Zelllinien bestimmt. Jedes Experiment wurde mindestens fünfmal durchgeführt.

Alle sechs Promotoren waren in allen fünf Zelllinien aktiv (Abbildung 2399): In den Zelllinien HEK-293 und HeLa-S3 war der H3/n-Promotor am aktivsten, während in den Zelllinien Hep-G2, Tera-2 und IMR-90 der H3/d-Promotor am aktivsten war. Das Aktivitätsmuster der vier Promotoren H3/h-, H3/i-, H3/m- und $\mathrm{H} 3 / \mathrm{n}$ war in den untersuchten Zelllinien bemerkenswert ähnlich: Von diesen vier Promotoren war der $\mathrm{H} 3 / \mathrm{n}$-Promotor jeweils der Aktivste, gefolgt von $\mathrm{H} 3 / \mathrm{m}$ mit durchschnittlich $40 \% \mathrm{H} 3 / \mathrm{n}$ Aktivität, $\mathrm{H} 3 / \mathrm{h}$ mit durchschnittlich $21 \% \mathrm{H} 3 / \mathrm{n}$-Aktivität und $\mathrm{H} 3 / \mathrm{i}$ mit durchschnittlich 6,8\% H3/n-Aktivität.

Das Verhältnis der Promotoraktivitäten vom H3/d- und vom $\mathrm{H} 3 / \mathrm{k}$-Promotor war in den untersuchten fünf Zelllinien ebenfalls vergleichbar. Die H3/k-Aktivität betrug durchschnittlich $22 \%$ der $\mathrm{H} 3 / \mathrm{d}$-Aktivität. Je nach Zelllinie variierte die Aktivität von $\mathrm{H} 3 / \mathrm{d}$ und H3/k im Vergleich zur Aktivität der vier Promotoren H3/h-, H3/i-, H3/m- und $\mathrm{H} 3 / \mathrm{n}$. Dies berechtigt zur Einteilung der untersuchten H3-Promotoren in zwei Gruppen: Gruppe A umfasst die H3/h-, H3/i-, H3/m- und H3/n-Promotoren und Gruppe B umfasst die H3/d- und H3/k-Promotoren. In den Zelllinien HEK-293 und HeLa-S3 zeigten die Gruppe-B-Promotoren relativ zu den Gruppe-A-Promotoren eine niedrige Aktivität, während diese relativ zur Gruppe A in den Zelllinien Tera-2 und IMR-90 intermediär und in der Zelllinie Hep-G2 relativ zur Gruppe A hoch war. 
293

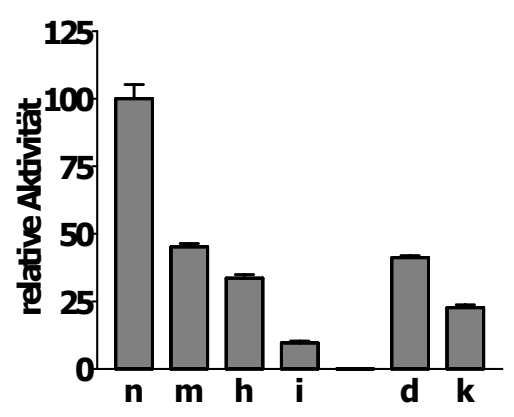

Histon $\mathrm{HB} / \mathbf{n - K}$

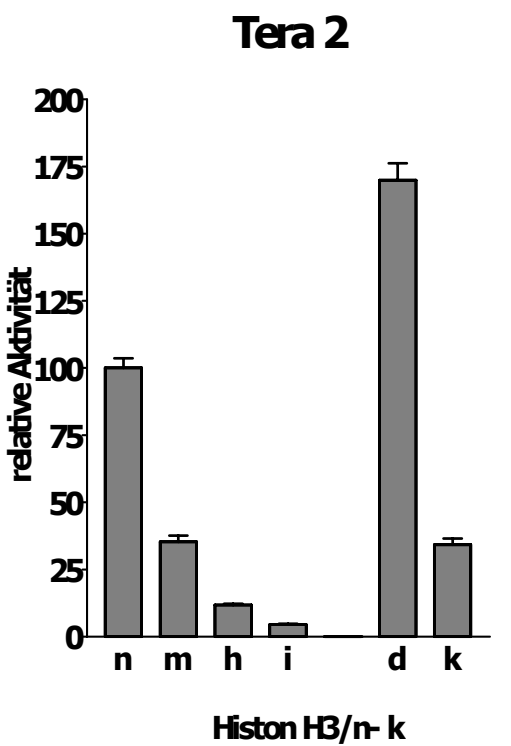

Helas3

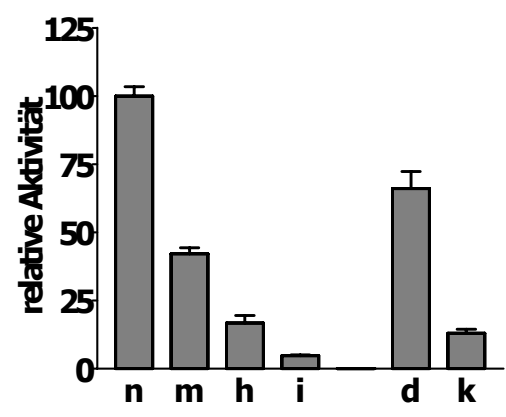

Histon $\mathrm{HB} / \mathrm{n}-\mathrm{k}$

Hep G2

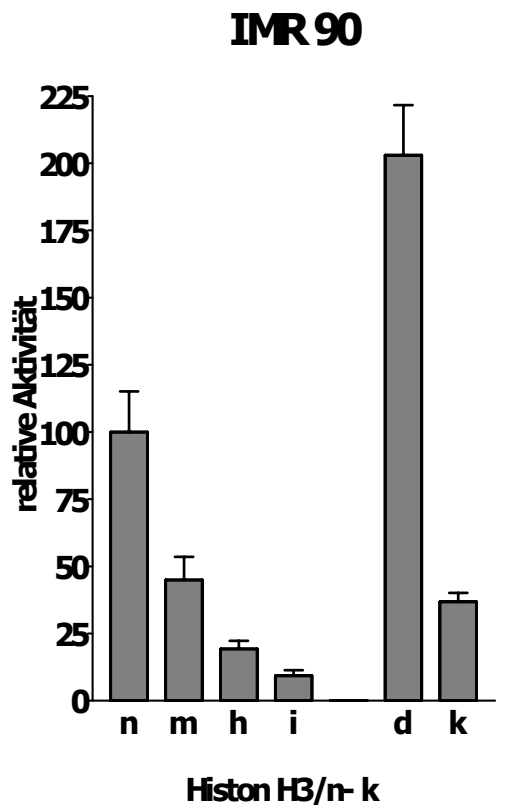

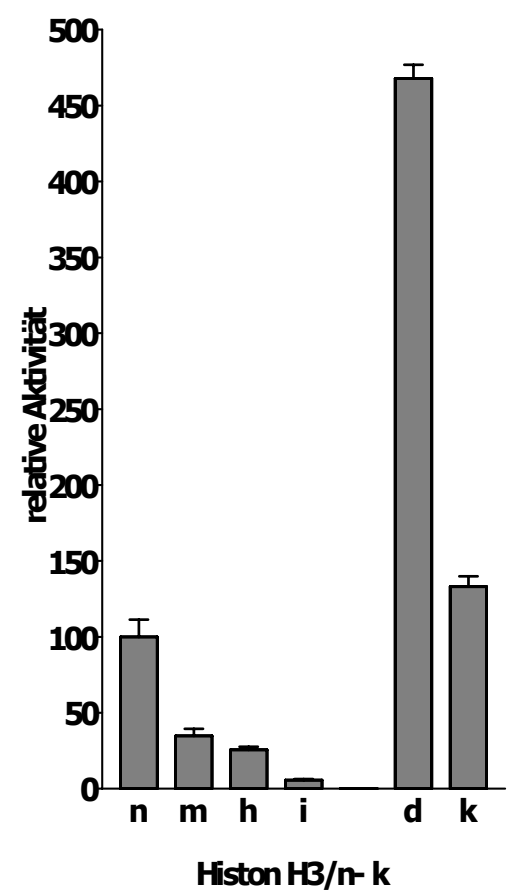

Abbildung 23: Promotoraktivität von sechs H3-Promotoren in fünf Zelllinien

Reportergenaktivität der Promotoren n: H3/n, Konstrukt N6, m: H3/m, Konstrukt M7, h: H3/h, Konstrukt H10, i: H3/i, Konstrukt 18, d: H3/d, Konstrukt D7, k: H3/k, Konstrukt K10 in fünf Zelllinien. Statistik aus fünf Messreihen mit SEM (H3/n (n) = Indexwert 100\%).

Die Promotoraktivitäten der Gene H3/d, H3/h, H3/i, H3/k, H3/m und H3/n wurden in fünf Zelllinien untereinander verglichen. Alle Promotoren waren in allen Zelllinien aktiv. Aufgrund der Aktivitätsmuster der H3-Promotoren in den fünf untersuchten Zelllinien konnten die Promotoren in zwei Gruppen unterteilt werden: Gruppe A ( $\mathrm{H} 3 / \mathrm{h}, \mathrm{H} 3 / \mathrm{m}, \mathrm{H} 3 / \mathrm{h}, \mathrm{H} 3 / \mathrm{i})$ und Gruppe $B(\mathrm{H} 3 / \mathrm{d}$ und $\mathrm{H} 3 / \mathrm{k}$ ) (siehe Abbildung 23/9). Innerhalb der Gruppen waren die Aktivitäten der Promotoren relativ zueinander im wesentlichen Zelltyp-unabhängig. 


\subsection{Distaler Aktivierungseffekt}

Die Aktivität des $\mathrm{H} 3 / \mathrm{m}$-Promotors verdreifachte sich, wenn das davorliegende $\mathrm{H} 2 \mathrm{~A} / \mathrm{m}$-Gen im Reportergenkonstrukt enthalten war. Es sollte erstens untersucht werden, ob dieser "distale Aktivierungseffekt" nicht artifiziell durch eine hypothetische polycistronische mRNA hervorgerufen wurde. Zweitens sollte untersucht werden, ob der Aktivierungseffekt des $\mathrm{H} 2 \mathrm{~A} / \mathrm{m}$-Gens von der Richtung dieses Gens abhängt und von welchen Bereichen im Gen er verursacht wird. Um zu untersuchen, inwieweit der Aktivierungseffekt spezifisch für das $\mathrm{H} 3 / \mathrm{m}-\mathrm{Gen}$ bzw. für H3-Gene ist, sollte drittens der Einfluss des $\mathrm{H} 2 \mathrm{~A} / \mathrm{m}-\mathrm{Gens}$ auf andere Promotoren bestimmt werden.

Eine Idee zur Deutung der Aktivitätssteigerung war, dass die erhöhte Aktivität eine Folge der Bildung einer hypothetischen polycistronischen mRNA sein könnte. Wenn die Transkription des $\mathrm{H} 2 \mathrm{~A} / \mathrm{m}$-Gens von dem transient transfizierten Plasmid nicht korrekt terminiert würde, würde als Folge davon eine mRNA gebildet, die zusätzlich zum $\mathrm{H} 2 \mathrm{~A} / \mathrm{m}-\mathrm{Gen}$ das Reportergen enthalten würde. Diese polycistronische mRNA könnte dann für die Aktivitätssteigerung verantwortlich sein. Diese Idee bestätigte sich nicht.

In einer ersten Versuchsreihe wurde erfolglos versucht, mit Hilfe eines Northern Blots die Länge der vorhandenen Luziferase-mRNA zu bestimmen. Wenn eine solche polycistronische mRNA gebildet werden würde, müsste sie erheblich länger sein als die normale Luziferase-mRNA, die ausgehend vom $\mathrm{H} 3 / \mathrm{m}$-Promotor gebildet wurde. Nach der Isolierung der mRNA aus den transient transfizierten Zellen wurde mit einer Sonde aus der Luziferase-kodierenden Sequenz ein Northern Blot durchgeführt. Obwohl mit einer Actin-Sonde gezeigt werden konnte, dass der Blot selbst funktioniert hatte und Actin-mRNA nachgewiesen werden konnte, konnte keine Luziferase-mRNA nachgewiesen und damit natürlich auch nicht ihre Länge bestimmt werden (Daten werden nicht gezeigt). Es ist zu vermuten, dass die LuziferasemRNA-Konzentration nach Transfektion mit dem Reportergenkonstrukt unter der Nachweisgrenze liegt.

Damit war die Frage einer möglichen polycistronischen mRNA weiterhin ungeklärt. Deshalb wurden neue Reportergenkonstrukte hergestellt, die den distalen Aktivierungseffekt näher charakterisieren sollten. Im Konstrukt M8inv1 wurde das komplette $\mathrm{H} 2 \mathrm{~A} / \mathrm{m}$-Gen umgedreht und im Konstrukt M8inv2 wurde der $\mathrm{H} 2 \mathrm{~A} / \mathrm{m}$ Promotor und ein kleiner Abschnitt im Beginn der H2A/m kodierenden Sequenz 
invertiert. Beide Konstrukte waren so konstruiert, dass in keinem Fall eine hypothetische polycistronische mRNA mehr gebildet werden konnte. Das Konstrukt M8ins1 enthielt das synthetische Poly(A)-Signal aus dem pGL3-basic Vektor, welcher hinter das $\mathrm{H} 2 \mathrm{~A} / \mathrm{m}-\mathrm{Gen}$ kloniert wurde, um eine zusätzliche sichere Transkriptionstermination zu schaffen. Dieser Kunstgriff verhindert ebenfalls die Bildung einer polycistronischen mRNA. Im Konstrukt M8ins2 war das Poly(A)-Signal in umgekehrter Richtung einkloniert. Sämtliche der neuen Konstrukte waren im Rahmen der bereits erläuterten Schwankungsbreite genauso aktiv wie das Ausgangskonstrukt M8 (Abbildung 24\$2).

Das Experiment beweist zweierlei. Einmal kann man eine polycistronische mRNA als Ursache für die beobachteten Aktivitätssteigerungen klar ausschließen. Zum zweiten zeigte sich, dass der distale Aktivierungseffekt trotz einer Invertierung des Gens sowie trotz einer leichten Vergrößerung des Abstandes zwischen $\mathrm{H} 2 \mathrm{~A} / \mathrm{m}-\mathrm{Gens}$ und $\mathrm{H} 3 / \mathrm{m}-$ Gen erhalten blieb.

Zur weiteren Erforschung sollte der distale Aktivierungseffekt des $\mathrm{H} 2 \mathrm{~A} / \mathrm{m}-\mathrm{Gens}$ näher eingegrenzt werden. Dazu wurden zwei Konstrukte kloniert: Das eine, M8del1, enthält nur noch den Promotor des H2A/m-Gens ohne TATA-Box. Dazu wurden die kodierende Sequenz und die 3'-UTR herausgeschnitten. Das andere Konstrukt M9 enthält nur die kodierende Sequenz und die 3'-UTR des H2A/m-Gens. Das Konstrukt M8del1 behielt im Vergleich zum Ausgangskonstrukt M8 seine Aktivität (Abbildung $25_{63}$ ). Auch das Konstrukt M9 besaß im Vergleich zum Konstrukt M7 (ohne distale Aktivierung) eine deutlich erhöhte Aktivität. Sowohl der H2A/m Promotor als auch die $\mathrm{H} 2 \mathrm{~A} / \mathrm{m}$ kodierende Sequenz mit $3^{\prime}-\mathrm{UTR}$ bewirkten im Experiment den distalen Aktivierungseffekt des $\mathrm{H} 3 / \mathrm{m}-$ Gens.

In einer zweiten Versuchsreihe sollte untersucht werden, ob das $\mathrm{H} 2 \mathrm{~A} / \mathrm{m}-\mathrm{Gen}$ nur speziell die Promotoraktivität des $\mathrm{H} 3 / \mathrm{m}$-Gens erhöht oder ob es generell die Promotoraktivität eines jeden Gens erhöht. Dazu wurde das H2A/m-Gen in zwei Orientierungen in den pGL3-promoter Vektor kloniert, der zum Test für putative Enhancer entwickelt wurde. Der Einbau erfolgte vor dem SV40-"Early"-Promotor, der wiederum die Expression des Reportergens Luziferase ermöglicht. 

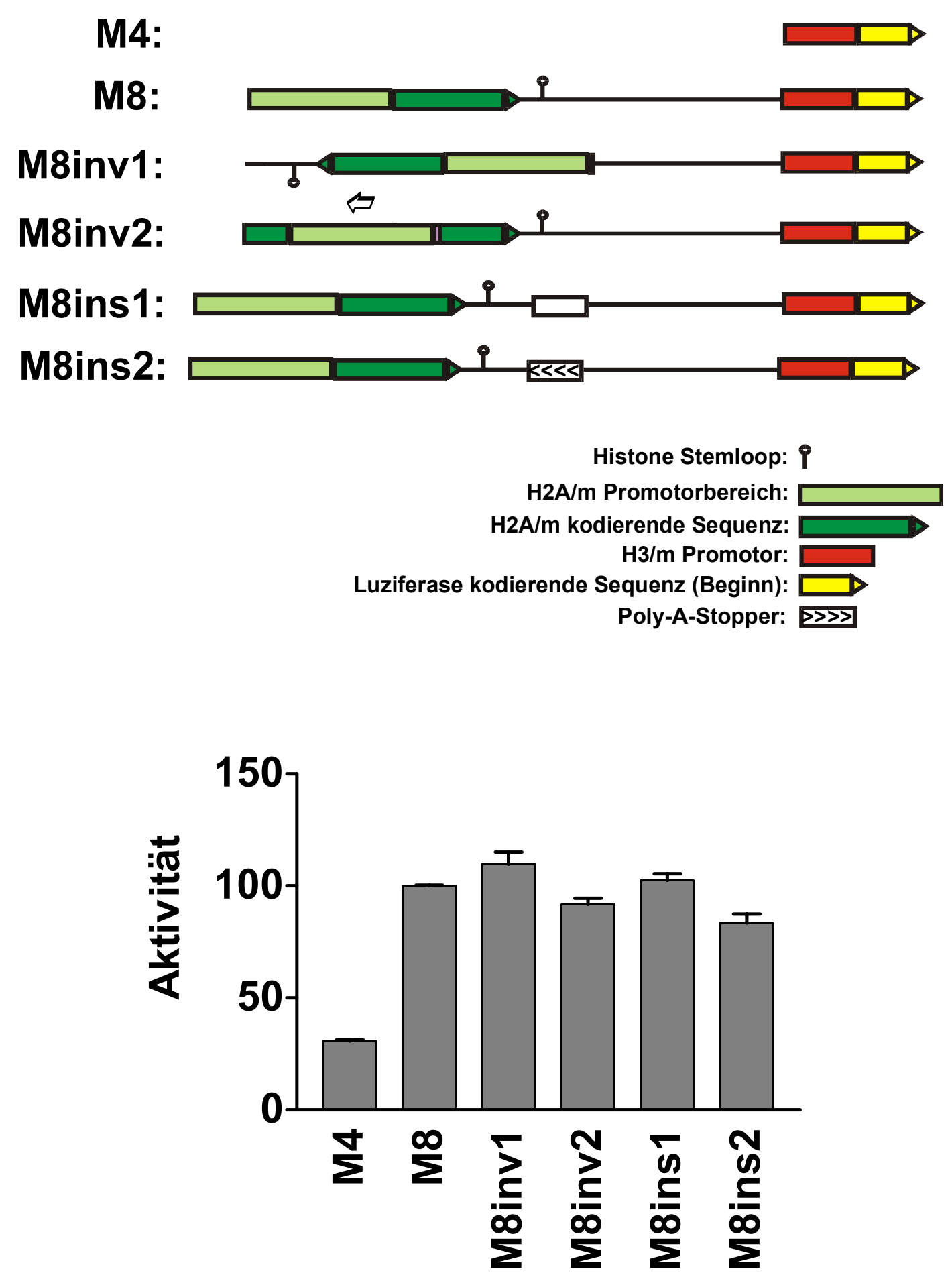

Abbildung 24: Aktivitätsbestimmung von Reportergenkonstrukten zum distalen $\mathrm{H} 2 \mathrm{~A} / \mathrm{m}$-Effekt (I)

Oben: Schematische Darstellung der untersuchten Reportergenkonstrukte (siehe Bild-Legende). Unten: Aktivitäten der Konstrukte in Reportergenassays in der Zelllinie HEK-293; Statistik aus vier unabhängigen Experimenten mit Standardabweichung (SEM). Die Aktivität des M8-Konstruktes wurde auf den Indexwert $100 \%$ gesetzt. 

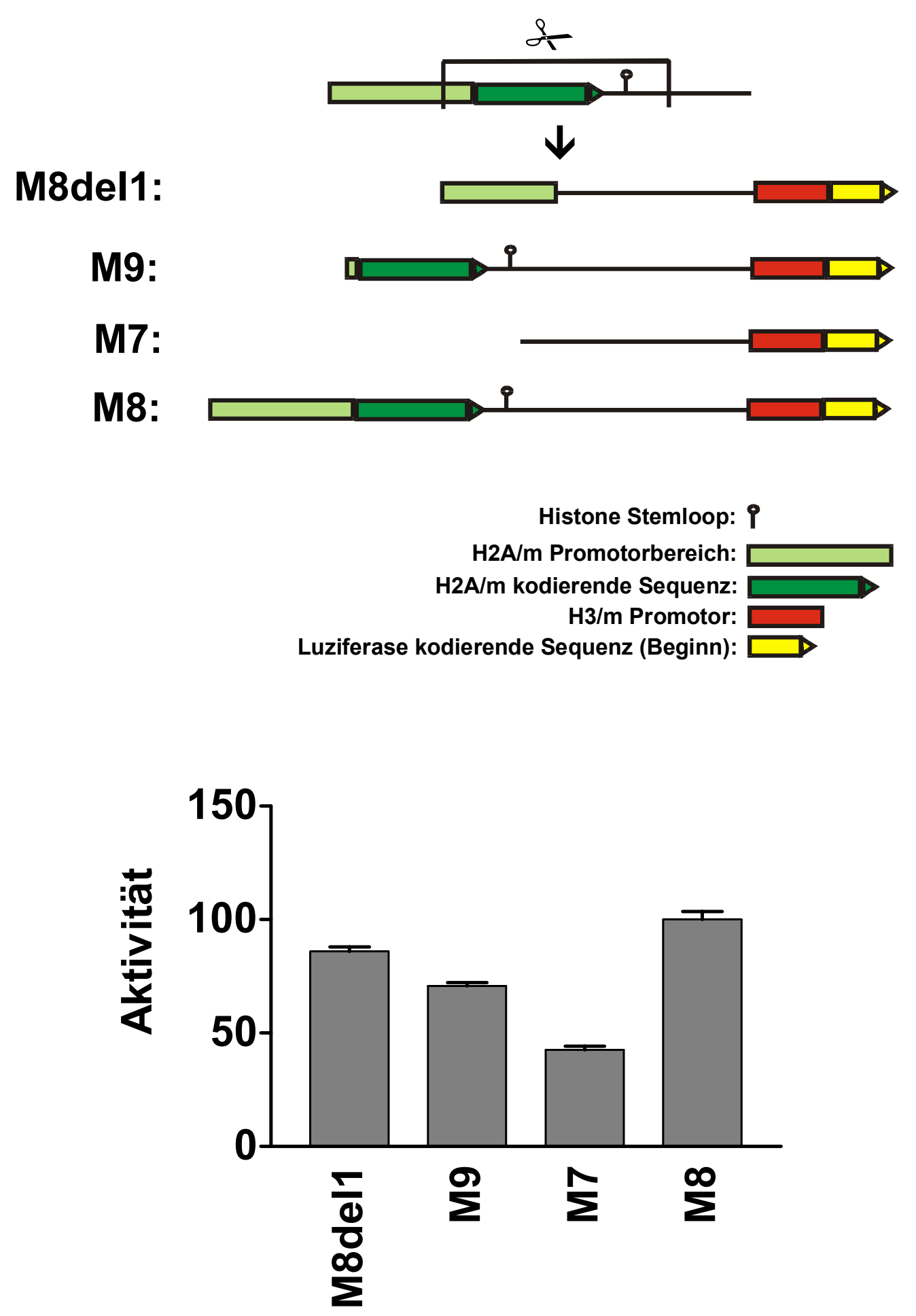

Abbildung 25: Aktivitätsbestimmung von Reportergenkonstrukten zum distalen $\mathrm{H} 2 \mathrm{~A} / \mathrm{m}$-Effekt (II)

Oben: Schematische Darstellung der untersuchten Reportergenkonstrukte (siehe Bild-Legende). Unten: Aktivitäten der Konstrukte in Reportergenassays in der Zelllinie HEK-293; Statistik aus neun unabhängigen Experimenten mit Standardabweichung (SEM). Die Aktivität des M8-Konstruktes wurde auf den Indexwert 100\% gesetzt. 
pGL3promoter:
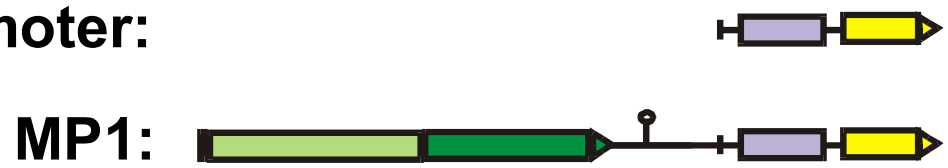

MP2:

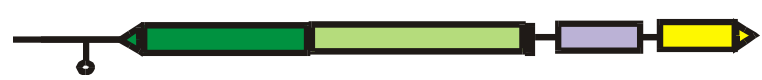

Histone Stemloop: 9

H2A/m Promotorbereich:

H2A/m kodierende Sequenz:

SV40 "Early"-Promotor:

Luziferase kodierende Sequenz (Beginn):

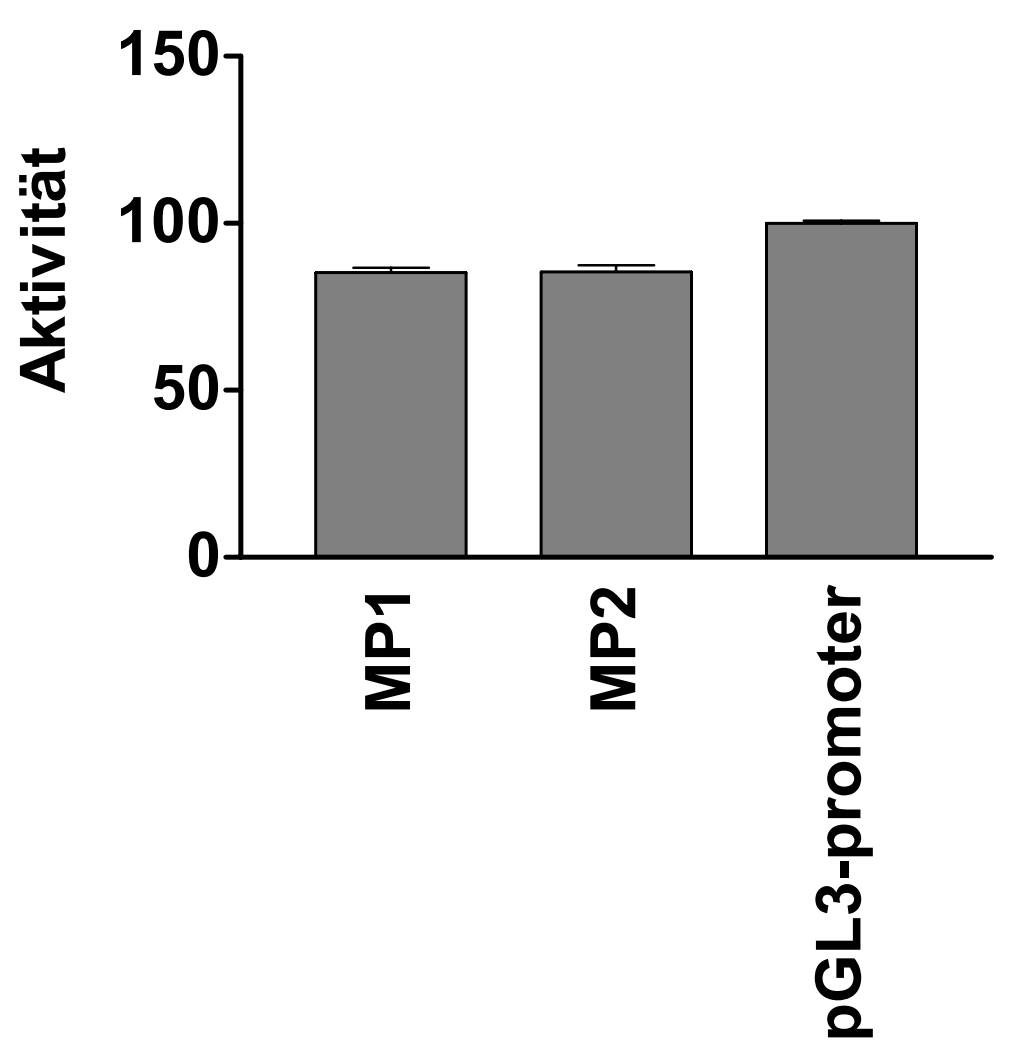

Abbildung 26: Aktivitätsbestimmung von Reportergenkonstrukten zum distalen $\mathrm{H} 2 \mathrm{~A} / \mathrm{m}$-Effekt (III)

Oben: Schematische Darstellung der untersuchten Reportergenkonstrukte (siehe Bild-Legende). Unten: Aktivitäten der Konstrukte in Reportergenassays in der Zelllinie HEK-293; Statistik aus vier unabhängigen Experimenten mit Standardabweichung (SEM). Die Aktivität des pGL3-promoterKonstruktes wurde auf den Indexwert 100\% gesetzt. 
Ein Einbau von $\mathrm{H} 2 \mathrm{~A} / \mathrm{m}$ in den Vektor führte in keiner der beiden Orientierungen zu einem Anstieg der Reportergenaktivität (Abbildung 26 $5_{4}$ ). Das H2A/m-Gen fungierte in diesem Versuchssystem also nicht als genereller Enhancer bzw. Aktivator.

In der nächsten Versuchsreihe wurde untersucht, ob das $\mathrm{H} 2 \mathrm{~A} / \mathrm{m}$-Gen aktivierend auf andere H3-Promotoren wirkt. Dazu wurde das H2A/m-Gen upstream des H3/kPromotors an das Ende des Konstruktes K8 kloniert. Das H2A/m-Gen verdreifachte die Aktivität des $\mathrm{H} 3 / \mathrm{k}$-Promotors (Abbildung $27 \% 6$, nächste Seite). Damit wirkt das $\mathrm{H} 2 \mathrm{~A} / \mathrm{m}$-Gen nicht nur beim $\mathrm{H} 3 / \mathrm{m}$-Gen aktivierend. Vor dem $\mathrm{H} 3 / \mathrm{k}-\mathrm{Gen}$ befindet sich natürlicherweise das $\mathrm{H} 2 \mathrm{~B} / \mathrm{c}-\mathrm{H} 2 \mathrm{~A} / \mathrm{c}$ Genpaar. Wurde der bipartite $\mathrm{H} 2 \mathrm{~A} / \mathrm{c}-\mathrm{H} 2 \mathrm{~B} / \mathrm{c}-$ Promotor zusätzlich zur H2A/c kodierenden Sequenz im Reportergenkonstrukt K13 eingebunden, führte dies zu einem Anstieg der H3/k-Promotoraktivität (Abbildung 2766, nächste Seite). Somit kann auch das H2A/c-Gen aktivierend auf den H3/kPromotor wirken, wenn auch nicht in der gleichen Höhe wie das $\mathrm{H} 2 \mathrm{~A} / \mathrm{m}-\mathrm{Gen}$.

Zusammenfassend zeigen die Experimente zum distalen Aktivierungseffekt des $\mathrm{H} 2 \mathrm{~A} / \mathrm{m}$-Gens auf den $\mathrm{H} 3 / \mathrm{m}$-Promotors (dreifache Steigerung der Reportergenaktivität), dass dieser nicht durch eine hypothetische polycistronische mRNA in der transienten Transfektion verursacht wurde. Der Aktivierungseffekt des $\mathrm{H} 2 \mathrm{~A} / \mathrm{m}$-Gens war Richtungs-unabhängig. Sowohl die H2A/m-kodierende Sequenz als auch der $\mathrm{H} 2 \mathrm{~A} / \mathrm{m}$-Promotor konnten den Aktivierungseffekt alleine bewirken. Der Mechanismus des distalen Aktivierungseffekts konnte nicht geklärt werden. Wohl aber konnte gezeigt werden, dass das $\mathrm{H} 2 \mathrm{~A} / \mathrm{m}-\mathrm{Gen}$ auch auf andere Promotoren aktivierend wirkt.

\subsection{CRAS-Effekt}

Hurt et al. (1991) haben innerhalb einer Histon-H3 kodierenden Sequenz (bei den H3.2-Genen in den Genomen der Maus und des Hamsters) ein Sequenz-Element beschrieben, das für die Transkription der Gene aktivierend wirken sollte, und das als CRAS-Element (CRAS: Coding region activating sequence) bezeichnet wurde. Dieser CRAS-Effekt kann in dieser Allgemeinheit nicht bestätigt werden, wenn man das folgende experimentelle System verwendet. Es wurden Reportergenkonstrukte hergestellt, bei denen der $\mathrm{H} 3 / \mathrm{m}$-Promotor mitsamt einem Großteil der H3/mkodierenden Sequenz vor das Reportergen kloniert wurde. So sollte ein Fusionsprotein bestehend aus $\mathrm{H} 3 / \mathrm{m}$ und Luziferase exprimiert werden. 

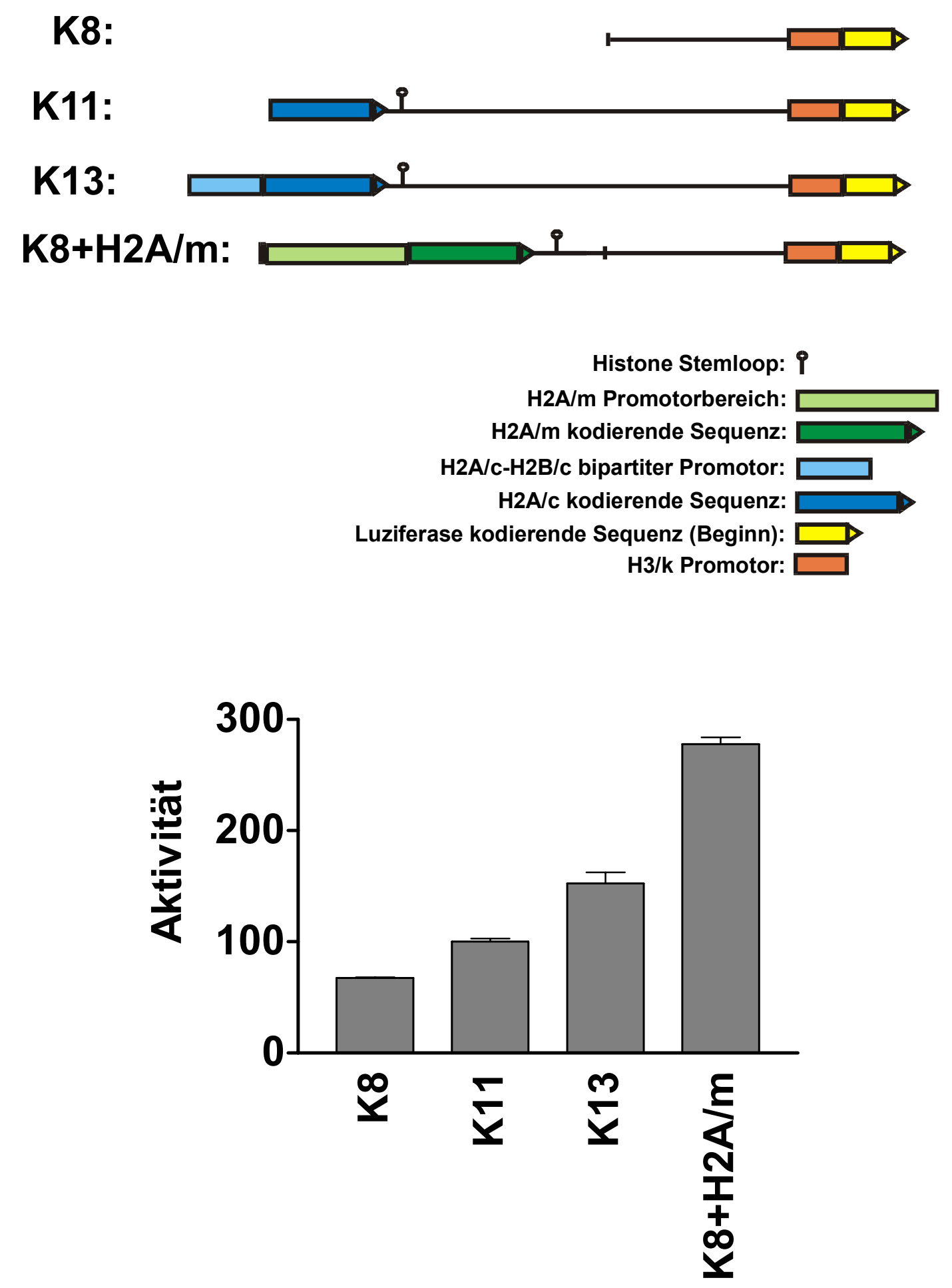

Abbildung 27: Aktivitätsbestimmung von Reportergenkonstrukten zum distalen $\mathrm{H} 2 \mathrm{~A} / \mathrm{m}$-Effekt (IV)

Oben: Schematische Darstellung der untersuchten Reportergenkonstrukte (siehe Bild-Legende). Unten: Aktivitäten der Konstrukte in Reportergenassays in der Zelllinie HEK-293; Statistik aus vier unabhängigen Experimenten mit Standardabweichung (SEM). Die Aktivität des K11-Konstruktes wurde auf den Indexwert 100\% gesetzt. 
Dies war bei den Konstrukten MCRAS1 und MCRAS2 der Fall (Abbildung 28 ${ }_{7}$ ). Bei den Konstrukten MCRAS1mut1 und MCRAS2mut1 wurde das beschriebene Element mutiert. Die Mutationen führten gegenüber den nicht mutierten Konstrukten zu keiner verringerten Reportergenaktivität in der Zelllinie HEK-293 (Abbildung 28 77 ). Die CRAS-Sequenzen in den Reportergenkonstrukten wirkten also nicht aktivierend auf die Transkription des Reportergens, d.h. ein CRAS-Effekt wurde nicht beobachtet.
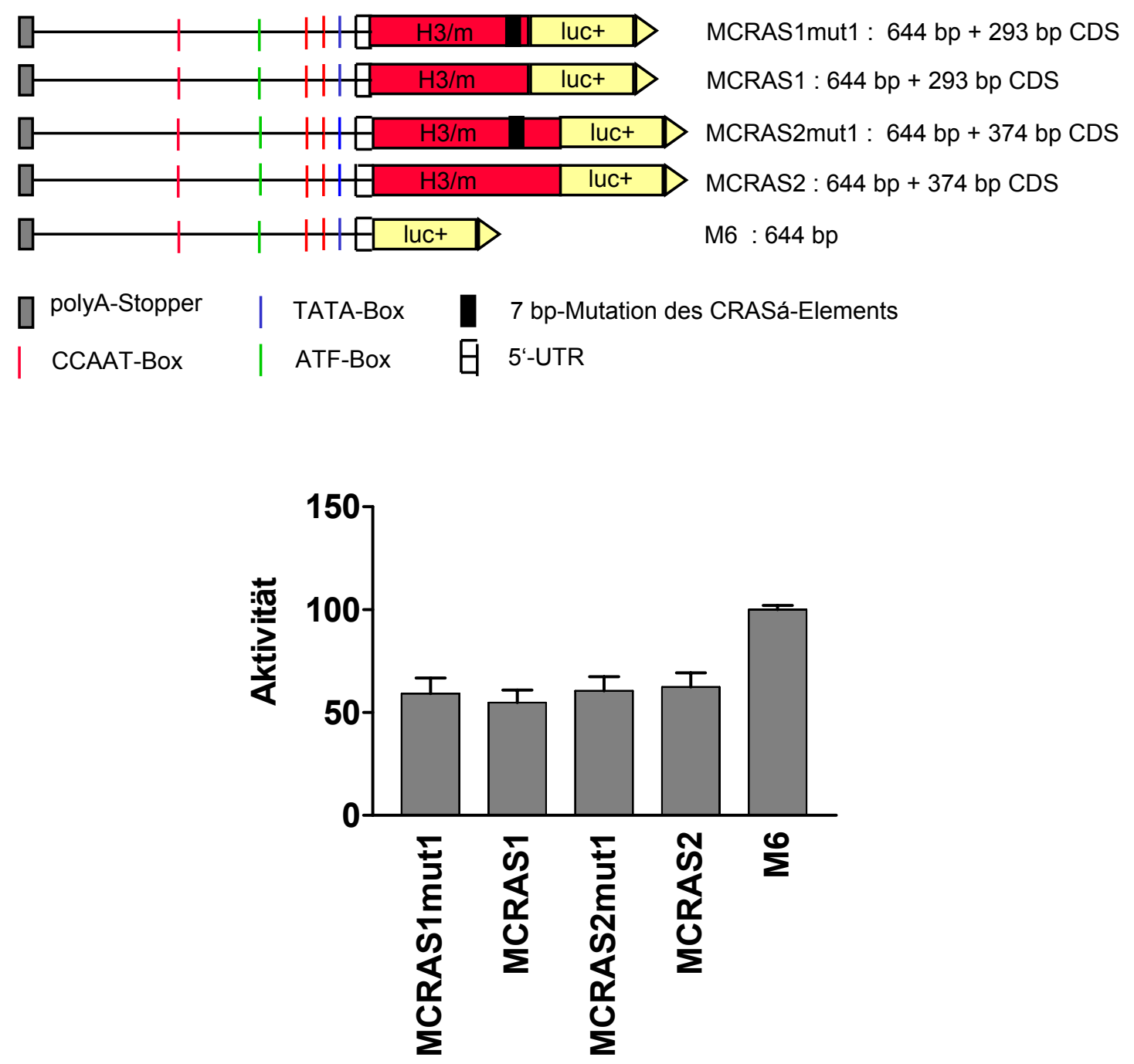

Abbildung 28: Aktivitätsbestimmung von Reportergenkonstrukten zum CRAS-Effekt

Oben: Schematische Darstellung der untersuchten Reportergenkonstrukte (siehe auch Bild-Legende). Alle MCRAS-Konstrukte enthalten 644 bp des Promotors und die ersten 293 bp der kodierenden Sequenz des $\mathrm{H} 3 / \mathrm{m}$-Gens (in MCRAS1) bzw. die ersten $374 \mathrm{bp}$ der kodierende Sequenz (in MCRAS2). In den Konstrukten MCRAS1mut1 und MCRAS2mut1 sind 7 bp in der H3/m-kodierenden Sequenz mutiert (CRAS $\alpha$-Element). Große rote Boxen: H3/m kodierende Sequenz; luc+: FireflyLuziferase-kodierende Sequenz. Unten: Aktivitäten der Konstrukte in Reportergenassays in der Zelllinie HEK-293; Statistik aus fünf unabhängigen Experimenten mit Standardabweichung (SEM). Die Aktivität des M6-Konstruktes wurde auf den Indexwert 100\% gesetzt. 


\subsection{Absuchende Mutagenese}

Nachdem in den Deletionsreihen einzelne Abschnitte der H3-Promotoren als relevant für die Promotorstärke identifiziert worden waren, wurden im Folgenden diese Abschnitte auf relevante cis-Elemente untersucht. Dies geschah mit Hilfe der absuchenden Mutagenese in den Promotoren des $\mathrm{H} 3 / \mathrm{k}$ - und des $\mathrm{H} 3 / \mathrm{m}-\mathrm{Gens}$. Die Mutagenese erfasste alle Bereiche der mit Hilfe der H3-Promotor-Deletionsreihen ermittelten Rumpf-Promotoren: beim H3/k-Promotor 133 bp und beim H3/mPromotor 129 bp. Beim H3/m-Promotor wurden zusätzlich zwei Mutationskonstrukte hergestellt, die die weiter oberhalb gelegene ATF-Box und ihre Umgebung mutierten. Zur Untersuchung wurden jeweils Bereiche von 5 bis 19 bp mutiert, indem jedes $A$ in ein $C$ und jedes $G$ in ein $T$ überführt wurde und umgekehrt. Die Abstände zwischen den mutierten Bereichen betrugen 4 bp. In der Annahme, dass ein relevantes cisElement länger als 4 Basen lang sein muss, bestand somit keine Gefahr, dass ein relevantes cis-Element übersehen wurde.

Die mutierten Konstrukte wurden mit dem Promega in vitro site-directed Mutagenese-System hergestellt, in E. coli DH5 alpha transformiert und in Endotoxinfreier Qualität präpariert. Die Transfektion der Zellen und die Messung der Reportergenaktivität erfolgte wie bei den Deletionsreihen. Bei den Mutationsreihen wurden pro Konstrukt mindestens vier unabhängige Transfektionen durchgeführt.

Unter den gewählten Bedingungen der transienten Transfektion waren im wesentlichen drei cis-Elemente für die Funktion des $\mathrm{H} 3 / \mathrm{k}$-Promotors verantwortlich (Abbildung 29,9): die TATA-Box und die beiden CCAAT-Boxen. Die Mutation der TATA-Box im Konstrukt K5mut8 hatte einen nahezu vollständigen Aktivitätsverlust zur Folge. Gleiches gilt für die Mutation der proximalen CCAAT-Box im Konstrukt K5mut7. Die Mutation der distalen CCAAT-Box im Konktrukt K5mut4 führte zu einem Aktivitätsverlust des H3/k-Promotors von $86 \%$ (14\% Restaktivität). Darüber hinaus führte eine Mutation des Bereiches downstream der distalen CCAAT Box in Konstrukt K5mut5 zu einem Aktivitätsverlust von $50 \%$. Dieser Bereich spielte also ebenfalls für eine volle Funktionsfähigkeit des Promotors eine Rolle.

Beim H3/m-Promotor zeigten Mutationen der TATA-Box (M4mut8), sowie der proximalen (M4mut6) und distalen (M4mut3) CCAAT-Box die deutlichsten Aktivitätsverluste von $80-90 \%$. Bei keiner Mutation wurde eine vollständige Inaktivierung beobachtet (Abbildung 30\%0). 

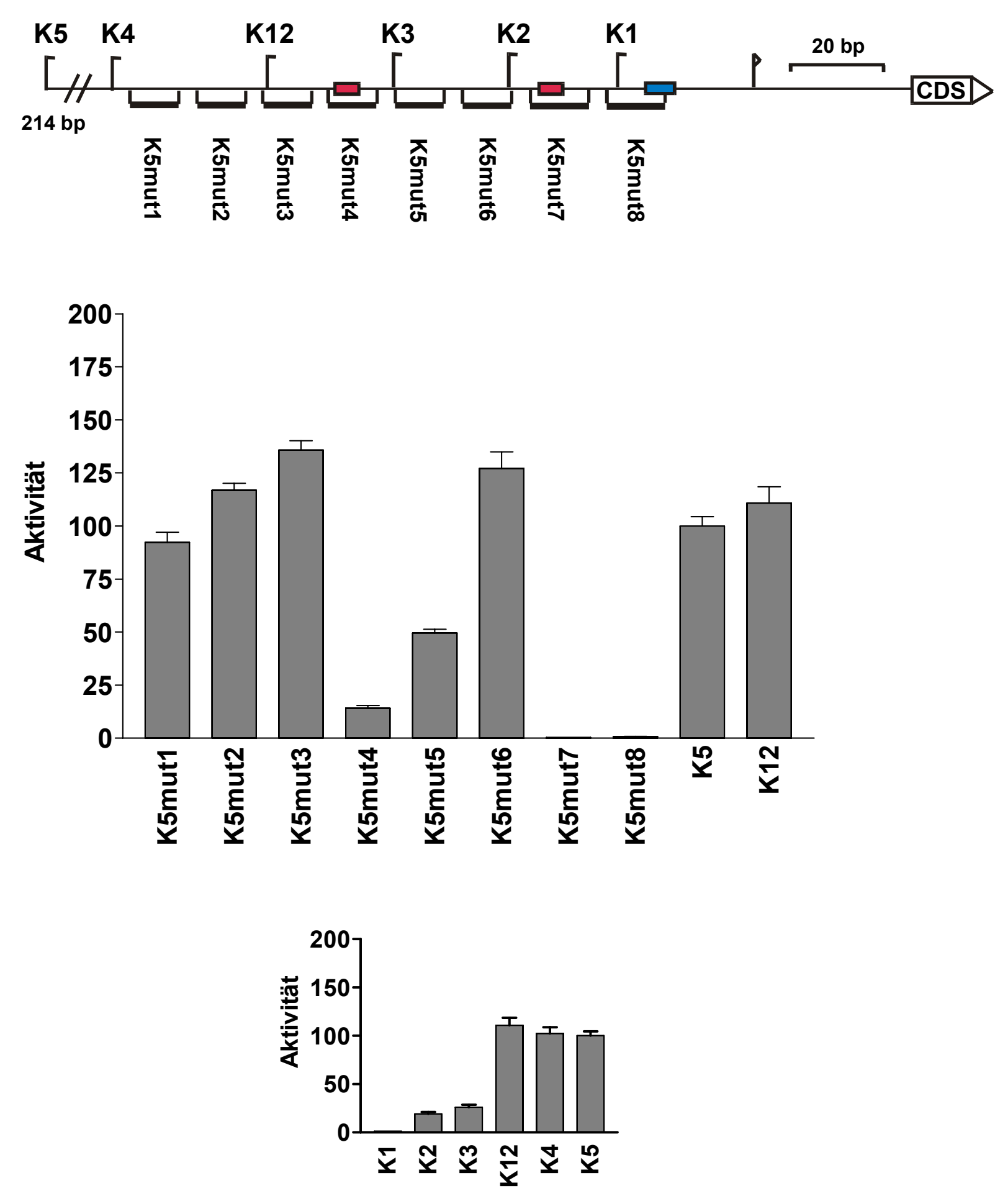

Abbildung 29: Absuchende Mutagenese im H3/k-Promotor

Oben: Schematische Darstellung der Mutationskonstrukte im H3/k-Promotor. Rote Boxen: CCAATBoxen; Blaue Box: TATA-Box. Die gekennzeichneten Bereiche wurden in den Konstrukten komplett mutiert (siehe Text). Die oberen Häkchen zeigen zur Orientierung die Lage der Deletionskonstrukte (Länge des K5-Promotors: 214 bp bis Transkriptionsstart). Mitte: Reportergenaktivität der Mutationskonstrukte in der HEK-293-Zelllinie; Statistik aus vier unabhängigen Experimenten mit Standardabweichung SEM. Die Aktivität des K5-Konstruktes wurde auf den Indexwert $100 \%$ gesetzt. Unten: Zur Orientierung die Reportergenaktivitäten der Deletionskonstrukte (aus fünf Experimenten mit SEM; Aktivität von K5 = Indexwert 100\%). 

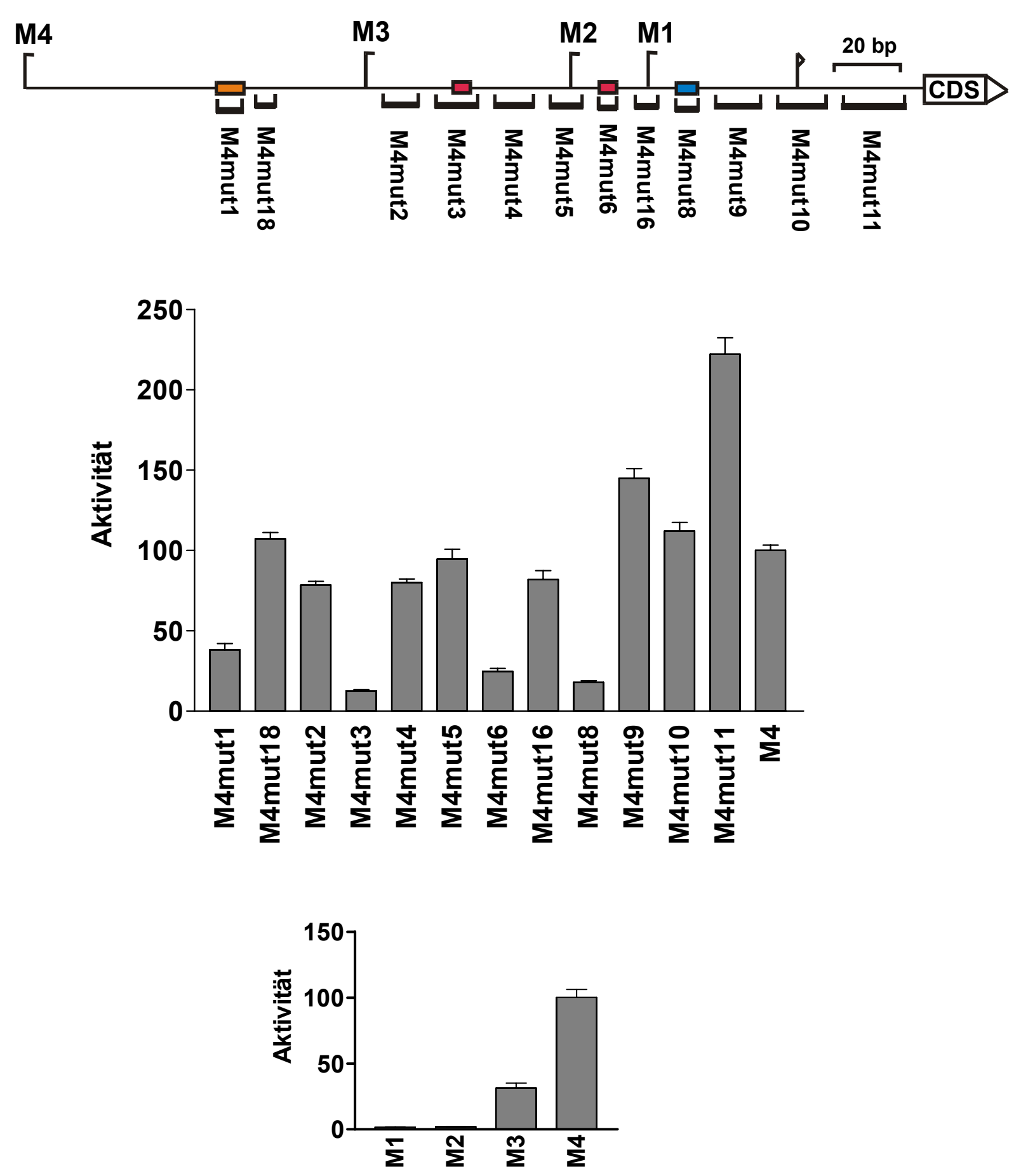

Abbildung 30: Absuchende Mutagenese im H3/m-Promotor

Oben: Schematische Darstellung der Mutationskonstrukte im H3/m-Promotor. Rote Boxen: CCAATBoxen; Blaue Box: TATA-Box; Orange Box: ATF-Box. Die gekennzeichneten Bereiche wurden in den Konstrukten komplett mutiert (siehe Text). Die oberen Häkchen zeigen zur Orientierung die Lage der Deletionskonstrukte. Mitte: Reportergenaktivität der Mutationskonstrukte in der HEK-293-Zelllinie; Statistik aus vier unabhängigen Experimenten mit Standardabweichung SEM. Die Aktivität des M4-Konstruktes wurde auf den Indexwert 100\% gesetzt. Unten: Zur Orientierung die Reportergenaktivitäten der Deletionskonstrukte (aus fünf Experimenten mit SEM; Aktivität von M4 = Indexwert 100\%). 
Auch die Mutagenese der ATF-Box (M4mut1) führte zu einem 60\%igem Aktivitätsverlust. Dagegen führten die Mutagenesen aller übrigen Bereiche, insbesondere des Transkriptionsstartes, zu keiner Aktivitätssenkung. Im Falle der Mutagenese der 5'-UTR im Konstrukt M4mut11 trat sogar überraschenderweise eine deutliche Aktivitätssteigerung um den Faktor 2 auf $200 \%$ auf, die nicht erklärt werden konnte.

Absuchende Mutagenesen im $\mathrm{H} 3 / \mathrm{k}$ - und $\mathrm{H} 3 / \mathrm{m}$-Promotor zeigten, dass zwei CCAATBoxen und die TATA-Box die entscheidenden cis-Elemente in den H3-Promotoren sind. Im H3/m-Promotor wurde die ATF-Box als weiteres cis-Element identifziert.

\subsection{Mutagenese der CCAAT-Boxen des H3/k-Promotors}

Die beiden CCAAT-Boxen im H3/k-Promotor wurden in der absuchenden Mutagenese als neben der TATA-Box wichtigste cis-Elemente identifiziert. Mit einer detaillierteren Mutagenese sollte geklärt werden, welche Basen in und um die CCAAT-Boxen für deren Funktion im Promotor nötig sind. Dadurch sollte man Hinweise auf den dort bindenden Transkriptionsfaktor erhalten. Als Transkriptionsfaktoren kamen der trimere Komplex NF-Y (auch CBF genannt), der Faktor CDP/Cut (alleine oder im HiNF-D-Komplex) sowie weitere CCAAT-Boxbindende Proteine in Frage (siehe 5.3.2 100).

Für die detaillierte Mutagenese wurden zunächst drei spezielle Reportergenplasmide konstruiert, in denen die proximale CCAAT-Box des H3/k-Promotors mutiert wurde: K5mut10 war eine Mutation, in der sämtliche 5 Basen des "CCAAT" mutiert wurden. Hier sollte die etwas breitere Mutation des Konstrukts K5mut7 genauer spezifiziert werden. Moon et al. (2000) beschrieben, dass das Protein CDP/Cut auch an CCAATBoxen binden kann, die nicht ganz den fünf Basen des "CCAAT" ensprechen, z.B "ACGAT". Daher sollte mit Konstrukt K5mut11 geklärt werden, ob eine Änderung des proximalen CCAAT-Motivs zu "ACGAT" zu einem Aktivitätsverlust führen würde. K5mut12 schließlich enthielt das unveränderte "CCAAT" mit drei mutierten Basen upstream und zwei mutierten Basen downstream, die eine Bindung von NF-Y (Bi et al. 1997) möglichst erschweren sollten. Alle durchgeführten Mutationen hatten einen nahezu vollständigen Aktivitätsverlust zur Folge (Abbildung $31_{2}$ ). Dies zeigt dreierlei:

1. Für den Aktivitätsverlust des Konstrukts K5mut7 war tatsächlich die CCAAT-Box verantwortlich (K5mut10). 


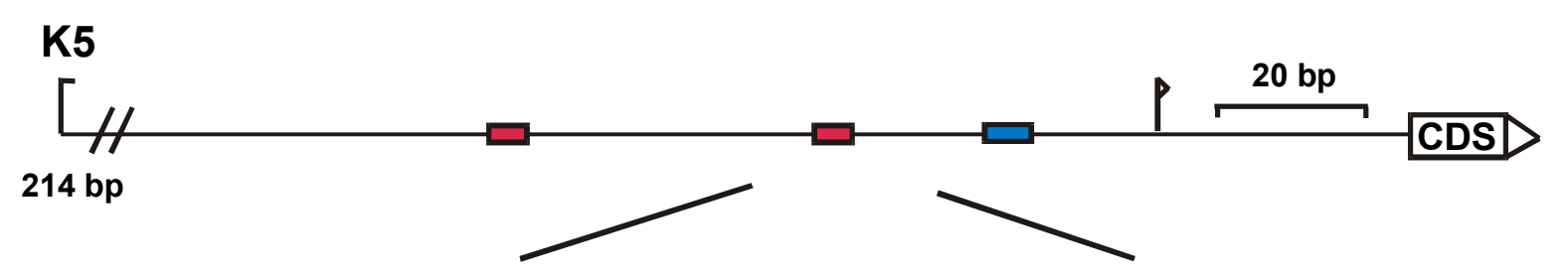

K5 (wt): ATACTTTTGTCCAATCAGCTTCAGACT

K5mut7: ATACTtTTtGAACCGACTAGTCAgAct

K5mut10: ATACTTTTGIAACCGCAGCTTCAGACT

K5mut11: AtACTTtTGiAcGATCAgCtTCAgAct

K5mut12: AтAстTTGCCCCAATTTGCTTCAGACT

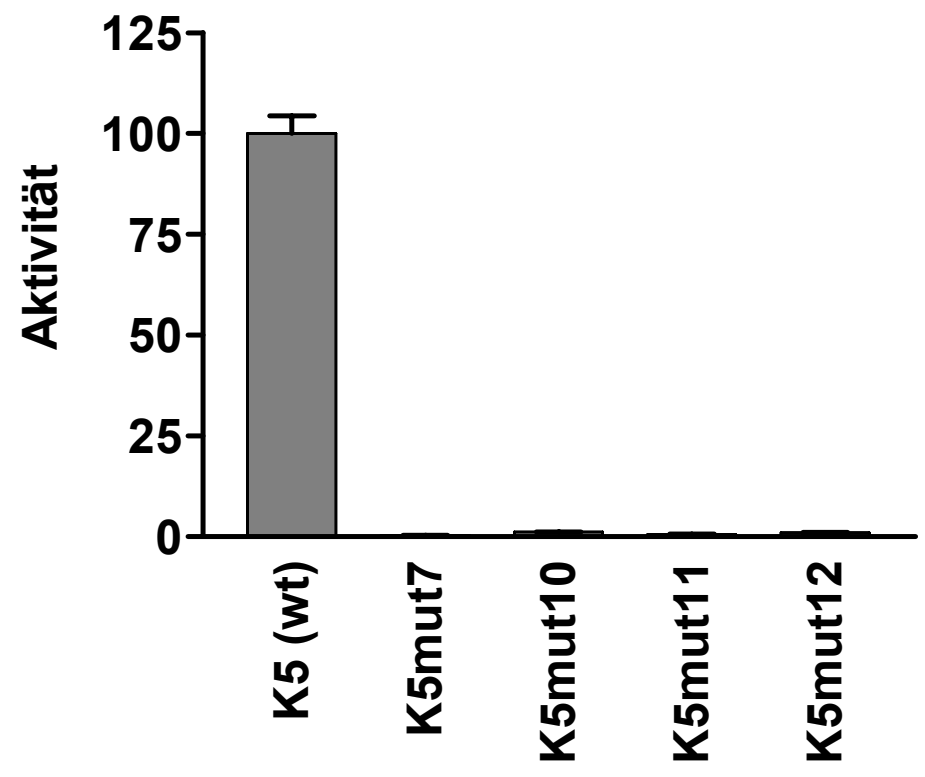

Abbildung 31: Spezifische Mutagenese der proximalen CCAAT-Box des H3/k-Promotors

Oben: Schematische Darstellung des H3/k-Promotors; rote Boxen: CCAAT-Boxen; blaue Box: TATABox; Häkchen: Transkriptionsstart; CDS: kodierende Sequenz; Länge des K5-Konstruktes bis Transkriptionsstart: 214 bp. Mitte: Sequenzen der verschiedenen Mutationskonstrukte; rote Markierung: zentrales CCAAT-Motiv; schwarze Markierung: mutierte Bereiche. Unten: Reportergenaktivität der oben gezeigten Konstrukte in der Zelllinie HEK-293; die Aktivität des K5Konstruktes wurde auf den Indexwert 100\% gesetzt. Die Ergebnisse sind eine Statistik aus vier unabhängigen Experimenten mit Standardabweichung SEM. 

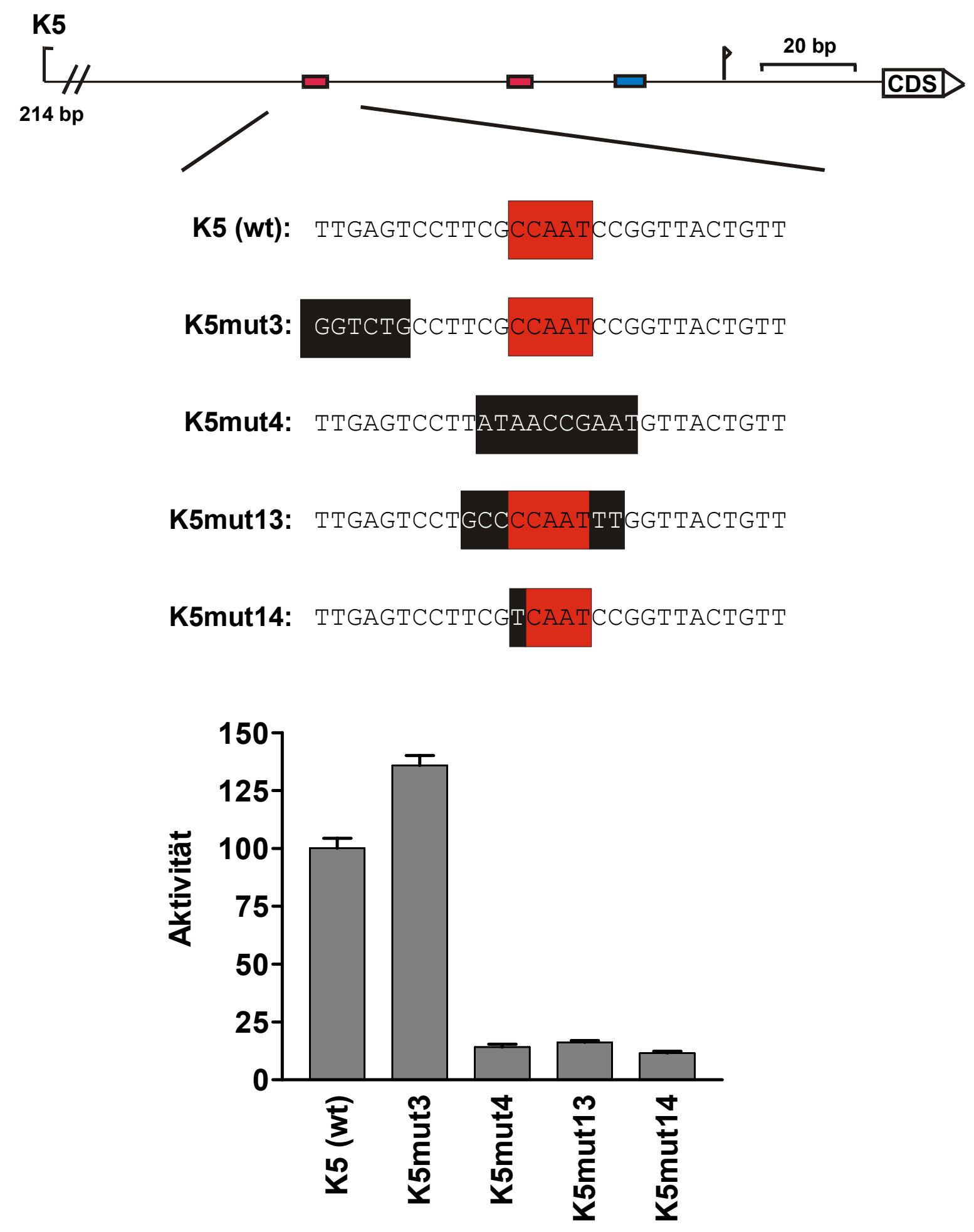

Abbildung 32: Spezifische Mutagenese der distalen CCAAT-Box des H3/k-Promotors

Oben: Schematische Darstellung des H3/k-Promotors; rote Boxen: CCAAT-Boxen; blaue Box: TATABox; Häkchen: Transkriptionsstart; CDS: kodierende Sequenz; Länge des K5-Konstruktes bis Transkriptionsstart: 214 bp. Mitte: Sequenzen der verschiedenen Mutationskonstrukte; rote Markierung: zentrales CCAAT-Motiv; schwarze Markierung: mutierte Bereiche. Unten: Reportergenaktivität der oben gezeigten Konstrukte in der Zelllinie HEK-293; die Aktivität des K5Konstruktes wurde auf den Indexwert 100\% gesetzt. Die Ergebnisse sind eine Statistik aus vier unabhängigen Experimenten mit Standardabweichung SEM. 
2. Eine "ACGAT" Sequenz kann die proximale "CCAAT"-Sequenz nicht ersetzen (K5mut11).

3. Eine NF-Y-bindungshemmende Basenfolge upstream und downstream von der proximalen "CCAAT"-Sequenz führt zum fast vollständigem Aktivitätsverlust des Promotors (K5mut12).

In analoger Weise wurde bei der distalen CCAAT-Box des H3/k-Promotors mit zwei neuen Mutationskonstrukten der aktivierende Effekt der CCAAT-Box näher untersucht. In Konstrukt K5mut13 wurden 3 Basen upstream und 2 Basen downstream der "CCAAT"-Sequenz in einer für NF-Y ungünstigen Weise mutiert, und in Konstrukt K5mut14 wurde eine Punktmutation der Sequenz "CCAAT" zu "TCAAT" durchgeführt. Diese Punktmutation sollte nach Mantovani (1998) zu einem Verlust der Bindung von NF-Y, aber nach Moon et al. (2000) nicht unbedingt zu einem Verlust der Bindung von CDP/Cut führen. Die Ergebnisse zeigen, dass beide Mutationen zu dem gleichen Aktivitätsverlust des Promotors führten wie die komplette Mutation der ganzen "CCAAT"-Sequenz (Abbildung 32. 3 ).

In den beiden CCAAT-Boxen des $\mathrm{H} 3 / \mathrm{k}$-Promotors waren also die fünf Basen des CCAAT-Motivs vollständig für die Funktion des Promotors nötig. Mutationen der umliegenden Basen zu Nicht-Konsensus-NF-Y-Sequenzen führten in beiden CCAAT-Boxen zu vollständigen Aktivitätsverlusten.

\subsection{Mutagenese der putativen HiNF-D-Bindungsstellen des $\mathrm{H} 3 / \mathrm{m}$ - Promotors}

Aufgrund von Sequenzvergleichen identifizierten van den Ent et al. (1994) im H3/mPromotor zwei mögliche HiNF-D-Bindungsstellen, die sogenannten AG-Motive. HiNF-D ist ein Komplex aus Cdc2 (Cdk1), Cyclin A, pRb (p105) und CDP/Cut und ist in die Regulation des H4/n-Promotors involviert (van Wijnen et al. 1994). Ein Motiv befindet sich in der Nähe der ATF-Box (downstream von ihr) und ein zweites Motiv befindet sich dicht bei der distalen CCAAT-Box (upstream von ihr). Um einen Einfluss dieser Stellen auf die Aktivität des $\mathrm{H} 3 / \mathrm{m}$-Promotors zu prüfen, sollten beide möglichen Bindungstellen mutiert werden.

Im Konstrukt M4mut18 wurde die downstream der ATF-Box gelegene Stelle mutiert und in Konstrukt M4mut19 wurde die upstream der distalen CCAAT-Box gelegene 
Stelle mutiert. In den Experimenten konnte ein Aktivitätsverlust nur bei der Mutation von einer der möglichen zwei HiNF-D-Bindungstellen (M4mut19) festgestellt werden (Abbildung 336).

Da die ursprüngliche Mutation der distalen CCAAT-Box in M4mut3 zusätzlich den Bereich upstream der "CCAAT"-Sequenz mitmutierte, wurde eine zweite Mutante M4mut20 erstellt, in welcher lediglich die "CCAAT"-Sequenz mutiert ist. Sowohl die Mutation der "CCAAT"-Sequenz selbst als auch eine Mutation upstream der "CCAAT"-Sequenz in der einen zu prüfenden HiNF-D-Bindungstelle führte zu einem vergleichbaren Aktivitätsverlust (Abbildung 336). Dagegen führt die Mutation der anderen möglichen HiNF-D-Bindungstelle in Konstrukt M4mut18 zu keinem Aktivitätsverlust des Promotors.

Von den zwei beschriebenen putativen HiNF-D-Bindungsstellen war also nur eine für die $\mathrm{H} 3 / \mathrm{m}$-Promotoraktivität wichtig. Die aktivierende Wirkung dieser putativen HiNF-D-Bindungsstelle erforderte eine intakte benachbarte CCAAT-Box.

\subsection{Abstandsveränderungen im H3/k-Promotor}

Die Abstände zwischen proximaler CCAAT-Box und TATA-Box, sowie zwischen proximaler und distaler CCAAT-Box sind in den H3-Promotoren annähernd gleich (siehe Abbildung $6_{35}$ ). Es sollte daher untersucht werden, welche Bedeutung diese Abstände für die Promotoraktivität besitzen.

Der Abstand zwischen proximaler CCAAT-Box und TATA-Box beträgt in fast allen Promotoren $22 \mathrm{bp}$ (gemessen von den Startpunkten der Motive) (siehe Abbildung $6_{35}$ ). Lediglich im $\mathrm{H} 3 / \mathrm{c}-$ und $\mathrm{H} 3 / \mathrm{h}$-Promotor ist der Abstand zwischen den beiden Boxen um zwei Basen verkürzt. In den folgenden Analysen sollte geklärt werden, inwieweit dieser Abstand eine funktionale Bedeutung besitzt. Exemplarisch am H3/kPromotor wurde der Abstand der Boxen um 10 bzw. 11 Basen verlängert (Konstrukte K5mut20 und K5mut21), was einer Verlängerung um eine DNA-Helixwindung entspricht. Nach der Prüfung der verlängerten DNA mit dem Programm MatInspektor \{Genomatix Software GmbH; Quandt et al 1995\} auf mögliche neue cis-Elemente wurde die Aktivität der Konstrukte bestimmt. Man beobachtete einen Aktivitätsverlust von ca. 75\% (Abbildung 34 8 , übernächste Abbildung). 

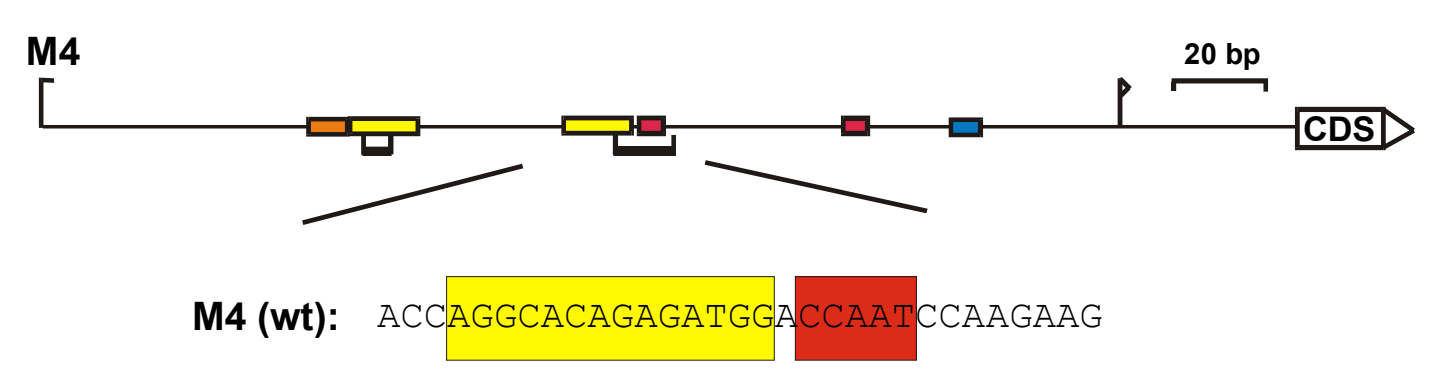

M4mut3: ACCAGGCACAGATCGTTCAACCGAAAAGAAG

M4mut19: ACCAGGCACCACCATGGACCAATCCAAGAAG

M4mut20: ACCAGGCACAGAGATGGACTCCICCAAGAAG

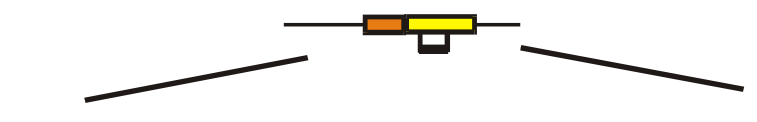

M4mut18: AAATGACGTCAGAGACTTGTCGGTAAT

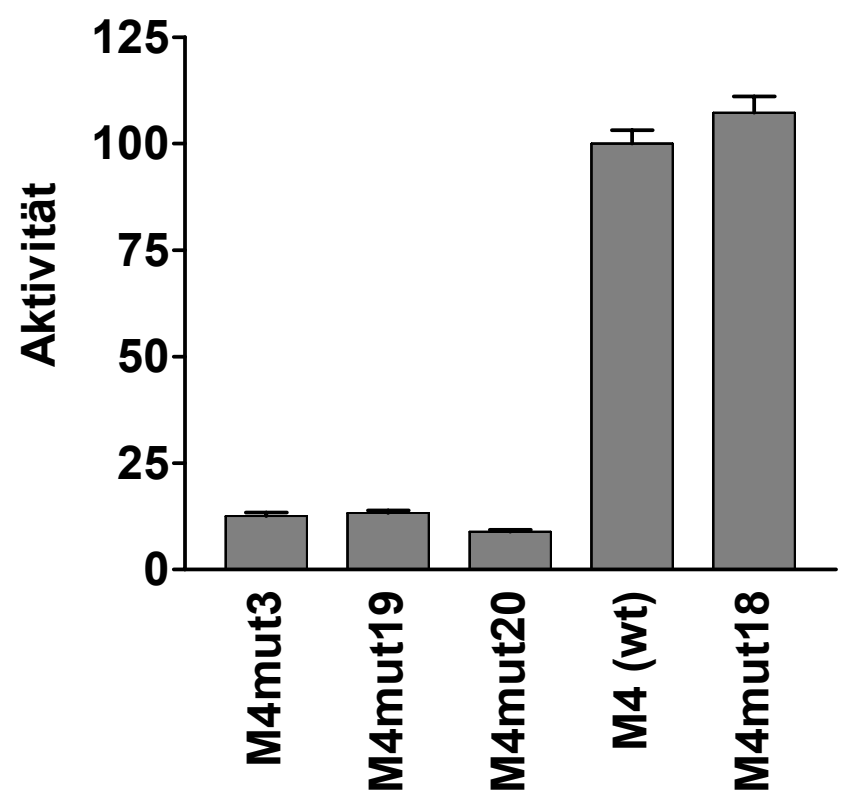

Abbildung 33: Spezifische Mutagenese der distalen CCAAT-Box des $\mathrm{H} 3 / \mathrm{m}$-Promotors

Oben: Schematische Darstellung des H3/m-Promotors; rote Boxen: CCAAT-Boxen; blaue Box: TATABox; orange Box: ATF-Box; gelbe Boxen: putative HiNF-D-Bindungsstellen. Häkchen: Transkriptionsstart; CDS: kodierende Sequenz; M4: Länge des M4-Konstruktes. Mitte: Sequenzen der verschiedenen Mutationskonstrukte; rote Markierung: zentrales CCAAT-Motiv; gelbe Markierung: putative HiNF-D-Bindungsstelle; orange Markierung: ATF-Motiv; schwarze Markierung: mutierte Bereiche. Unten: Reportergenaktivität der oben gezeigten Konstrukte in der Zellinie HEK-293; die Aktivität des K5-Konstruktes wurde auf den Indexwert 100\% gesetzt. Die Ergebnisse sind eine Statistik aus vier unabhängigen Experimenten mit Standardabweichung SEM. 
Der Sequenzvergleich der H3-Promotoren ergab, dass sieben der elf Promotoren eine distale CCAAT-Box mit einem Abstand von 41 bzw. 42 bp (bezogen auf Startpunkte der Motive) zur proximalen CCAAT-Box besitzen. Auch hier wurde, exemplarisch am H3/k-Promotor, die Beziehung zwischen Abstand der Boxen und Aktivität des Promotors erforscht. Hierzu wurden vier Konstrukte hergestellt: In K5mut16 wurde eine komplette Helixwindung (10 bp) deletiert und der Abstand zwischen distaler und proximaler CCAAT-Box auf 32 bp verkürzt. Im zweiten Konstrukt K5mut17 wurde eine halbe Helixwindung (5 bp) deletiert und der Abstand auf 37 bp verkürzt. Dadurch wurde die distale CCAAT-Box relativ zur proximalen CCAAT-Box auf die andere Seite der Helix gedreht. Im dritten Konstrukt K5mut18 insertierte man eine halbe Helixdrehung ( $5 \mathrm{bp}$ ), so dass der Abstand auf $47 \mathrm{bp}$ anwuchs und die distale CCAAT-Box auf die andere Seite der Helixachse gedreht wurde - relativ zur proximalen CCAAT-Box. Im vierten Konstrukt K5mut19 erfolgte die Insertion einer ganzen Helixwindung (10 bp) und der Abstand wuchs zwischen den beiden CCAAT-Boxen auf 52 bp an. Die Aktivitätsbestimmung der Konstrukte ergab folgendes (Abbildung 35 9 ):

1. Jede Veränderung des Abstandes führte zum Aktivitätsverlust.

2. Der Aktivitätsverlust war besonders hoch (65\%) wenn die beiden CCAAT-Boxen durch Deletion oder Insertion um eine halbe Helixwindung (5 bp) gegeneinander verdreht wurden (K5mut17 und K5mut18).

3. Eine Verlängerung des Abstandes um eine Helixwindung führte (K5mut19) zu einem schwachen Aktivitätsverlust von $22 \%$, während eine Verkürzung zu einem größeren Aktivitätsverlust von $50 \%$ führte.

Die Verlängerung des Abstands zwischen proximaler CCAAT-Box und TATA-Box im H3/k-Promotor führte also zu einem starken Aktivitätsverlust. Veränderungen des Abstands zwischen proximaler und distaler CCAAT-Box führten ebenfalls zu z.T. starken Aktivitätsverlusten, die besonders hoch waren, wenn die Positionen der Boxen auf der Helixachse zueinander verdreht wurden. 

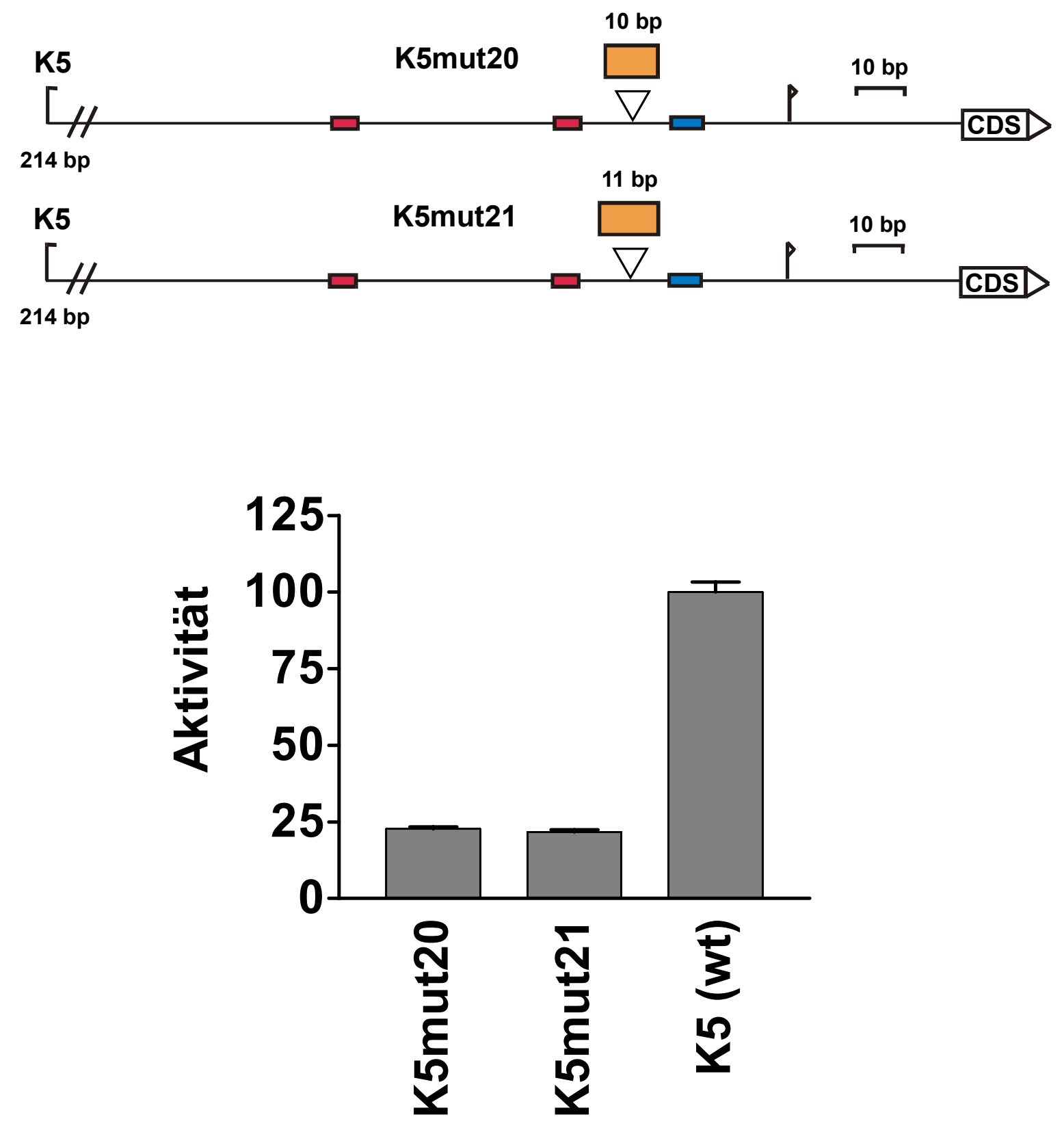

Abbildung 34: Vergrößerung des Abstandes zwischen CCAAT- und TATA-Box

Oben: Schematische Darstellung der Mutationskonstrukte des H3/k-Promotors; rote Boxen: CCAATBoxen; blaue Box: TATA-Box; Häkchen: Transkriptionsstart; CDS: Luziferase-kodierende Sequenz; Länge des K5-Konstruktes bis Transkriptionsstart: 214 bp; orange Boxen: Insertion von 10 bzw 11 Basen zwischen proximaler CCAAT-Box und TATA-Box. Unten: Reportergenaktivität der oben gezeigten Konstrukte in der Zelllinie HEK-293; die Aktivität des K5-Konstruktes wurde auf den Indexwert 100\% gesetzt. Die Ergebnisse sind eine Statistik aus vier unabhängigen Experimenten mit Standardabweichung SEM. 

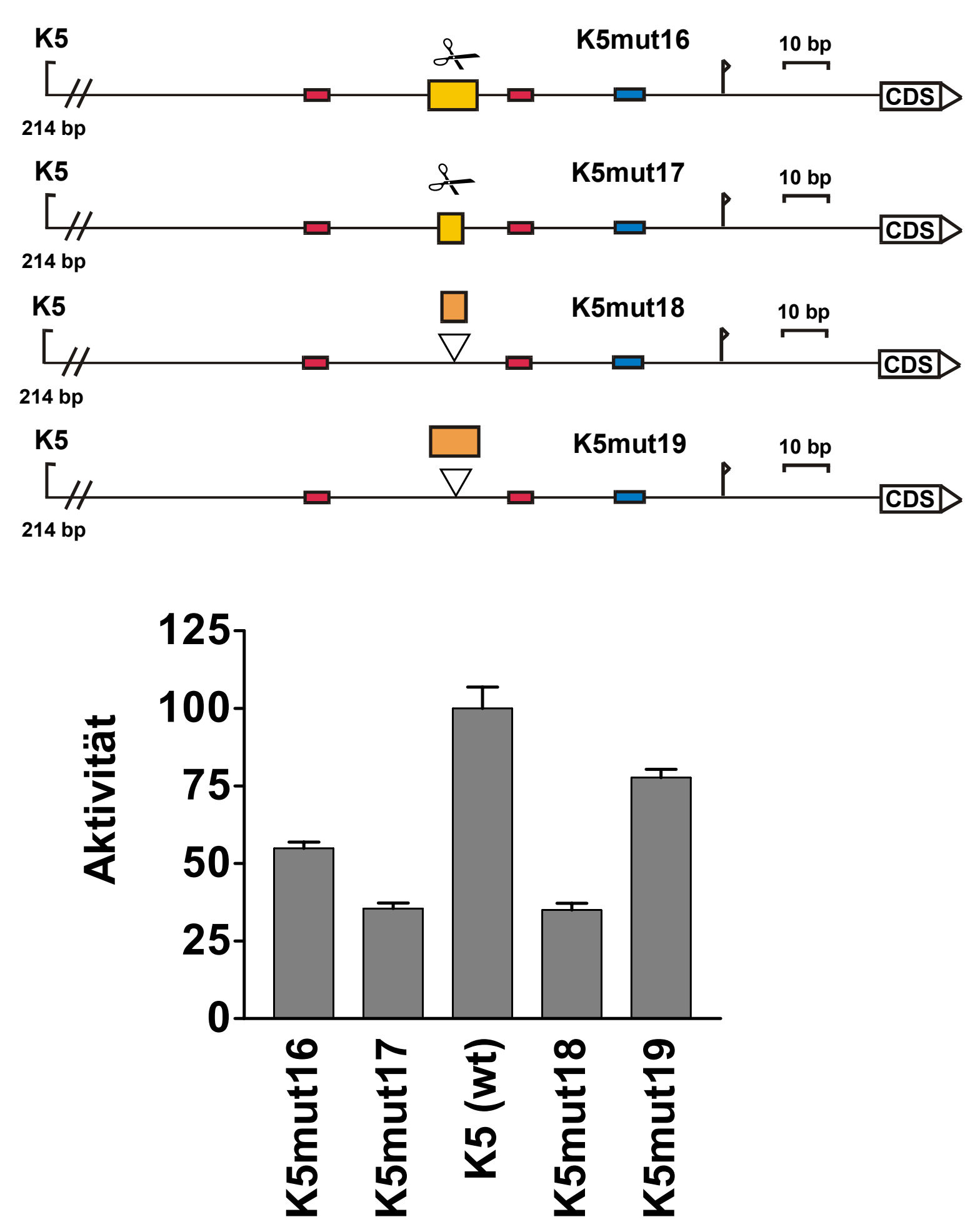

Abbildung 35: Veränderung des Abstands zwischen proximaler und distaler CCAAT-Box

Oben: Schematische Darstellung der Mutationskonstrukte des H3/k-Promotors; rote Boxen: CCAATBoxen; blaue Box: TATA-Box; Häkchen: Transkriptionsstart; CDS: Luziferase-kodierende Sequenz; Länge des K5-Konstruktes bis Transkriptionsstart: 214 bp; gelbe Boxen mit Schere: deletierte Bereiche von 10 bzw 5 Basen; orange Boxen: Insertion von 5 bzw 10 Basen zwischen distaler und proximaler CCAAT-Box. Unten: Reportergenaktivität der oben gezeigten Konstrukte in der Zelllinie HEK-293; die Aktivität des K5-Konstruktes wurde auf den Indexwert 100\% gesetzt. Die Ergebnisse sind eine Statistik aus vier unabhängigen Experimenten mit Standardabweichung SEM. 


\subsection{Bandshift-Analyse der CCAAT-Boxen des H3/k- und H3/m- Promotors}

Wie unter 5.3.2 00 beschrieben existiert eine Vielzahl von Transkriptionsfaktoren, die an CCAAT-Boxen binden können. Mit Hilfe von EMSA-Experimenten sollten daher abschließend die Transkriptionsfaktoren charakterisiert werden, die an die identifizierten CCAAT-Boxen binden. Die proximalen und distalen CCAAT-Boxen waren durch Mutationsexperimente sowohl im H3/k- als auch im H3/m-Promotor als wesentliche Promotorelemente identifiziert worden. Für die Versuchsreihen wurden 30 bp lange doppelsträngige (ds) Oligonukleotide eingesetzt, die der natürlichen Sequenz entsprechen. Die Nukleotide enthielten die CCAAT-Boxen an der Position 16-20 und wurden bei den EMSA-Experimenten eingesetzt (siehe 3.9 EMSAAnalyse 33 ).

Die proximale CCAAT-Box von H3/k, hier „KProx“ genannt, lieferte im Experiment zwei Shift-Banden. Bei der oberen Bande handelte es sich um eine Doppelbande; wobei deren untere Bande intensiver war (Abbildung 36 $\}_{1}$ ). Sowohl die Doppelbande als auch die andere Bande ließen sich durch unmarkiertes KProx kompetieren. Die Doppelbande lief exakt auf der gleichen Höhe wie die Doppelbande, die sich mit markiertem NF-Y-Konsensus-Oligonukleotid ergab und ließ sich darüber hinaus vollständig von diesem Oligonukleotid kompetieren. Bei der oberen Doppelbande handelt es sich daher mit hoher Sicherheit um einen NF-Y-Komplex. Die untere Bande kann sowohl durch unmarkiertes KProx als auch durch unmarkiertes KProxmut, welches eine mutierte CCAAT-Box enthält, kompetiert werden. Dieser Shift-Komplex benötigt also keine intakte CCAAT-Box.

Die distale CCAAT-Box von H3/k, hier „KDist“ genannt, lieferte im Experiment mehrere Shift-Banden (Abbildung 36, ${ }_{1}$ ). Lediglich eine davon ließ sich durch unmarkiertes KDist vollständig kompetieren. Wie bei der oberen Doppelbande des KProx-Oligonukleotids handelte es sich bei dieser Bande um eine Doppelbande mit einer erheblich stärkeren unteren Bande. Die Bande lief genau auf der Höhe der NF-Y- Doppelbande und ließ sich vom NF-Y-Konsensusoligonukleotid vollständig kompetieren. Ebenfalls wie beim KProx handelte es sich bei dieser Bande also mit hoher Sicherheit um einen NF-Y-Komplex. Die Ursache der übrigen Banden blieb ungeklärt; sie ließen sich nicht von unmarkiertem KDist kompetieren, so dass sie als unspezifisch anzusehen sind. 

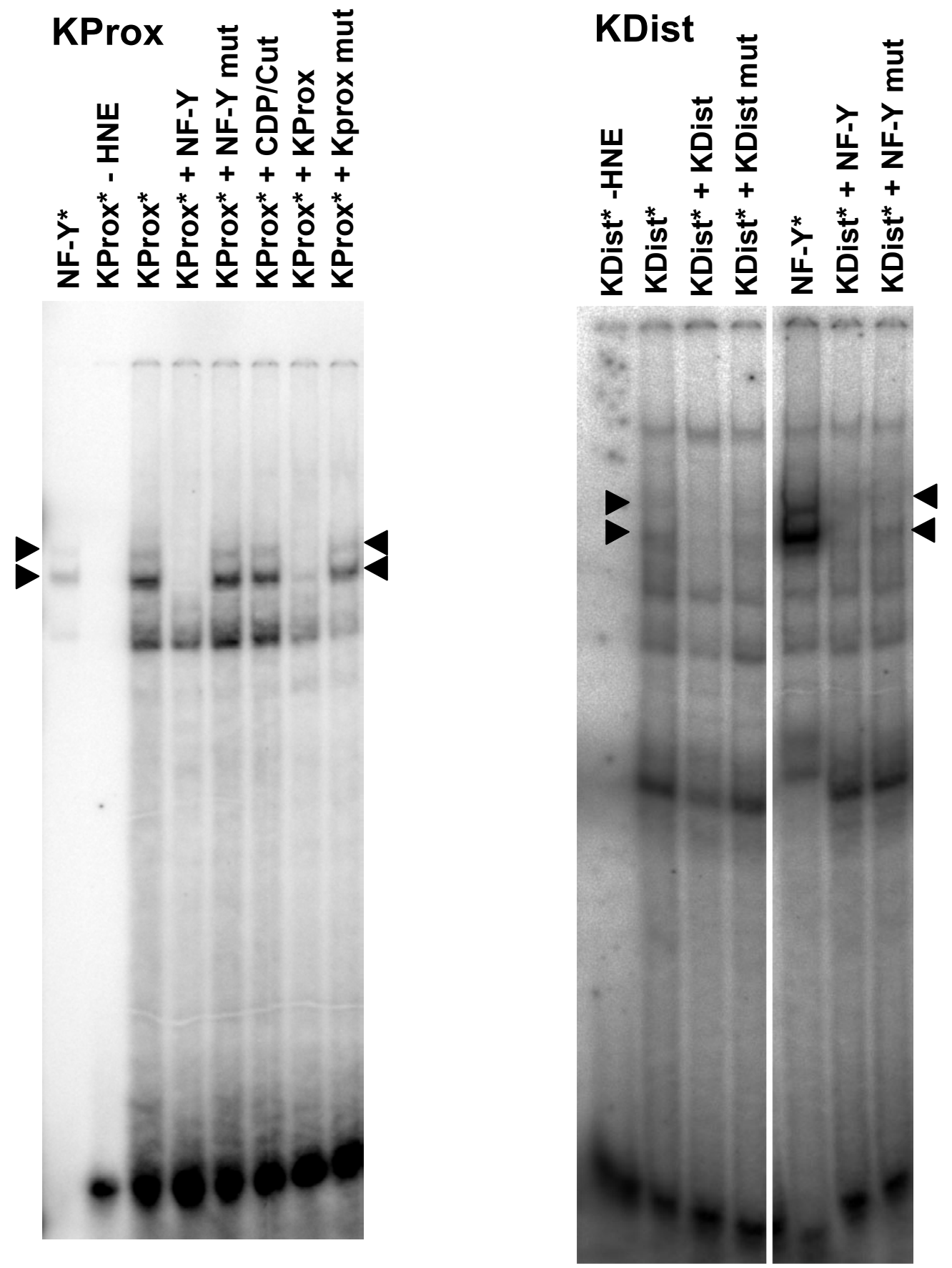

Abbildung 36: Autoradiogramme der EMSA-Assays der H3/k-CCAAT-Boxen

Die markierten Oligonukleotide (gekennzeichnet in der Beschriftung mit einem Sternchen) wurden mit HeLa-Kernextrakt (HNE) inkubiert und gelelektrophoretisch aufgetrennt (siehe 3.9. $]_{3}$ ). Einigen Ansätzen wurde ein unmarkierter Kompetitor im 80-fachem Überschuss zugesetzt (gekennzeichnet in der Beschriftung mit einem Pluszeichen). -HNE: Spuren ohne HeLa-Kernextrakt. Links: Bandshift-Gel mit markiertem KProx-Oligonukleotid(linke Spur: markiertes NF-Y-Oligo) und verschiedenen Kompetitoren. Die NF-Y-Doppelbande ist mit zwei Pfeilspitzen markiert. Rechts: Bandshift-Gel mit markiertem KDist-Oligonukleotid(fünfte Spur: markiertes NF-Y-Oligo) und verschiedenen Kompetitoren. Die NF-Y-Doppelbande ist mit zwei Pfeilspitzen markiert. 

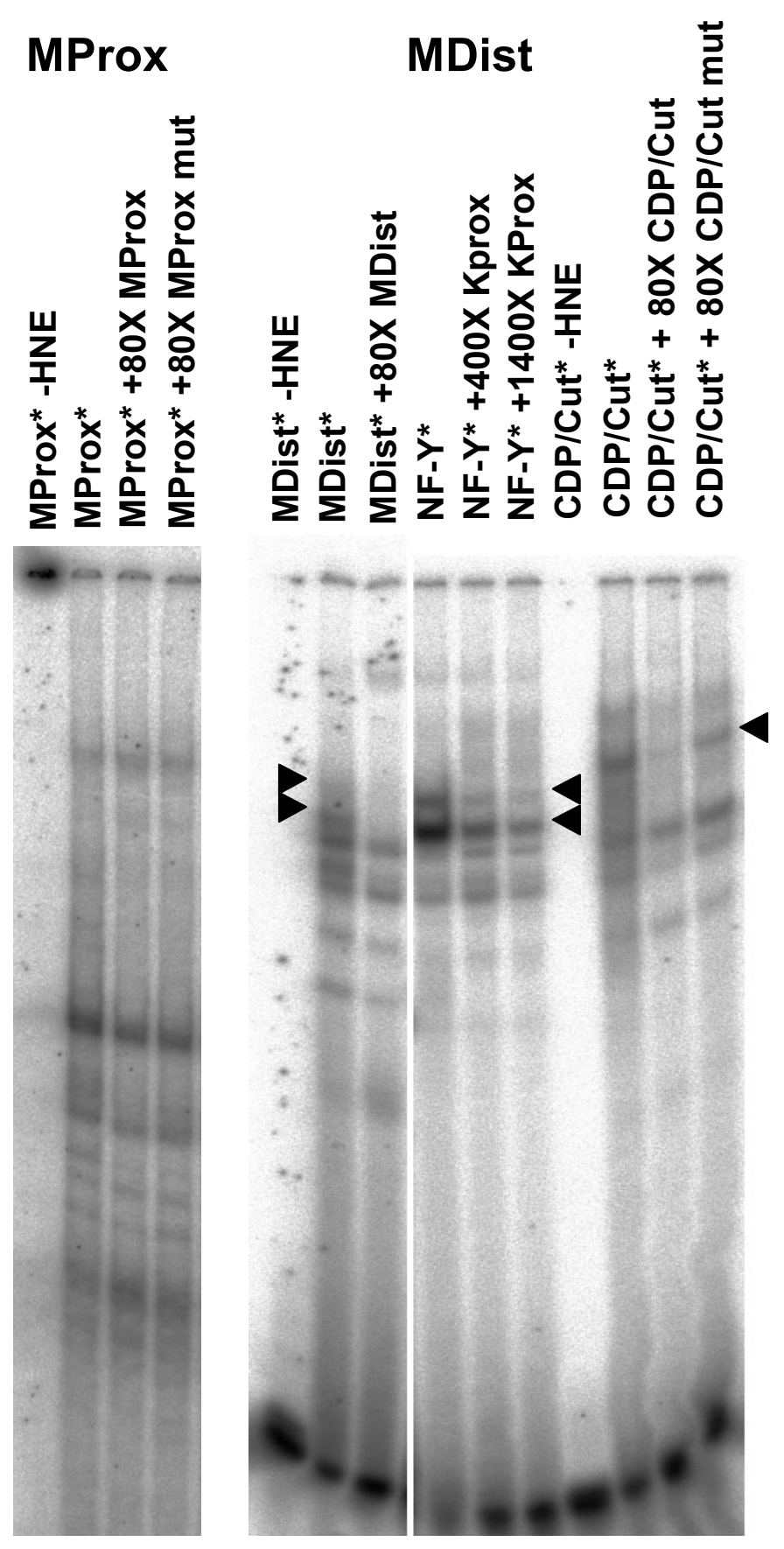

\section{Abbildung 37: Autoradiogramme der EMSA-Assays der H3/m-CCAAT-Boxen}

Die markierten Oligonukleotide (gekennzeichnet in der Beschriftung mit einem Sternchen) wurden mit HeLa-Kernextrakt (HNE) inkubiert und gelelektrophoretisch aufgetrennt (siehe 3.9,3). Einigen Ansätzen wurde ein unmarkierter Kompetitor im 80-fachem bzw. 1400-fachem Überschuss zugesetzt (gekennzeichnet in der Beschriftung mit einem Pluszeichen). -HNE: Spuren ohne HeLa-Kernextrakt. Links: Bandshift-Gel mit markiertem MProx-Oligonukleotidund verschiedenen Kompetitoren. Rechts: Bandshift-Gel mit markierten MDist-, NF-Y- und CDP/Cut-Oligonukleotide (siehe Beschriftung) und verschiedenen Kompetitoren. Die NF-Y-Doppelbande ist mit zwei Pfeilspitzen markiert. Die spezifische CDP/Cut-Bande ist mit einer einzelnen Pfeilspitze rechts oben markiert. 


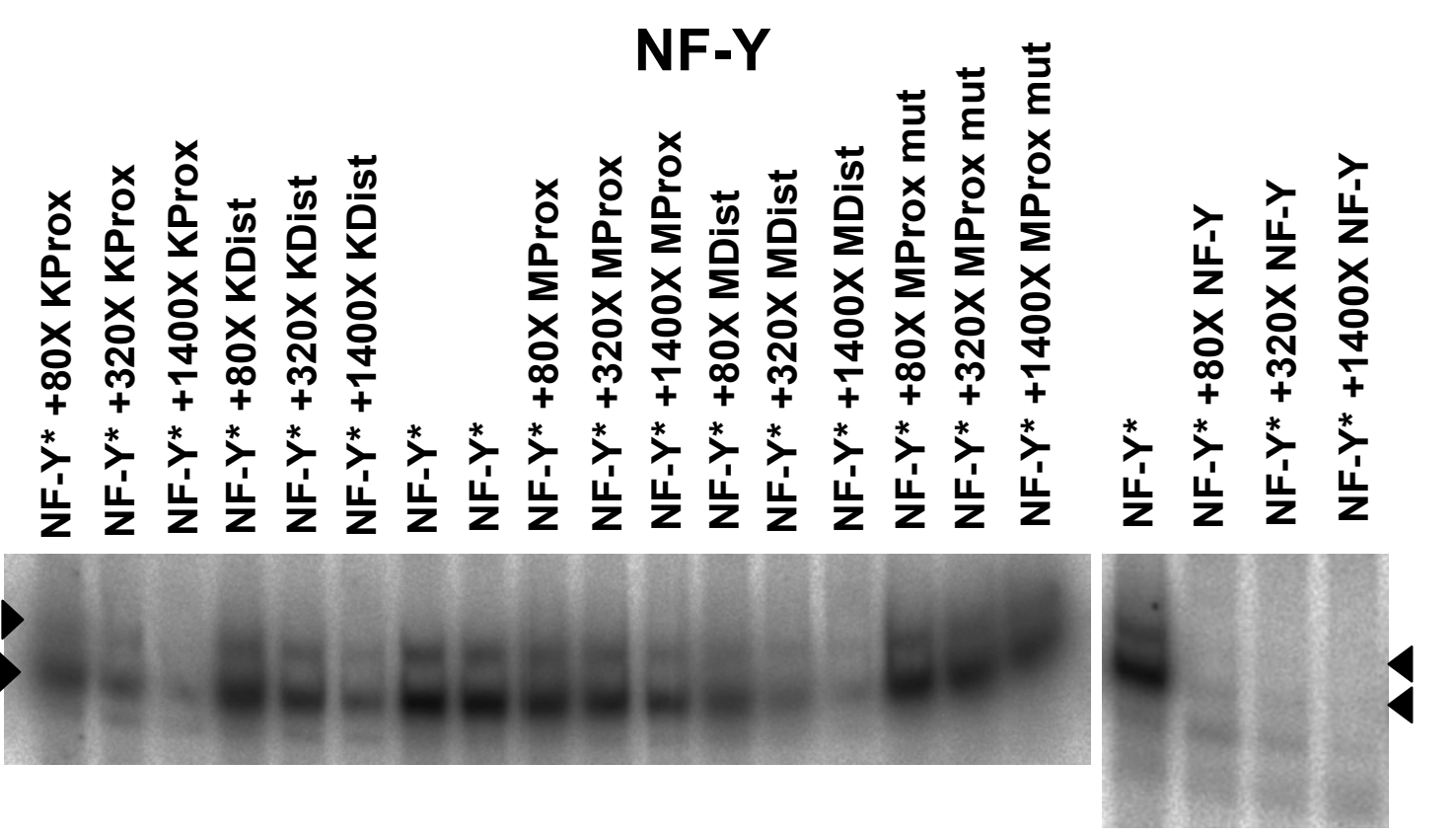

KProx-Kompetitor

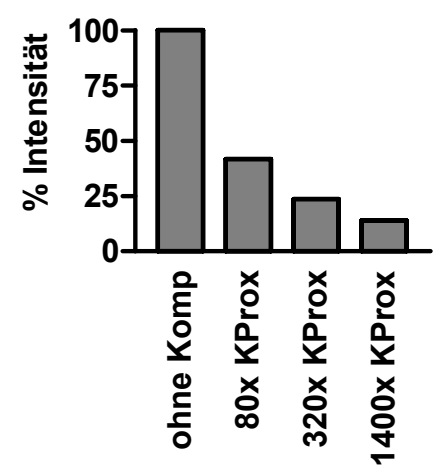

MDist-Kompetitor

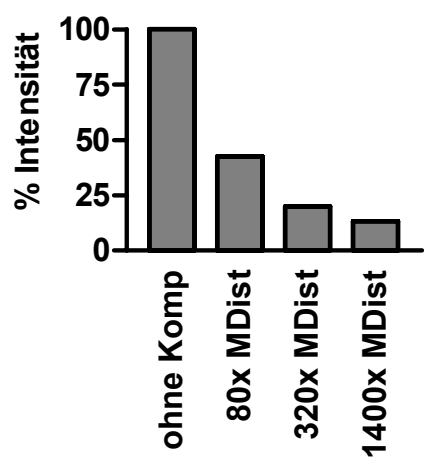

KDist-Kompetitor

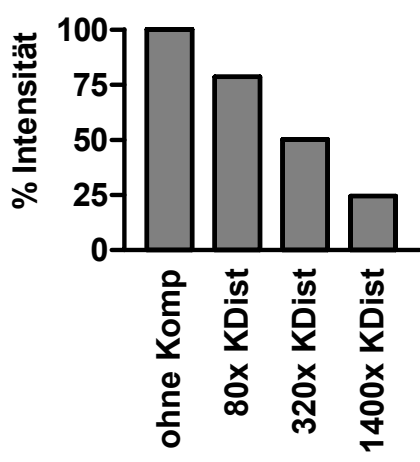

MProxmut-Kompetitor

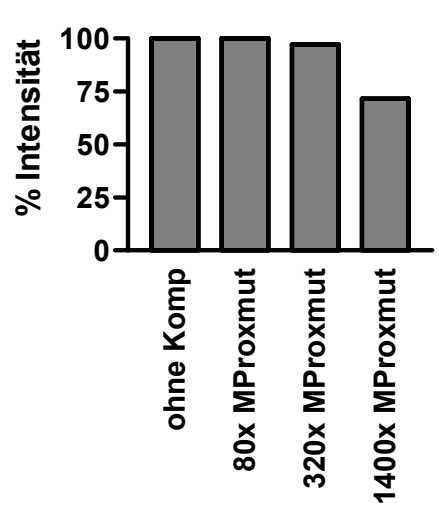

MProx-Kompetitor

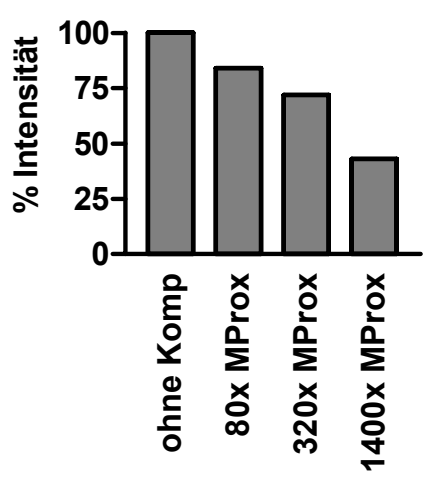

NF-Y-Kompetitor

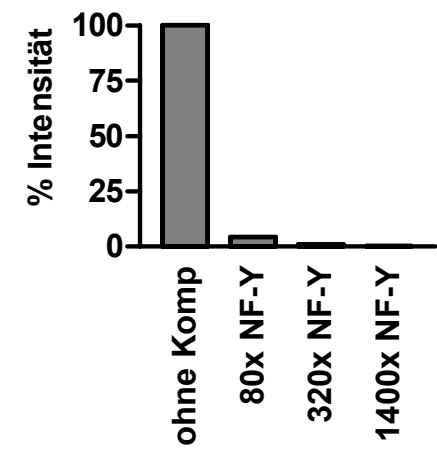

Abbildung 38: Kompetition des NF-Y-Komplexes durch CCAAT-Oligonukleotide

Markierte NF-Y-Oligonukleotide (NF-Y*) wurden mit HeLa-Kernextrakt mit oder ohne unmarkierten Kompetitoroligonukleotide inkubiert und gelelektrophoretisch aufgetrennt (siehe $3.9_{3}$ ) In der Beschriftung sind die Kompetitoren und die Höhe des Überschusses angegeben. Gezeigt wird der Gelausschnitt (Autoradiogramm), der die NF-Y-Banden enthält. Die NF-Y-Doppelbanden sind mit zwei Pfeilspitzen markiert. Unten: Intensitäten der oben gezeigten Banden nach Quantifizierung. Die Bande ohne Kompetitor (ohne Komp) wurde auf den Indexwert 100\% gesetzt. Unten angegeben sind die Kompetitoren und die Höhe des Überschusses. 
Die proximale CCAAT-Box von H3/m, hier "MProx" gennant, lieferte im Experiment mehrere Shift-Banden (Abbildung 37 ${ }_{2}$ ). Allerdings ließen sich die Banden weder durch unmarkiertes MProx noch durch unmarkiertes MProxmut, bei dem die CCAATBox mutiert ist, kompetieren. Das MProx-Oligonukleotid zeigte somit keine spezifischen Banden.

Die distale CCAAT-Box von $\mathrm{H} 3 / \mathrm{m}$, hier "MDist" genannt, lieferte im Experiment mehrere Shift-Banden (Abbildung $37 \oint_{2}$ ). Die Doppelbande, die die bekannte NF-YStruktur aufwies (eine obere schwächere und eine untere stärkere Bande mit charakteristischem Abstand), ließ sich durch unmarkiertes MDist kompetieren. Diese Bande lief genau auf der Höhe der NF-Y-Doppelbande und ließ sich auch vom NF-YKompetitoroligonukleotid kompetieren (nicht gezeigt). MDist band somit spezifisch einen Faktor, bei dem es sich mit hoher Sicherheit um NF-Y handelte. Auf dem gleichen Gel ist rechts zu erkennen, dass das CDP/Cut-Konsensusoligonukleotid eine spezifische Shift-Bande ergab (Pfeilmarkierung), die erheblich höher läuft als die NF-Y-Doppelbande und in keinem Shift-Experiment der CCAAT-Oligonukleotide zu sehen war.

Abschließend wurde mit Kompetitionsreihen die Affinität der einzelnen CCAATBoxen zum Faktor NF-Y bestimmt. Dazu wurden zu markiertem, ds NF-YKonsensusoligonukleotid die unmarkierten ds CCAAT-Oligonukleotide als Kompetitoren in 80fachem, 320fachem und 1400 fachem Überschuss zugegeben. Die einzelnen CCAAT-Boxen hatten eine unterschiedliche Affinität zu dem Faktor NF-Y (Abbildung 38,33): Gut - aber wesentlich schlechter als die Positivkontrolle ds NF-YKonsensusoligonukleotid - kompetitierten KProx und MDist, mittelmäßig KDist. Schlecht kompetitierte MProx. Als Negativkontrolle diente MProxmut mit mutierter CCAAT-Box.

Die proximalen und distalen CCAAT-Boxen des $\mathrm{H} 3 / \mathrm{k}$ - und des $\mathrm{H} 3 / \mathrm{m}$-Promotors banden also in vitro mit unterschiedlicher Affinität den Faktor CBF/NF-Y. Die Affinität des Faktors CBF/NF-Y zu den CCAAT-Boxen des H3/k- und H3/m-Promotors war niedriger als zum NF-Y-Konsensusoligonukleotid. Es wurden keine weiteren spezifischen Banden, d.h. Proteinbindungen, in den EMSA-Experimenten mit den H3/k- und H3/m-CCAAT-Box-Oligonukleotiden beobachtet. 


\section{Diskussion}

\subsection{Histon-H3-Genexpression in humanem Gewebe und Tumorzelllinien}

Die individuellen mRNA-Spiegel von allen elf replikationsabhängig-exprimierten H3-Histongenen (die im Folgenden "replikationsabhängige H3-Histongene" genannt werden) wurden in den drei humanen fötalen Geweben Harnblase, Leber und Lunge (Abbildung 9, 9 und Abbildung 114 1 ) sowie in den acht humanen Zelllinien Capan-1, HeLa-S3, HEK-293, Hep-G2, HL-60, IMR-90, SaOS-2, und Tera-2 (Abbildung 124 $3_{3}$ Abbildung 14 ${ }_{5}$ ) bestimmt. Das Expressionsmuster der H3-Gene war in den drei fötalen Geweben recht ähnlich. Das bedeutet, dass entweder alle elf $\mathrm{H} 3-\mathrm{Gene}$ einer gemeinsamen Regulation mit den gleichen Transkriptionsfaktoren unterliegen oder, falls unterschiedliche Faktoren involviert sind, liegen diese zumindest in funktionell ähnlichen Konzentrationen in den Geweben vor.

Das Ergebnis deutet also im Kontrast zu Heintz (1991), Liu und Gorovsky (1996) und van der Meijden et al. (1998) darauf hin, dass es in der Expression der replikationsabhängigen H3-Gene keine wesentlichen Zelltyp-spezifischen Faktoren gibt.

In der diploiden Zelllinie IMR-90 ähnelt das H3-Expressionsmuster dem der drei fötalen Gewebearten, während die übrigen untersuchten Zelllinien, die Tumorzellinien sind, davon stark abweichende, anormale d.h. aberrante Expressionsmuster zeigten: Die Gesamt-H3-mRNA bestand in diesen Zellinien im wesentlichen aus nur zwei bis fünf verschiedenen individuellen H3-mRNAs, und einige Gene wurden gar nicht oder nur sehr schwach exprimiert (4.2.3.1 1 ).

Ein ähnliches Expressionsverhalten in Tumorzellinien wurde auch bei den anderen Histongenklassen von anderen Autoren beobachtet, wobei die Expressionsmuster der Gene in den Zellinien nur semi-quantitativ bestimmt wurden: Albig et al. (1999) beobachteten eine untereinander variierende Expression von acht humanen $\mathrm{H} 2 \mathrm{~A}$ und zehn H2B Genen in vier humanen Tumorzelllinien. Hampe (2000) beobachtete eine untereinander variierende Expression von fünf $\mathrm{H} 4-\mathrm{Genen}$ in fünf humanen Zelllinien - ein Gen wurde dabei in zwei Zelllinien nicht exprimiert. Meergans et al. (1997) beobachteten eine differentielle Expression der sechs humanen H1-SubtypGene in neun humanen Zelllinien. Die Histongene H1.1, H1.3 und H1.5 wurden nicht in allen Zelllinien exprimiert. 
Es handelt sich also bei dem in der vorliegenden Arbeit beobachteten aberranten Expressionsmuster der $\mathrm{H} 3-$ Gene in Tumorzelllinien offenbar nicht um einen Sonderfall innerhalb der fünf Histongenklassen.

\subsubsection{Das aberrante Expressionsmuster von H3-Histongenen in Tumorzellinien}

Das aberrante Expressionsmuster der H3-Histogene in Tumorzellinien lässt sich theoretisch auf eine Reihe verschiedener Ursachen zurückführen, weil die Genexpression an verschiedenen Stufen reguliert sein kann (siehe Abbildung 3 ). In der vorliegenden Arbeit wurde die Relevanz denkbarer Ursachen untersucht.

Mutationen oder Deletionen in den betroffenen H3-Genen oder ihren Promotoren könnten die Expression der Gene in den Tumorzelllinien auf genetischer Ebene schwächen oder verhindern. Um diese Möglichkeit auszuschließen, wurde in der vorliegenden Arbeit exemplarisch in vier Fällen mit Hilfe von PCR-Amplifikation und anschließender Sequenzierung der PCR-Produkte nachgewiesen, dass nicht exprimierte H3-Gene ohne Mutationen in den Zelllinien vorkamen: H3/h und H3/i sind ohne Mutationen in der HL-60 Zellinie vorhanden und H3/c und H3/h sind ohne Mutationen in HEK-293 Zelllinie vorhanden. Deshalb kann ausgeschlossen werden, dass genetische Mutationen die generelle Ursache für die fehlende Expression einzelner Gene und damit für das aberrante Expressionsmuster sind.

Eine zweite Möglichkeit für das abweichende Expressionsmuster in den Tumorzellinien könnte in Veränderungen der Histon-mRNA-3'-Prozessierung oder der Histon-mRNA-Stabilität bestehen. Diese Aberration müsste selektiv die mRNAProzessierung individueller Gene inaktivieren oder selektiv die mRNA-Stabilität individueller Gene herabsenken (Eine nicht-selektive Inaktivierung oder Absenkung reicht nicht aus, da sonst alle H3-Gene gleichermaßen betroffen wären. Die beobachtete Abweichung der H3-Expression in den Tumorzellinien bestand jedoch in einer selektiven Veränderung der relativen Expressionstärke einzelner H3-Gene.). Für eine solche selektive Aberration müssten die individuellen H3-Gene separaten 3'-Prozessierungswegen bzw. mRNA-Abbauwegen folgen. Die mRNA-3'-Enden der H3-Gene, die für die Regulation der 3'-Prozessierung und der mRNA-Stabilität entscheidend sind (Marzluff und Duronio 2002), sind sich aber sehr ähnlich

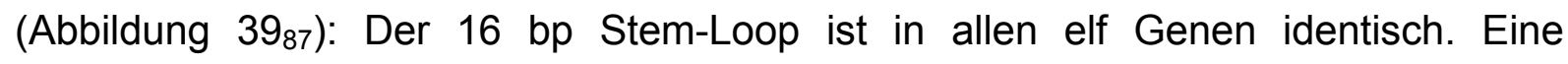


Ausnahme ist das H3/h-Gen, welches eine Nicht-Konsensus Base an der einzig variablen (variabel ist die Stelle im Vergleich der Histongenklassen) Stelle im Loop aufweist. Die "Histone Downstream Elements" (HDEs) der elf H3-Gene, die die Bindungsstellen des U7sRNP-Partikels sind, enthalten maximal eine NichtKonsensus Base an Position 5 oder 7 ((G/U)-RNA-Paarungen gelten als erlaubt). Eine Ausnahme ist das H3/i-Gen mit zwei Nicht-Konsensus Basen. Der Abstand zwischen den HDEs und der Prozessierungsstelle beträgt in allen Genen zwischen 8 und 10 Nukleotiden, und die Prozessierungsstelle enthält bei neun Genen das konservierte Motiv AC, während die anderen beiden Gene CC oder AA Motive aufweisen, die nach Furger et al. (1998) ebenfalls funktionell in der Prozessierung sind (Abbildung 39 37 ).

\begin{tabular}{|c|c|c|c|c|c|c|}
\hline \multicolumn{2}{|l|}{ Elemente: } & $16 \mathrm{bp}$-Stem-Loop & PS & \multicolumn{3}{|c|}{ U7-BS (HDE) } \\
\hline $\mathrm{H} 3 / \mathrm{a}: 28 \mathrm{bp}$ & AAA & GGCTCTTTTCAGAGCC & ACCACCT & TTTCAAGT & AAAGTAGCTG & TAAGAAACCAA \\
\hline н3/b: & $\mathrm{AAA}$ & GGCTCTTTTCAGAGCC & ACCCACA & TGCGCGCTG & AAAAGATCTG & TTTCTCTCAGGA \\
\hline н3/c: & $\mathrm{AAA}$ & GGCTCTTTTCAGAGCC & ACTCACA & ATTTCACTTA & AAAACAGTTG & TAACCCATTCGG \\
\hline H3/d: & AAA & GGCTCTTCTCAGAGCC & AACCACT & TTGTCCGTG & AAAAGGGCTG & TAATCCTTTGAG \\
\hline H3/f: & $\mathrm{AAA}$ & GGCTCTTTTCAGAGCC & ССТСААТ & TGTCACCAA & AAGGAAGCTG & TAGCTTTTGAGA \\
\hline H3/h: & $\mathrm{AAA}$ & GGCTCTTTTAAGAGCC & GCCTACT & TTCACCCG & AAAATAGCTG & TGATTAACTAAT \\
\hline H3/i : & $\mathrm{AAA}$ & GGCTCTTTTCAGAGCC & ACCAACA & ATTTCAGTT & GAAAGCGCCG & TAGCACTAGGGA \\
\hline н3/j : & AAA & GGCTCTTTTCAGAGCC & АСТTACA & TTCTCACTG & AGGATAGCTG & TCACACCATTGG \\
\hline H3/k : & AAA & GGCTCTTTTCAGAGCC & ACCCACA & TGCGCGCTG & AAAAGATCTG & TTTCTCTCAGGA \\
\hline H3/m: & AAA & GGCTCTTTTCAGAGCC & ACCCACT & TATTCCAACG & AAAGTAGCTG & TGATAATTTTT \\
\hline H3/n : & AAA & GGCTCTTTTCAGAGCC & ACCCACA & TCAGCACTTG & GAAGAAGCTG & TACCGCTTGCCC \\
\hline Konsensus: & AAA & GGCTCTTTTCAGAGCC & ACCCACA & & AAAAGAGCTG & \\
\hline
\end{tabular}

Abbildung 39: Sequenzvergleich der 3'-Prozessierungselemente der $11 \mathrm{H} 3-$ Histongene

PS: Prozessierungsstelle; U7-BS: U7-snRNP-Bindungsstelle (HDE: „Histone Downstream Element“); Die Entfernung der gezeigten Sequenzbereiche zum Stopcodon ist in bp angegeben.Die komplementäre U7-RNA-Sequenz lautet UUUUCUCGAC. Nicht-Konsensus-Basen im 16 bp-StemLoop und in der U7-BS sind rot markiert. (G/U)-RNA-Paarungen gelten als erlaubt.

Aufgrund der hohen Ähnlichkeit der 3'-Prozessierungselemente der H3-Histongene ist eine unterschiedliche Prozessierungseffizienz unwahrscheinlich. Weiter sind weder unterschiedliche Histon-3'-Prozessierungswege noch unterschiedliche HistonmRNA-Abbauwege bekannt (Marzluff und Duronio 2002). Die hohe Ähnlichkeit der 3'-Prozessierungselemente der individuellen H3-Gene lässt zudem unterschiedliche 3'-Prozessierungswege oder mRNA-Abbauwege als Erklärung für das aberrante Expressionsmuster unwahrscheinlich erscheinen. Eine Aberration in der HistonmRNA-3'-Prozessierung oder in der Histon-mRNA-Stabilität ist daher nach den bisherigen Beobachtungen nicht die Ursache für das beobachtete aberrante H3-Expressionsmuster in den Tumorzelllinien. 
Nach der bisherigen Diskussion könnte das aberrante Expressionsmuster auf der Ebene der Transkription verursacht werden. Hier sind zwei Varianten denkbar: Entweder sind aberrante Transkriptionsfaktor-Konzentrationen in den Zelllinien ursächlich für die unterschiedliche H3-Expression oder die differentielle H3-Expression wird durch eine übergeordnete Transkriptionsregulation verursacht. Unter einer übergeordneten Transkriptionsregulation wären sämtliche Einflüsse auf die Transkriptionsaktivität zu verstehen, die durch die Chromatin-Struktur im allgemeinen (z.B. Nukleosomen-Anordnung), Histon-Modifizierungen (z.B. Acetylierung), DNA-Modifizierungen (z.B. Methylierung) oder durch permanente Anlagerung von Proteinen verursacht werden.

\subsubsection{Vergleich der Aktivität von Histon-H3-Promotoren in verschiedenen Zelllinien}

Eine Erklärung für das von den fötalen Geweben abweichende H3-Expressionsmuster in den Tumorzellinien kann auch darin bestehen, dass die verschiedenen Histongene von unterschiedlichen Transkriptionsfaktoren aktiviert wurden, die in den Tumorzelllinien in aberranten Konzentrationen vorkamen. In diesem Fall sollten die isolierten Promotoraktivitäten der $\mathrm{H} 3$-Histongene in transienter Transfektion der endogenen Expression der Gene in den jeweiligen Zelllinien entsprechen. Zur Überprüfung wurde die Aktivität von sechs H3-Promotoren in fünf Zelllinien in Reportergenassays bestimmt. Sowohl die H3Gene (siehe $5.2_{1}$ ) als auch die Zellinien wurden repräsentativ ausgewählt Alle untersuchten H3-Promotoren waren in allen Zellinien aktiv. Dies war erstaunlicherweise auch in Zelllinien der Fall, in denen das endogene H3-Gen gar nicht exprimiert wurde: H3/h in der HEK-293- und der Hep-G2-Zellinie und H3/d in der HEK-293-, HeLa-S3- und Hep-G2-Zelllinie (Abbildung 23\$9). Die Aktivität der H3-Promotoren, die mit Hilfe der Kotransfektion des Renilla-Luziferase-Kontruktes standardisiert wurde (die sogenannte relative Aktivität), variierte von Zelllinie zu Zellinie, aber die relativen Aktivitäten einiger Promotoren einer Gruppe blieben relativ zueinander in den untersuchten Zelllinien konstant. Lediglich die Aktivität von Promotoren aus unterschiedlichen Gruppen variierte relativ zueinander je nach Zelllinie. Nach diesen Kriterien konnten die Promotoren in eine Gruppe $A$ und eine Gruppe B eingeteilt werden: H3/n, H3/m , H3/h und H3/i (Gruppe A) und H3/d und 
H3/k (Gruppe B). In der Gruppe A war der H3/n-Promotor am aktivsten, gefolgt vom H3/m-, H3/h- und H3/i-Promotor $(H 3 / n>H 3 / m>H 3 / h>H 3 / i)$. In der Gruppe B war der H3/d-Promotor aktiver als der H3/k-Promotor (H3/d > H3/k) (Abbildung 23.59).

Innerhalb der Gruppe A bzw. Gruppe B waren die Aktivitäten der isolierten H3-Promotoren relativ zueinander nicht Zelltyp-spezifisch. Das kann einerseits bedeuten, dass alle Histongene einer Gruppe die gleichen Transkriptionsfaktoren benutzen. Falls sie aber andererseits unterschiedliche Transkriptionsfaktoren verwenden, so müssen diese in gleichen oder sättigenden Konzentrationen in den untersuchten Zelllinien vorkommen (ansonsten würden ja die Aktivitäten der Promotoren relativ zueinander in verschiedenen Zelllinien variieren). Die Ursache des Unterschieds zwischen den Gruppe-A- und den Gruppe-B-Promotoren ist unklar. In den H3-Promotoren sind auf Sequenzebene keine Elemente vorhanden, die den Unterschied erklären könnten (siehe 4.1,5) und auch nachfolgende Promotoranalysen konnten keine solchen Elemente auffinden (siehe $5.2 \mathrm{ff}_{1}$.).

Die Aktivitäten der isolierten H3-Promotoren in den untersuchten Zelllinien korrelierten nicht mit der endogenen H3-Expression in diesen Zelllinien (vergleiche Abbildung 23, 39 und Abbildung 11 1 ). Besonders auffällig ist, dass die Gene, die in einer bestimmten Zellinie nicht oder nur schwach exprimiert wurden, dennoch einen in dieser Zelllinie aktiven Promotor aufwiesen. Das aberrante Expressionsmuster der

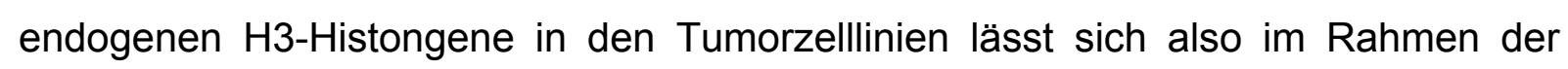
gemachten Experimente nicht auf variierende Transkriptionsfaktor-Konzentrationen zurückführen.

\subsubsection{Hypothesen zur Natur des aberranten H3-Expressionsmusters}

Somit war gezeigt, dass unterschiedliche Transkriptionsfaktor-Konzentrationen nicht die Ursache für das aberrante H3-Expressionsmuster sind. Wenn dennoch eine variierte Transkription für das abweichende Expressionsmuster ursächlich wäre, dann müssten übergeordnete Transkriptionsregulations-Mechanismen, die sich auf der Ebene der Chromatinstrukturen manifestieren, die abweichende Expression verursachen. Da das aberrante H3-Expressionsmuster erblich ist (weil es charakteristisch für eine Zellinie ist), aber weder genetische Ursachen hat noch von 
löslichen Faktoren bedingt ist, muss es sich um einen epigenetischen Effekt ${ }^{2}$ handeln.

Diese Hypothese würde die Bedeutung der übergeordneten Regulation in der Histongenexpression betonen, die durch den Chromatin-Kontext vermittelt wird und die in den Tumorzelllinien offensichtlich verändert ist. Die Hypothese würde zudem erklären, warum die Aktivitäten der isolierten H3-Promotoren nicht mit den Expressionsstärken der entsprechenden Gene in den fötalen Geweben und in der Zelllinie IMR-90 korrelieren (siehe Abbildung 40,0). Auch dieser Befund ließe sich mit dem Einfluß einer übergeordneten Regulation erklären, die über den ChromatinKontext vermittelt werden könnte.

\section{Endogene Expression in drei Geweben}

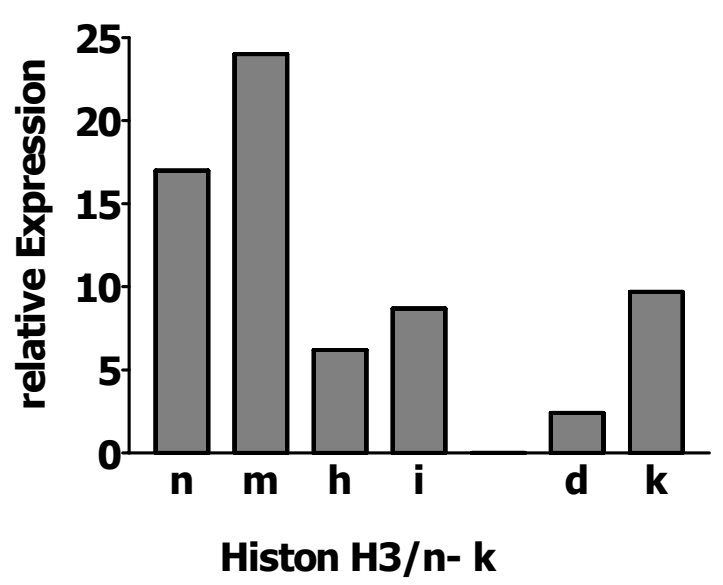
Promotoraktivität in fünf
Zelllinien

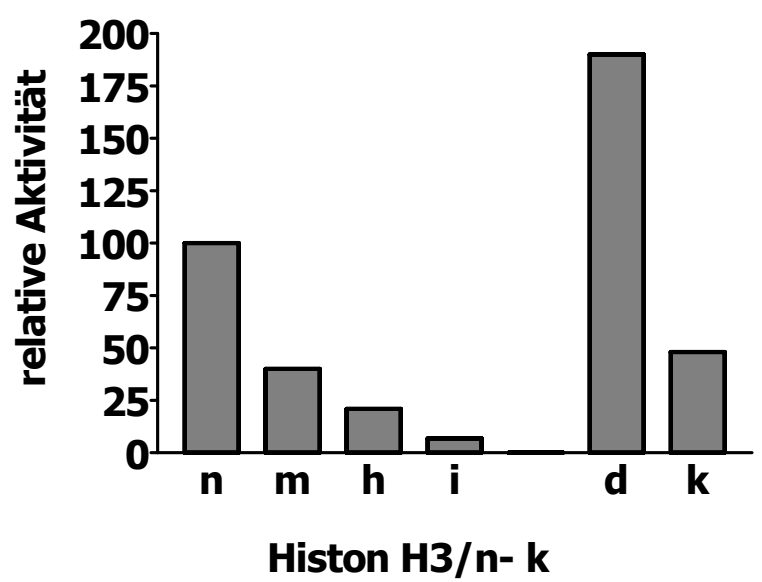

Abbildung 40: Vergleich der endogenen Expression und der Promotoraktivität von sechs H3-Genen Links: Endogene Expression der sechs H3-Gene in den drei fötalen humanen Geweben Lunge, Blase und Leber (in Prozent der gesamten H3-mRNA, Durchschitt in den drei Geweben). Das H3-Expressionsmuster in der IMR-90-Zelllinie ist ähnlich (vergleiche Abbildung 14 ${ }_{5}$ ) Rechts: H3-Promotoraktivität in den fünf Zelllinien HeLa-S3, HEK-293, IMR-90, Tera-2 und Hep-G2 (Durchschnitt, die Aktivität von $\mathrm{H} 3 / \mathrm{n}$ wurde als $100 \%$ gesetzt)

Ein Vergleich von stark und schwach exprimierten Histongenen in den fötalen Geweben zeigt, dass die am stärksten exprimierten Gene (H3/m, H3/n, H3/k und $\mathrm{H} 3 / \mathrm{b}$ ) downstream von einem H2A-Gen liegen. Möglicherweise üben die H2A-Gene eine aktivierende Wirkung auf die H3-Expression aus. Es könnte sein, dass benachbarte Histongene ihre Expression gegenseitig stimulieren. Dies wäre eine mögliche Erklärung für die Clusteranordnung der replikationsabhängigen Histongene. Nun befinden sich innerhalb von 8 kb oberhalb und unterhalb des H3/d-Gens keine

\footnotetext{
${ }^{2}$ Epigenetik ist ein Gebiet, das die erblichen Unterschiede in Genexpressions-Mustern untersucht, die nicht auf Veränderungen der DNA-Primärsequenz zurückzuführen sind.
} 
benachbarten Histongene. Nach dieser Hypothese muss die Expression des H3/d-Gens sehr schwach sein, obwohl es gemäß der Untersuchung bei den Reportergenassays einen der stärksten Promotoren hat. Experimentell wird dies auch gefunden.

Dieser hypothetische "Nachbar-Effekt" könnte dadurch entstehen, dass benachbarte Gene gemeinsam den Chromatin-Kontext in der betreffenden Region in einem aktivierten Status halten oder sich gegenseitig bei der Rekrutierung von Transkriptionsfaktoren helfen.

Die vermutete Aberration in den höheren Chromatin-Strukturen in den Tumorzellinien könnte eine Region von 20 kb oder mehr betreffen, weil die benachbarten H3-Gene H3/i und H3/h (20 kb Abstand) und H3/j und H3/f (18 kb Abstand) in den Tumorzelllinien gemeinsam inaktiviert oder exprimiert wurden. Ähnlichkeiten in der Expressionstärke in Zelllinien waren auch bei den benachbarten Genen H3/h und H2B/k in HeLa-S3, Hep-G2 und Tera-2 vorhanden (diese Arbeit und Albig et al. (1999)).

Die epigenetischen Faktoren, die zu der aberranten Histongen-Expression in den Tumorzellinien führen könnten, könnten den lokalen Chromatin-Kontext, HistonModifizierungen, DNA Metylierung oder permanente Anlagerung von SilencerProteinen beinhalten.

\subsection{Histon-H3-Promotoranalyse}

Die funktionelle Struktur der H3-Promotoren wurde in Reportergenassays mit Deletionsreihen der folgenden sechs H3-Gene aufgeklärt: H3/d, H3/h, H3/i, H3/k, $H 3 / m$ und H3/n. Dabei wurde die funktionale Länge der Promotoren, die Lage von cis-Elementen und der mögliche Einfluß von Upstream-Sequenzen bestimmt. Diese sechs Histongene stellten $68 \%$ der gesamten H3-mRNA in den drei untersuchten fötalen Geweben und einen Großteil der gesamten H3-mRNA in den untersuchten Zelllinien. Diese Auswahl von H3-Genen enthielt zudem jeweils mindestens ein Gen aus drei der vier Histongencluster. Weiter enthielt die Auswahl die drei Gene H3/k, $H 3 / m$ und $H 3 / n$, die sowohl im humanen fötalen Gewebe als auch in humanen Zelllinien am stärksten exprimiert wurden. Das H3/n Gen ist zugleich das einzige replikationsabhängige H3-Gen, das die Proteinvariante H3.2 kodiert. Das H3/h- und H3/i-Gen wurden ausgewählt, weil sie in den getesteten Zellinien sehr 
unterschiedlich exprimiert wurden. Das H3/d Gen wurde ausgewählt, weil es in den meisten Zelllinien nicht exprimiert wurde. Somit stellen die sechs ausgewählten Gene eine repräsentative Auswahl der elf replikationsabhängigen $\mathrm{H} 3$-Histongene dar.

Betrachtet man nur die proximalen Promotorkonstrukte, d.h Promotorkonstrukte mit einer Länge bis zu etwa 500 Basenpaaren, so zeigten fünf der sechs untersuchten H3-Promotoren in den Reportergenassays nahezu maximale Aktivität schon bei Längen von 99 - 228 bp (bezogen auf den Transkriptionsstart): H3/m 228 bp, H3/k 99 bp, H3/h 115 bp, H3/n 186 bp und H3/d 176 bp. Beim H3/i Gen konnte kein klar umrissener proximaler Promotor identifiziert werden. Die proximalen Promotoren der H3-Gene sind somit zwischen zirka 100 bp und zirka 230 bp lang.

Die H3-Promotoren ähneln sich vor allem in der Existenz einer TATA-Box mit knapp davor liegender CCAAT-Box und in der Existenz von weiteren CCAAT-Boxen. Im $\mathrm{H} 3 / \mathrm{m}$ - und H3/n-Promotor gibt es darüber hinaus noch eine sogenannte ATF-Box. Durch standardisierte Transfektion der verschiedenen H3-Promotoren in parallelen Experimenten konnte ihre Stärke in der Zellinie HEK-293 miteinander verglichen werden (Abbildung 22\$7).

Bezogen auf den in der Zellinie HEK-293 stärksten proximalen H3-Promotor H3/n (Konstrukt N3, siehe Abbildung 20,4), besaßen die Promotordeletionskonstrukte, die allein die TATA-Box enthielten, nur beim H3/m- und H3/d-Gen eine Aktivität, die mit $1,3 \%$ respektive $2,3 \%$ wesentlich über der Aktivität der Negativkontrolle $(0,35 \%)$ lag.

Die Promotor-Konstrukte, die zusätzlich zur TATA-Box eine proximale CCAAT-Box enthielten, besaßen eine Aktivität von durchschnittlich 3,6\% bezogen auf den $\mathrm{H} 3 / \mathrm{n}$ Promotor. Die proximale CCAAT-Box brachte also eine gesteigerte Aktivität für die H3-Promotoren. Die beiden Elemente TATA-Box und proximale CCAAT Box waren jedoch für eine volle Aktivität der untersuchten H3-Promotoren nicht ausreichend. Im übrigen variierte die Aktivität dieser Konstrukte je nach Gen sehr stark: von 0,9\% beim H3/h Gen bis zu 7,8\% beim H3/k Gen (bezogen auf den proximalen H3/nPromotor).

Die Promotor-Konstrukte, die zusätzlich zur proximalen CCAAT-Box eine weitere CCAAT-Box enthielten, waren in allen Genen mit einer durchschnittliche Aktivität: von $41 \%$ (bezogen auf den proximalen $\mathrm{H} 3 /$ n-Promotor) bereits zu einem hohen Grad funktional. Offenbar sind die zweiten, distalen CCAAT-Boxen wichtige Elemente in den H3-Promotoren. Das H3/i-Gen, welches keine zweite CCAAT-Box in den ersten 
350 bp des Promotors besitzt, weist keinen derartigen Aktivitätssprung von einem vergleichbar langen Konstrukt auf. Das ist ein weiterer Hinweis auf die große Bedeutung dieser zweiten CCAAT-Box.

Die Promotor-Konstrukte des H3/m- bzw. H3/h-Gens, die weitere Bereiche mit einer ATF-Box (im H3/m-Promotor) bzw. weitere CCAAT-Boxen (im H3/h Promotor) enthielten, waren mit einer Aktivität von $76 \%$ bzw. $80 \%$ aktiver als die entsprechenden Konstrukte ohne diese Bereiche (die eine Aktivität von $24 \%$ bzw. $34 \%$ besaßen). Offenbar üben diese Elemente einen aktivierenden Effekt auf die jeweilige H3-Expression aus.

Die Konstrukte, die lediglich die TATA-Box und zwei CCAAT-Boxen als identifizierbare wichtige Elemente enthalten, haben eine durchaus vergleichbare Aktivität von $24 \%$ (M3) über $34 \%(\mathrm{H} 3)$ bis $42 \%$ (K4, jeweils bezogen auf den $\mathrm{H} 3 / \mathrm{n}$ Promotor). Da es aufgrund von Sequenzvergleichen die einzigen Elemente sind, die die Ähnlichkeit der Aktivitäten begründen können, sind die TATA-Box und die beiden CCAAT-Boxen offenbar die wesentlichen Elemente für die Aktivität der Konstrukte.

Die Deletionsreihen geben zwar im Detail keine Auskunft über die relevanten cisElemente. Eine Rumpfstruktur der H3-Promotoren mit der TATA-Box, der proximalen CCAAT-Box und einer zweiten CCAAT-Box wird jedoch deutlich. Darüber hinaus existieren zum Teil, je nach H3-Gen, ein bis zwei weitere CCAAT-Boxen oder eine ATF-Box, die vermutlich für die höheren Aktivitäten der längeren PromotorKonstrukte ursächlich sind. Die Ähnlichkeit in dieser Rumpfstruktur ist ein Hinweis darauf, dass alle H3-Gene nach dem gleichen prinzipiellen Mechanismus reguliert werden.

\subsubsection{Aktivierungs-Effekt des $\mathrm{H} 2 \mathrm{~A} / \mathrm{m}$-Gens}

In den Deletionsexperimenten wurde ein aktivierender Effekt des $\mathrm{H} 2 \mathrm{~A} / \mathrm{m}$-Gens auf die H3/m-Promotoraktivität ausgemacht. Weitere Reportergenassays mit neuen Konstrukten ergaben, dass das $\mathrm{H} 2 \mathrm{~A} / \mathrm{m}$-Gen auch auf den H3/k-Promotor, nicht jedoch auf den SV40-Promotor aktivierend wirkte.

Die Bereiche upstream der proximalen H3-Promotoren von 500 bp bis 1900 bp Abstand zum Transkriptionsstart spielten in den Reportergenassays je nach Gen eine unterschiedliche Rolle: Beim $\mathrm{H} 3 / \mathrm{h}$ - und $\mathrm{H} 3 / \mathrm{k}-$ Gen ergab sich keine Steigerung 
der Aktivität durch die upstream gelegenen Bereiche, beim H3/d- und H3/n-Gen verdoppelte sich die Promotoraktivität durch diese Bereiche, beim H3/i-Gen nahm die Promotoraktivität mit zunehmender Länge stetig zu und beim H3/m-Gen verdreifachte sich die Promotoraktivät durch den oberhalb gelegenen Bereich. Beim H3/d- und beim H3/n-Gen wurde die Ursache der Aktivitätssteigerung durch den oberhalb gelegenen Bereich bisher nicht herausgearbeitet. Beim H3/m-Gen wurde die Promotoraktivität durch den Bereich verdreifacht, der das komplette $\mathrm{H} 2 \mathrm{~A} / \mathrm{m}-\mathrm{Gen}$ enthält. Die aktivierende Wirkung des $\mathrm{H} 2 \mathrm{~A} / \mathrm{m}$-Gens hätte dadurch zustande kommen können, dass die Transkription des Gens nicht korrekt terminiert wurde und somit eine polycistronische mRNA mit dem Reportergen am Ende gebildet wurde. Um diese Möglichkeit auszuschließen, wurde ein Konstrukt hergestellt, bei dem hinter das $\mathrm{H} 2 \mathrm{~A} / \mathrm{m}$-Gen ein synthetisches Poly(A)-Signal einkloniert wurde, das dem pGL3basic-Vektor (siehe Abbildung 4 $k_{1}$ ) entnommen wurde,. In weiteren Versuchsreihen wurden zwei Konstrukte kloniert, bei denen das $\mathrm{H} 2 \mathrm{~A} / \mathrm{m}-\mathrm{Gen}$ ganz oder teilweise invertiert wurde (Abbildung 24\$2). Die aktivierende Wirkung des $\mathrm{H} 2 \mathrm{~A} / \mathrm{m}-\mathrm{Gens}$ blieb bei allen Konstrukten erhalten, obwohl die Konstrukte aufgrund ihrer Orientierung oder aufgrund der Anwesenheit eines Poly(A)-Signals nicht mehr in der Lage waren, polycistronische mRNA herzustellen. Eine polycistronische mRNA schied damit als Erklärung für die erhöhte Promotoraktivität aus.

Die Versuche zeigten außerdem, dass die aktivierende Wirkung des H2A/m-Gens von seiner Orientierung unabhängig war. Dies ist eine Eigenschaft, die Enhancer kennzeichnet, und führte zur Untersuchung, ob das $\mathrm{H} 2 \mathrm{~A} / \mathrm{m}-\mathrm{Gen}$ auch auf die Aktivität anderer Promotoren stimulierend wirken würde. Hierzu wurde das Gen in den pGL3promoter Vektor kloniert, der entwickelt wurde, um DNA-Fragmente auf Enhancerwirkung zu testen. Das Gen aktivierte den SV40-Promotor im pGL3promoter Konstrukt jedoch nicht (Abbildung 26, 4 ). Das Gen ist nach diesem Befund kein genereller Enhancer. Als das $\mathrm{H} 2 \mathrm{~A} / \mathrm{m}$-Gen jedoch an vergleichbarer Position vor den H3/k-Promotor kloniert wurde, wurde der H3/k-Promotor in gleichem Maße wie

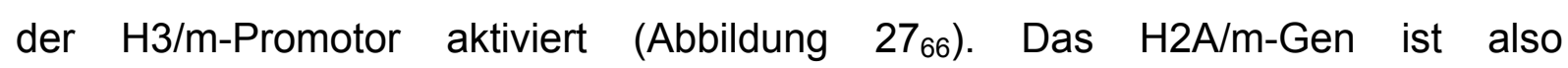
möglicherweise ein Aktivator, der spezifisch für Histongene oder sogar spezifisch für H3-Histongene ist.

Interessanterweise konnte die aktivierende Wirkung des $\mathrm{H} 2 \mathrm{~A} / \mathrm{m}-\mathrm{Gens}$ nicht näher eingegrenzt werden: Sowohl der $\mathrm{H} 2 \mathrm{~A} / \mathrm{m}$-Promotor als auch die $\mathrm{H} 2 \mathrm{~A} / \mathrm{m}$-kodierende Sequenz mit 3'-UTR besaßen für sich alleine schon eine aktivierende Wirkung, auch 
wenn diese jeweils etwas schwächer war als die des ganzen Fragmentes Abbildung 2563). Die aktivierende Wirkung scheint also von mehreren cis-Elementen im $\mathrm{H} 2 \mathrm{~A} / \mathrm{m}-\mathrm{Gen}$ auszugehen.

Es ist vorstellbar, dass Faktoren, die an das $\mathrm{H} 2 \mathrm{~A} / \mathrm{m}-\mathrm{Gen}$ binden, über ChromatinLoops direkt aktivierend auf das benachbarte H3-Gen wirken. Eine andere Möglichkeit besteht darin, dass große Proteinkomplexe an das $\mathrm{H} 2 \mathrm{~A} / \mathrm{m}-\mathrm{Gen}$ binden, die zugleich an das $\mathrm{H} 3 / \mathrm{m}-$ Gen binden oder zumindest die lokale Konzentration an geeigneten Transkriptionsfaktoren am H3/m-Gen erhöhen. Bei diesen Proteinkomplexen könnte es sich um die sogenannten Cajal Bodies handeln, die in der S-Phase an den Histongenclustern zu finden sind (Ma et al. 2000; Zhao et al. 2000). Diese Vermutung erklärt auch die Histongen-spezifische Aktivatoreigenschaft des $\mathrm{H} 2 \mathrm{~A} / \mathrm{m}-\mathrm{Gens}$, denn eine Rekrutierung von Histongen-spezifischen Cajal Bodies sollte vermutlich nur Histongene aktivieren.

Mit der Entdeckung der aktivierenden Wirkung des $\mathrm{H} 2 \mathrm{~A} / \mathrm{m}-\mathrm{Gens}$ auf die H3-Genexpression ergab sich die Frage, ob noch andere Histongene ihre benachbarten Gene aktivieren. In den Reportergenassays gab es Hinweise, dass neben dem H2A/m-Gen auch andere Gene aktivierend auf ihre Nachbarn wirken: Das H2A/c-Gen übte eine aktivierende Wirkung auf die H3/k-Promotoraktivität aus, wenn es komplett vorhanden war. (Die Wirkung war wesentlicher schwächer als die aktivierende Wirkung des $\mathrm{H} 2 \mathrm{~A} / \mathrm{m}$-Gens.) Auch das $\mathrm{H} 2 \mathrm{~B} / \mathrm{j}-\mathrm{Gen}$ wirkte offenbar stimulierend auf die H3/i-Aktivität. Einige der Histongene aktivieren also möglicherweise ihre Nachbarn. Diese gegenseitige Aktivierung könnte in der Rekrutierung von Histon-spezifischen Faktoren oder in der Ausbildung von Komplexen wie den Cajal Bodies bestehen, oder könnte eine Aktivierung der Chromatin-Umgebung beinhalten. Sie wäre auch eine Erklärung für die Clusteranordnung der replikationsabhängigen Histongene.

\subsection{Mutagenese im H3/k- und H3/m-Promotor}

Bereits die Promotor-Deletionsreihen gaben Hinweise, dass zwei CCAAT-Boxen für die Aktivität der H3-Promotoren entscheidend sind (siehe 5.2 Histon-H3Promotoranalyse (1) $_{1}$. Um diese Vermutung experimentell zu validieren, wurden die Promotoren des H3/k- und des H3/m-Gens mit Hilfe der absuchenden Mutagenese auf relevante cis-Elemente untersucht. Das Experiment sollte darüber hinaus klären, 
ob und mit welcher Aktivität weitere cis-Elemente an der Regulation der H3-Promotoren beteiligt sind.

Das $\mathrm{H} 3 / \mathrm{k}$ und das $\mathrm{H} 3 / \mathrm{m}$ Gen wurden für die Analyse ausgewählt, weil sie beide sowohl in den Zelllinien als auch im fötalen Gewebe recht stark exprimiert wurden und weil sie verschiedenen Histongenclustern zugehören. Die Mutagenese erfasste den ganzen proximalen H3/k-Promotor (99 bp bezogen auf den Transkriptionsstart) sowie den kompletten Downstream-Bereich des proximalen H3/m-Promotors (228 bp bezogen auf Transkriptitonsstart) und Mutationen im oberen Bereich des proximalen H3/m-Promotors, sowie Mutationen der Transkriptionsstartstelle und der 5'-UTR im $\mathrm{H} 3 / \mathrm{m}$-Promotor (Abbildung 29, 99 und Abbildung 30,0).

Im H3/k-Promotor führten Mutationen der TATA-Box und der beiden CCAAT-Boxen $z u$ erheblichen Aktivitätsverlusten. Mutationen der TATA-Box und der proximalen CCAAT-Box führten sogar zu einem nahezu vollständigen Aktivitätsverlust. Die TATA-Box und die beiden CCAAT-Boxen offenbarten sich so als die wesentlichen cis-Elemente im H3/k-Promotor. Ein weiterer Bereich knapp downstream der distalen CCAAT-Box, dessen Mutation zu einer 50\%igen Aktivitätssenkung führte, spielt möglicherweise noch eine zusätzliche Rolle. Der Bereich umfasst eine potentielle c-myb-Bindungsstelle (MatInspektor V2.2, Quandt et al. (1995)). Möglich wäre jedoch auch, dass dieser Bereich für die optimale Bindung eines Proteins an die distale CCAAT-Box nötig ist. Die Mutationen der übrigen Bereiche führten zu keiner bedeutenden Aktivitätsabnahme. Diese Bereiche spielen somit (unter den gewählten experimentellen Bedingungen) für die Aktivität des H3/k-Promotors keine Rolle.

Die absuchende Mutagenese beim H3/m-Promotor zeigte wie beim H3/k-Promotor, dass drei Elemente für die Aktivität des Promotors essenziell sind: die TATA-Box und die beiden CCAAT-Boxen. Darüber hinaus war die ATF-Box für eine vollständige Aktivität vonnöten. Mutationen der übrigen Bereiche im H3/m-Promotor, auch der Transkriptionsstartstelle, führten zu keinem Aktivitätsverlust. Somit sind offenbar lediglich 4 Elemente für die Funktion des H3/m-Promotors entscheidend: TATA-Box, zwei CCAAT-Boxen und eine ATF-Box. Eine Mutation innerhalb der 5'UTR-Sequenz führte sogar zu einer Aktivitätssteigerung von mehr als $100 \%$. Es ist unklar, ob es sich dabei um einen transkriptionalen oder posttranskriptionalen Effekt handelt. Im Unterschied zum H3/k-Promotor führten im H3/m-Promotor Mutationen der TATABox und der proximalen CCAAT-Box zu keinem vollständigen Aktivitätsverlust. 
Möglicherweise verhindert die ATF-Box im H3/m-Promotor einen vollständigen Aktivitätsverlust nach Ausfall der TATA- bzw. proximalen CCAAT-Box.

Die absuchenden Mutagenesen im H3/k- und H3/m-Promotor zeigen also, dass zwei CCAAT-Boxen und die TATA-Box die entscheidenden cis-Elemente in den H3-Promotoren sind. Damit zeigt sich die Bedeutung multipler CCAAT-Boxen für die H3-Promotoraktivität. Mantovani (1998) fand interessanterweise bei der Untersuchung von 178 CCAAT-Boxen, dass viele Zellzyklus-regulierte Promotoren, z.B cdc2, E2F-1 oder cdc25, zwei oder mehr CCAAT-Boxen enthalten. Auch die bipartiten Histon-H2A/H2B-Promotoren enthalten multiple CCAAT-Boxen (Trappe et al. 1999).

Im Vergleich mit den Promotoren der übrigen replikationsabhängigen Histongenklassen besitzten die H3-Promotoren eine erstaunlich geringe Zahl und Vielfalt von relevanten cis-Elementen:

1. Im H1-Promotor wurden 6 verschiedene cis-Elemente beschrieben (siehe 1.3.1 H1-Promotoren;) (Coles und Wells 1985; Gallinari et al. 1989; Duncliffe et al. 1995; Meergans et al. 1998; Ohshima et al. 2003). Zwei davon finden sich in den H3-Promotoren wieder: eine TATA-Box und eine proximale CCAAT-Box, die den gleichen Abstand zur TATA-Box aufweist wie in den H3-Promotoren. Nach Gallinari et al. (1989) bindet an die proximalen CCAAT-Boxen der H1-Promotoren der noch nicht vollständig charakterisierte Faktor H1TF2. Eine Bindung des Faktors H1TF2 an die H3-Promotoren konnte jedoch nicht beobachtet werden (siehe $4.11_{\$ 0}$ ). Es ist somit unklar, ob die proximalen CCAATBoxen der H3-Promotoren und der H1-Promotoren die gleiche Funktion haben.

2. Die bipartiten H2A/H2B-Promotoren unterteilen sich in zwei Gruppen (siehe 1.3.2 H2A/H2B-Promotoren, 0 ) (Albig et al. 1999). In den Gruppe-I-Promotoren befinden sich zu jeder Seite eine TATA-Box, drei CCAAT-Boxen und zwei Oct-1Boxen (Sive und Roeder 1986; Trappe et al. 1999). In den Gruppe-II-Promotoren befinden sich zusätzlich 4 weitere cis-Elemente (siehe 1.3.2 H2A/H2BPromotoren $_{0}$ ). Eine Gemeinsamkeit zu den H3-Promotoren besteht in beiden Gruppen neben den TATA-Boxen im Auftreten multipler CCAAT-Boxen. Da noch keine Faktoren beschrieben wurden, die an die H2A/H2B-CCAAT-Boxen binden, ist es offen, ob diese Boxen die gleiche Funktion wie die CCAAT-Boxen der H3-Promotoren besitzen. Interessant ist jedoch die bereits erwähnte Tatsache, 
dass die Promotoren vieler Zellzyklus-regulierter Gene multiple CCAAT-Boxen enthalten.

3. Die H4-Promotoren besitzen eine TATA-Box und zwei aktivierende Bereiche (Site I und Site II) mit insgesamt fünf cis-Elementen (siehe 1.3.4 H4Promotoren $_{3}$ ) (Pauli et al. 1987; van Wijnen et al. 1989; Ramsey-Ewing et al. 1994; Birnbaum et al. 1995). Abgesehen von der gemeinsamen Anwesenheit einer TATA-Box besteht keine Ähnlichkeit zu den H3-Promotoren.

Die geringe Ähnlichkeit des in der vorliegenden Arbeit bestimmten H3-Promotoraufbaus insbesondere mit dem H4-Promotoraufbau bedeutet, dass es in der Zelle offenbar unterschiedliche Mechanismen gibt, um die Höhe und Zellzyklusabhängigkeit der Expression der replikationsabhängigen Histongene zu regulieren.

Die in der vorliegenden Arbeit identifizierten cis-Elemente in den replikationsabhängigen $\mathrm{H} 3$-Promotoren unterscheiden sich von den identifizierten relevanten cis-Elementen in den Promotoren der H3-Replacement-Histongene H3.3A (drei putative Sp1-Elemente) (Frank et al. 2003) und H3.3B (ein Oct- und ein CRE/TRE-Element) (Witt et al. 1997). Damit spiegeln sich die Unterschiede im Expressionsverhalten der replikationsabhängigen H3-Gene und der ReplacementH3-Gene in den Promotoren wieder.

\subsubsection{Mutagenese von putativen HiNF-D Bindungsstellen}

In der vorliegenden Arbeit wurden zwei von van den Ent et al. (1994) auf Grund von Sequenzhomologien postulierte HiNF-D-Bindungsstellen (zu HiNF-D siehe 1.3.4 Promotoren $_{3}$ und 1.3.3 H3-Promotoren ${ }_{1}$ ) im H3/m-Promotor überprüft. Um ihre Funktion zu testen, wurden beide putativen HiNF-D-Bindungsstellen mutiert und die Aktivität der mutierten Promotoren in Reportergenassays überprüft: die putative Bindungsstelle, die knapp unterhalb der ATF-Box liegt, schien für die Aktivität des Promotors keine Rolle zu spielen. Die andere putative Bindungsstelle, die knapp oberhalb der distalen CCAAT-Box von $\mathrm{H} 3 / \mathrm{m}$ positioniert ist, war für die Promotoraktivität wichtig. Ihre Mutation führte zum gleichen Aktivitätsverlust wie die Mutation der knapp downstream liegenden CCAAT-Box bzw. die Mutation der CCAAT-Box mitsamt der putativen HiNF-D-Bindungsstelle (Abbildung 336). Das bedeutet, dass das putative HiNF-D-Element nur zusammen mit der distalen CCAAT-Box funktionieren kann und umgekehrt. Es handelt sich im Grunde um ein 
Element oder um ein Komposit-Element. Den Daten kann jedoch nicht entnommen werden, welcher Faktor bzw. welche Faktoren hier in vivo binden.

Von den von van den Ent et al. (1994) aufgrund von Sequenzähnlichkeiten postulierten zwei HiNF-D-Bindungsstellen im H3/m-Promotor war also lediglich eine in den Reportergenassays funktional. Die Sequenzähnlichkeiten der postulierten HiNF-D-Bindungsstellen sind allerdings schwach, es darf meiner Meinung nach von keiner signifikanten Konsensussequenz gesprochen werden. Die in der vorliegenden Arbeit durchgeführten Mutationsexperimente liefern keine eindeutigen Anhaltspunkte für eine Beteiligung von HiNF-D an der H3/m-Promotorregulation.

Für eine Beteiligung von HiNF-D an der Regulation der übrigen H3-Promotoren gibt es keine Hinweise: Zum einen kommt die ATF-Box, die von van den Ent et al. (1994) als oberer Anker des HiNF-D-Faktors postuliert wurde, nur in zwei H3-Promotoren vor: $H 3 / m$ und $H 3 / n$, und sie ist in diesen beiden Promotoren auch noch an unterschiedlichen Stellen lokalisiert (Abbildung 7 \$6). Die Promotoren des H3/a-, H3/b-, H3/c-, H3/d-, H3/f-, H3/h-, H3/i-, H3/j- und H3/k-Gens enthalten keine ATFBox. Des weiteren existiert kein Sequenzmotiv in den H3-Promotoren, das man spezifisch HiNF-D zuordnen kann. Außerdem spielt, wie die hier durchgeführten Experimente gezeigt haben, im H3/k-Promotor der Bereich knapp upstream der distalen CCAAT-Box, der im $\mathrm{H} 3 / \mathrm{m}$-Promotor die relevante putative HiNF-DBindungsstelle enthält, keine Rolle für dessen Aktivität (siehe Konstrukt K5mut3 in Abbildung $323_{3}$ ). Es ist daher als unwahrscheinlich anzunehmen, dass es in den übrigen H3-Promotoren besondere HiNF-D Bindungstellen gibt.

Die Frage, ob und gegebenenfalls wie HiNF-D in vivo an der Regulation der H3Histongene mitwirkt, bleibt unklar. Luong et al. (2002) entfernten in Mäusen homozygot genetisch den C-Terminus' des CDP/Cut-Proteins, das ein Bestandteil des HiNF-D-Komplexes ist. Obwohl kein HiNF-D-Komplex mehr nachweisbar war, wurde insgesamt keine Störung der Histongen-Expression beobachtet. Die in der vorliegenden Arbeit durchgeführten Sequenzvergleiche, Deletions- und Mutationsexperimente liefern keine Anhaltspunkte für eine Beteiligung von HiNF-D an der Promotorregulation der humanen H3-Histongene. 


\subsubsection{Einfluss der Sequenz der CCAAT-Boxen im H3/k-Promotor}

Auf Grund der Ergebnisse der absuchenden Mutagenese sind die beiden CCAATBoxen im H3/k-Promotor für die Regulation des Promotors entscheidend. Weiter deuten die Veränderungen der Sequenzen der CCAAT-Boxen auf CBF/NF-Y als relevanten Transkriptionsfaktor hin. Der heterotrimere, ubiquitäre Transkriptionsfaktor $\mathrm{CBF} / \mathrm{NF}-\mathrm{Y}$ ist an der Aktivierung einer großen Anzahl von humanen Genen beteiligt. Auch ist die Aktivierung vieler Zellzyklus-regulierter Gene beschrieben (Maity und de Crombrugghe 1998). Seine DNA-Sequenzspezifität wurde von Bi et al. (1997) als YRRCCAATCA bestimmt ( $Y=$ Pyrimidinbase, $R=$ Purinbase). Mantovani (1998) fand in einem Vergleich von $178 \mathrm{NF}$-Y-bindenden CCAAT-Boxen das präferenzielle Motiv CRRCCAAT(C/G)(A/G)G(A/C)G. Es sind jedoch eine Vielzahl weiterer CCAAT-Boxbindender Proteine beschrieben, die an die in der vorliegenden Arbeit identifizierten CCAAT-Boxen in den H3-Promotoren binden könnten, um sie zu aktivieren oder zu deaktivieren:

1. Der tetramere Faktor H1TF2 („H1 Transcription Factor 2") wurde als CCAATBox-bindender Transkriptionsaktivator der H1-Gene isoliert (Martinelli und Heintz 1994). Der in ersten Ansätzen charakterisierte Faktor besteht aus vier Polypeptidketten. Seine genaue DNA-Sequenzspezifität ist nicht bekannt.

2. Die Y-Box-Proteine sind multifunktionale Regulatoren der Genexpression, z.B. YB-1 (dbpB) (Didier et al. 1988) und dbpA (Ito et al. 1994). Sie können an doppel- und einzelsträngige CCAAT-Boxen binden und präferieren das SequenzMotiv TTGGCCAATCAG (Y-Box), das eine spezifischere Variante des NF-YMotivs ist.

3. CBP/cycA ist ein CCAAT-Box-bindender Proteinkomplex, der in die Zellzyklusregulation des Cyclin A-Promotors involviert ist. Er besteht aus NF-Y und einem noch nicht näher charakterisierten 115 kDa-Protein (Kramer et al. 1997). Seine genaue DNA-Sequenzspezifität ist nicht bekannt.

4. CBP/cdc2 ist ein CCAAT-Box-bindenes Protein der Masse $110 \mathrm{kDa}$, das in transformierten Zellen überexprimiert ist und den cdc2-Promotor aktiviert (Tanimoto et al. 1998).

5. HSP-CBF ist ein CCAAT-Box-bindendes $114 \mathrm{kDa}$-Protein, welches nach Lum et al. (1990) den hsp70-Promotor aktiviert. Imbriano et al. (2001) zeigten, dass 
HSP-CBF unter ihren experimentellen Bedingungen nicht direkt an DNA bindet, sondern ein Koaktivator von NF-Y ist.

6. Das Protein CDP/Cut wurde als CCAAT-Box bindender Repressor beschrieben (siehe Review Nepveu (2001)). Seine DNA-Bindungseigenschaften sind noch unzureichend charakterisiert. In in vitro-Analysen bindet es präferenziell an zwei benachbarte CCAAT-Boxen, deren Sequenz aber durchaus Mutationen in dem CCAAT-Motiv zulässt (Moon et al. 2000). CDP/Cut spielt vor allem für die Regulation von Genen eine Rolle, die erst in einem bestimmten Stadium der Differenzierung angeschaltet werden. Last et al. (1998) beschrieben eine reprimierende Wirkung von drei Elementen innerhalb der ersten 200 Basenpaare der H4/n kodierenden Sequenz, an die CDP/Cut band. Erstaunlicherweise enthalten die drei identifizierten Repressor-Elemente jedoch keine CCAATBoxen. Der HiNF-D-Komplex (siehe 1.3.4 H4-Promotoren mit dem Bestandteil CDP/Cut wurde im Gegensatz zum nackten CDP/Cut ursprünglich als Transkriptionsaktivator beschrieben (van Wijnen et al. 1996). Gupta et al. (2003) berichteten aber von einer reprimierenden Wirkung von CDP/Cut als Teil des HiNF-D-Komplexes auf die H4/n-Promotoraktivität.

Einige der CCAAT-Box bindenden Proteine haben aus verschiedenen Gründen keinen Einfluss auf die H3-Promotoraktivität: Das CCAAT-Box-bindende Protein c/EBP dürfte keine Bedeutung für die H3-Promotorregulation haben, da es vorwiegend in differenzierten Zellen Zelltyp-spezifisch exprimiert wird (LekstromHimes und Xanthopoulos 1998). Auch der CCAAT-Box-bindende Silencer CTF/NF-I dürfte aufgrund seiner DNA-Sequenzspezifität, die in den H3-Promotoren nicht zu finden ist, nicht in die H3-Promotorregulation involviert sein (Osada et al. 1997).

Die in der vorliegenden Arbeit identifizierten zwei CCAAT-Boxen im H3/k-Promotor wurden mit einer spezifischeren Mutagenese untersucht, um die Sequenzerfordernisse des dort bindenden aktivierenden Faktors bzw. der dort bindenden aktivierenden Faktoren spezifischer zu bestimmen. Im Detail war zu klären, welche Basen in und um die CCAAT-Box für die Funktion der CCAAT-Box im H3/k-Promotor nötig sind.

Nepveu (2001) beschrieb, dass das Protein CDP/Cut als Bestandteil von HiNF-D auch an CCAAT-Boxen binden kann, in denen das zentrale "CCAAT“-Motiv zum Beispiel zu "ACGAT" mutiert ist. Entsprechende spezifische Mutationen führten bei 
beiden der H3/k-CCAAT-Boxen zum vollständigen Aktivitätsverlust (siehe Abbildung $31_{72}$ und Abbildung 32 3 ). Wurden die beiden H3/k-CCAAT-Boxen durch Mutation der umliegenden Basen zu Nicht-Konsensus-NF-Y-CCAAT-Boxen mutiert, führte dies zum vollständigen Aktivitätsverlust. Somit tolerierten beide H3/k-CCAAT-Boxen keine Änderung im zentralen CCAAT-Motiv und sie tolerierten auch keine Änderung der umliegenden Basen zu einer Nicht-Konsensus-NF-Y-Sequenz. Somit ist es unwahrscheinlich, dass der Proteinkomplex HiNF-D mit seinem Bestandteil CDP/Cut eine aktivierende Rolle in der $\mathrm{H} 3 / \mathrm{k}$-Promotorregulation besitzt. Eine Beteiligung von CDP/Cut als Repressor (im Wechselspiel mit CCAAT-Box-Aktivatoren) an der H3-Promotorregulation kann allerdings aufgrund der Daten nicht ausgeschlossen werden.

Das Verhalten deutet auf CBF/NF-Y als relevanten Transkriptionsfaktor hin. Man kann die meisten der übrigen, oben beschriebenen CCAAT-Box-bindenden Proteine nicht ausschließen, da deren Bindungseigenschaften noch unzureichend bekannt sind bzw. mit der CBF/NF-Y-Bindungssequenz überlappen.

\subsubsection{Einfluss der Lage der CCAAT-Boxen im H3/k-Promotor}

Veränderungen des Abstands zwischen den beiden CCAAT-Boxen sowie zwischen der proximalen CCAAT-Box und der TATA-Box im H3/k-Promotor führten zu starken Aktivitätsverlusten.

Nach den Deletions- und Mutationsexperimenten beruht die Funktion der H3-Promotoren auf einer TATA-Box und zwei CCAAT-Boxen, die in etwa NF-YKonsensus-CCAAT-Boxen entsprechen. Ein Sequenzvergleich der H3-Promotoren zeigt, dass der Abstand zwischen der TATA-Box und der proximalen CCAAT-Box hochkonserviert ist (22 bp Start zu Start, siehe Abbildung 6 $\beta_{5}$ ). Auch der Abstand zwischen den beiden CCAAT-Boxen beträgt in den meisten Promotoren 41 oder 42 bp (Start zu Start). Dies entspricht in etwa vier Helixwindungen.

Eine Vergrößerung bzw. Verkleinerung des Abstandes der beiden CCAAT-Boxen hatte beim H3/k-Promotor Aktivitätsverluste zur Folge (Abbildung 3579). Dies zeigt, dass die Ähnlichkeit der Abstände zwischen den beiden CCAAT-Boxen in den $\mathrm{H} 3-$ Promotoren eine funktionale Bedeutung hat. Es zeigte sich, dass die H3/kPromotor-Konstrukte nur dann voll aktiv waren, wenn die beiden CCAAT-Boxen auf der gleichen Seite der Helix positioniert waren und das im Idealfall im Wildtyp- 
Abstand von vier Helixwindungen. Die Ergebnisse weisen auch darauf hin, dass die CCAAT-Box-bindenden aktivierenden Transkriptionsfaktoren nur dann voll wirken, wenn sie relativ zur TATA-Box eine bestimmte Position einnehmen. Möglich wäre, dass sich an den H3-Promotoren ein Aktivierungskomplex von Transkriptionsfaktoren mit definierter Struktur und begrenzter Flexibilität ausbildet, bei dem die Proteine, die an die CCAAT-Boxen binden, in einem Proteinkomplex miteinander verbunden sind. Für diese Hypothese spricht, dass die Promotorkonstrukte mit relativ zueinander auf der Helixachse verdrehten CCAAT-Boxen eine geringere Aktivität haben. Dies lässt sich damit erklären, dass sich ein möglicher Aktivierungkomplex bevorzugt auf einer Seite der Helixachse ausbildet.

Eine Vergrößerung des Abstandes zwischen TATA-Box und proximaler CCAAT-Box um 10 bzw. 11 Basen führte zu einem drastischen Aktivitätsverlust von 75\% (Abbildung 3478). Der beobachtete starke Aktivitätsabfall deutet an, dass ein Transkriptionsfaktor oder ein Transkriptionsfaktor-Komplex, der an die proximale CCAAT-Box bindet, in einer räumlich klar definierten Art und Weise wirkt. Die Nähe zur TATA-Box deutet an, dass der Faktor bzw. Komplex direkt mit den generellen Transkriptionsfaktoren interagiert, welche den RNA-Polymerase II-Initiationskomplex aufbauen. Bellorini et al. (1997) und Frontini et al. (2002) zeigten, dass der Faktor NF-Y mit dem generellen Transkriptionsfaktor TFII-D interagiert, der an TATA-Boxen bindet und den Aufbau des Polymerase II-Initiationskomplexes initiiert. Möglicherweise bindet also NF-Y an die proximale CCAAT-Box der H3-Promotoren und erleichtert bzw. stabilisiert die Bindung von TFII-D an die benachbarte TATA-Box in einer räumlich klar definierten Art und Weise.

\subsubsection{Bindung von Proteinen an die CCAAT-Boxen}

In EMSA-Analysen wurde eine Bindung des Transkriptionsfaktors CBF/NF-Y an die CCAAT-Boxen der $\mathrm{H} 3 / \mathrm{k}$ - und $\mathrm{H} 3 / \mathrm{m}$-Promotoren gefunden. Eine Bindung von weiteren Transkriptionsfaktoren an die CCAAT-Boxen wurde nicht beobachtet.

In EMSA-Analysen mit Oligonukleotiden, die die CCAAT-Boxen enthielten, und Kernextrakt aus HeLa-Zellen wurden die Transkriptionsfaktoren gesucht, die an die CCAAT-Boxen binden. Es wurden jeweils beide CCAAT-Boxen der proximalen $\mathrm{H} 3 / \mathrm{m}$ - und H3/k-Promotoren als Oligonukleotide eingesetzt. Drei der vier untersuchten Oligonukleotide zeigten Bandshift-Doppelbanden, die in Art und 
Laufhöhe genau der Doppelbande glichen, die durch ein NF-YKonsensusoligonukleotid hervorgerufen wurde (Abbildung 36\%1 und Abbildung 37\%2). Darüber hinaus verschwanden die Doppelbanden spezifisch, wenn NF-YKompetitoroligonukleotid zugesetzt wurde. Die Doppelbanden wurden also mit hoher Sicherheit durch Bindung von NF-Y hervorgerufen. Die übrigen Banden, die in den EMSA-Assays mit den markierten CCAAT-Boxen auftraten, waren mit einer Ausnahme nicht spezifisch: die proximale CCAAT-Box des H3/k-Promotors (KProx) zeigte neben der NF-Y-Doppelbande eine weitere Bande, deren Ursache unbekannt ist. Da diese Bande sich jedoch von dem Oligonukleotid KProxmut (bei dem die proximale CCAAT-Box mutiert ist) aber nicht von dem NF-YKonsensusoligonukleotid kompetieren ließ, handelt es sich jedoch um einen Komplex, der nicht von der proximalen CCAAT-Box selbst, sondern vermutlich von einem angrenzenden Bereich ausgeht.

Somit zeigen die Ergebnisse, dass drei der vier CCAAT-Boxen mehr oder weniger gut NF-Y binden konnten. Um die Affinität der einzelnen CCAAT-Boxen für NF-Y zu vergleichen, wurden die CCAAT-Box-Oligonukleotide als Kompetitoren in EMSAExperimenten des NF-Y-Konsensusoligonukleotide eingesetzt (Abbildung 38,33). Die Bindung des NF-Y an die CCAAT-Boxen von $H 3 / k$ und $H 3 / m$ erwies sich als erheblich schwächer als die Bindung an die CCAAT-Box des NF-YKonsensusoligonukleotids. Dies erklärt die größere Intensität der NF-Y-Doppelbande des NF-Y-Konsensusoligonukleotids im Vergleich zu den NF-Y-Doppelbanden der H3-CCAAT-Boxen.

Die höchste Affinität für NF-Y hatten die KProx- und die MDist-CCAAT-Box, gefolgt von der KDist-CCAAT-Box mit schwächerer Affinität und der MProx-CCAAT-Box mit noch schwächerer Affinität. Die CCAAT-Boxen unterschieden sich also in ihrer Affinität für NF-Y. Interessanterweise ergaben die Reportergenassays, dass die proximale CCAAT-Box des H3/m-Promotors (MProx) auf einem Konstrukt für sich alleine (mit der TATA-Box) keine Aktivität besaß, während die proximale CCAAT-Box des H3/k-Promotors (KProx) für sich alleine (zusammen mit der TATA-Box) eine gewisse Aktivität zeigte. Dies ließe sich mit einer besseren NF-Y-Bindung an KProx erklären. Eine Deletion der MProx-Box im kompletten Promotor führte jedoch zu einem starken Aktivitätsabfall. Das zeigt die Wichtigkeit der MProx-Box für den H3/mPromotor. 
Liberati et al. (1999) konnten zeigen, dass NF-Y an zwei benachbarte CCAAT-Boxen kooperativ band. Diese Kooperativität war am höchsten, wenn die CCAAT-Boxen auf der gleichen Seite der Helix positioniert waren. Möglicherweise bindet NF-Y kooperativ an die CCAAT-Boxen der H3-Promotoren. Dies würde erklären, warum NF-Y trotz der eher schwachen Bindungsaffinität der einzelnen H3-CCAAT-Boxen für NF-Y ein aktivierender Transkriptionsfaktor in der H3-Histongenexpression sein könnte.

\subsection{Ausblick}

Die Ergebnisse der vorliegenden Arbeit bieten Anlass für vielfältige Forschungsrichtungen. Es wurde gezeigt, dass Tumorzelllinien ein aberrantes Expressionsmuster der H3-Histongene aufweisen und dass dies wahrscheinlich epigenetische Ursachen hat. Zukünftige Studien könnten erforschen, welche Strukturen diese epigenetische Aberration bedingen, und wie und wo diese Strukturen in Tumorzellen verglichen mit normalen diploiden Zellen auftreten. Diese Studien könnten fundamentale Regulationsmechanismen in der eukaryontischen Genregulation aufdecken und zugleich ein neues Licht auf die Anwendbarkeit von Tumorzellinien als Modellsysteme werfen.

Aus wissenschaftlicher Sicht ebenfalls interessant ist die Tatsache, dass einige der Histongene als Aktivatoren ihrer Histongen-Nachbarn fungieren. Künftige Studien könnten die Ursache dieses Verhaltens und damit einen möglicherweise wichtigen eukaryontischen Regulationsmechanismus aufklären.

In der vorliegenden Arbeit wurden als wesentliche Elemente der Histon-H3Promotoren eine TATA-Box und zwei CCAAT-Boxen identifiziert, die für optimale Funktion in einer bestimmten Art und Weise angeordnet sein müssen. In vitro wurde eine Bindung von CBF/NF-Y an die CCAAT-Boxen beobachtet. Da eine Vielzahl von CCAAT-Box-bindenden Faktoren beschrieben wurden, könnten zukünftige Studien die Bedeutung von CBF/NF-Y in vivo absichern und möglicherweise ein dynamisches Zusammenspiel mit anderen CCAAT-Box-bindenden Faktoren aufdecken. Da die CCAAT-Boxen in humanen Promotoren, besonders in Zellzyklusregulierten Promotoren, weit verbreitet sind, könnten die Studien ein weitergehendes Verständnis der CCAAT-Boxen und der CCAAT-Box-bindenden Faktoren ermöglichen. 
Da sich an dem Histon-H3/k-Promotor offenbar ein räumlich definierter Aktivierungskomplex ausbildet, könnte dieser Promotor ein interessanter Modellpromotor sein um zu erforschen, welche Strukturen sich an eukaryontischen Promotoren ausbilden und welche Vorgänge zur Transkriptionsinitiation führen. Die kleine Zahl von cis-Elementen (drei im H3/k-Promotor) könnte dabei ein Vorteil sein, da es die Komplexität der Untersuchungen vermindert. 


\section{Zusammenfassung}

Die Expression der Histongene und die Regulation der Histonproduktion ist essentiell für die Zellteilung. Für die vorliegende Arbeit wurde die Expression der $\mathrm{H} 3$-Histongene mit quantitativen RNase-Protektionsassays bestimmt. Als Probenmaterial dienten drei unterschiedliche humane fötale Gewebe (Blase, Leber und Lunge) und acht humane Zelllinien. Die drei fötalen Gewebe und die diploide Zellinie IMR-90 zeigten ein ähnliches H3-Expressionsmuster. Augenscheinlich spielten dort Zelltyp-spezifische Faktoren in der Expression der replikationsabhängigen $\mathrm{H} 3$-Histongene nur eine untergeordnete Rolle.

In den drei fötalen Geweben und der diploiden Zellinie IMR-90 beobachtete man bei zwei Genen ( $H 3 / m, H 3 / n)$ eine starke Expression, bei vier Genen ( $H 3 / b, H 3 / c, H 3 / i$ und $H 3 / k)$ eine mittelstarke und bei fünf Genen (H3/a, H3/d, H3/f, H3/h, H3/j) eine schwach ausgeprägte Expression. Im Gegensatz dazu zeigten die sieben Tumorzelllinien ein stark abweichendes, aberrantes H3-Expressionsmuster, das sich vor allem in einer Vielzahl von nicht oder nur schwach exprimierten H3-Genen zeigte. Die Aberration ließ sich nicht auf genetische Mutationen zurückführen, wie mit PCRAmplifikationen und Sequenzierung der PCR-Produkte gezeigt werden konnte. Weitergehend konnte durch exemplarische Promotor-Analysen ausgeschlossen werden, dass variierende Transkriptionsfaktor-Konzentrationen ursächlich sind für das abweichende H3-Expressionmuster in den Tumorzellinien. Da das abweichende H3-Expressionsmuster erblich ist (weil es charakteristisch für eine Zelllinie ist), aber weder genetische Ursachen hat noch von löslichen Faktoren bedingt ist, handelt es sich wahrscheinlich um einen epigenetischen Effekt. Wahrscheinlich verursachen epigenetische Faktoren auf der Ebene der Chromatinstruktur, z.B. DNA-Methylierung oder Histon-Modifizierung, die aberrante Expression.

Die Transkriptionsrate an den verschiedenen $\mathrm{H} 3-\mathrm{Histongenen}$ ist entscheidend für die H3-Expression. Um die Transkriptionsregulation der H3-Histongene zu erforschen, wurden in Reportergenassays mit Deletionsreihen die PromotorStrukturen der Gene H3/d, H3/h, H3/i, H3/k, H3/m und H3/n bestimmt. Mit Ausnahme von $\mathrm{H} 3 / \mathrm{i}$ hatten alle Promotoren schon bei Längen von 99-228 bp nahezu maximale Aktivität (funktionale Promotoren): H3/m 228 bp, H3/k 99 bp, H3/h 115 bp, H3/n 186 bp und H3/d 176 bp. Innerhalb dieser funktionalen Promotoren befinden sich als 
putative cis-Elemente eine TATA-Box, eine proximale und eine distale CCAAT-Box, sowie ggf. weitere CCAAT-Boxen oder eine ATF-Box.

Zusätzlich steigern bestimmte benachbarte Gene die Aktivität der H3-Promotoren. Unabhängig von der Einbaurichtung verstärkte das $\mathrm{H} 2 \mathrm{~A} / \mathrm{m}-\mathrm{Gen}$ die Aktivität des H3/m-Promotors (Faktor 3) und des H3/k-Promotors - aber nicht die Aktivität des SV40-Promotors. Das $\mathrm{H} 2 \mathrm{~A} / \mathrm{m}-\mathrm{Gen}$ zeigt Eigenschaften eines (H3-)Histongenspezifischen Aktivators. Andere Histongene wirken auch aktivierend auf $\mathrm{H} 3-$ Promotoren: Das H2A/c-Gen auf den H3/k-Promotor und das H2B/j-Gen auf den H3/i-Promotor. Diese Beobachtung lässt die Clusteranordnung der replikationsabhängigen Histongene in einer neuen Sicht erscheinen, da sich die Histongene scheinbar gegenseitig aktivieren.

Die Promotoren des H3/m- und des H3/k-Gens wurden mit Hilfe der absuchenden Mutagenese auf relevante cis-Elemente untersucht. Im H3/m-Promotor wurden die TATA-Box, die proximale und distale CCAAT-Box und eine ATF-Box identifiziert. Im H3/k-Promotor wurden als wesentliche Elemente die TATA-Box und die proximale und distale CCAAT-Box identifiziert. Der funktionelle Grundaufbau der H3-Promotoren besteht also aus einer TATA-Box, der proximalen CCAAT-Box und der distalen CCAAT-Box (Abbildung 41,08). In den beiden CCAAT-Boxen waren die fünf Basen des CCAAT-Motivs vollständig für die Funktion des Promotors nötig. Die umliegenden Basen entsprechen für die Funktion in etwa einer NF-YKonsensusbindungstelle. In EMSA-Analysen band der Transkriptionsfaktor CBF/NF-Y mit unterschiedlicher Intensität an die CCAAT-Boxen des H3/k- und des H3/m-Promotors. Weitere spezifische Banden wurden nicht beobachtet. Die Bindungsaffinität des Faktors NF-Y für die CCAAT-Boxen war niedriger als für eine NF-Y-Konsensusbindungsstelle.

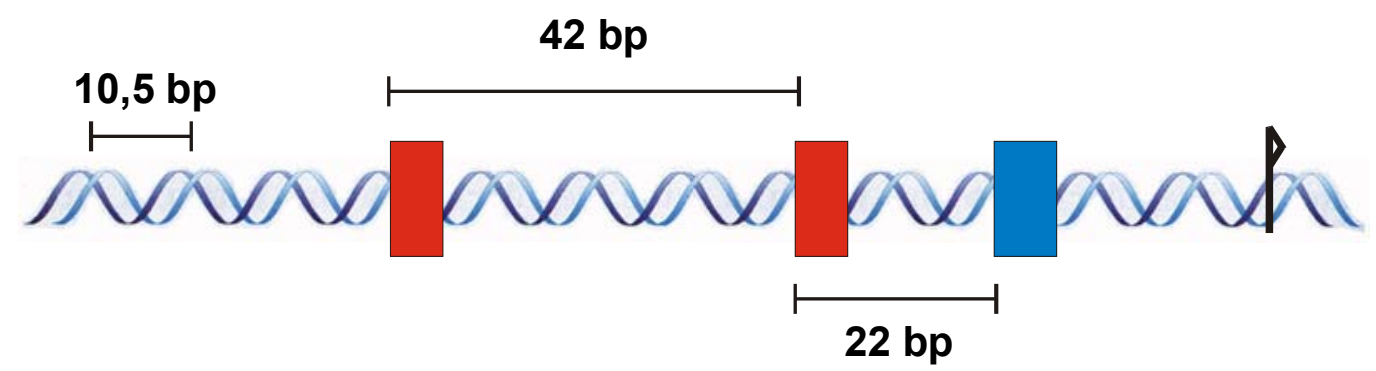

Abbildung 41: Der funktionelle Grundaufbau der H3-Promotoren (schematische Darstellung)

Blaue Windungen: DNA-Doppelhelix (10,5 bp pro Windung); Rote Boxen: CCAAT-Boxen (nur die zentralen 5 bp sind rot markiert); blaue Box: TATA-Box (das 6 bp-TATA\{T/A\}A-Motiv ist markiert); Fahne: Transkriptionsstart. Der Transkriptionsstart ist in den 11 H3-Gene durchschnittlich 29,5 bp vom Start der TATA-Box entfernt (Bandbreite 21-35 bp). 
Für die volle Aktivität des $\mathrm{H} 3 / \mathrm{k}$-Promotors durften die Wildtyp-Abstände zwischen den CCAAT-Boxen nicht verändert werden. Wenn man in Reportergenkonstrukten die beiden CCAAT-Boxen durch Insertion oder Deletion einer halben Helixwindung (5 bp) zueinander verdrehte, war der Aktivitätsverlust hoch; aber auch eine Verlängerung um eine Helixwindung (10 bp) führte zu merklicher Aktivitätsabnahme. Auch eine Verlängerung des Abstandes zwischen proximaler CCAAT- und TATABox hatte einen drastischen Aktivitätsverlust zur Folge. Wahrscheinlich bildet der H3-Promotor mit den Transkriptionsfaktoren einen Aktivierungskomplex definierter Struktur und begrenzter Flexibilität. 


\section{Literaturverzeichnis}

Adesnik, M., M. Salditt, W. Thomas und J. E. Darnell (1972). "Evidence that all messenger RNA molecules (except histone messenger RNA) contain Poly $(A)$ sequences and that the Poly $(A)$ has a nuclear function." $\underline{\mathrm{J} \mathrm{Mol} \mathrm{Biol}}$ 71(1): 21-30.

Ahn, J. und J. R. Gruen (1999). "The genomic organization of the histone clusters on human 6p21.3." Mamm Genome 10(7): 768-70.

Albig, W., B. Bramlage, K. Gruber, H. G. Klobeck, J. Kunz und D. Doenecke (1995). "The human replacement histone H3.3B gene (H3F3B)." Genomics 30(2): 264-72.

Albig, W. und D. Doenecke (1997). "The human histone gene cluster at the D6S105 locus." Hum Genet 101(3): 284-94.

Albig, W., J. Ebentheuer, G. Klobeck, J. Kunz und D. Doenecke (1996). "A solitary human H3 histone gene on chromosome 1." Hum Genet 97(4): 486-91.

Albig, W., E. Kardalinou, B. Drabent, A. Zimmer und D. Doenecke (1991). "Isolation and characterization of two human $\mathrm{H} 1$ histone genes within clusters of core histone genes." Genomics 10(4): 940-8.

Albig, W., P. Kioschis, A. Poustka, K. Meergans und D. Doenecke (1997a). "Human histone gene organization: nonregular arrangement within a large cluster." Genomics 40(2): 314-22.

Albig, W., T. Meergans und D. Doenecke (1997b). "Characterization of the H1.5 gene completes the set of human H1 subtype genes." Gene 184(2): 141-8.

Albig, W., R. Trappe, E. Kardalinou, S. Eick und D. Doenecke (1999). "The human H2A and H2B histone gene complement." Biol Chem 380(1): 7-18.

Allan, J., P. G. Hartman, C. Crane-Robinson und F. X. Aviles (1980). "The structure of histone H1 and its location in chromatin." Nature 288(5792): 675-9.

Allen, B. S., J. L. Stein, G. S. Stein und H. Ostrer (1991). "Single-copy flanking sequences in human histone gene clusters map to chromosomes 1 and 6." Genomics 10(2): 486-8.

Andrews, P. W. (1988). "Human teratocarcinomas." Biochim Biophys Acta 948(1): 17-36.

Aziz, F., A. J. van Wijnen, J. L. Stein und G. S. Stein (1998). "HiNF-D (CDP-cut/CDC2/cyclin A/pRBcomplex) influences the timing of IRF- 2-dependent cell cycle activation of human histone $\mathrm{H} 4$ gene transcription at the G1/S phase transition." J Cell Physiol 177(3): 453-64.

Bellorini, M., D. K. Lee, J. C. Dantonel, K. Zemzoumi, R. G. Roeder, L. Tora und R. Mantovani (1997). "CCAAT binding NF-Y-TBP interactions: NF-YB and NF-YC require short domains adjacent to their histone fold motifs for association with TBP basic residues." Nucleic Acids Res 25(11): 2174-81.

Bi, W., L. Wu, F. Coustry, B. de Crombrugghe und S. N. Maity (1997). "DNA binding specificity of the CCAAT-binding factor CBF/NF-Y." J Biol Chem 272(42): 26562-72.

Birnbaum, M. J., K. L. Wright, A. J. van Wijnen, A. L. Ramsey-Ewing, M. T. Bourke, T. J. Last, F. Aziz, B. Frenkel, B. R. Rao, N. Aronin und et al. (1995). "Functional role for Sp1 in the transcriptional amplification of a cell cycle regulated histone H4 gene." Biochemistry 34(23): 7648-58. 
Bowman, T. L. und M. M. Hurt (1995). "The coding sequences of mouse H2A and H3 histone genes contains a conserved seven nucleotide element that interacts with nuclear factors and is necessary for normal expression." Nucleic Acids Res 23(16): 3083-92.

Bowman, T. L., N. K. Kaludov, M. Klein und M. M. Hurt (1996). "An H3 coding region regulatory element is common to all four nucleosomal classes of mouse histone-encoding genes." Gene 176(1-2): 1-8.

Brown, D. T., S. E. Wellman und D. B. Sittman (1985). "Changes in the levels of three different classes of histone mRNA during murine erythroleukemia cell differentiation." Mol Cell Biol 5(11): 2879-86.

Brush, D., J. B. Dodgson, O. R. Choi, P. W. Stevens und J. D. Engel (1985). "Replacement variant histone genes contain intervening sequences." Mol Cell Biol 5(6): 1307-17.

Bucher, P. (1990). "Weight matrix descriptions of four eukaryotic RNA polymerase II promoter elements derived from 502 unrelated promoter sequences." J Mol Biol 212(4): 563-78.

Bucher, P. und E. N. Trifonov (1988). "CCAAT box revisited: bidirectionality, location and context." $\underline{J}$ Biomol Struct Dyn 5(6): 1231-6.

Coles, L. S. und J. R. Wells (1985). "An H1 histone gene-specific 5' element and evolution of H1 and H5 genes." Nucleic Acids Res 13(2): 585-94.

Dalton, S. und J. R. Wells (1988). "A gene-specific promoter element is required for optimal expression of the histone H1 gene in S-phase." Embo J 7(1): 49-56.

DeLisle, A. J., R. A. Graves, W. F. Marzluff und L. F. Johnson (1983). "Regulation of histone mRNA production and stability in serum-stimulated mouse 3T6 fibroblasts." Mol Cell Biol 3(11): 19209.

Didier, D. K., J. Schiffenbauer, S. L. Woulfe, M. Zacheis und B. D. Schwartz (1988). "Characterization of the cDNA encoding a protein binding to the major histocompatibility complex class II Y box." Proc Natl Acad Sci U S A 85(19): 7322-6.

Doenecke, D., W. Albig, H. Bouterfa und B. Drabent (1994). "Organization and expression of H1 histone and $\mathrm{H} 1$ replacement histone genes." J Cell Biochem 54(4): 423-31.

Dominski, Z., J. A. Erkmann, X. Yang, R. Sanchez und W. F. Marzluff (2002). "A novel zinc finger protein is associated with U7 snRNP and interacts with the stem-loop binding protein in the histone pre-mRNP to stimulate 3'-end processing." Genes Dev 16(1): 58-71.

Dominski, Z. und W. F. Marzluff (1999). "Formation of the 3' end of histone mRNA." Gene 239(1): 114.

Duncliffe, K. N., M. E. Rondahl und J. R. Wells (1995). "A H1 histone gene-specific AC-box-related element influences transcription from a major chicken H1 promoter." Gene 163(2): 227-32.

Eliassen, K. A., A. Baldwin, E. M. Sikorski und M. M. Hurt (1998). "Role for a YY1-binding element in replication-dependent mouse histone gene expression." Mol Cell Biol 18(12): 7106-18.

Fletcher, C., N. Heintz und R. G. Roeder (1987). "Purification and characterization of OTF-1, a transcription factor regulating cell cycle expression of a human histone H2b gene." Cell 51(5): $773-81$.

Frank, D., D. Doenecke und W. Albig (2003). "Differential expression of human replacement and cell cycle dependent H3 histone genes." Gene 312: 135-43.

Frontini, M., C. Imbriano, A. diSilvio, B. Bell, A. Bogni, C. Romier, D. Moras, L. Tora, I. Davidson und R. Mantovani (2002). "NF-Y recruitment of TFIID, multiple interactions with histone fold TAF(II)s." J Biol Chem 277(8): 5841-8. 
Furger, A., A. Schaller und D. Schümperli (1998). "Functional importance of conserved nucleotides at the histone RNA 3' processing site." Rna 4(3): 246-56.

Gallinari, P., F. La Bella und N. Heintz (1989). "Characterization and purification of H1TF2, a novel CCAAT-binding protein that interacts with a histone $\mathrm{H} 1$ subtype-specific consensus element." Mol Cell Biol 9(4): 1566-75.

Graves, R. A., N. B. Pandey, N. Chodchoy und W. F. Marzluff (1987). "Translation is required for regulation of histone mRNA degradation." Cell 48(4): 615-26.

Guo, B., J. L. Stein, A. J. van Wijnen und G. S. Stein (1997). "ATF1 and CREB trans-activate a cell cycle regulated histone $\mathrm{H} 4$ gene at a distal nuclear matrix associated promoter element." Biochemistry 36(47): 14447-55.

Gupta, S., M. X. Luong, S. A. Bleuming, A. Miele, M. Luong, D. Young, E. S. Knudsen, A. J. Van Wijnen, J. L. Stein und G. S. Stein (2003). "Tumor suppressor pRB functions as a corepressor of the CCAAT displacement protein (CDP/cut) to regulate cell cycle controlled histone H4 transcription." J Cell Physiol 196(3): 541-56.

Hampe, C. (2000). Differentielle Expression von menschlichen Histon-H4-Genen. Diplomarbeit Fachbereich Biologie. Göttingen, Universität Göttingen: 1-112.

Heintz, N. (1991). "The regulation of histone gene expression during the cell cycle." Biochim Biophys Acta 1088(3): 327-39.

Heintz, N., H. L. Sive und R. G. Roeder (1983). "Regulation of human histone gene expression: kinetics of accumulation and changes in the rate of synthesis and in the half-lives of individual histone mRNAs during the HeLa cell cycle." Mol Cell Biol 3(4): 539-50.

Helms, S. R., A. J. van Wijnen, P. Kroeger, A. Shiels, C. Stewart, J. Hirshman, J. L. Stein und G. S. Stein (1987). "Identification of an enhancer-like element upstream from a cell cycle dependent human H4 histone gene." J Cell Physiol 132(3): 552-8.

Hurt, M. M., T. L. Bowman und W. F. Marzluff (1991). "A common transcriptional activator is located in the coding region of two replication-dependent mouse histone genes." Mol Cell Biol 11(6): 2929-36.

Hurt, M. M., N. B. Pandey und W. F. Marzluff (1989). "A region in the coding sequence is required for high-level expression of murine histone H3 gene." Proc Natl Acad Sci U S A 86(12): 4450-4.

Imbriano, C., F. Bolognese, A. Gurtner, G. Piaggio und R. Mantovani (2001). "HSP-CBF is an NF-Ydependent coactivator of the heat shock promoters CCAAT boxes." J Biol Chem 276(28): 26332-9.

Ito, K., K. Tsutsumi, T. Kuzumaki, P. F. Gomez, K. Otsu und K. Ishikawa (1994). "A novel growthinducible gene that encodes a protein with a conserved cold-shock domain." Nucleic Acids Res 22(11): 2036-41.

Kardalinou, E., S. Eick, W. Albig und D. Doenecke (1993). "Association of a human H1 histone gene with an H2A pseudogene and genes encoding H2B.1 and H3.1 histones." J Cell Biochem 52(4): 375-83.

Kornberg, R. D. (1974). "Chromatin structure: a repeating unit of histones and DNA." Science 184(139): 868-71.

Kornberg, R. D. (1977). "Structure of chromatin." Annu Rev Biochem 46: 931-54.

Kornberg, R. D. und J. O. Thomas (1974). "Chromatin structure; oligomers of the histones." Science 184(139): 865-8. 
Kramer, A., C. P. Carstens, W. W. Wasserman und W. E. Fahl (1997). "CBP/cycA, a CCAAT-binding protein necessary for adhesion-dependent cyclin A transcription, consists of NF-Y and a novel Mr 115,000 subunit." Cancer Res 57(22): 5117-21.

Kroeger, P., C. Stewart, T. Schaap, A. van Wijnen, J. Hirshman, S. Helms, G. Stein und J. Stein (1987). "Proximal and distal regulatory elements that influence in vivo expression of a cell cycle-dependent human H4 histone gene." Proc Natl Acad Sci U S A 84(12): 3982-6.

La Bella, F., P. Gallinari, J. McKinney und N. Heintz (1989). "Histone H1 subtype-specific consensus elements mediate cell cycle- regulated transcription in vitro." Genes Dev 3(12A): 1982-90.

LaBella, F., H. L. Sive, R. G. Roeder und N. Heintz (1988). "Cell-cycle regulation of a human histone $\mathrm{H} 2 \mathrm{~b}$ gene is mediated by the H2b subtype-specific consensus element." Genes Dev 2(1): 329.

Larson, D. E., I. Hoffmann, P. Zahradka, M. L. Birnstiel und B. H. Sells (1992). "Histone H4 mRNA levels are down-regulated by $3^{\prime}$ RNA processing during terminal differentiation of myoblasts." Biochim Biophys Acta 1131(2): 139-44.

Larson, D. E., P. Zahradka, G. Stein, J. Stein und B. H. Sells (1989). "Down-regulation of histone H3 and H4 gene transcription in differentiated L6 myotubes." Biochim Biophys Acta 1009(2): 17783.

Last, T. J., M. Birnbaum, A. J. van Wijnen, G. S. Stein und J. L. Stein (1998). "Repressor elements in the coding region of the human histone $\mathrm{H} 4$ gene interact with the transcription factor CDP/cut." Gene 221(2): 267-77.

Last, T. J., A. J. van Wijnen, M. J. Birnbaum, G. S. Stein und J. L. Stein (1999). "Multiple interactions of the transcription factor $\mathrm{YY} 1$ with human histone $\mathrm{H} 4$ gene regulatory elements." J Cell Biochem 72(4): 507-16.

Lekstrom-Himes, J. und K. G. Xanthopoulos (1998). "Biological role of the CCAAT/enhancer-binding protein family of transcription factors." J Biol Chem 273(44): 28545-8.

Liberati, C., A. di Silvio, S. Ottolenghi und R. Mantovani (1999). "NF-Y binding to twin CCAAT boxes: role of Q-rich domains and histone fold helices." $\underline{\mathrm{J} \mathrm{Mol} \mathrm{Biol}}$ 285(4): 1441-55.

Liu, X. und M. A. Gorovsky (1996). "Cloning and characterization of the major histone H2A genes completes the cloning and sequencing of known histone genes of Tetrahymena thermophila." Nucleic Acids Res 24(15): 3023-30.

Luger, K., A. W. Mader, R. K. Richmond, D. F. Sargent und T. J. Richmond (1997). "Crystal structure of the nucleosome core particle at 2.8 A resolution." Nature 389(6648): 251-60.

Lum, L. S. Y., L. A. Sultzman, R. J. Kaufman, D. I. H. Linzer und B. J. Wu (1990). "A Cloned Human Ccaat-Box-Binding Factor Stimulates Transcription from the Human Hsp70 Promoter." Molecular and Cellular Biology 10(12): 6709-6717.

Luong, M. X., C. M. van der Meijden, D. Xing, R. Hesselton, E. S. Monuki, S. N. Jones, J. B. Lian, J. L. Stein, G. S. Stein, E. J. Neufeld und A. J. van Wijnen (2002). "Genetic ablation of the $\mathrm{CDP} / \mathrm{Cux}$ protein $\mathrm{C}$ terminus results in hair cycle defects and reduced male fertility." Mol Cell Biol 22(5): 1424-37.

Ma, T., B. A. Van Tine, Y. Wei, M. D. Garrett, D. Nelson, P. D. Adams, J. Wang, J. Qin, L. T. Chow und J. W. Harper (2000). "Cell cycle-regulated phosphorylation of p220(NPAT) by cyclin E/Cdk2 in Cajal bodies promotes histone gene transcription." Genes Dev 14(18): 2298-313.

Maity, S. N. und B. de Crombrugghe (1998). "Role of the CCAAT-binding protein CBF/NF-Y in transcription." Trends Biochem Sci 23(5): 174-8. 
Mantovani, R. (1998). "A survey of 178 NF-Y binding CCAAT boxes." Nucleic Acids Res 26(5): 113543.

Marashi, F., S. Helms, A. Shiels, S. Silverstein, D. S. Greenspan, G. Stein und J. Stein (1986). "Enhancer-facilitated expression of prokaryotic and eukaryotic genes using human histone gene 5' regulatory sequences." Biochem Cell Biol 64(4): 277-89.

Martinelli, R. und N. Heintz (1994). "H1TF2A, the large subunit of a heterodimeric, glutamine-rich CCAAT- binding transcription factor involved in histone $\mathrm{H} 1$ cell cycle regulation." Mol Cell Biol 14(12): 8322-32.

Marzluff, W. F. und R. J. Duronio (2002). "Histone mRNA expression: multiple levels of cell cycle regulation and important developmental consequences." Curr Opin Cell Biol 14(6): 692-9.

Marzluff, W. F. und N. B. Pandey (1988). "Multiple regulatory steps control histone mRNA concentrations." Trends Biochem Sci 13(2): 49-52.

Meergans, T., W. Albig und D. Doenecke (1997). "Varied expression patterns of human H1 histone genes in different cell lines." DNA Cell Biol 16(9): 1041-9.

Meergans, T., W. Albig und D. Doenecke (1998). "Conserved sequence elements in human main type-H1 histone gene promoters: their role in $\mathrm{H} 1$ gene expression." Eur J Biochem 256(2): 436-46.

Moon, N. S., G. Berube und A. Nepveu (2000). "CCAAT displacement activity involves CUT repeats 1 and 2, not the CUT homeodomain." J Biol Chem 275(40): 31325-34.

Nepveu, A. (2001). "Role of the multifunctional CDP/Cut/Cux homeodomain transcription factor in regulating differentiation, cell growth and development." Gene 270(1-2): 1-15.

Ohshima, N., M. Takahashi und F. Hirose (2003). "Identification of a human homologue of the DREF transcription factor with a potential role in regulation of the histone $\mathrm{H} 1$ gene." $\underline{\mathrm{J} \text { Biol Chem }}$ 278(25): 22928-38.

Osada, S., S. Daimon, T. Ikeda, T. Nishihara, K. Yano, M. Yamasaki und M. Imagawa (1997). "Nuclear factor 1 family proteins bind to the silencer element in the rat glutathione transferase P gene." J Biochem (Tokyo) 121(2): 355-63.

Osley, M. A. (1991). "The regulation of histone synthesis in the cell cycle." Annu Rev Biochem 60: 827-61.

Oswald, F., T. Dobner und M. Lipp (1996). "The E2F transcription factor activates a replicationdependent human H2A gene in early S phase of the cell cycle." Mol Cell Biol 16(5): 1889-95.

Oudet, P., M. Gross-Bellard und P. Chambon (1975). "Electron microscopic and biochemical evidence that chromatin structure is a repeating unit." Cell 4(4): 281-300.

Pandey, N. B. und W. F. Marzluff (1987). "The stem-loop structure at the 3' end of histone mRNA is necessary and sufficient for regulation of histone mRNA stability." Mol Cell Biol 7(12): 4557-9.

Pauli, U., S. Chrysogelos, H. Nick, G. Stein und J. Stein (1989). "In vivo protein binding sites and nuclease hypersensitivity in the promoter region of a cell cycle regulated human $\mathrm{H} 3$ histone gene." Nucleic Acids Res 17(6): 2333-50.

Pauli, U., S. Chrysogelos, G. Stein, J. Stein und H. Nick (1987). "Protein-DNA interactions in vivo upstream of a cell cycle-regulated human H4 histone gene." Science 236(4806): 1308-11.

Pillai, R. S., C. L. Will, R. Luhrmann, D. Schümperli und B. Muller (2001). "Purified U7 snRNPs lack the Sm proteins D1 and D2 but contain Lsm10, a new $14 \mathrm{kDa}$ Sm D1-like protein." Embo J 20(19): 5470-9. 
Quandt, K., K. Frech, H. Karas, E. Wingender und T. Werner (1995). "MatInd and MatInspector: new fast and versatile tools for detection of consensus matches in nucleotide sequence data." Nucleic Acids Res 23(23): 4878-84.

Ramsey-Ewing, A., A. J. Van Wijnen, G. S. Stein und J. L. Stein (1994). "Delineation of a human histone $\mathrm{H} 4$ cell cycle element in vivo: the master switch for $\mathrm{H} 4$ gene transcription." Proc Natl Acad Sci U S A 91(10): 4475-9.

Ramsey-Ewing, A. L., R. Bortell, G. S. Stein und J. L. Stein (1995). "Histone H4 proximal promoter mediates a complex transcriptional response during differentiation of 3T3L1 adipocytes." $\underline{\mathrm{J}}$ Cell Physiol 163(2): 312-20.

Schuler, G. D., S. F. Altschul und D. J. Lipman (1991). "A workbench for multiple alignment construction and analysis." Proteins 9(3): 180-90.

Schümperli, D. (1986). "Cell-cycle regulation of histone gene expression." Cell 45(4): 471-2.

Schümperli, D., U. Albrecht, T. W. Koning, L. Melin, D. Soldati, C. Stauber und R. Luhrmann (1990). "Biochemical studies of U7 snRNPs and of histone RNA 3' processing." Mol Biol Rep 14(2-3): 205-6.

Shopland, L. S., M. Byron, J. L. Stein, J. B. Lian, G. S. Stein und J. B. Lawrence (2001). "Replicationdependent histone gene expression is related to Cajal body (CB) association but does not require sustained CB contact." Mol Biol Cell 12(3): 565-76.

Simpson, R. T. (1978). "Structure of the chromatosome, a chromatin particle containing 160 base pairs of DNA and all the histones." Biochemistry 17(25): 5524-31.

Sittman, D. B., R. A. Graves und W. F. Marzluff (1983). "Histone mRNA concentrations are regulated at the level of transcription and mRNA degradation." Proc Natl Acad Sci U S A 80(7): 1849-53.

Sive, H. L. und R. G. Roeder (1986). "Interaction of a common factor with conserved promoter and enhancer sequences in histone H2B, immunoglobulin, and U2 small nuclear RNA (snRNA) genes." Proc Natl Acad Sci U S A 83(17): 6382-6.

Stauber, C., B. Lüscher, R. Eckner, E. Lotscher und D. Schümperli (1986). "A signal regulating mouse histone $\mathrm{H} 4$ mRNA levels in a mammalian cell cycle mutant and sequences controlling RNA 3' processing are both contained within the same 80-bp fragment." Embo J 5(12): 3297-303.

Stauber, C. und D. Schümperli (1988). "3' processing of pre-mRNA plays a major role in proliferationdependent regulation of histone gene expression." Nucleic Acids Res 16(20): 9399-414.

Stein, G., J. Lian, J. Stein, R. Briggs, V. Shalhoub, K. Wright, U. Pauli und A. van Wijnen (1989). "Altered binding of human histone gene transcription factors during the shutdown of proliferation and onset of differentiation in HL-60 cells." Proc Natl Acad Sci U S A 86(6): 18659.

Stein, G. S., J. L. Stein, A. J. van Wijnen und J. B. Lian (1992). "Regulation of histone gene expression." Curr Opin Cell Biol 4(2): 166-73.

Sturm, R. A., S. Dalton und J. R. Wells (1988). "Conservation of histone H2A/H2B intergene regions: a role for the H2B specific element in divergent transcription." Nucleic Acids Res 16(17): 857186.

Tanimoto, A., C. Y. Kao, C. C. Chang, Y. Sasaguri und R. Padmanabhan (1998). "Deregulation of cdc2 gene expression correlates with overexpression of a $110 \mathrm{kDa}$ CCAAT box binding factor in transformed cells." Carcinogenesis 19(10): 1735-41.

Thoma, F., T. Koller und A. Klug (1979). "Involvement of histone H1 in the organization of the nucleosome and of the salt-dependent superstructures of chromatin." J Cell Biol $83(2 \mathrm{Pt} 1)$ : 403-27. 
Trappe, R., D. Doenecke und W. Albig (1999). "The expression of human H2A-H2B histone gene pairs is regulated by multiple sequence elements in their joint promoters." Biochim Biophys Acta 1446(3): 341-51.

Tripputi, P., B. S. Emanuel, C. M. Croce, L. G. Green, G. S. Stein und J. L. Stein (1986). "Human histone genes map to multiple chromosomes." Proc Natl Acad Sci U S A 83(10): 3185-8.

van den Ent, F. M., A. J. van Wijnen, J. B. Lian, J. L. Stein und G. S. Stein (1994). "Cell cycle controlled histone $\mathrm{H} 1, \mathrm{H} 3$, and $\mathrm{H} 4$ genes share unusual arrangements of recognition motifs for HiNF-D supporting a coordinate promoter binding mechanism." J Cell Physiol 159(3): 515-30.

van der Houven van Oordt, C. W., A. J. van Wijnen, R. Carter, K. Soprano, J. B. Lian, G. S. Stein und J. L. Stein (1992). "Protein-DNA interactions at the H4-site III upstream transcriptional element of a cell cycle regulated histone $\mathrm{H} 4$ gene: differences in normal versus tumor cells." $\mathrm{J}$ Cell Biochem 49(1): 93-110.

van der Meijden, C. M., P. S. Vaughan, A. Staal, W. Albig, D. Doenecke, J. L. Stein, G. S. Stein und A. J. van Wijnen (1998). "Selective expression of specific histone $\mathrm{H} 4$ genes reflects distinctions in transcription factor interactions with divergent $\mathrm{H} 4$ promoter elements." Biochim Biophys Acta 1442(1): 82-100.

van Wijnen, A. J., F. Aziz, X. Grana, A. De Luca, R. K. Desai, K. Jaarsveld, T. J. Last, K. Soprano, A. Giordano, J. B. Lian und et al. (1994). "Transcription of histone H4, H3, and H1 cell cycle genes: promoter factor HiNF-D contains CDC2, cyclin A, and an RB-related protein." Proc Natl Acad Sci U S A 91(26): 12882-6.

van Wijnen, A. J., T. K. Choi, T. A. Owen, K. L. Wright, J. B. Lian, R. Jaenisch, J. L. Stein und G. S. Stein (1991a). "Involvement of the cell cycle-regulated nuclear factor HiNF-D in cell growth control of a human $\mathrm{H} 4$ histone gene during hepatic development in transgenic mice." Proc Natl Acad Sci U S A 88(6): 2573-7.

van Wijnen, A. J., J. B. Lian, J. L. Stein und G. S. Stein (1991b). "Protein/DNA interactions involving ATF/AP1-, CCAAT-, and HiNF-D-related factors in the human H3-ST519 histone promoter: cross-competition with transcription regulatory sites in cell cycle controlled $\mathrm{H} 4$ and $\mathrm{H} 1$ histone genes." J Cell Biochem 47(4): 337-51.

van Wijnen, A. J., A. L. Ramsey-Ewing, R. Bortell, T. A. Owen, J. B. Lian, J. L. Stein und G. S. Stein (1991c). "Transcriptional element $\mathrm{H} 4$-site II of cell cycle regulated human $\mathrm{H} 4$ histone genes is a multipartite protein/DNA interaction site for factors HiNF-D, HiNF-M, and HiNF-P:

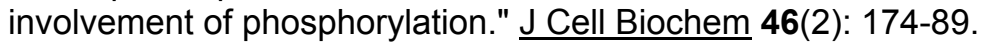

van Wijnen, A. J., M. F. van Gurp, M. C. de Ridder, C. Tufarelli, T. J. Last, M. Birnbaum, P. S. Vaughan, A. Giordano, W. Krek, E. J. Neufeld, J. L. Stein und G. S. Stein (1996). "CDP/cut is the DNA-binding subunit of histone gene transcription factor HiNF-D: a mechanism for gene regulation at the $\mathrm{G} 1 / \mathrm{S}$ phase cell cycle transition point independent of transcription factor E2F." Proc Natl Acad Sci U S A 93(21): 11516-21.

van Wijnen, A. J., K. L. Wright, J. B. Lian, J. L. Stein und G. S. Stein (1989). "Human H4 histone gene transcription requires the proliferation-specific nuclear factor HiNF-D. Auxiliary roles for HiNFC (Sp1-like) and HiNF-A (high mobility group-like)." J Biol Chem 264(25): 15034-42.

Vasserot, A. P., F. J. Schaufele und M. L. Birnstiel (1989). "Conserved terminal hairpin sequences of histone mRNA precursors are not involved in duplex formation with the U7 RNA but act as a target site for a distinct processing factor." Proc Natl Acad Sci U S A 86(12): 4345-9.

Vaughan, P. S., F. Aziz, A. J. van Wijnen, S. Wu, H. Harada, T. Taniguchi, K. J. Soprano, J. L. Stein und G. S. Stein (1995). "Activation of a cell-cycle-regulated histone gene by the oncogenic transcription factor IRF-2." Nature 377(6547): 362-5. 
Vaughan, P. S., C. M. van der Meijden, F. Aziz, H. Harada, T. Taniguchi, A. J. van Wijnen, J. L. Stein und G. S. Stein (1998). "Cell cycle regulation of histone H4 gene transcription requires the oncogenic factor IRF-2." J Biol Chem 273(1): 194-9.

Whitfield, M. L., L. X. Zheng, A. Baldwin, T. Ohta, M. M. Hurt und W. F. Marzluff (2000). "Stem-loop binding protein, the protein that binds the 3 ' end of histone mRNA, is cell cycle regulated by both translational and posttranslational mechanisms." Mol Cell Biol 20(12): 4188-98.

Williams, A. S., T. C. Ingledue, 3rd, B. K. Kay und W. F. Marzluff (1994). "Changes in the stem-loop at the 3 ' terminus of histone mRNA affects its nucleocytoplasmic transport and cytoplasmic regulation." Nucleic Acids Res 22(22): 4660-6.

Witt, O., W. Albig und D. Doenecke (1996). "Testis-specific expression of a novel human H3 histone gene." Exp Cell Res 229(2): 301-6.

Witt, O., W. Albig und D. Doenecke (1997). "Transcriptional regulation of the human replacement histone gene H3.3B." FEBS Lett 408(3): 255-60.

Wu, F. und A. S. Lee (1998). "Identification of AP-2 as an interactive target of Rb and a regulator of the G1/S control element of the hamster histone H3.2 promoter." Nucleic Acids Res 26(21): 4837-45.

Wu, F. und A. S. Lee (2001). "YY1 as a regulator of replication-dependent hamster histone H3.2 promoter and an interactive partner of AP-2." J Biol Chem 276(1): 28-34.

Wu, R. S. und W. M. Bonner (1981). "Separation of basal histone synthesis from S-phase histone synthesis in dividing cells." Cell 27(2 Pt 1): 321-30.

Xie, R., A. J. van Wijnen, C. van Der Meijden, M. X. Luong, J. L. Stein und G. S. Stein (2001). "The cell cycle control element of histone $\mathrm{H} 4$ gene transcription is maximally responsive to interferon regulatory factor pairs IRF-1/IRF-3 and IRF-1/IRF-7." J Biol Chem 276(21): 1862432.

Zhao, J., B. K. Kennedy, B. D. Lawrence, D. A. Barbie, A. G. Matera, J. A. Fletcher und E. Harlow (2000). "NPAT links cyclin E-Cdk2 to the regulation of replication-dependent histone gene transcription." Genes Dev 14(18): 2283-97.

Zhong, R., R. G. Roeder und N. Heintz (1983). "The primary structure and expression of four cloned human histone genes." Nucleic Acids Res 11(21): 7409-25. 


\section{Anhang}

\subsection{Verwendete Oligonukleotide}

RV3: a) Sequenz: 5'- CTAGCAAAAT AGGCTGTC-3' b) Beschreibung: Sequenzierprimer für pGL3-basic-Konstrukte. Bindet upstream der MCS in Richtung der MCS und des FF-Luziferase-Gens.

GL2: a) Sequenz: 5'- CTTCCAGCGG ATAGAATG-3' b) Beschreibung: Sequenzierprimer für pGL3-basic-Konstrukte. Bindet innerhalb des FFLuziferase-Gens in Richtung der MCS.

OHK1: a) Sequenz: 5'- TCTCGAAGGG GCACCTGTGA ACTC-3' b) Beschreibung: Klonierungsprimer $\mathrm{H} 3 / \mathrm{n}$ bindet downstream der kodierenden Sequenz von H2A/O c) Komplementär zu OHK2 und OHK3

OHK2: a) Sequenz: $5^{\prime}-$ GGTAGCGGTG CGGCTTCTTC AC $\quad-3^{\prime} \quad$ b) Beschreibung:Klonierungsprimer $\mathrm{H} 3 / \mathrm{n}$; bindet innerhalb der kodierenden Sequenz von H3/n in Richtung von H2A/O c) Komplementär zu OHK1

OHK3: a) Sequenz: 5'- AGTGGGGCGA CAATCGGATC TGAAG -3' b) Beschreibung: Klonierungsprimer $\mathrm{H} 3 / \mathrm{n}$; bindet downstream von $\mathrm{H} 4 / \mathrm{n}$ in Richtung von $\mathrm{H} 2 \mathrm{~A} / \mathrm{O}$ und $\mathrm{H} 3 / \mathrm{n}$ c) Komplementär zu OHK1

OHK4-12: PCR-Primer zur Erstellung der H3/m-Promotor-Deletionskonstrukte M1-M8 :

OHK4: a) Sequenz: 5'- GGATTTCCGA GCTGTCTGTT TAGTACG -3' b) Beschreibung: Primer zur Erzeugung der H3/m-Promotor-Deletionsmutanten M1-M9. Bindet downstream des Startcodons von H3/m. c) Komplementär zu OHK5-OHK12, sowie OHK 112

OHK5-12: b) Beschreibung: Primer zur Erzeugung der H3/m-PromotorDeletionsmutanten M1-M8; enthalten alle eine angehängte BglIISchnittstelle. c) Sie sind komplementär zu oHK13.

OHK5: (M1) a) Sequenz: 5'- CGAGATCTGA CTCTATAAAA GAAGAGTAGC -3'

OHK6:(M2) a) Sequenz: 5'- GTAGATCTTG GGTCCAATAG TTGGTGG -3'

OHK7:(M3) a) Sequenz: 5'- CAAGATCTGC AACCAGGCAC AGAGAT -3'

OHK8: (M4) a) Sequenz: 5'- CGAGATCTTT TCCAGTACAA GACTTGTCC -3'

OHK9:(M5) a) Sequenz: 5'- CGAGATCTAA TTGCCCACAC TTCTTATGC -3'

OHK10: (M6) a) Sequenz: 5'- CGAGATCTGA GAGCACACAC ATTACC -3'

OHK11:(M7) a) Sequenz: 5'- CGAGATCTGT TGTGCTTTGG ATTATGCC -3'

OHK12:(M8) a) Sequenz: 5'- AtAgAtCTGG TATTACGgGC ATGAGCC -3'

OHK13-21: PCR-Primer zur Erstellung der H3/d Promotor-Deletionskonstrukte
D1-D8:

OHK13: a) Sequenz: 5'- TACGCGCCAT GGTTCATCTG CAAAGTA -3' b) Beschreibung: Primer zur Erzeugung der H3/d Promotor-Deletionsmutanten D1-D8. Bindet an und um das Startcodon von H3/d. Generiert eine NcoI-Schnittstelle am Startcodon c) Komplementär zu OHK14-OHK21

OHK14-21: b) Beschreibung: Primer zur Erzeugung der H3/d PromotorDeletionsmutanten D1-D8. Enthalten alle angehängte BglII-Schnittstellen. c) Jeweils komplementär zu OHK13.

OHK14:(D1) a) Sequenz: 5'- CGAGATCTGT TCCTATATAG AGGGGCA -3' 


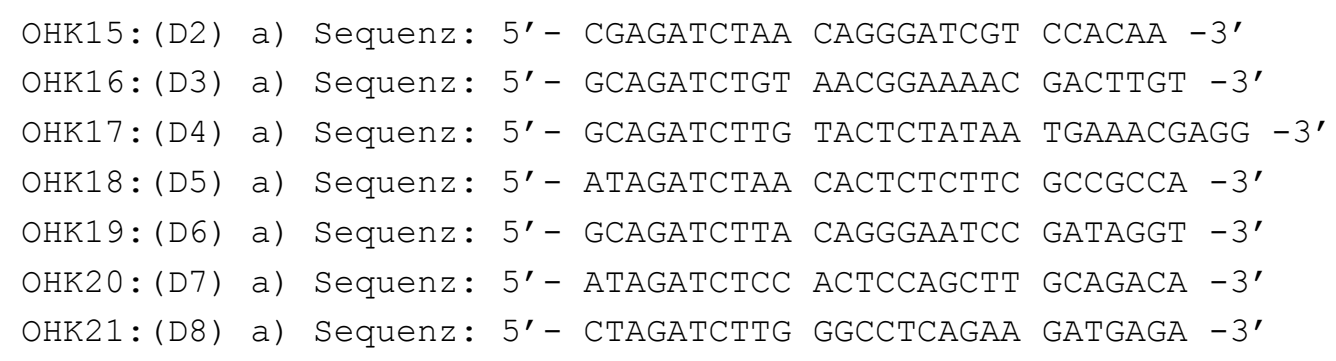

\section{OHK22-33: PCR-Primer zur Erstellung der H3/k-Promotor-Deletionskonstrukte $\mathrm{K} 1-\mathrm{K} 11$ :}

OHK22: a) Sequenz: 5'- TGCTTCGTAC GCGCCATGGC TTCAGA -3' b) Beschreibung: Primer zur Erzeugung der H3/k-Promotor-Deletionsmutanten K1-K11. Bindet an und um das startcodon von H3/k. Generiert eine NcoI-Schnittstelle am Startcodon. c) Komplementär zu OHK23-OHK33

OHK23-33: b) Beschreibung: Primer zur Erzeugung der H3/k-PromotorDeletionsmutanten K1-K11. OHK23-OHK29 (K1-K7): Mit angehängter BglIISchnittstelle. OHK30 (K8): Mit interner BglII-Schnittstelle. OHK31-OHK33 (K9-K11): Mit angehängter XhoI-Schnittstelle. c) Jeweils komplementär zu OHK22.

OHK23:(K1) a) Sequenz: 5'- CGAGATCTCA CTATAAATAA GCGGCTAG -3

OHK2 4:(K2) a) Sequenz: 5'- CGAGATCTTT TGTCCAATCA GCTTCAGA -3'

OHK25:(K3) a) Sequenz: 5'-ATAGATCTGT TGGGTAGGCC TTCAGC -3'

OHK26:(K4) a) Sequenz: 5' - CGAGATCTAA GTCTGTCAGA GGAATAGG -3'

OHK27:(K5) a) Sequenz: 5'- CGAGATCTCA TTTCCACTGG AAATCGC -3'

OHK28:(K6) a) Sequenz: 5'- CGAGATCTGT TGGCTATATT GGATTAAGC -3'

OHK29:(K7) a) Sequenz: 5'- CTAGATCTGA GGGGACAGGT GTATAAG -3'

OHK30:(K8) a) Sequenz: 5'- TCTGAATCAG ATCTGGATGT ACGAATG -3'

OHK31:(K9) a) Sequenz: 5'- CACTCGAGAT CAACGACTTG GATTCTTC -3'

OHK32: (K10) a) Sequenz: 5'- ATCTCGAGCC TGGATTAGTT TGCAGCA -3'

OHK33:(K11) a) Sequenz: 5'-ATCTCGAGGC AAAGCTCGCG CCAAG -3'

\section{OHK34-45: PCR-Primer zur Erstellung der H3/h Promotor-Deletionskonstrukte H1-H11:}

OHK34: a) Sequenz: 5'- TGCTTGGTGCGGGCCATGGCAGAC -3' b) Beschreibung: Primer zur Erzeugung der $\mathrm{H} 3 / \mathrm{h}$ Promotor-Deletionsmutanten H1-H11. Bindet an und um das Startcodon von H3/h. Generiert eine NcoI-Schnittstelle am Startcodon. Eine Verbesserte Version von OHK34, die dem gleichen Zweck dient, ist OHK67 c) Komplementär zu OHK35-45

OHK35-45: b) Beschreibung: Primer zur Erzeugung der H3/h PromotorDeletionsmutanten H1-H11. Mit angehängter BglII-Schnittstelle. c) Jeweils komplementär zu OHK34 bzw. OHK67.

OHK35: (H1) a) Sequenz: 5'- CGAGATCTGA GTATATATAA GGGCAGTTTC -3'

OHK36:(H2) a) Sequenz: 5'- CGAGATCTCA ACAAGGCCAA TTAGAATG -3'

OHK37:(H3) a) Sequenz: 5'- CGAGATCTTC AGCCAATGGT TTTGTTG -3'

OHK38: (H4) a) Sequenz: 5'- CGAGATCTGA TTCATCCAAT CAGATTTTC -3'

OHK39:(H5) a) Sequenz: 5'- TCAGATCTTG GATCGCAGAC TAACCGA -3'

OHK40:(H6) a) Sequenz: 5'- TAAGATCTGG CCCCACAACA CATCTAC -3'

OHK41: (H7) a) Sequenz: 5'- CGAGATCTCA ACCGAAGCAA AACACCA -3'

OHK 42: (H8) a) Sequenz: 5'- CGAGATCTCA AGTAAGTGCT TTAATGTAG -3'

OHK43:(H9) a) Sequenz: 5'- TAAGATCTTC CAGGGCTGGT CTCCAG -3'

OHK 4 : (H10) a) Sequenz: 5'- CGAGATCTGA GTTTCGGTT TCTCATTGG -3' 
OHK 45: (H11) a) Sequenz: 5'- TAAGATCTCC CTGGAAGTG ATGGTCGA -3'

\section{OHK46-55: PCR-Primer zur Erstellung der H3/i Promotor-Deletionskonstrukte I1-I9:}

OHK46: a) Sequenz: 5'- TTTGCTTCGT GCGTGCCATG GGAATG -3' b) Beschreibung: Primer zur Erzeugung der H3/i Promotor-Deletionsmutanten I1-I9. Bindet an und um das Startcodon von H3/h. Generiert eine NcoI-Schnittstelle am Startcodon. Eine verbesserter Primer, der dem gleichen Zweck dient, ist OHK66 c) Komplementär zu OHK47-55

OHK47-55: b) Beschreibung: Primer zur Erzeugung der H3/i PromotorDeletionsmutanten I1-I9. Mit angehängter BglII-Schnittstelle. c) Jeweils komplementär zu OHK46 bzw. OHK66.

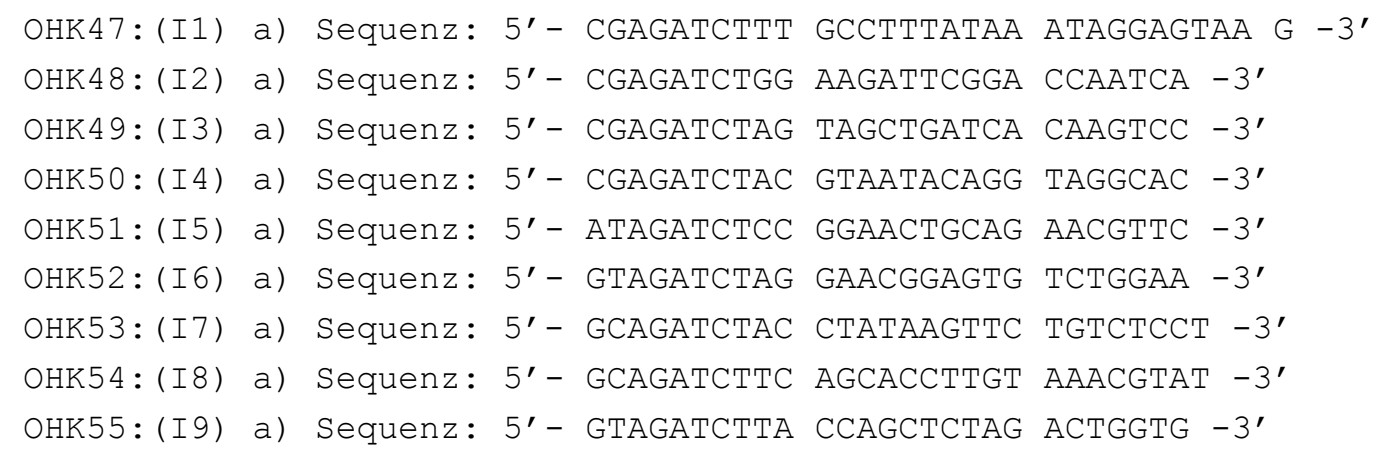

OHK56-63: PCR-Primer zur Erstellung der H3/n Promotor-Deletionskonstrukte N1-N7 :

OHK56: a) Sequenz: 5'- CTGCTTAGTA CGGGCCATGG CGAAC -3' b) Beschreibung: Primer zur Erzeugung der H3/n Promotor-Deletionsmutanten N1-N7. Bindet an und um das Startcodon von H3/n. Generiert eine NcoI-Schnittstelle am Startcodon. c) Komplementär zu OHK57-63

OHK57-63: b) Beschreibung: Primer zur Erzeugung der H3/n PromotorDeletionsmutanten N1-N7. Mit angehängter BglII-Schnittstelle. c) Jeweils komplementär zu OHK56.

OHK57:(N1) a) Sequenz: 5'- CGAGATCTGT GCTTATAAAG ACGGCTG -3'

OHK58:(N2) a) Sequenz: 5'- ATAGATCTAT TGTTCCGCCC AATCGGG -3'

OHK59:(N3) a) Sequenz: 5'-ATAGATCTGC CCAAGCCAAC CGGTGA -3'

OHK60: (N4) a) Sequenz: 5'- CTAGATCTTT CACCCTGAAG GAAAGGG -3'

OHK61:(N5) a) Sequenz: 5'- CTAGATCTGG AAGAATGAGG TTCCACG -3'

OHK62:(N6) a) Sequenz: 5'- ATAGATCTAT GGCCGGACAC TTAGACC -3'

OHK63:(N7) a) Sequenz: 5'- CTAGATCTTT TCAGAGCCAC CCACGTT -3'

OHK64: a) Sequenz: 5'- ATACATGTCA CAAGCCTCCT GCAGTCTAGA AACCGCAGAG CTCTGG -3' b) Beschreibung: Primer dient der Erzeugung des Konstrukts MCRASlmut1, er bindet an sogenannten CRAS- $\alpha$ Bereich im $\mathrm{H} 3 / \mathrm{m}$ Gen und mutiert diesen. Enthält AflIII-Schnittstelle. c) Komplementär zu OHK10

OHK65: a) Sequenz: 5'-ATACATGTCA CAAGCCTCCT GCAGCG -3' b) Beschreibung: Primer dient der Erzeugung des Konstrukts MCRAS1, er bindet downstream des sogenannten CRAS $\alpha$ Bereich in der $\mathrm{H} 3 / \mathrm{m}$ kodierenden sequenz ohne die Wildtyp Sequenz zu mutieren. Enthält AflIII-Schnittstelle c) Komplementär zu OHK10

OHK66: a) Sequenz: 5'- TGCGTGCCAT GGGAATGGGT TTCAAG -3' b) Beschreibung: Primer zur Erzeugung der H3/i Promotor-Deletionsmutanten I1-I9. Bindet an und um das Startcodon von H3/h. Generiert eine NcoI-Schnittstelle am Startcodon. OHK66 ist eine Verbesserung von OHK46 c) Komplementär zu OHK $4-55$ 
OHK67: a) Sequenz: 5'- CGGGCCATGG CAGACTACCT GAAAG -3' b) Beschreibung: Primer zur Erzeugung der $\mathrm{H} 3 / \mathrm{h}$ Promotor-Deletionsmutanten H1-H11. Bindet an und um das Startcodon von H3/h. Generiert eine NcoI-Schnittstelle am Startcodon. OHK67 ist eine Verbesserung von OHK34 c) Komplementär zu OHK35-45

\section{OHK69-76: H3/k Mutationsprimer (für Erstellung von K5mut1-8)}

OHK69: a) Sequenz: 5'- GGAGACCATG AACTGCTAAT GAGTGACTCG GAATAGGTGA ACAACAAAAA TTTGAG -3' 56 bp b) Beschreibung: H3/k Mutationsprimer 1; für Herstellung von K5mut1; 10 bp Fehlpaarung

OHK70: a) Sequenz: 5'- GAACTGCTAA GTCTGTCAGA GGAAGCTTGT CCACACAAAA ATTTGAGTCC TTCGCC -3' 56 bp b) Beschreibung: H3/k Mutationsprimer 2; für Herstellung von K5mut2; 10 bp Fehlpaarung

OHK71: a) Sequenz: 5'- GTCAGAGGAA TAGGTGAACA ACAACCCGGG TCTGCCTTCG CCAATCCGGT TACTGTTGG -3' 59 bp b) Beschreibung: H3/k Mutationsprimer 3; für Herstellung von K5mut3; 10 bp Fehlpaarung

OHK72: a) Sequenz: 5'- GGTGAACAAC AAAAATTTGA GTCCTTATAA CCGAATGTTA CTGTTGGGTA GGCCTTCAGC -3' 60 bp b) Beschreibung: H3/k Mutationsprimer 4; für Herstellung von K5mut4; 10 bp Fehlpaarung

OHK73: a) Sequenz: 5'- GAGTCCTTCG CCAATCCGGT TAAGTGGTTT GCGGCCTTCA GCATACTTTT GTCC -3' 54 bp b) Beschreibung: H3/k Mutationsprimer 5; für Herstellung von K5mut5; 10 bp Fehlpaarung

OHK74: a) Sequenz: 5'- CCGGTTACTG TTGGGTAGGC CGGACTACGC ATTTTGTCCA ATCAGCTTCA GACTCTC -3' 57 bp b) Beschreibung: H3/k Mutationsprimer 6; für Herstellung von K5mut6; 10 bp Fehlpaarung

OHK75: a) Sequenz: 5'- GGGTAGGCCT TCAGCATACT TTTTGAACCG ACTAGTCAGA СTCTCACTAT AAATAAGCGG C -3'61 bp b) Beschreibung: H3/k Mutationsprimer 7; für Herstellung von K5mut7; 12 bp Fehlpaarung

OHK76: a) Sequenz: 5'- GCATACTTTT GTCCAATCAG CTTCAGCAGA GACAGCGCAA TAAGCGGCTA GCTTTCTCTT TCTCC -3' 65 bp b) Beschreibung: H3/k Mutationsprimer 8; für Herstellung von K5mut8; 12 bp Fehlpaarung

\section{OHK77-87: H3/m Mutationsprimer (für Erstellung von M4mut1-11)}

OHK77: a) Sequenz: 52 bp 5'- GCAGCTAAGG GGTTAACAAA AGTCATGACG AGTAGCTACG GTAATGGGCA GG -3' 52 bp b) Beschreibung: H3/m Mutationsprimer 1; für Herstellung von M4mut1; 8 bp Fehlpaarung

OHK78: a) Sequenz: 5'- GGGCAGGAGC CTCTCTTAAT CTTACCAACT TACCAGAGAT GGACCAATCC AAGAAGGGC -3' 59 bp b) Beschreibung: H3/m Mutationsprimer 2; für Herstellung von M4mut2; 11 bp Fehlpaarung

OHK79: a) Sequenz: 5'- CAAAAATCCC CGCGCCCTTC TTTTCGGTTG AACGATCTGT GCCTGGTTGC AGATTAAGAG $-3^{\prime}=60 \mathrm{bp}$ b) Beschreibung: H3/m Mutationsprimer 3; für Herstellung von M4mut3; 13 bp Fehlpaarung; invers!

OHK80: a) Sequenz: 5'- GCACAGAGAT GGACCAATCC AAGACTTTAT ATTTTCTTTT TGAATTTTCT TGGGTCCAAT AG $-3^{\prime}=62 \mathrm{bp}$ b) Beschreibung: $\mathrm{H} 3 / \mathrm{m}$ Mutationsprimer 4; für Herstellung von M4mut4; 12 bp Fehlpaarung

OHK81: a) Sequenz: 5'- CCAAGAAgGg CGCGgGgAtT TTGTCCGgGg AgTGgGTCCA ATAGTTGGTG GTCTG -3' 55 bp b) Beschreibung: H3/m Mutationsprimer 5; für Herstellung von M4mut5; 10 bp Fehlpaarung

OHK82: a) Sequenz: 5'- GAGTCAGACC ACCAACTCGG TTACCCAAGA AAATTCAAAA ATCC 3' $44 \mathrm{bp}$ b) Beschreibung: H3/m Mutationsprimer 6; für Herstellung von M4mut6; 5 bp Fehlpaarung; invers! 
OHK83: a) Sequenz: 5'- GAATTTTCTT GGGTCCAATA GTTTTGTTGA GTACTCTATA AAAGAAGAGT AGCTCTTTCC -3' 60 bp b) Beschreibung: H3/m Mutationsprimer 7; für Herstellung von M4mut7; 9 bp Fehlpaarung

OHK84: a) Sequenz: 5'- CCAATAGTTG GTGGTCTGAC TCGCGCCCCG AAGAGTAGCT CTTTCCTTTC C -3' 51 bp b) Beschreibung: H3/m Mutationsprimer 8; für Herstellung von M4mut8; 7 bp Fehlpaarung

OHK85: a) Sequenz: 5'- GGTGGTCTGA CTCTATAAAA GAAGCTGCTA GAGGGAAGT CCTCCACAGA CGTCTCTGCA GGC -3' 63 bp b) Beschreibung: H3/m Mutationsprimer 9; für Herstellung von M4mut9; 14 bp Fehlpaarung

OHK86: a) Sequenz: 5'- GAAGAGTAGC TCTTTCCTTT CCGAACACTC ATGAGAGGCA GGCAAGCTTT TCTGTGGTTT TGCC -3' 64 bp b) Beschreibung: H3/m Mutationsprimer 10; für Herstellung von M4mut10; 15 bp Fehlpaarung

OHK87: a) Sequenz: 5'- GTTTTTGGCG TCTTCCATGG CACCCAACAC TCCCCTAGGT ACTGCAGAGA CGTCTGTGGA GGAAAGG $-3^{\prime} 67$ bp b) Beschreibung: H3/m Mutationsprimer 11; für Herstellung von M4mut11; 19 bp Fehlpaarung; invers!

OHK88: a) Sequenz: 5'- CGACATGTCT TTGGGCATAA TAGTCAC -3' b) Beschreibung: Primer dient der Erzeugung des Konstrukts MCRAS2, er bindet downstream des sogenannten CRAS- $\alpha$ Bereich im H3/m Gen ohne die Wildtyp Sequenz zu mutieren; enthält AflIII-Schnittstelle; hat ähnliche Funktion wie OHK 65, bindet nur weiter downstream in der $\mathrm{H3} / \mathrm{m}$ codierenden Sequenz c) Komplementär zu OHK10

OHK93: a) Sequenz: 5'- TACTCGAGGT AGTGGGAAGG TCTCTG -3' b) Beschreibung: Primer zur Erzeugung der H3/k-Promotor-Deletionsmutante K13; mit angehängter XhoI-Schnittstelle. c) Komplementär zu OHK22

\section{OHK94-98: H3/k Mutationsprimer (für Erstellung von K5mut10-14)}

OHK94: a) Sequenz: 5'- CCTTCAgCAT ACTTTTGTAA CCGCAGCTTC AgACTCTC -3' 38 bp b) Beschreibung: H3/k Mutationsprimer 10; für Herstellung von K5mut10; 5 bp Fehlpaarung

OHK95: a) Sequenz: 5'- CCTTCAGCAT ACTTTTGTTC GATCAGCTTC AGACTCTC -3' 38 bp b) Beschreibung: H3/k Mutationsprimer 11; für Herstellung von K5mut11; 3 bp Fehlpaarung

OHK96: a) Sequenz: 5'- GGGTAGGCCT TCAGCATACT TTGCCCCAAT TTGCTTCAGA CT -3' $42 \mathrm{bp}$ b) Beschreibung: H3/k Mutationsprimer 12; für Herstellung von K5mut10; 5 bp Fehlpaarung

OHK97: a) Sequenz: 5'- GGTGAACAAC AAAAATTTGA GTCCTGCCCC AATTTGGTTA CT -3' $42 \mathrm{bp}$ b) Beschreibung: H3/k Mutationsprimer 13; für Herstellung von K5mut13; 5 bp Fehlpaarung

OHK98: a) Sequenz: 5'- TTGAGTCCTT CGTCAATCCG GTTAC -3' 25 bp b) Beschreibung: H3/k Mutationsprimer 14; für Herstellung von K5mut14; 1 bp Fehlpaarung.

OHK102: a) Sequenz: 5'- GAATTTTCTT GGGTCCAATA GTTGTGTTGA GGACTCTATA AAAGAAGAGT AGCTCTTTCC -3' b) Beschreibung: H3/m Mutationsprimer 16; für Herstellung von M4mut16.

OHK104: a) Sequenz: 5'- GgGGTTAACA AAATGACGTC AGAGACTTGT CGGTAATGGG CAGGAGCCTC TC -3' b) Beschreibung: H3/m Mutationsprimer 18; für Herstellung von M4mut18.

OHK105: a) Sequenz: 5'- CTTAATCTGC AACCAGGCAC CACCATGGAC CAATCCAAGA AGGG 3' b) Beschreibung: H3/m Mutationsprimer 19; für Herstellung von M4mut 19. 
OHK106: a) Sequenz: 5'- CTTCGCTTCC AgAgCTCTGC GgTCCTCGTT CTGCAgGAgG CTTGTGAGGCC-3' b) Beschreibung: H3/m Mutationsprimer 20; für Herstellung von M4mut20.

\section{OHK108-111: H3/k Mutationsprimer (für Erstellung von K5mut16-19)}

OHK108: a) Sequenz: 5'- CCGgTtACTG TTGgGTAgGC CTTTTGTCCA ATCAgCTTCA GACTCTC -3' b) Beschreibung: H3/k Mutationsprimer 16; für Herstellung von K5mut16; Deletion von $10 \mathrm{bp}$.

OHK109: a) Sequenz: 5'-CCGGTTACTG TTGgGtAgGC CTTTACTtTT GTCCAATCAG CTTCAGACTC -3' b) Beschreibung: H3/k Mutationsprimer 17; für Herstellung von K5mut17; Deletion von $5 \mathrm{bp}$.

OHK110: a) Sequenz: 5'- GGTTACTGTT GGGTAGGCCT TCAGTTGACC ATACTTTTGT CCAATCAGCT TCAGAC -3' b) Beschreibung: H3/k Mutationsprimer 18; für Herstellung von K5mut18; Insertion von $5 \mathrm{bp}$.

OHK111: a) Sequenz: 5'- GGTTACTGTT GGGTAGGCCT TCAGCATTCT ACAGCATACT TTTGTCCAAT CAGCTTCAGA -3' b) Beschreibung: H3/k Mutationsprimer 19; für Herstellung von K5mut19; Insertion von 10 bp.

OHK112: a) Sequenz: 5'- CGAGATCTTG TGGCGATTTT CCCTTATCAG $-3^{\prime}$ b) Beschreibung: Primer zur Erzeugung der H3/m-Promotor-Deletionsmutante M9. Mit angehängter BglII-Schnittstelle. c)Komplementär zu OHK4

OHK116: a) Sequenz: 5'- CTGCAACCAG GCACAGAGAT GGACTCCTCC AAG AAGGGC GCGGGG -3' b) Beschreibung: Beschreibung: H3/m Mutationsprimer 20; für Herstellung von M4mut20; 3bp Fehlpaarung.

OHK118: a) Sequenz: 5'- GCATACTTTT GTCCAATCAG CTTCAGACAT TCTACTTCTC TCACTATAAA TAAGCGGCTA GC -3' b) Beschreibung: H3/k Mutationsprimer 20; für Herstellung von K5mut20; Insertion von $10 \mathrm{bp}$.

\section{OHK119-146: Oligonukleotide zur Erzeugung von doppelsträngigen EMSA- Oligonukleotiden}

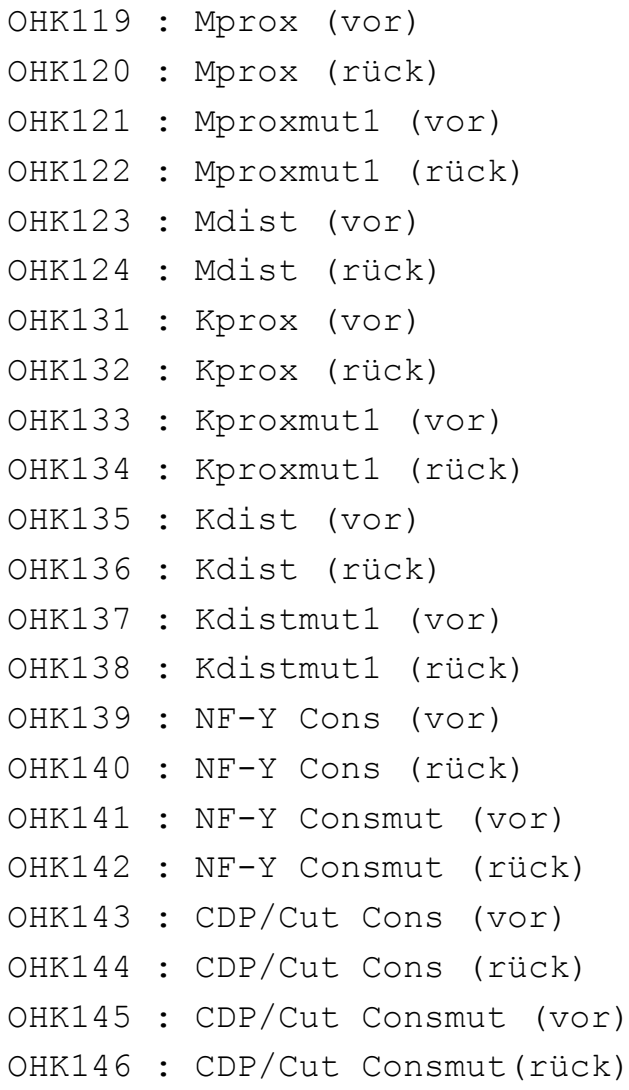

TGAATTTTCT TGGGTCCAAT AGTTGGTGGT ACCACCAACT ATTGGACCCA AGAAAATTCA TGAATTTTCT TGGGTAACCG AgTTGgTGgT ACCACCAACT CGGTTACCCA AGAAAATTCA AGGCACAGAG ATGGACCAAT CCAAGAAGGG CCCTTCTTGG ATTGGTCCAT CTCTGTGCCT TCAGCATACT TTTGTCCAAT CAGCTTCAGA TCTGAAGCTG AtTGGACAAA AgtATGCTGA TCAGCATACT TTTGTACGAT CAGCTTCAGA TCTGAAGCTG ATCGTACAAA AgtATGCTGA AATTTGAGTC CTTCGCCAAT CCGGTTACTG CAGTAACCGG ATtGGCGAAG GACTCAAATT AATTTGAGTC CTTCGTCAAT CCGGTTACTG CAGTAACCGG ATTGACGAAG GACTCAAATT AGACCGTACG TGATTGGTTA ATCTCTT AAGAGATTAA CCAATCACGT ACGGTCT AGACCGTACG AAATACGgGA ATCTCTT AAGAGATTCC CGTATTTCGT ACGGTCT ACCCAATGAT TATTAGCCAA TTTCTGA TCAGAAATT GCTAATAATC ATTGgGt ACCCAATGGC CGTTAGCCAA TTTCTGA TCAGAAATTG GCTAACGGCC ATTGGGT 
OHK147-152: PCR-Primer zur Amplifikation der Gene H3/h, H3/i und H3/C $($ Startcodon $=$ Position 2000)

OHK147: H3/h 1771-> : TAACGTTCTT GGATCGCAGA CTAACCG

OHK148: H3/h <-2591: GCACGGGAAC AAATATAGCA AGCTTACC

OHK149: H3/i 1848-> : TGAGACCTAG TAGCTGATCA CAAGTCC

OHK150: H3/i<-2523: CCTCCTTGTT TTAGGAGACA TTACTCCC

OHK151: H3/C 1666-> : TTTCAAGTCC CACTCAAACT TACTGAATCG G

OHK152 : H3/C <-2542 : CTTGTGTGTA GTTATCACCT TTATATCTCC TGG 


\subsection{RNase-Protektions-Gele (Einzelsonden-Experimente)}

Die folgenden Abbildungen zeigen die RNase-Protektionsgele, die mit jeweils einer einzigen H3-Sonde (wie angegeben) und Gesamt-RNA aus den acht untersuchten humanen Zellinien durchgeführt wurden. Folgende Legende gilt für alle 11 Abbildungen: M: Markerspuren mit pUC19/ Sau 3AI-Fragmenten; rechts von den Gelen sind die Größen der Fragmente in Basenpaaren angegeben. Oberhalb der Spuren ist jeweils die Zelllinie genannt, aus der die Gesamt-RNA stammte. Die protektierten H3-mRNA-Fragmente sind am Rand mit einer schwarzen Pfeilspitze markiert. In Tabelle $2{ }_{25}$ sind die Auswertungen der RPA-Assays und die Berechnung der H3-Expressionsmuster je Zelllinie dargelegt.

Tabelle 2: Auswertung der Autoradiogramme der Einzelsonden-Experimente

Quantitative Auswertung der RPA-Assays mit jeweils einer Histongensonde und acht Zelllinien. In den Spalten sind die quantifizierten, mit der $\beta$-Actin-Bande standardisierten Bandenintensitäten der jeweiligen H3-Sonde je Zelllinie angegeben (arbiträre Werte) (eine Spalte entspricht jeweils einem der in diesem Kapitel gezeigten Gele). Die Werte einer Spalte (eines Einzelsonden-Experiments) waren zunächst nicht mit den Werten der übrigen Spalten vergleichbar, da die Versuchsbedingungen von Gel zu Gel leicht variierten. Mit Hilfe der 10-Sonden-Experimente, in denen RPA-Assays mit jeweils 10 Sonden (alle Histongene außer H3/d) und RNA der Zelllinien HeLa-S3, HEK-293, Tera-2 und SaO2-2 durchgeführt wurden (siehe 4.2.3.1.1), konnte die Höhe der Werte der jeweiligen Einzelgen-Assays (Spalten) jedoch relativ zueinander korrekt festgelegt werden. In diesen Experimenten wurde das H3Expressionsmuster (mit Ausnahme von $\mathrm{H} 3 / \mathrm{d}$ ), in den genannten Zelllinien bestimmt, was in der Tabelle einer Zeile entspricht. Die Werte in den Spalten wurden dann mit einem selbstgeschriebenem Programm so gewichtet, dass die Übereinstimmung der entsprechenden Zeilen mit den H3Expressionsmustern in den Zelllinien HeLa-S3, HEK-293, Tera-2 und SaO2-2 möglichst groß wurde (Prinzip der kleinsten Fehlerquadratsumme). Durch die korrekte Gewichtung der einzelnen Spaltenwerte mit den vier bestimmten H3-Expressionsmustern in den Zelllinien HeLa-S3, HEK-293, Tera-2 und SaO2-2 ergaben sich somit die H3-Expressionsmuster für die Zelllinien Capan-1, HL-60, IMR-90 und Hep-G2 als Zeilenwerte in dieser Tabelle der Einzelsonden-Experimente. Die H3Expressionsmuster in den Zellinien HeLa-S3, HEK-293, Tera-2 und SaO2-2 wurden also wie in (4.2.1 37 ) beschrieben als Multisonden-Experimente bestimmt. Die H3-Expressionsmuster der Zelllinien Capan-1, HL-60, IMR-90 und Hep-G2 ergaben sich nach dem in dieser Tabellenbeschreibung geschilderten Verfahren aus den Einzelsonden-Experimenten. Die H3/d-Werte waren nicht einzuordnen (Stern-Markierung), da H3/d in den 10-Sonden-Experimenten nicht enthalten war.

\begin{tabular}{|c|c|c|c|c|c|c|c|c|c|c|c|}
\hline & $H 3 / a$ & $H 3 / b$ & $H 3 / c$ & $H 3 / d$ & $H 3 / f$ & $H 3 / h$ & $H 3 / I$ & $H 3 / \mathrm{J}$ & $H 3 / k$ & $H 3 / m$ & $H 3 / n$ \\
\hline Capan-1 & 1,553 & 1,837 & 3,575 & 0,0 & 1,808 & 0,0 & 1,892 & 1,079 & 3,629 & 4,167 & 12,59 \\
\hline HeLa-S3 & 1,779 & 3,185 & 0,161 & 0,0 & 0,0 & 7,469 & 5,548 & 0,050 & 8,339 & 17,06 & 20,76 \\
\hline HEK-293 & 4,377 & 1,185 & 0,830 & 0,0 & 0,061 & 0,0 & 1,829 & 0,0 & 12,33 & 29,47 & 42,03 \\
\hline Tera-2 & 5,805 & 5,723 & 5,533 & $2,00^{*}$ & 3,680 & 4,844 & 2,372 & 3,963 & 7,327 & 14,29 & 19,83 \\
\hline HL-60 & 5,905 & 12,1 & 5,731 & 0,0 & 7,688 & 0,0 & 0,0 & 7,77 & 17,12 & 22,91 & 20,90 \\
\hline IMR-90 & 1,185 & 1,575 & 0,686 & $0,60^{*}$ & 0,836 & 1,746 & 0,768 & 0,643 & 1,580 & 3,242 & 3,420 \\
\hline SaOS-2 & 1,204 & 3,419 & 0,0 & 0,0 & 3,285 & 2,146 & 1,692 & 0,085 & 6,078 & 17,42 & 22,81 \\
\hline Hep-G2 & 0,0 & 9,855 & 10,01 & 0,0 & 0,026 & 0,0 & 0,849 & 0,184 & 11,20 & 21,86 & 19,43 \\
\hline
\end{tabular}




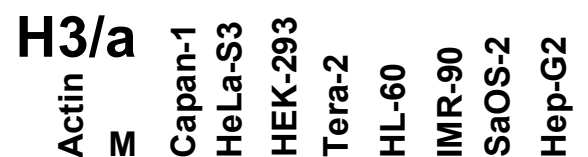

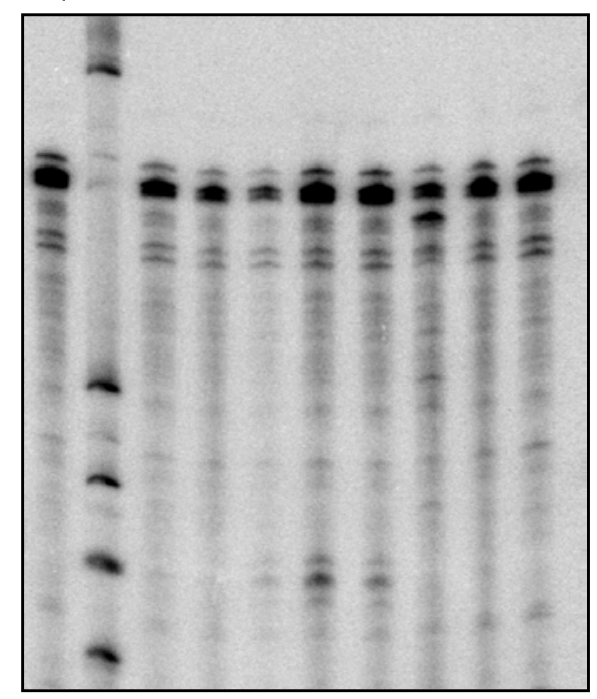

105

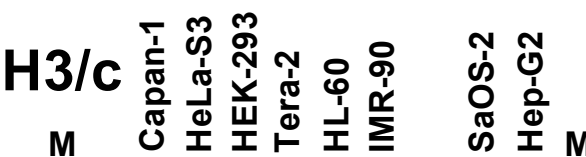

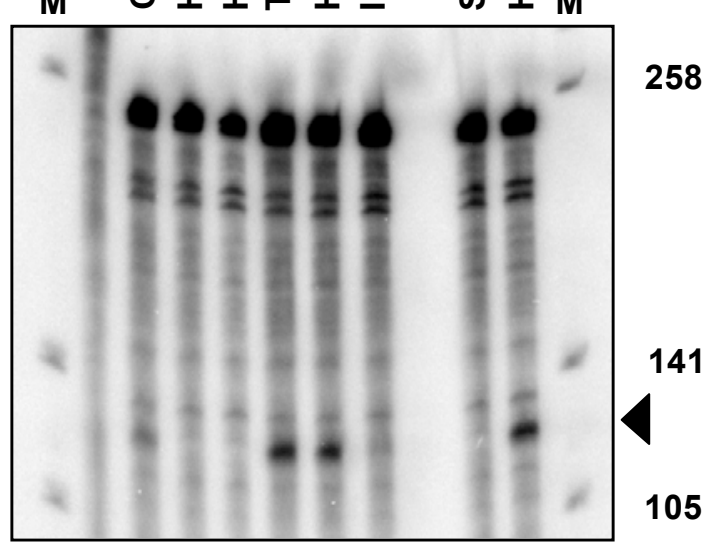

H3/b 衣

웡

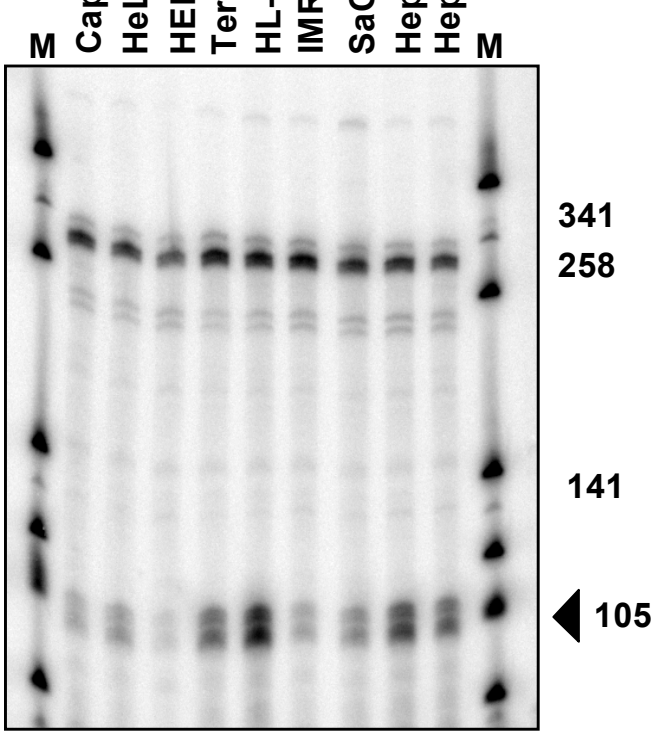

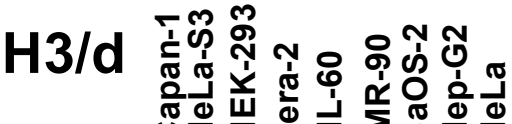
M M

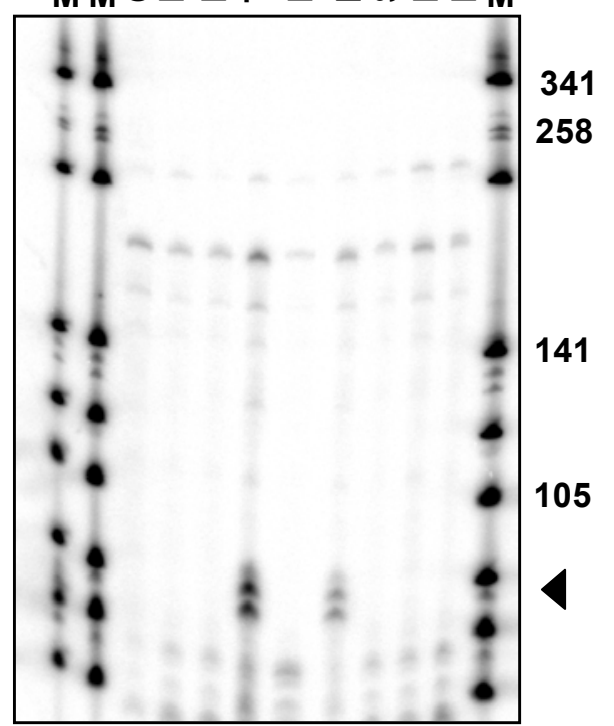




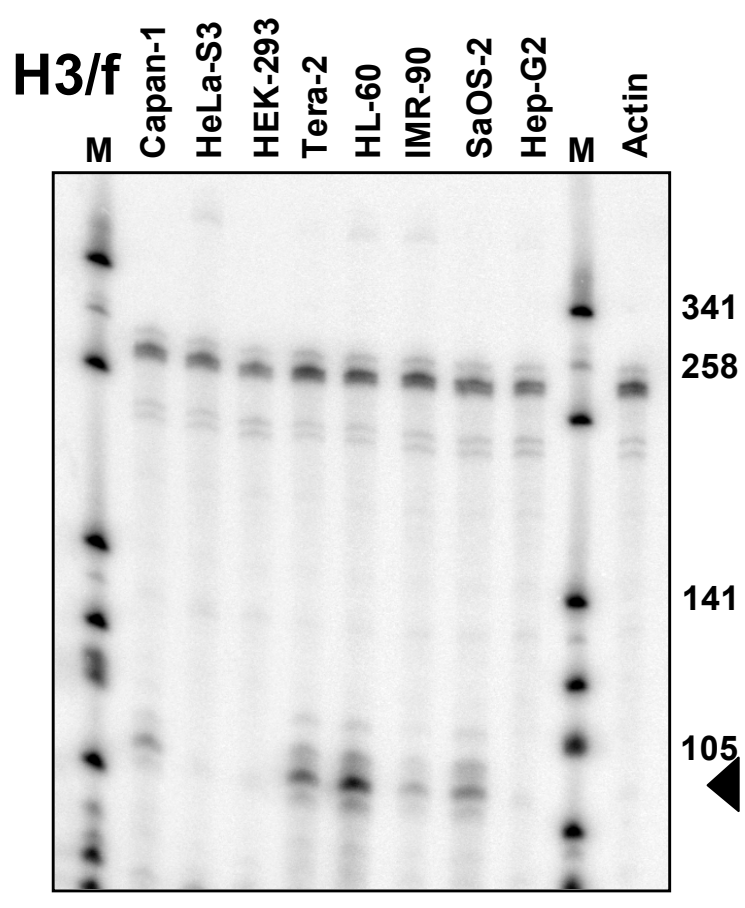

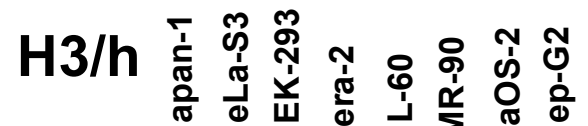
M 仓ั๊

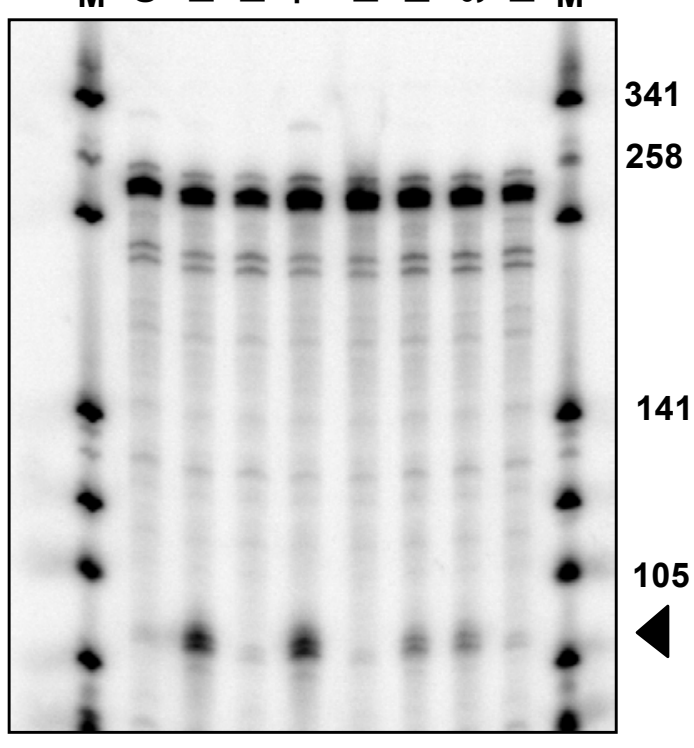

H3/i

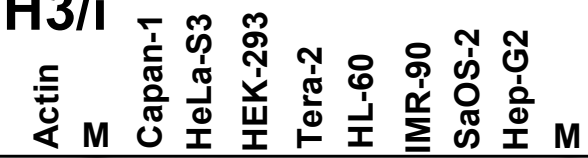

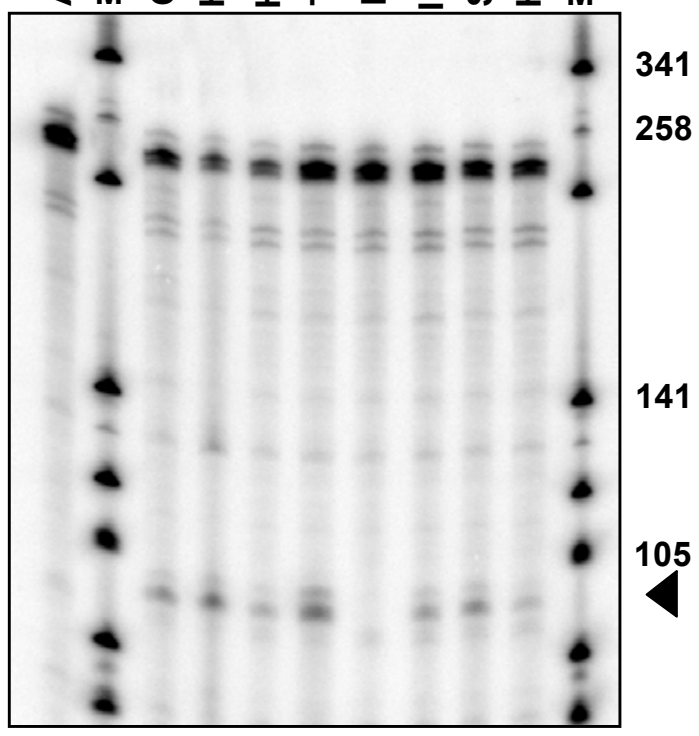

H3/j

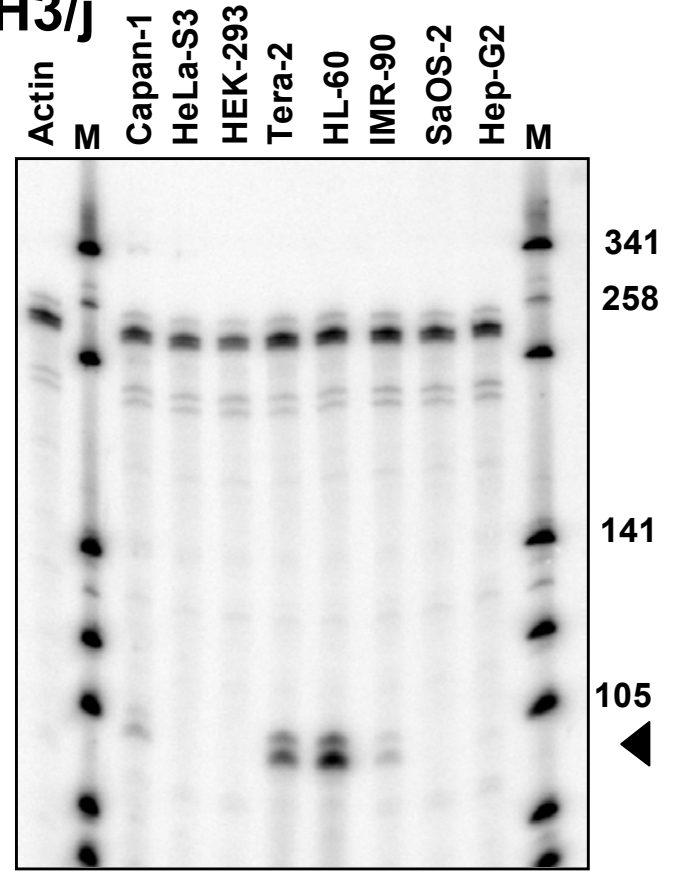



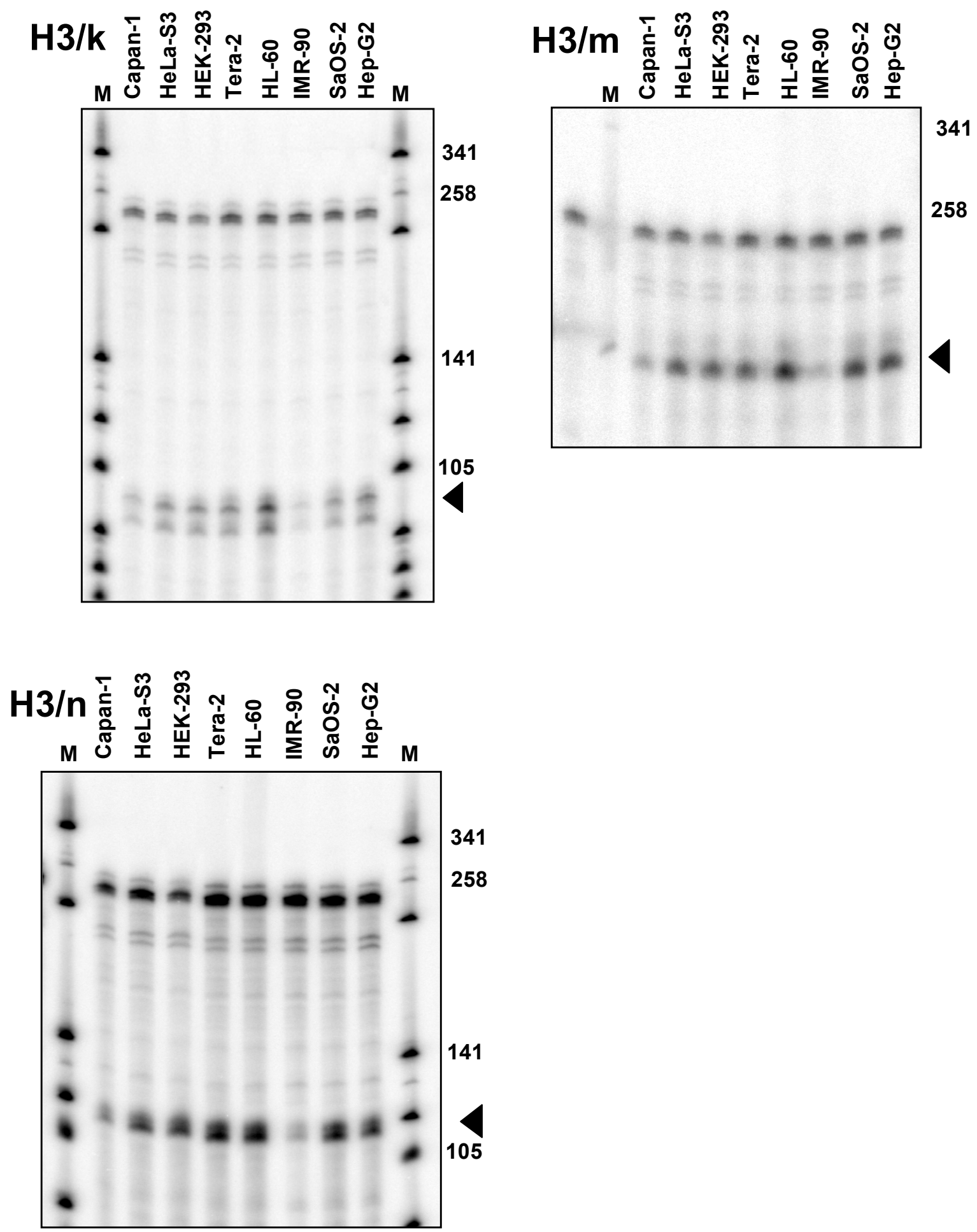


\section{Danksagung}

An erster Stelle möchte ich mich bei Herrn Prof. Dr. Detlef Doenecke für die Überlassung des Themas, die Betreuung und Begleitung der Dissertation und die darüber hinausgehende wissenschaftliche Förderung herzlich bedanken.

Bei Herrn PD Dr. Werner Albig möchte ich mich für die fachliche Begleitung der Experimente und der Dissertation sowie für anregende Diskussionen bedanken.

Herrn Prof. Dr. Ulrich Grossbach danke ich für die Übernahme des Korreferats.

Bei Frau Nicole Döring, Frau Dr. Sabine Rabini, Frau Christa Bode, Frau Kristina Hänecke und den übrigen Laborkollegen möchte ich mich für Ratschläge und Informationen im Labor bedanken.

Bei allen Mitarbeitern der Abteilung Molekularbiologie bedanke ich mich für die freundliche Arbeitsatmosphäre (mein Dank gilt auch den inzwischen ehemaligen Mitarbeitern).

Herrn Andreas Nolte danke ich für die zahlreichen guten Sequenzen, die er ausgehend von den in der Arbeit durchgeführten Sequenzierreaktionen erstellt hat.

Schließlich danke ich Herrn PD Dr. Werner Albig, Frau Christa Bode und Dr. Dieter Porth herzlich für die Durchsicht des Manuskripts. 


\section{Lebenslauf}

Persönliche Daten: Name:

geboren am:

Staatsangehörigkeit: deutsch

Eltern:

Schulausbildung:

08/1982-07/1988

09/1988-06/1989

08/1989-06/1991

Zivildienst:

Studium:

Diplomarbeit:

wissenschaftlicher Werdegang:

\section{Begleitende} Tätigkeiten

09/1991-09/1992

10/1992-10/1998

11/1997-10/1998

11/1998-04/1999

seit 05/1999

10/1996-02/1998
Heiner Kössler

03. April 1972 in Bonn

Bernd Rüdiger Kössler

Ingrid Kössler, geb. Meyer

Grundschule Oedekoven bei Bonn

Helmholtz-Gymnasium Bonn-Duisdorf

Senior High-School in Utica, N.Y.-State, USA

Helmholtz-Gymnasium Bonn-Duisdorf

Abschluß: Allgemeine Hochschulreife

Mobiler Sozialer Hilfsdienst (MSHD) beim

Deutschen Roten Kreuz (DRK) Bonn

Chemie an der Philipps-Universität Marburg Abschluss: Diplom Chemiker mit der Gesamtnote gut $(1,7)$

Bei Prof. M. A. Marahiel (Bereich Biochemie)

„Expression und biochemische Charakterisierung des lle-Cys dimodularen Teils der BacitracinSynthetase 1 aus Bacillus licheniformis"

Projektarbeit im Arbeitskreis Prof. M. A. Marahiel: Erzeugung und Charakteriserung von PPSUnterbrechungsmutanten in Pseudomonas fluorescens YK 437

Arbeit zur vorliegenden Dissertation „Die Regulation der humanen H3-Histongene" unter der Betreuung von Prof. Dr. D. Doenecke am Institut für Biochemie und Molekulare Zellbiologie, Abteilung Molekularbiologie, Universität Göttingen. Die Arbeit wurde mit DFGFördermitteln gefördert.

Studentische Hilfskraft: Betreuung des ChemiePraktikums für Mediziner, Universität Marburg

04/2000-02/2003 Betreuung des Biochemie-Praktikums für Mediziner, Universität Göttingen

07/2001-08/2001 Teilnahme an einem dreiwöchigen CSHL-Sommerkurs zur eukaryontischen Transkriptionsregulation, Cold Spring Harbor Laboratories, N.Y., USA 